Florida International University FIU Digital Commons

$6-25-2018$

\title{
Modulating Adipogenesis: Key Role of Ras-related Protein Rab5 and its Effectors
}

\author{
Yongjun Huang
}

hyong001@fiu.edu

DOI: $10.25148 /$ etd.FIDC006840

Follow this and additional works at: https://digitalcommons.fiu.edu/etd

Part of the Biochemistry Commons, and the Molecular Biology Commons

\section{Recommended Citation}

Huang, Yongjun, "Modulating Adipogenesis: Key Role of Ras-related Protein Rab5 and its Effectors" (2018). FIU Electronic Theses and Dissertations. 3793.

https://digitalcommons.fiu.edu/etd/3793

This work is brought to you for free and open access by the University Graduate School at FIU Digital Commons. It has been accepted for inclusion in FIU Electronic Theses and Dissertations by an authorized administrator of FIU Digital Commons. For more information, please contact dcc@fiu.edu. 


\title{
FLORIDA INTERNATIONAL UNIVERSITY
}

\author{
Miami, Florida
}

\section{MODULATING ADIPOGENESIS: KEY ROLE OF RAS-RELATED PROTEIN RAB5 AND ITS EFFECTORS}

\author{
A dissertation submitted in partial fulfillment of \\ the requirements for the degree of \\ DOCTOR OF PHILOSOPHY \\ in \\ BIOCHEMISTRY \\ by \\ Yongjun Huang
}


To: Dean Michael R. Heithaus

College of Arts, Sciences and Education

This dissertation, written by Yongjun Huang, and entitled Modulating Adipogenesis: Key Role of Ras-Related Protein Rab5 and Its Effectors, having been approved in respect to style and intellectual content, is referred to you for judgment.

We have read this dissertation and recommend that it be approved.

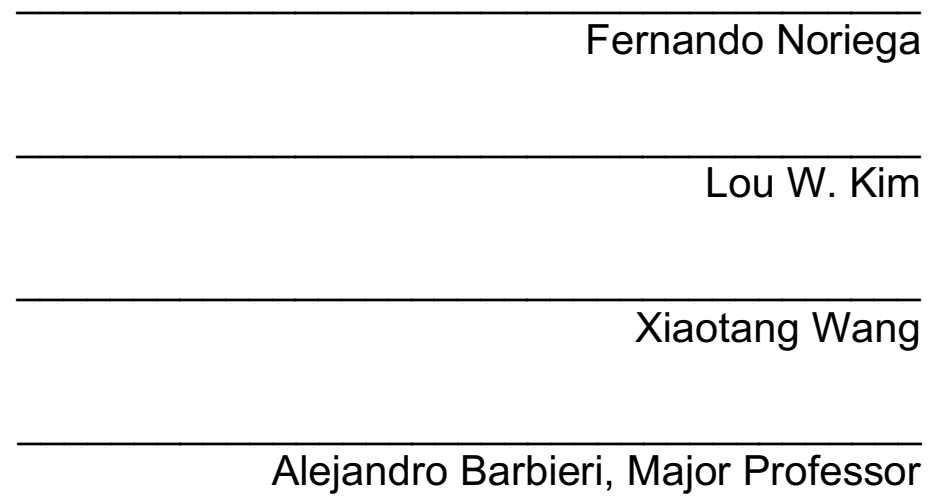

Date of Defense: June 25, 2018

The dissertation of Yongjun Huang is approved.

Dean Michael R. Heithaus

College of Arts, Sciences and Education

Andres G. Gil

Vice President for Research and Economic Development

And Dean of University Graduate School

Florida International University, 2018 
- Copyright 2018 by Yongjun Huang

All rights reserved. 


\section{ACKNOWLEDGMENT}

First and foremost, I would like to express my sincere gratitude to my major advisor, Dr. Alejandro Barbieri, for being an excellent mentor and for providing me this interesting and promising project. His profound and immense knowledge guided me to continuously think about my research and coming up with new ideas. I am so grateful for the generous guidance, limitless patience, and ongoing encouragement he gave me throughout the entire process. I could not have achieved any success in the past five years without his help.

I want to thank all my committee members, Dr. Wang, Dr. Kim, and Dr. Noriega for following my progress closely and providing helpful suggestions and insightful remarks on the journey. Thank Dr. Wang for giving me the chance to take a rotation in his lab where I learned to start lab work. Thank Dr. Kim for reminding me and guiding me to keep track of the Biochemistry Ph. D. program. Thank Dr. Noriega for always be so patient and encourage me to stay on the track.

I want to thank Dr. Rosen and Dr. Venkadesh for making beautiful 3D structure for my protein-protein interaction experiment.

I also would like to thank my family for the love and support. Their words of inspiration made me feel beloved and gave me the strength not to give up.

Finally, I want to thank my friends who heartened me when I felt depressed. I want to thank Maria-Luisa for all the considerate advises she suggested, thank Elwood for driving me home when I did not have a car, thank Wenjie and Xiaoqing for accompanying me when I felt lonely, thank Zhiwei for 
the amazing food he served, thank Orestes for a lot of joy he brought to me, and thank Ivy for her support in my project. And special thanks to my boyfriend, who never show up during these five years so that I can focus on my research, as well as my cat and dog who I will meet in the nearby future. 
ABSTRACT OF THE DISSERTATION

MODULATING ADIPOGENESIS: KEY ROLE OF RAS-RELATED PROTEIN

RAB5 AND ITS EFFECTORS

by

Yongjun Huang

Florida International University, 2018

Miami, Florida

Professor Alejandro Barbieri, Major Advisor

The formation of adipocytes is a complicated process in which insulin and IGF1 signaling pathways and numerous transcription factors control the conversion of precursor cells to mature fat cells. The Rab5 protein acts as a rate-limiting protein during receptor-mediated endocytosis by switching between a GDP-bound inactive form and a GTP-bound active form. The inactivation and activation of Rab5 are regulated by several Rab5 GTPase activating proteins (GAPs) and Rab5 guanine nucleotide exchange factors (GEFs), respectively.

This dissertation demonstrated that the activity of the small GTPase Rab5 and its regulators are essential for the differentiation of 3T3-L1 pre-adipocytes. Specifically, it showed that Rab5 activation is detrimental to the differentiation process. The overexpression of a dominant-negative Rab5:S34N mutant, but not an active counterpart (Rab5:Q79L), stimulated the differentiation of 3T3-L1 preadipocytes. Consequently, the expression of Rab5:S34N increased the expression of two adipogenic-specific transcriptional factors, PPARY and C/EBPa. siRNAmediated depletion of Rab5 inhibited the differentiation of 3T3-L1 pre-adipocytes, 
providing further evidence for the requirement of Rab5 in the process of adipogenesis.

A dramatic decrease of the Rab5-GTP level is also observed during the differentiation of 3T3-L1 pre-adipocytes. Consistent with these observations, I found that the expression of Rab5 GEFs (i.e., RIN1, Rabex-5, and RAP6), which increased the GTP-bound form of Rab5, blocked the differentiation process. In contrast, the expression of Rab5 GAPs (i.e., RN-tre and RabGAP-5), which decreased the GTP-bound form of Rab5, stimulated differentiation of 3T3-L1 preadipocytes.

I also found a novel interaction between the VPS9 domain of the Rab5 GEFs and the activated insulin receptor. This interaction is specific since the VPS9 domain did not interact with the catalytic inactive mutant of the insulin receptor and the Rab5 GAPs (no VPS9 domain) did not bind to the activated insulin receptor.

The data point out that a reduction on the GTP-bound form of Rab5 is required for the rapid differentiation of 3T3-L1 pre-adipocytes, identifying Rab5 inactivation as an important contributor of adipogenesis. Also, these observations suggest a novel cellular mechanism of Rab5 activity in the adipogenesis process in connection with the insulin receptor, the Rab5 GAPs, and the Rab5 GEFs. 


\section{TABLE OF CONTENTS}

CHAPTER

PAGE

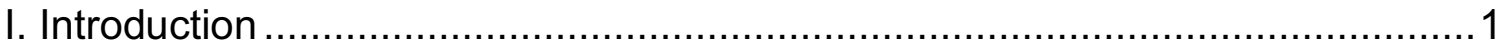

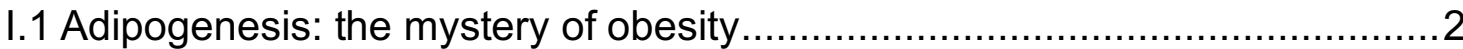

I.1.1 Obesity: a global health problem .................................................

I.1.1.1 Obesity in history and modern life: from a symbol of beauty to the

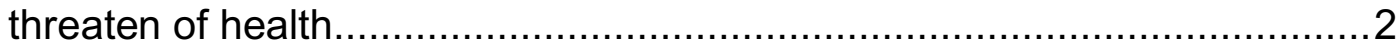

I.1.1.2 Adipose tissue: not only a fat storehouse ................................ 4

I.1.1.3 White, brown, and beige: different colors with different functions? ...7

I.1.1.4 Current therapies of obesity: a long way to go.............................13

I.1.2 Process of adipogenesis in vitro: the lipids factory under precise

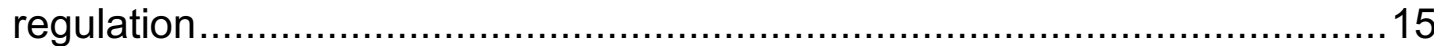

I.1.2.1 Lipids and lipid droplets in adipocytes ....................................17

I.1.2.2 Insulin, dexamethasone, 3-isobutyl-1-methylxanthine: the three

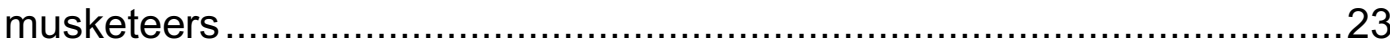

I.1.2.3 Adipogenesis in vitro: the mitotic clonal expansion phase and the morphological change/terminal differentiation phase.............................26

I.1.2.4 The adipogenic markers: C/EBPs (C/EBPa, C/EBP $\beta$, and

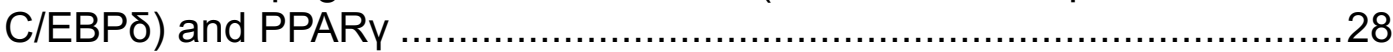

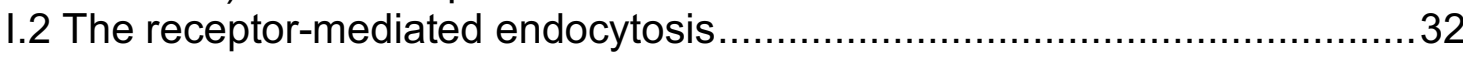

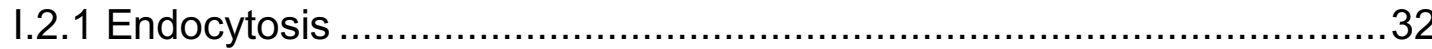

I.2.2 Mechanism of receptor-mediated endocytosis: how the initial signal is implemented - magnification V.S. quenching.......................................34

I.2.2.1 The ligands and the receptor tyrosine kinases: the soulmates .......34

I.2.2.2 The internalization of ligand-receptor complexes: engulfment does not mean suppression ..................................................................... 36

I.2.2.3 The small GTPase Rab proteins in the receptor-mediated endocytosis: the logistic company to control the delivery ........................41

I.2.3 Structure of the receptor tyrosine kinases ......................................45

I.3 The insulin signaling pathways: the essential determinant of adipogenesis 46

I.3.1 Insulin receptor and its structure ...................................................4

I.3.2 Insulin-like growth factor receptor 1 and its structure.........................52

I.3.3 Signaling transduction in adipocyte differentiation ............................56

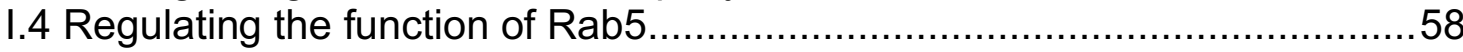

I.4.1 The small GTPase Rab5: small but essential .................................58

I.4.2 Guanine nucleotide exchange factors, GTPase-activating proteins,

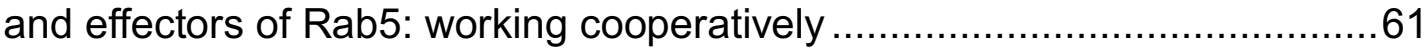

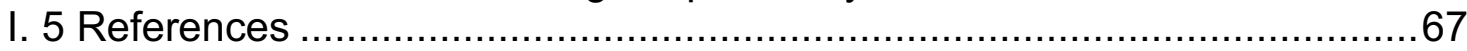

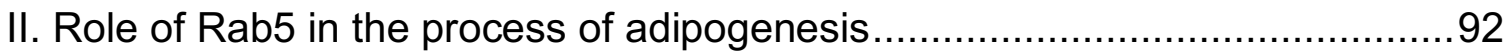

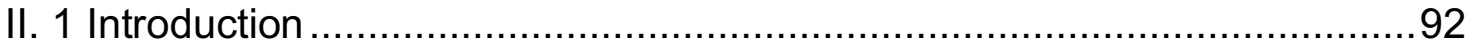

II.2 Specific aims and research design ..................................................97

II.2.1 Specific aim 1: To examine the key determinants of Rab5 that are

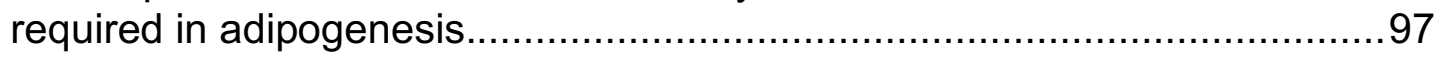




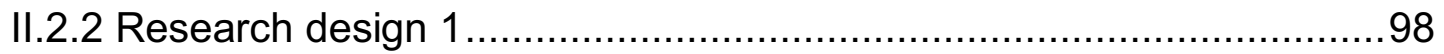

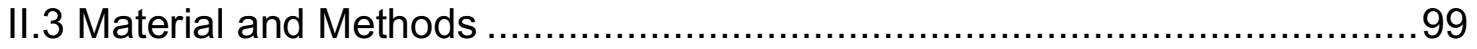

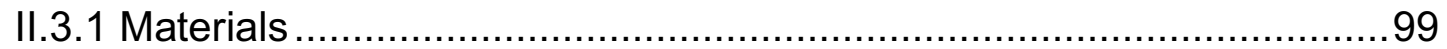

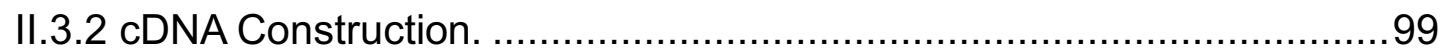

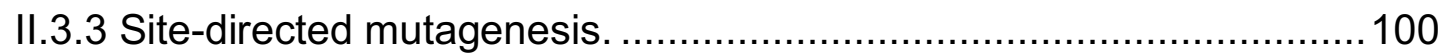

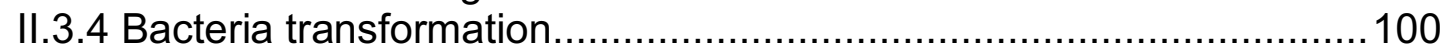

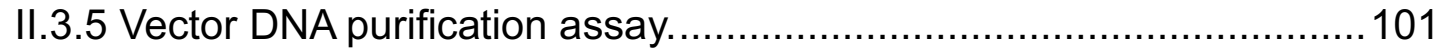

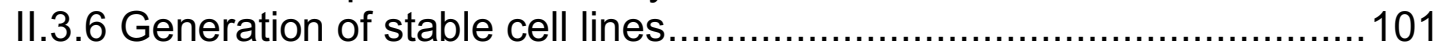

II.3.7 Cell culture and 3T3-L1 cell differentiation...................................102

II.3.8 Oil Red O (ORO) staining and quantification................................. 102

II.3.9 Bright-field microscopy, confocal microscopy, and live-cell

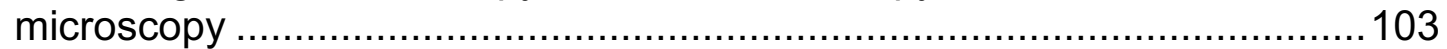

II.3.10 Lysate preparation, protein quantification, and Western blotting .....104

II.3.10.1 Lysate preparation ............................................................. 104

II.3.10.2 Protein quantification - the Pierce BCA Protein Assay .............. 104

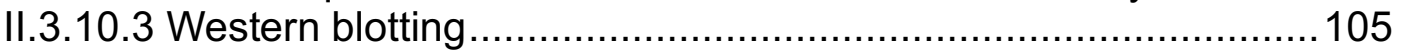

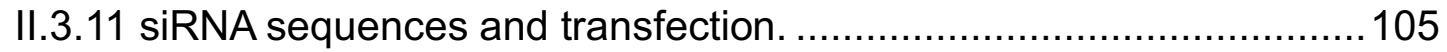

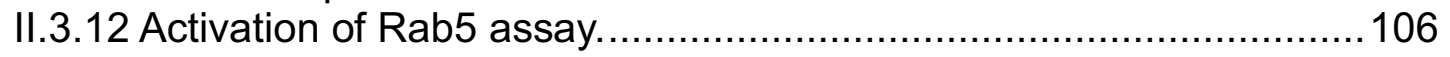

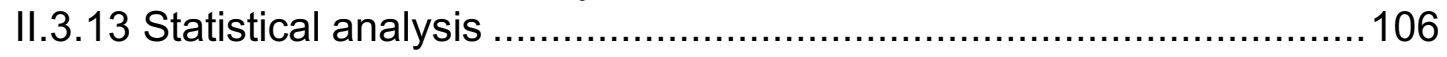

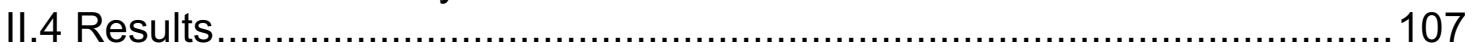

II.4.1 Nucleotide status of Rab5 is critical for the differentiation of 3T3-L1

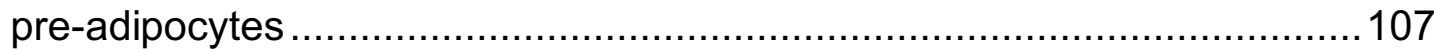

II.4.1.1 The induction of pMX-puro retroviral vector expression-system did not alter the differentiation process ................................................ 107

II.4.1.2 The overexpression or deletion of individual Rab5 isoforms inhibited the differentiation of 3T3-L1 pre-adipocytes ............................. 109

II.4.1.3 The GTP-bound Rab5 decreased during adipogenesis.............. 111

II.4.1.4 Increase the Rab5-GTP level hampered the differentiation of

3T3-L1 pre-adipocytes................................................................ 113

II.4.2 The determinants of Rab5 in promoting adipogenesis..................... 118

II.4.3 Rab5 plays an irreplaceable role in the regulation of adipogenesis... 123

II.4.4 Rab5 performs its function via the insulin signaling pathway during

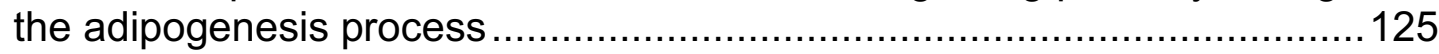

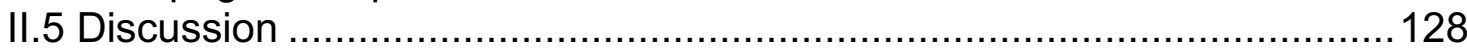

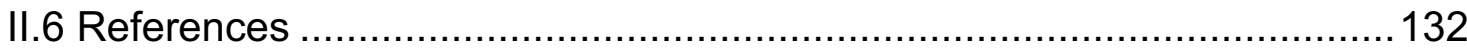

III. Role of Rab5 regulators and effectors in the process of adipogenesis .......138

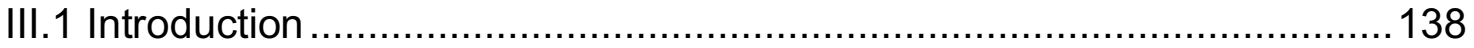

III.2 Specific aims and research design ................................................ 143

III.2.1 Specific aim 2: To determine the effect of Rab5 regulators on

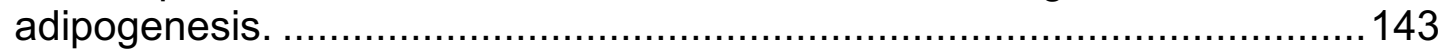

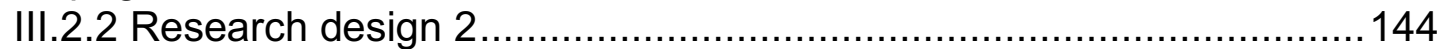

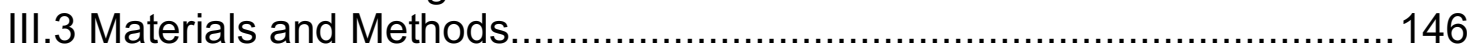

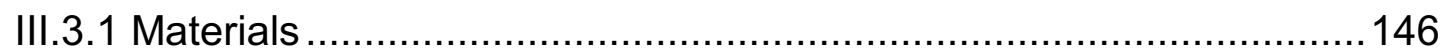

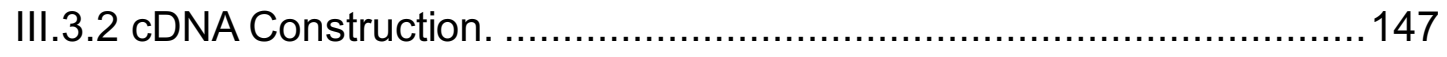




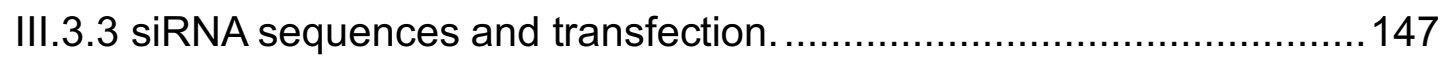

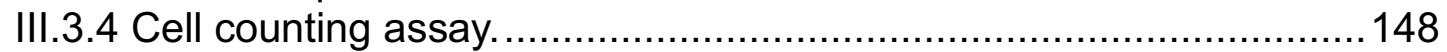

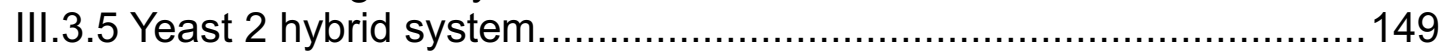

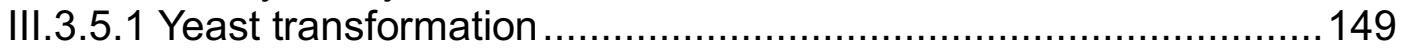

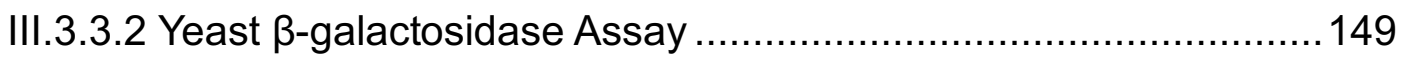

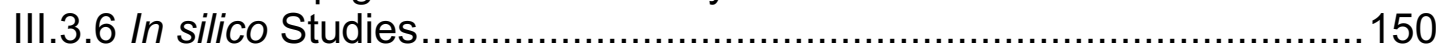

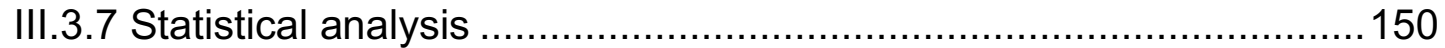

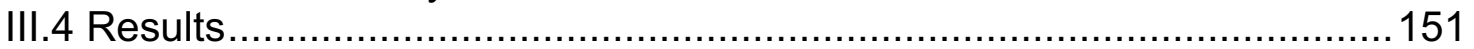

III.4.1 Rab5 GEFs were down-regulated during the differentiation of

3T3-L1 pre-adipocytes.................................................................... 151

III.4.2 The Rab5 GEFs downregulated the accumulation of lipids in the differentiated 3T3-L1 cells. ................................................................ 153

III.4.3 Selective effect of RIN1 and its mutants on insulin signaling during

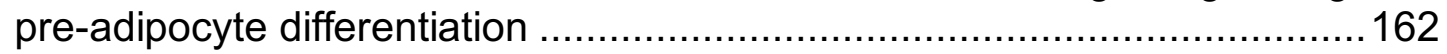

III.4.3.1 RIN1 overexpression inhibited adipogenesis in vitro .................162

III.4.3.2 Two RIN1 selective mutants rescued the inhibitory effects of RIN1 on adipogenesis ................................................................... 164

III.4.3.3 RIN1 mutants recovered both Erk1/2 and Akt signaling in compare with RIN1-WT ................................................................ 167

III.4.3.4 RIN1 mutants promote cell proliferation in clonal expansion

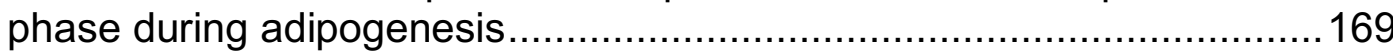

III.4.5 Selective association of IR with Rab5 GEFs.............................176

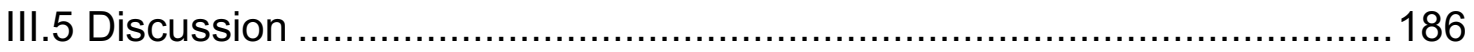

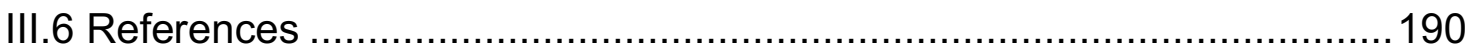

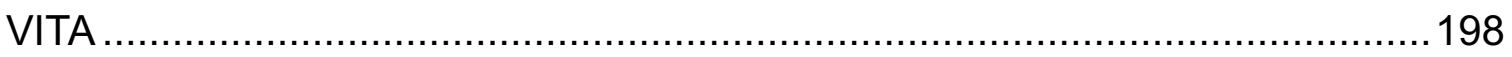




\section{LIST OF TABLES}

TABLE

PAGE

Table 1. Similarities and diversities of white, brown, and beige adipose tissue... 11

Table 2. Locations and functions of essential amino acids on the $\beta$-subunit of the IR and the IGF-1R.

A. Locations of essential amino acid residues on the $\beta$-subunit.....................54

B. Functions of essential amino acid residues on the $\beta$-subunit of the IR-B. ...54

C. Effects of essential amino acid residue mutants on the $\beta$-subunit of the

IR-B.

Table 3. Rab5 regulators and effectors.

61

Table 4. In silico analysis of the interaction between the VPS9-HB ${ }^{1}$ domain of

RIN1 and the IR-tail ${ }^{2}$

Table 4.A Hydrophobic interactions between the VPS9-HB domain of RIN1

and the IR-tail

Table 4.B Cation-Pi interactions between the VPS9-HB domain of RIN1 and

the IR-tail within $6 \AA$.

Table 4.C Aromatic-aromatic Interactions between VPS9-HB and IR-tail

within 4.5 and $7 \AA$

Table 4.D lonic interactions between VPS9-HB and IR-tail within $6 \AA$ 181

Table 4.E Hydrogen bond interactions between VPS9-HB and IR-tail. 


\section{LIST OF FIGURES}

FIGURE

PAGE

Figure 1. Origins and characteristics of white and brown adipocytes................10

Figure 2. Structure and formation of lipid droplets (LD) in adipocytes...............21

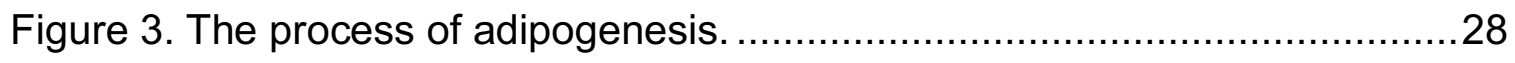

Figure 4. The regulation of transcription factors during adipogenesis................30

Figure 5. The tyrosine kinase domain of RTKs and receptor-mediated

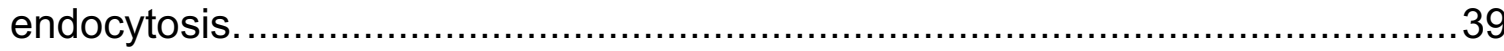

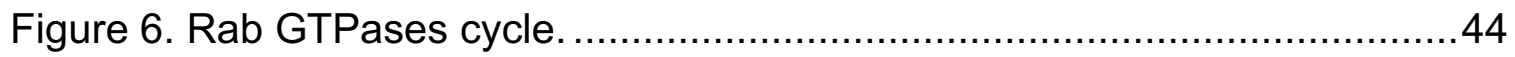

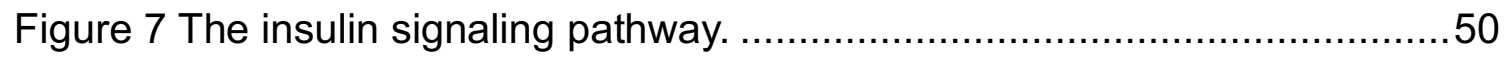

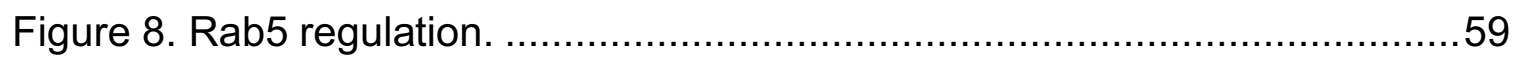

Figure 9. Differentiation of un-transfected and GFP-overexpressing 3T3-L1

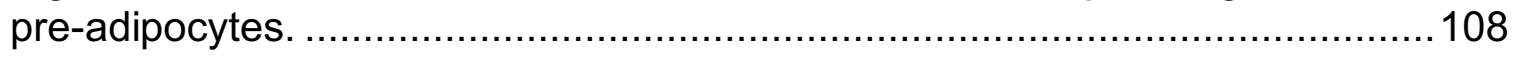

Figure 10. Selective effect of Rab5 isoforms on the differentiation of 3T3-L1

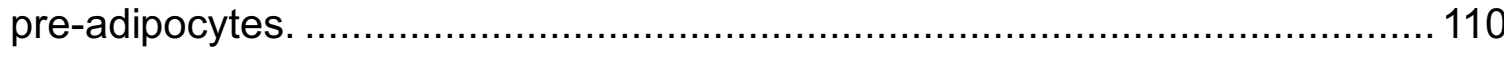

Figure 11. GTP levels of endogenous Rab5 in comparison with expression of PPARy during the differentiation of 3T3-L1 pre-adipocytes.

Figure 12. Selective effect of Rab5 constructs on the differentiation of 3T3-L1 pre-adipocytes.

Figure 13. Confocal images of 3T3-L1 cells overexpressing GFP and GFPconjugated Rab5 constructs.

Figure 14. Effect of Rab5 constructs on the expression of PPARy and CEB/Pa.

Figure 15. Selective effects of Rab5:Q79L double mutants on the differentiation of 3T3-L1 pre-adipocytes.

Figure 16. Bright-field images of 3T3-L1 cells overexpressing GFP,

Rab5:Q79L, or Rab5:Q79L double mutants.

Figure 17. Selective effect of Rab5 constructs on the differentiation of 3T3-L1 pre-adipocytes. 
Figure 18. A. Selective effect of Rab proteins on the differentiation of 3T3-L1 pre-adipocytes.

Figure 19. Effect of Rab5 and the Rab5 mutations on the expression and phosphorylation of the IR.

Figure 20. Effect of Rab5 constructs on the activation of Akt and Erk1/2 _........127

Figure 21. Effect of Rab5 and the Rab5 mutants on the expression of GLUT4.128

Figure 22. Representative Western blot of the content of Rab5 GEPs, Rab5 GAPs, typical adipogenic markers, and GAPDH.

Figure 23. Selective effect of RabGAP-5 on the differentiation of 3T3-L1 preadipocytes.

Figure 24. Selective effect of RN-tre on the differentiation of 3T3-L1 preadipocytes.

Figure 25. Selective effect of RIN1 on the differentiation of 3T3-L1 preadipocytes.

Figure 26. Selective effect of Rabex-5 on the differentiation of 3T3-L1 preadipocytes. 160

Figure 27. Selective effect of RAP6 on the differentiation of 3T3-L1 preadipocytes.

Figure 28. RIN1 effect on the differentiation of 3T3-L1 pre-adipocytes. 162

Figure 29. Effect of RIN1:WT on transcription factors. 163

Figure 30. Effect of RIN1 selective mutants on adipogenesis. 166

Figure 31. The activity of Akt and Erk1/2 before (0) and 15 minutes after hormone treatment.

Figure 32. Cell proliferation of GFP-, RIN1-, RIN1:R94A-, or RIN1:Y561Foverexpressed cells in the first $48 \mathrm{~h}$ after hormone induction. 169

Figure 33. Bright-field images of GFP-, RIN1-, RIN1:R94A-, or RIN1:Y561Foverexpressed cells in the first $48 \mathrm{~h}$ after hormone induction.

Figure 34. Differentiation of GFP and VPS34 overexpressed cells 172

Figure 35 . The activity of Akt and Erk1/2 at $0 \mathrm{~h}, 15 \mathrm{~min} 24 \mathrm{~h}$, and $48 \mathrm{~h}$ after hormone treatment. 
Figure 36. The activity of Akt and Erk1/2 at $0 \mathrm{~h}, 15 \mathrm{~min} 24 \mathrm{~h}$, and $48 \mathrm{~h}$ after hormone treatment.

Figure 37. Bright-field images of GFP and GFP-VPS34 overexpressed cells in the first $48 \mathrm{~h}$ after hormone induction.

Figure 38. Interaction of the IR-cytoplasmic tail and VPS9 containing proteins.

Figure 39. Analysis of the interaction between the IR-cytoplasmic tail and the RIN1:VPS9 mutants.

Figure 40. Analysis of interaction between the IR-cytoplasmic tail (IR- $\beta$ ) and RIN1:VPS9 mutants or IR- $\beta$ mutants and the RIN1:VPS9 domain.

Figure 41. Analysis of interaction between the IR-cytoplasmic tail (IR- $\beta$ ) and RIN1:SH2 domain. 


\section{ABBREVIATIONS}

ACBP: acyl-CoA-binding protein

ACC: acetyl-CoA carboxylase

ACS: acyl-CoA synthetase

AGPAT: 1-acylglycerol-3-phosphate acyltransferase

Akt: Protein kinase B

APS: adapter protein containing a $\mathrm{PH}$ and $\mathrm{SH} 2$ domain

ATGL: adipose triglyceride lipase

BAT: brown adipose tissue

BDNF: brain-derived neurotrophic factor

BHK: body hamster kidney

BMI: body-mass index

BMP: bone morphogenetic protein

BRFSS: Behavioral Risk Factor Surveillance System

C/EBP: CCAAT/enhancer-binding protein

cAMP: cyclic adenosine monophosphate

CC: coiled-coil

CCP: clathrin-coated pit

CCT: CTP:phosphocholine cytidylytransferase

CDK2: Cyclin-dependent kinase 2

$\mathrm{CHC}$ : clathrin heavy chain

CHRDL1: chordin and chordin-like-1

Cide: cell death-inducing DFF45-like effector 
CLC: clathrin light chain

CME: clathrin-mediated endocytosis

DAG: diacylglycerol

DGAT: diacylglycerol acyltransferase

EEA1: early endosome antigen 1

EGF: epidermal growth factor

EGFR: epidermal growth factor receptor

ER: endoplasmic reticulum

Erk: extracellular signal regulated kinase

FA-CoA: fatty acyl-CoA

FABP4: fatty acid binding protein 4

FAS: fatty acid synthase

FAT: fatty acid transporter

FATP: fatty acid transport protein

FDA: Food and Drug Administration

FGF: fibroblast growth factor

G3P: glycerol 3-phosphate

GAP: GTPase activating protein

GAPex-5: GTPase activating protein and exchange factor of Rab5

GDF: GDI displacement factor

GDI: guanine nucleotide dissociation inhibitor

GDP: guanosine di phosphate

GEF: guanine nucleotide exchange factor 
GFP: green fluorescent protein

GLUT4: glucose transporter type 4

GPAT: glycerol 3-phosphate acyltransferase

Grb2: growth factor receptor bound protein 2

GREB: cAMP response element-binding protein

GST: glutathione-S-transferase

GSV: GLUT4 storage vesicle

GTP: guanosine triphosphate

HB: helical bundle

HGF-1: hepatocyte growth factor 1

HSL: hormone-sensitive lipase

IGF-1R: insulin-like growth factor receptor 1

IGF: insulin-like growth factor

IL-1: interleukin 1

$\mathrm{IP}_{3}$ : inositol 1,4,5-trisphosphate

IR: insulin receptor

IRS: insulin receptor substrate

JNK: Jun N-terminal kinase

LD: lipid droplet

LDL: low density lipoprotein

MAPK: mitogen-activated protein kinases

MCE: mitotic clonal expansion

MEK: MAPK/Erk kinase 
MOG: myelin oligodendrocyte glycoprotein

MSC: mesenchymal stem cell

mTORC1: mammalian target of rapamycin complex 1

Myf5: myogenic factor 5

NGF: nerve growth factor

NHANES: National Health and Nutrition Examination Survey

PAP: phosphatidate phosphohydrolase

PI: phosphoinositide

PI3K: phosphoinositide 3 kinase

PI3P: phosphatidylinositol 3-phosphate

PIP2: phosphatidyl inositol-4,5-bisphosphate

PIP3: phosphatidyl inositol-3,4,5-triphosphate

PKA: protein kinase $A$

PLC-ү1: phosphoinositide phospholipase C

Plin: perilipin

PMSF: phenylmethane sulfonyl fluoride or phenylmethylsulfonyl fluoride

PPARY: peroxisome proliferator-activated receptor

PR: proline rich

PTB: phosphor-tyrosine-binding

RA: Ras association

Rab: Ras-related GTP-binding protein

Rab5: Ras-related protein 5

Rabex-5: Rabaptin-5 associated exchange factor for Rab5 
Raf: Rapidly Accelerated Fibrosarcoma

RAP6: Rab5-activating protein 6

Ras: rat sarcoma

$\mathrm{Rb}$ : retinoblastoma

RGC: RAL-GAP complex

RIN1: Ras interference 1

RME-6: receptor-mediated endocytosis protein 6

RME: receptor-mediated endocytosis

$\mathrm{RN}$-tre: related to the $\mathrm{N}$ terminus of tre oncogene

ROS: reactive oxygen species

RTK: receptor-tyrosine kinases

SDS-PAGE: sodium dodecyl sulfate polyacrylamide gel electrophoresis

SH2: SRC homology 2

SNS: sympathetic nervous system

SOS: son of sevenless

Src: sarcoma

SVF: stromal vascular fraction

TAG: triacylglycerols

TGF- $\alpha / \beta$ : transforming growth factor alpha/beta

TKD: tyrosine kinase domain

TNF-a: tumor necrosis factor alpha

TrkA/B: tropomyosin receptor kinase $A / B$

UCP1: uncoupling protein 1 
VEGF: vascular endothelial growth factor

VPS9: vacuolar protein sorting associated protein 9

WAT: white adipose tissue

WT: wild-type

B3-AR: $\beta 3$-adrenergic receptor 


\section{CHAPTER I}

\section{Introduction}

Adipose tissue includes a diversity of cell types, including endothelial cells, blood cells, fibroblasts, pre-adipocytes, and macrophages, with mature adipocytes as the main cell type.

Adipogenesis is an insulin receptor-driven signaling cascade that promote pre-adipocytes to differentiate into mature (brown and white) adipocytes through

the participation of some key transcription factors (Lowe et al., 2011). Specifically, adipogenesis is a programmed and highly-regulated process that requires factors like peroxisome proliferator-activated receptor $\mathrm{Y}$ (PPARY) and other transcription factor families, including CCAAT/enhancer-binding proteins (C/EBPs), signal transducers and activators of transcription (STATs), and Kruppel-like factor (KLF) proteins (Ali et al., 2013).

On the other hand, the intracellular membrane trafficking of the insulin receptor is an extremely complex process during which the receptor encounters its adaptor proteins as well as a variety of enzymes. One of them, the small GTPase Rab5, acts as a rate-limiting protein and governs the early stage of insulin receptor-mediated endocytosis. How this cellular process is regulated by the small GTPase Rab5 and its effectors during adipogenesis is not clearly understood. The specific roles of these intracellular factors, including the transcription factors, Rab5, and Rab5 regulators, their targets and the corresponding signaling events will be described. Thus, the working hypotheses and specific aims are proposed and 
discussed on the basis of the current knowledge and the information provided in this chapter.

\section{I.1 Adipogenesis: the mystery of obesity}

Along with the development of the society and the more comfortable and convenient accessibility of food source, obesity, as one of the most severe global health problems, receives attention all around the world. Meanwhile, adipogenesis has been extensively studied in the past four decades because of the increase in the number of obese people.

\section{I.1.1 Obesity: a global health problem}

\section{I.1.1.1 Obesity in history and modern life: from a symbol of beauty to the threaten of health}

Obesity is a medical condition in which excessive fat is formed and accumulated in the body with a body-mass index (BMI) $\geq 30 \mathrm{~kg} / \mathrm{m}^{2}$ (Haslam \& James, 2005). Rather than be treated only as a metabolic disorder, obesity nowadays has been recognized as a multifactorial disease. Type 2 diabetes, high blood pressure, osteoarthritis, stroke, congenital disabilities, and menstrual disorders are related to the increase of body weight (Haslam \& James, 2005). Besides, animal and human data show that high glucose/fat food consumption sabotage the appetite control by impairing hippocampal-dependent memories, which suggests obesity is a threat to the central nervous system (Morris et al., 2015). What is more, the comorbidities not only reduce life expectancy and increase the economic burden of the society, but also are associated with 
increased incidence and mortality of multiple types of cancers, including liver, colon, bladder, endometrium, and breast cancer (Ezzati et al., 2004; Giovannucci et al., 2010)

Obesity is derived from the Latin word obesitas. The ancient Greeks and Egyptians were the first ones on record to recognize obesity as a medical disorder (Heitmann et al., 2012). In the 6th century B.C., an Indian surgeon Sushruta related obesity with diabetes and heart disorders (Dwivedi \& Dwivedi, 2007). During the Middle Ages and the Renaissance ( 1300 A.D. to 1700 A.D.), obesity was a sign of wealth and prosperity and the symbol of beauty, not only in Europe but also in Asian (Bloomgarden, 2003). The values towards beauty can be represented by the artistic works at that time, such as the Portrait of Alessandro del Borro, a Tuscan nobleman and soldier, who fought in the wars against Ottoman Empire, was painted as a confident and over obese man; the Madonna with the Christ Child and St. John the Baptist, in which Madonna and Jesus were represented as overtly obese woman and child; and the Venus at a Mirror and the Woman at the well, in which women were drawn as overweight (Ferrucci et al., 2010). During the 19th century, both height and weight of human bodies increased in the developed world, which was believed to be associated with the efficient and sufficient access to food and accumulated society wealth as a result of the Industrial Revolution (Caballero, 2007). However, it happened quite recently (around the 1980s) that obesity attracted the sight of the public and started being extensively studied by researchers, and it was only until the 20th century that obesity was recognized to associate with mortality increase (Eknoyan, 2006). 
Since the beginning of the 20th century, public's view towards ideal body weight and the relationship between obesity and wealth changed dramatically. The change is supported by the data that the height of pageant winners of Miss American increased less than $2 \%$, but the trend of BMI decreased from 22 to 17.5 , which even belongs to the range of undernutrition defined by the World Health Organization (WHO) (Rubinstein \& Caballero, 2000).

Nowadays, increasing evidence demonstrates that obesity is becoming a global disease. According to the National Health and Nutrition Examination Survey (NHANES), in the U. S., during $1999-2002,86.3 \%$ and $84.2 \%$ of men and women who were diagnosed as diabetes were obese or overweight with $53 \%$ and $58 \%$ of them being obese, respectively (Report, 2004). Studies also found that nearly $29 \%$ of the world population was overweight or obese in 2013 , and nearly two out of three of the obese population lived in developing countries (Mckay, 2014). What is worse, the data of Behavioral Risk Factor Surveillance System (BRFSS) from 1990 to 2008 , show that obesity prevalence increased by $33 \%$ and severe obesity prevalence increased by $130 \%$. Researchers predicted that by the year $2030,42 \%$ of the population will be obese with a severe obesity $\left(\mathrm{BMI} \geq 40 \mathrm{~kg} / \mathrm{m}^{2}\right)$ prevalence of 11\% (Finkelstein et al., 2011).

\section{I.1.1.2 Adipose tissue: not only a fat storehouse}

Obesity, as the name implies, always happen with the symptom of a gain of body weight. The gain of body weight, however, mostly attributes to the increase in the mass of adipose tissue. 
Adipose tissue is loose connective tissue containing adipocytes, which are also the dominant component of adipose tissue; stromal vascular fraction (SVF), which includes adipocyte precursors, mesenchymal stem cells (MSCs), and endothelial precursor cells; and immune cells such as adipose tissue macrophages (Riordan et al., 2009). The MSCs resemble fibroblasts morphologically and have the capacity to differentiate into adipocytes, chondrocytes, myocytes and osteocytes under proper stimulation (Zuk et al., 2001). The endothelial precursor cells are capable of stimulating angiogenesis either directly or indirectly by secreting insulin-like growth factor 1 (IGF-1), hepatocyte growth factor 1 (HGF-1), and vascular endothelial growth factor (VEGF) (Rehman et al., 2004; Sumi et al., 2007). The adipose tissue macrophages are responsible for the production of the majority of tumor necrosis factor alpha (TNF- $\alpha$ ), which affects glucose homeostasis in adipocytes, promotes lipolysis and inhibit lipogenesis, and has been shown to relate with insulin resistance and type 2 diabetes (Cawthorn \& Sethi, 2008). Three types of adipocyte precursors, preadipocytes, the CD $34^{+} / C D 31^{-}$cell population, and the human multipotent adipose tissue-derived stem cells, were found in the SVF of human adipose tissue (Symonds, 2012). These adipocyte precursors, which have the capacity to differentiate into adipocytes, resident in adipose tissue during adult life, undergo self-renewal to produce adipocytes, and allow the adipose tissue to expand as much as 15 -fold as a result of a constant excess of fat intake (Symonds, 2012).

Researchers mainly focused on the regulation of lipolysis and lipogenesis since adipose tissue was only considered to be an energy storage organ in the 
past. They started realizing the importance and complexity of adipose tissue in the recent 20 25 years when adipose tissue was widely and extensively studied because of the increasing prevalence of obesity. Adipose tissue is crucial and multifunctional in the body. It is 1) the primary energy storage site, where excessive fat that surpasses the requirement of body will be stored; 2) the insulating layer, which reduces heat loss and maintains the body temperature; 3) the protect and support structure of some organs; 4 ) an endocrine organ that secretes numerous endocrine mediators, including hormones (adipokines), cytokines, and lipids; 5) an immune organ that helps in the removal of debris and apoptotic cells, and the maintenance of tissue homeostasis (Mraz \& Haluzik, 2014; Vegiopoulos et al., 2017).

However, the functions of adipose tissue have been found to be different and, to some extent, harmful to obese individuals. Adipose tissue changes histologically, functionally, and metabolically in the obese microenvironment. In obese patients, most adipose depots visibly expand in size, adipocytes increase in numbers and sizes, while the proportions of other types of cells also changed. Specifically, the expanded volume of adipose tissue and increased adipocytes cell number are principally the result of the reduced removal rate of triacylglycerol (TAG), the main component of fat in adipocytes (Arner et al., 2011). Additionally, excessive accumulation of fat leads to an increase of number and activity of some immune cells, such as macrophages, but a decrease of some others (Cildir et al., 2013). The elevated number of macrophages increases the secretion of TNF- $\alpha$ in both adipose tissue and the circulatory system, which is related to insulin resistant 
in vitro (Plomgaard et al., 2005). Besides, adipose tissue of obese patients has relatively reduced blood vessels and neural structure, which form a hypoxic microenvironment in adipose tissue, and are thought to be responsible for insulin resistant of obese patients (Coppack, 2005). In response to the hypoxia stress, adipocytes activate the p38 mitogen-activated protein kinases (p38 MAPKs) and the Jun N-terminal kinases (JNKs), which correlate with glucose uptake and insulin sensitivity (M. Bluher, 2013). The dysregulated secretion of TNF- $\alpha$, hypoxia microenvironment, and the stress-induced changes in signaling pathways attribute to an obesity-induced specific type of inflammation named chronic low-grade sterile inflammation. This type of inflammation is characterized by the increase of immune factors in the circulatory system and the absence of clinical signs of inflammation. It is also believed to play a crucial role in the development of insulin resistance in obese individuals (Medzhitov, 2008; Oliver et al., 2010). Overall, adipose tissue is crucial for energy control and the homeostasis of the human body. Its dysfunction in obese patients is the leading cause of the obesity-related diseases.

\section{I.1.1.3 White, brown, and beige: different colors with different functions?}

The two functionally distinct types of adipose tissue found in mammals are classified as the white adipose tissue (WAT) and the brown adipose tissue (BAT), where the white adipocytes and the brown adipocytes cluster, respectively. It is generally believed that under specific situations, the white adipocytes undergo a 
"browning" process and gain the features of brown adipocytes. These whiteoriginal brown adipocytes are named beige, or brite adipocytes. However, evidence also shows that the beige cells could be a distinct type of adipocytes which arise from unique precursor cells that are different from the white or brown (J Wu et al., 2012). The introduction of this dissertation will only focus on discussion of the universally brief of beige origin.

The WAT, taking up the majority of the adipose tissue, could be found both subcutaneously and viscerally, and is one of the most abundant tissues in the human body. The abnormal expansion/hypertrophy of WAT is the dominant factor to contribute to the weight gain and dysfunction of adipose tissue during obesity progression because of the fact that the WAT is poorly vascularized with relatively rare neural structures (Vazquez-Vela et al., 2008). White adipocytes, the main component of WAT, manage the primary functions of WAT, such as rapid accumulation and release of fatty acids, lipogenesis, lipid storage, and regulation of insulin sensitivity (Symonds, 2012). Adipocytes arise from the mesoderm during fetal development (Enerback, 2009). The development of white adipocytes, for a long time, is believed to derive from a myogenic factor 5 (Myf5)-negative lineage (Timmons et al., 2007). However, developmental studies challenged the view by providing evidence of the existence of Myf5-positive precursors in WAT (Figure 1). The mature white adipocytes are round-shaped cells variable in size from $25 \mu \mathrm{m}$ to $200 \mu \mathrm{m}$. They contain a single giant lipid droplet in the cytoplasm and a flattened, peripherally located nucleus (Table 1). The content and function of mitochondria are one of the main differences between the white and brown adipocytes. 
Mitochondria in white adipocytes are, like in other tissues, the main source of ATP, thin and spindle in shape, and though variable, still relatively few in numbers (Table 1). The dysfunction of mitochondria could cause the imbalance between production and decomposition of reactive oxygen species (ROS), which is thought to play a role in the metabolic dysregulation of obesity (Cedikova et al., 2016).

The BAT was thought to only exist in infants and small animals to defend cold temperature and maintain body temperature in the past (Rothwell \& Stock, 1979). But it has been found to locate in supraclavicular, paravertebral, and neck regions and been suggested to play a potential role in the treatment of obesity in the past three decades. As the name of BAT implies, the brown adipocytes comprise the main portion of it. The brown adipocytes, derive from the Myf5positive cell lineage, are relatively smaller (size from $15 \mu \mathrm{m}$ to $60 \mu \mathrm{m}$ ) polygonal cells with multiple scattered lipid droplets in the cytoplasm and a round, eccentrically, yet not peripherally, located nucleus (Table 1). Mitochondria in brown adipocytes are bigger and contain more cristae than the ones in white adipocytes. These mitochondria have unique elliptical shape, exist in the cytoplasm with enormous numbers, and exclusively express a transmembrane protein, uncoupling protein 1 (UCP1) (Figure 1). Together with high vascularization, the cytochromes of numerous mitochondria give the BAT the visible brown color (Table 1). Unlike the WAT whose regulation is principally controlled by insulin, the BAT is primarily innervated by the sympathetic nervous system (SNS), which responses to energy defect or increased energy expenditure, via activating of numerous-expressed $\beta 3$-adrenergic receptors ( $\beta 3-A R$ ) on the membrane of 
mature brown adipocytes (Table 1). The activation of $\beta 3-A R$ enhances the expression of UCP1 and hormone-sensitive lipase (HSL), and eventually promotes lipolysis and thermogenesis (Geerling et al., 2014).

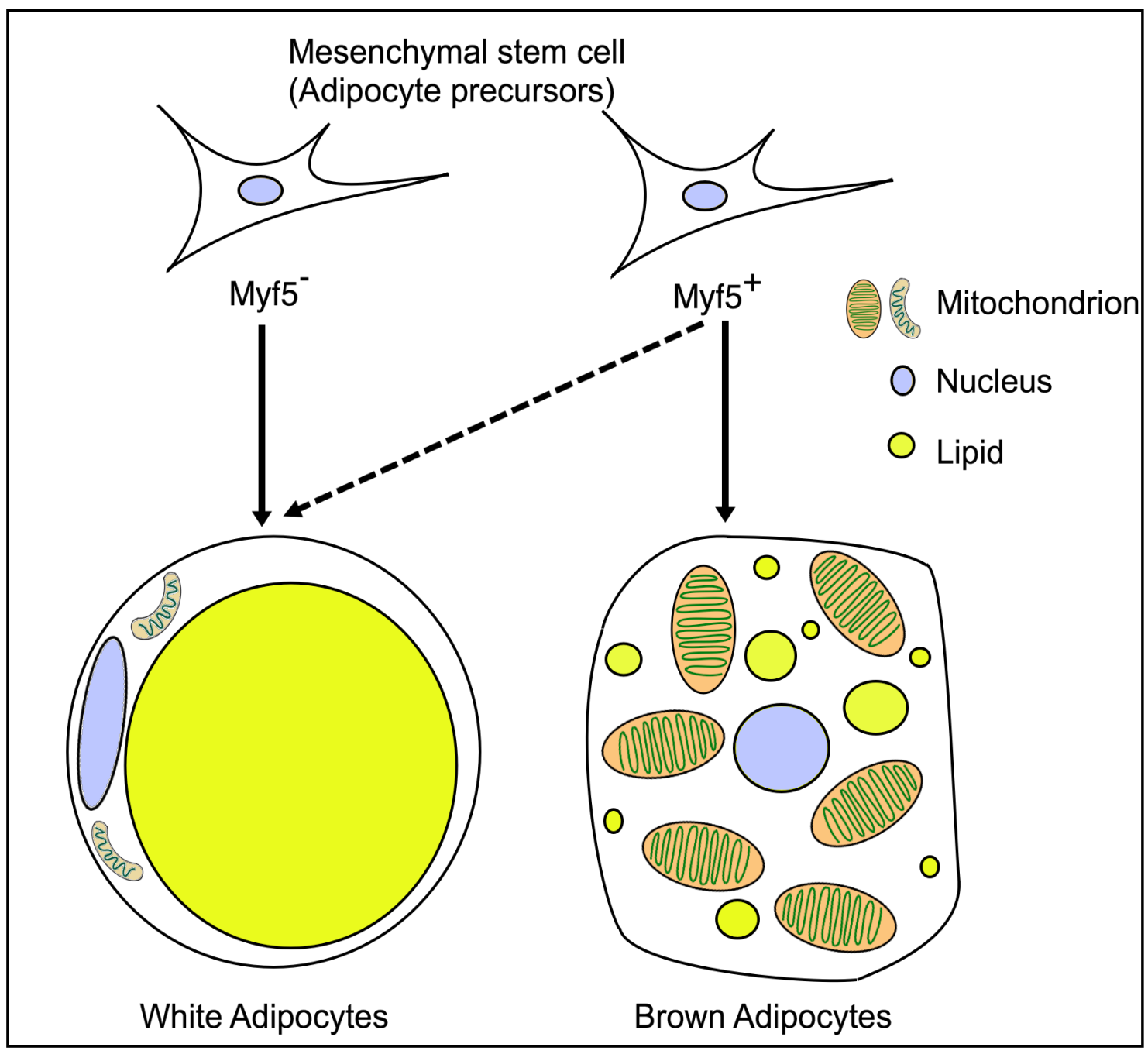

Figure 1. Origins and characteristics of white and brown adipocytes.

The white adipocytes are predominantly derived from Myf5- cells while the brown adipocytes are derived from $\mathrm{Myf5}^{+}$cells. Mature white adipocytes are round shaped cells containing a single giant lipid droplet in the cytoplasm, few mitochondria, and a flattened, peripherally located nucleus. Mature brown adipocytes are polygonal cells with multiple scattered lipid droplets in the cytoplasm, and a round, eccentrically, yet not peripherally, located nucleus. Brown adipocytes contain more mitochondria, which are bigger in size and have more cristae than the ones in white adipocytes. 
Table 1. Similarities and diversities of white, brown, and beige adipose tissue.

(Barneda et al., 2013; Cedikova et al., 2016; Kajimura et al., 2015; Saely et al., 2012; Sanchez-Gurmaches et al., 2012; Seale et al., 2008; Szentirmai \& Kapas, 2017; Vargas et al., 2015).

\begin{tabular}{|c|c|c|c|}
\hline Features & White & Brown & Beige \\
\hline Development & $\begin{array}{l}\text { Mesenchymal } \\
\text { stem cell; } \\
\text { Predominantly } \\
\text { Myf-negative } \\
\text { precursor cells }\end{array}$ & $\begin{array}{l}\text { Mesenchymal } \\
\text { stem cell; } \\
\text { Myf-positive } \\
\text { precursor cells }\end{array}$ & $\begin{array}{l}\text { Mesenchymal } \\
\text { stem cell; } \\
\text { Predominantly } \\
\text { Myf-negative } \\
\text { precursor cells }\end{array}$ \\
\hline Develop time & $\begin{array}{l}\text { Primarily after } \\
\text { birth }\end{array}$ & At neonatal stage & $\begin{array}{l}\text { Upon WAT } \\
\text { development }\end{array}$ \\
\hline Vasculature & $\begin{array}{l}\text { Poorly developed } \\
\text { Few capillaries }\end{array}$ & Highly developed & $N / A$ \\
\hline Nervous structure & Poor innervation & High innervation & $N / A$ \\
\hline Cell shape & Round & Polygonal & Round \\
\hline Cell size & $25 \mu \mathrm{m} \sim 200 \mu \mathrm{m}$ & $15 \mu \mathrm{m} \sim 60 \mu \mathrm{m}$ & $\begin{array}{l}\text { Variable } \\
\text { depending on } \\
\text { stimulation }\end{array}$ \\
\hline Nucleus & $\begin{array}{l}\text { Flattened, } \\
\text { peripherally } \\
\text { located }\end{array}$ & $\begin{array}{l}\text { Round, } \\
\text { eccentrically } \\
\text { located }\end{array}$ & $\begin{array}{l}\text { Depend on } \\
\text { stimulation }\end{array}$ \\
\hline $\begin{array}{l}\text { Lipid droplets } \\
\text { (LDs) }\end{array}$ & One giant LD & $\begin{array}{l}\text { Multiple small } \\
\text { LDs }\end{array}$ & $\begin{array}{l}\text { Multiple variable } \\
\text { sized LDs }\end{array}$ \\
\hline Mitochondria & $\begin{array}{l}\text { Few } \\
\text { Thin and spindle }\end{array}$ & $\begin{array}{l}\text { High amount } \\
\text { Large and } \\
\text { elliptical or round }\end{array}$ & $\begin{array}{l}\text { Variable } \\
\text { depending on } \\
\text { stimulation }\end{array}$ \\
\hline UCP1 expression & Undetectable & High & $\begin{array}{l}\text { Variable } \\
\text { depending on } \\
\text { stimulation }\end{array}$ \\
\hline $\begin{array}{l}\text { Endoplasmic } \\
\text { reticulum }\end{array}$ & Normal amount & Poor & $\begin{array}{l}\text { Depend on } \\
\text { stimulation }\end{array}$ \\
\hline Main function & Fat storage & Thermogenesis & $\begin{array}{l}\text { Adjust to cold } \\
\text { exposure; } \\
\text { thermogenesis }\end{array}$ \\
\hline Location & $\begin{array}{l}\text { Subcutaneous } \\
\text { and visceral }\end{array}$ & $\begin{array}{l}\text { Cervical, } \\
\text { supraclavicular, } \\
\text { paravertebral }\end{array}$ & Within WAT \\
\hline Role in obesity & Positive & Negative & Negative \\
\hline
\end{tabular}


The discovery and study of beige (or brite) adipocytes came up quite recently when researchers observed the trans-differentiation of brown-like adipocytes from white adipocytes in WAT depots after chronic cold exposure (Barbatelli et al., 2010). The first usage of the term "beige" to define the brown-like white adipocytes, to my knowledge, was in the comments to a published paper discussing de novo recruitment of brown adipocytes in 2010 (Vegiopoulos et al., 2010; Ishibashi \& Seale, 2010). The trigger of the browning process has not been fully elucidated but appears to be affected by the excitement of the SNS, levels of hormones, the tension of physical exercises, and time and extent of cold exposure (Poekes et al., 2015). Many studies support the decisive role of $\beta 3-A R$ in white adipocyte browning (Bartness \& Ryu, 2015). But controversial views came up towards the necessarily of the activation of $\beta 3-A R$, either by the norepinephrine or the $\beta 3$-adrenergic agonist, in the browning process. The passive role of $\beta 3-A R$ is supported by evidence that the $\beta 3-A R$ is dispensable for the browning process (de Jong et al., 2017). Since the beige cells are transdifferentiated from the white adipocytes, it is predictable that they share some features in morphology and function with the white adipocytes, such as sharing the same precursors as well as the same locations (Table 1). Upon the browning process, the beige cells will show intermediate features between the two types of adipocytes and generally transform towards the brown ones. The changes include increased expression of UCP1 in mitochondria, increased number but decreased size of lipid droplets and mitochondria, increased sensitivity of $\beta 3-A R$, increased innervation and vascularization (Table 1). Recently, the beige cells attract a broad interest from 
scientists as a result of its exercise- and temperature-inducible characteristics. More will be discussed in the next unit.

\section{I.1.1.4 Current therapies of obesity: a long way to go}

As one of the most severe and prevalent diseases raised recently, variable treatments towards obesity are offered for obese patients to choose from. Basic strategies of weight control include diet to control the total intake of calories, physical activities/exercises to consume energy, and behavior change/lifestyle therapies (Kushner, 2014). Multiple drugs, such as phentermine, orlistat, lorcaserin, and certain combinations such as phentermine/topiramate, functioning as either appetite suppressors or lipogenesis inhibitors, have been approved by the Food and Drug Administration (FDA) for the treatment of obesity. The most effective treatment for obesity may be bariatric surgery. However, only severe patients or patients with severe complications should be considered as surgery candidates. The decision to undergo surgery must be made on the basis of a comprehensive assessment evaluating both risks and benefits (Mechanick et al., 2013). As a consequence of the low patient compliance with physical therapies, unavoidable side effects of current medicines, restrict applicability of surgery, researchers and doctors are still looking for effective and safe ways to treat obesity.

Several studies have been done to detect the potential possibility of recruiting and activating the BAT and beige cells in obese patients for weight control because of the negative role of BAT and beige in obesity. Gene transgenic mice with ablated BAT were associated with insulin resistance and non-insulin- 
dependent diabetes mellitus, reduced rate of energy consumption, and considerable obesity even with a regular diet (Hamann et al., 1988). Besides, human studies showed that the BAT activity is negatively related with BMI and body fat percentage, but was positively associated with cold-induced thermogenesis (Vijgen et al., 2011; van Marken Lichtenbelt \& Daanen, 2003). Though some in vitro studies showed that activating $\beta 3-A R$ promotes lipolysis and thermogenesis of both brown and beige adipocytes as described above, the usage of $\beta 3-A R$ agonists for obesity treatment received disappointing results in humans so far (S Qian et al., 2015).

Bone morphogenetic protein 4 (BMP-4) agonist and BMP-4 inhibitors have recently been recommended as a potential medicine or drug target, respectively, for obesity treatment. An animal study showed that BMP-4 transgene mice exhibited a reduced WAT mass, decreased number of white adipocytes, and increased beige cells and SVF (SW Qian et al., 2013). Conversely, the BMP-4knockout mice had depressed UCP-1 expression, decreased mitochondria size, and increased lipogenesis along with diminished insulin sensitivity (SW Qian et al., 2013). Human studies showed that silencing of Gremlin-1, a potent BMP-4 inhibitor, dramatically increased both beige and BAT markers, while the silencing of chordin and chordin-like-1, a BMP-4 binding protein, markedly reduced adipogenesis markers, such as peroxisome proliferator-activated receptor-gamma (PPARY) and fatty acid binding protein 4 (FABP4) (Gustafson et al., 2015). However, since BMPs have a broad range of functions not only on adipocytes but also on 
angiogenesis and bone formation, the usage of BMP agonists on obese treatment needs to be intensely studied before being used on humans.

Other factors like IGF-1, fatty acids, glucocorticoids, macrophage colony stimulating factor, and prostaglandins, have been identified as stimulators of the adipogenesis process (MacDougald \& Mandrup, 2002). While some other factors, such as proteins from the Wnt family, transforming growth factor beta (TGF- $\beta$ ), interleukin 1 (IL-1), TNF- $\alpha$, and epidermal growth factor (EGF), all showed inhibitory role in adipogenesis (MacDougald \& Mandrup, 2002). However, it is difficult to use these intracellular or extracellular factors as targets since the stimulation or inhibition of them could result in complex cellular and systematic responses.

Quite recently, Gomisin N, a physiological lignan extracted from Schisandra chinensis, showed inhibitory effects on pre-adipocyte differentiation (Jang et al., 2017). But whether this lignan functions appropriately in vivo and whether it will induce severe side effect in the human body remain unknown.

In summary, to find a thorough and secure treatment for obesity still requires more lab work and clinical tests to be done.

\section{I.1.2 Process of adipogenesis in vitro: the lipids factory under precise regulation}

Adipogenesis is the formation of mature adipocytes differentiated from fibroblast-like pre-adipocytes. Thus, when considering obesity from a molecular level, the essential cause could be viewed as a result of the formation and 
accumulation of adipocytes both subcutaneously or/and viscerally. Besides, adipogenesis is a continuously happened normal physiological process that not only store lipids for energy expenses, but also regulate body metabolism and homeostasis.

The highly-controlled process of adipocyte differentiation, especially the white adipocyte differentiation, has been extensively studied in the past 30 years. Two types of in vitro experimental models have been used. One is the preadipocyte cell lines, such as the 3T3-L1 and the 3T3-F442A cell line, which is isolated from the Swiss $3 T 3$ cell line. These pre-adipocyte cell lines only have the ability to differentiate into adipocytes. The other is the multipotent stem cell lines, such as the $\mathrm{C} 3 \mathrm{H} 10 \mathrm{~T} 1 / 2$ cell line from $\mathrm{C} 3 \mathrm{H}$ mouse embryonic stem cell precursors and the adipose-derived stem cells from human adipose tissue. These multipotent cell lines have the potential to commit to different lineages, including adipose, bone, and muscle lineage (Moreno-Navarrete \& Fernández-Real, 2012).

To achieve a successful differentiation into mature adipocytes, morphology, transduction of signals, and protein expression of the pre-adipocytes change dramatically through a regulated process. All mature adipocytes are characterized by the existence and accumulation of big lipid droplets (comparing to other type of cells) in the cytosol, high expression of adipogenic transcription factors (such as PPARY and CCAAT/enhancer-binding proteins (C/EBPs)) and adipogenic markers (such as acetyl-CoA carboxylase (ACC), fatty acid synthase (FAS), and fatty acid binding protein 4 (FABP4)). However, the stimulation of differentiation and the 
adipogenesis process for the three types of adipocytes - the white, brown and beige cells - are not the same.

\section{I.1.2.1 Lipids and lipid droplets in adipocytes}

Lipid droplets (LDs) are lipid-rich cellular organelles that can be found in all eukaryotic organisms and even some prokaryotic cells (Grant \& Donaldson). The formation of lipid droplets in the cytosol, with a variable range from less than $1 \mu \mathrm{m}$ to more than $100 \mu \mathrm{m}$, is the main characteristic of mature adipocytes (Suzuki et al., 2011). Thus, it is of great importance to understand the structure and metabolism of the LDs (Figure 2).

In adipocytes, LDs are observed as round structures under the microscope. The lipid droplets are isolated from other organelles and the aqueous intracellular environment by a monolayer of phospholipid embedded or adhered by several types of proteins, including the perilipin (Plin) family proteins (Plin1 5), the cell death-inducing DFF45-like effector (Cide) family proteins (Cidea, Cideb, Cidec), adipose triglyceride lipase (ATGL), and some membrane-trafficking proteins (Barneda et al., 2013; Guo et al., 2009). The Plins stabilize the lipid droplets and govern lipolysis. The Cides regulate the size of LDs. The adipose triglyceride lipase hydrolyzes the first fatty acid of triacylglycerol (TAG) to start lipolysis. Membranetrafficking proteins, such as the Rab proteins, govern the fission and fusion of vesicles, deliver proteins to different cellular compartments, and regulate the signal transduction. With the phospholipid layer surrounded, the hydrophobic core of LDs in white adipocytes are predominately made up of triacylglycerols (TAGs) (Figure 
2.A). Thus, the formation and growth of LDs require the production and transportation of the core lipids (mainly TAGs with a small amount of sterol esters), the surface phospholipid monolayer and the lipid-related proteins. Several models have been proposed to describe the life cycle of LDs, but none of the models was successfully and sufficiently supported by current data. The following introduction will build on studies conducted on 3T3-L1 pre-adipocytes cell line in vitro or/and mice/human adipose tissue in vivo.

Generally, the life cycle of the LDs starts with fatty acids. The fatty acids can diffuse into the cell through fatty acid transporter (FAT, CD36) or fatty acid transport proteins (FATPs, especially the FATP1) that are located on the cell membrane. The fatty acids can also be synthesized through de novo lipogenesis that takes place in the cytoplasm (Figure 2.B). De novo lipogenesis normally contributes about $20 \%$ of the total adipose TAG formation. But this de novo lipogenesis process is able to provide all necessary fatty acids for adipogenesis process (Strawford et al., 2004; JM Collins et al., 2011). The fatty acid transport protein type 1 (FATP1) is highly expressed on the membrane of both WAT and BAT initially (Schaffer \& Lodish, 1994). Though insulin stimulation does not change the expression of FATP1, it facilitates the translocation of FATP1 to the plasma membrane from an intracellular compartment in the 3T3-L1 pre-adipocytes (Stahl et al., 2002). During de novo lipogenesis, palmitate (C16:0) is constructed by continuously adding malonyl-CoA to acetyl-CoA (Figure 2). Two key enzymes are involved in the process: ACC and FAS (JM Collins et al., 2011). First, acetyl-CoA, an intermediate product of glycolysis, is carboxylated into malonyl-CoA by ACC 
(Wakil \& Abu-Elheiga, 2009). Acetyl-CoA carboxylase (ACC) is a complex multifunctional biotin-containing enzyme system that performs the carboxylation reaction through two steps: 1) ACC acts as a biotin carboxylase in an ATPdependent manner; 2) ACC acts as a carboxyl transferase to transfer the carboxyl group from biotin to acetyl-CoA to form malonyl-CoA (Gurr et al., 2016). Next, the condensation reaction is conducted by FAS to form 16-carbon palmitate using acetyl-CoA and malonyl-CoA as substrates (Currie et al., 2013). The FAS is a giant multifunctional enzyme system formed by homodimer of two identical monomers (Berg et al., 2015). Each monomer has seven covalently linked catalytic sites, which are divided into three domains, to produce palmitate (Chirala \& Wakil, 2004). The chemically inert FAs, either diffuse into the cell or be generated endogenously, need to bind to cytosolic FABP4 and be esterified with CoA. The esterification is an ATP-dependent two-step reaction conducted by acyl-CoA synthetase (ACS) to enter the bioactive pool in the form of fatty acyl-CoA (FA-CoA) that binds to the acyl-CoA-binding protein (ACBP) (Figure 2.B). Fatty acid binding protein 4 (FABP4) belongs to the FABP family and is highly expressed in adipocytes. It is a $\sim 15 \mathrm{kDa}$ small protein, which acts as intracellular lipid carrier and transporter, to regulate lipid trafficking and targeting (Furuhashi et al., 2014).

The majority of TAGs are generated through the glycerol 3-phosphate (G3P) pathway at the endoplasmic reticulum (ER) membrane where the synthesis process is conducted by enzymes either permanently or transiently located (Pol et al., 2014). More specifically, the TAGs are formed and deposited between the leaflets of the ER membrane (Kohlwein et al., 2013). As the triose sugar backbone 
of TAG, G3P is mainly generated through 3 metabolic processes: 1) gluconeogenesis, in which dihydroxyacetone phosphate is reduced to G3P by G3P dehydrogenase during glycolysis, 2) phosphorylation of glycerol via glycerol kinase, and 3) glyceroneogenesis, in which G3P is formed from nonglycerol/glucose precursors, such as pyruvate, amino acids, and lactate (Reshef et al., 2003). Gluconeogenesis can be upregulated in obese individuals since the activity of G3P dehydrogenase from lean individuals is only half of that from the morbidly adipose tissue of obese individuals (Swierczynski et al., 2003). Under insulin stimulation, the PPARy-mediated increased expression and activity of glycerol kinase allow glycerol to be a direct source of G3P (Guan et al., 2002). However, by using the tritium $\left(\left[{ }^{3} \mathrm{H}_{2}\right] 0\right)$ to track body water, glyceroneogenesis was found to be the quantitatively dominant source of G3P in adipose tissue of rats (Nye et al., 2008).

Triacylglycerol synthesis is the esterification of the alcoholic groups of G3P in a row. Several reactions happen successively and are conducted by specific enzymes, including G3P acyltransferase (GPAT), 1-acylglycerol-3-phosphate acyltransferase (AGPAT), phosphatidate phosphohydrolase (PAP), and diacylglycerol acyltransferase (DGAT) (Figure 2.B). First, GPAT and AGPAT transfer acyl groups to G3P stepwise. Then PAP catalyzed the dephosphorylation reaction, and DGAT converts the generated diacylglycerol (DAG) to TAG (Saponaro et al., 2015). DGAT is one of the most important enzymes in the process. The expression and activity of DGAT can be upregulated by both insulin and 
glucose. However, the deletion of DGAT in adipocytes leads to depleted DGAT activity, TG synthesis, and LD formation (Harris et al., 2011; Meegalla et al., 2002).

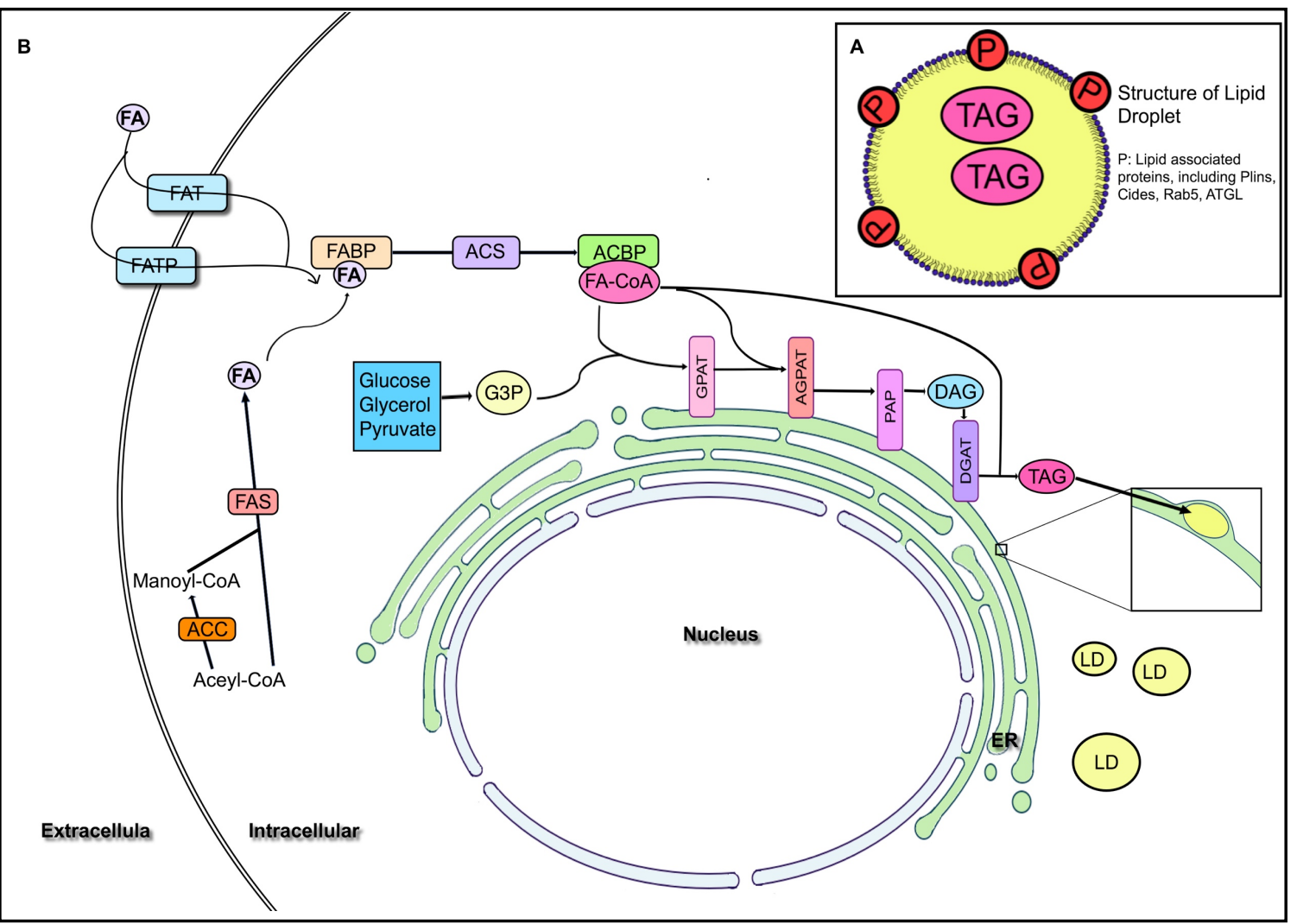

Figure 2. Structure and formation of lipid droplets (LD) in adipocytes.

A. LD structure. LD is observed as round structure with a hydrophobic core mainly made up of TAGs. LD is surrounded by a monolayer of phospholipid embedded or adhered by several types of proteins, including the Plins, the Cides, ATGL, Rab5, and Rab18. B. Formation of LDs. Fatty acids from the diet were either transported into adipocytes through FAT and FATP located on the plasma membrane or synthesized de novo in the cytosol from acetyl-CoA. The inert fatty acids will be activated by ACS to form FA-CoA. Then on the membrane of ER, TAG will be synthesized using G3P and FA-CoA as substrates via a chain of reactions mediated by GPAT, AGPAT, PAP, and DGAT.

(ACBP: acyl-CoA-binding protein; ACS: acyl-CoA synthetase; AGPAT: 1acylglycerol-3-phosphate acyltransferase; ATGL: adipose triglyceride lipase; Cide: cell death-inducing DFF45-like effector; DAG: diacylglycerol; DGAT: diacylglycerol acyltransferase; ER: endoplasmic reticulum; FA-CoA: fatty acyl-CoA; FAT: fatty acid transporter; FATP: fatty acid transport protein; G3P: glycerol 3-phosphate; GPAT: glycerol 3-phosphate acyltransferase; PAP: phosphatidate phosphohydrolase; Plin: perilipin; TAG: triacylglycerol.) (JM Collins et al., 2011; Ehehalt et al., 2006; Garrett \& Grisham, 2017; Pol et al., 2014; Gurr et al., 2016; Fujimoto \& Parton, 2011) 
Though it is widely believed that the TAGs are synthesized between the leaflets of the ER membrane, how the neutral lipids and LD-associated proteins are assembled, how and whether the mature LDs separate from the ER membrane remain incompletely understood (Hashemi \& Goodman, 2015). The exact pathways of LDs expansion and how much each possible pathway contribute to LDs expansion also remain unclear. Nevertheless, it is widely accepted that LDs can grow in size. One possibility is that the neutral lipids and phospholipids were transported to the LDs through LD-ER contact sites (Yang et al., 2012). The assumption was supported by electron and immunoelectron microscopy data showing that the small LDs (around $1 \mu \mathrm{m}$ in diameter) were surrounded by several layers of ER (Heid et al., 2014). Another possibility is that the neutral lipids and phospholipids were synthesized directly on the LDs membrane. This scenario is supported by localization of neutral lipids synthesis related proteins - such as GPATs, AGPATs, and DGATs - and phospholipid related proteins - such as CTP:phosphocholine cytidylyltransferase (CCT) - on the LDs membrane (Guo et al., 2008; Wilfling et al., 2013). Fusion of smaller LDs into bigger LDs also seems to contribute to the growth of LDs. The fusion event is rare in normal conditions but happens quite often in the 3T3-L1 pre-adipocytes upon insulin treatment (Guo et al., 2008; Ariotti et al., 2012).

In summary, the formation of LDs is a multistep process that is conducted by a series of enzymes whose expression and activity can be regulated by extracellular stimuli - such as insulin and glucose. 


\section{I.1.2.2 Insulin, dexamethasone, 3-isobutyl-1-methylxanthine: the three musketeers}

As is mentioned above, adipocyte differentiation is a highly regulated and complicated process in which numerous hormones, proteins, and signaling pathways function together and successively. Commonly, scientists mimic the trigger of pre-adipocyte differentiation by adding a hormone combination containing insulin, dexamethasone (DEX), and 3-isobutyl-1-methylxanthine (IBMX) in vitro. These three "musketeers" work together to help d'Artagnan - the preadipocytes - undergoing a regulated differentiation process. Though how exactly these hormones regulate adipogenesis is not fully explored, some basic functions will be discussed below.

Insulin is a major regulator of cell metabolism and also the most potent hormone among the three "musketeers" to initiate adipogenesis (Klemm et al., 2001). It is a hormone secreted by $B$ cells of the pancreas and performs its function of regulating carbohydrate metabolism by activating the insulin receptors (IRs) and the IGF receptors (IGFRs) located on the plasma membrane (details of the IR, the IGFR, the insulin signaling pathways, and how the pathways affect adipogenesis will be discussed later in another section). The human circulating (biological active) insulin is a monomer made up of two chains: an A chain with 21 amino acids and a B chain with 30 amino acids (De Meyts, 2004). In general, insulin alters body metabolism by affecting glucose transport and glycolysis, fatty acids and TAG synthesis, the rate of protein synthesis, and the expression of adipocyte differentiation-associated proteins (Dimitriadis et al., 2011). 
The capability of insulin to govern the transportation of glucose, which is essential for adipocyte differentiation as the source of energy and TAGs, mostly relays on its regulatory role towards the glucose transporter type 4 (GLUT4). The GLUT4, an insulin-sensitive glucose transport protein, is uniquely expressed on the plasma membrane of adipocytes (James et al., 1988). Under the normal state (without insulin stimulation), only a small portion of GLUT4s are found on the cell surface, while the majority of GLUT4s stay on specific intracellular compartmentsthe specialized GLUT4 storage vesicles (GSVs)-which locate peripherally close to the plasma membrane (Leto \& Saltiel, 2012). Insulin augments the cell surface GLUT4 of adipocytes by increasing exocytosis of the GSVs and decreasing endocytosis of GLUT4 on the plasma membrane (Czech \& Buxton, 1993; Jhun et al., 1992). These GLUT4 transporters were endocytosed into the cell through both clathrin-mediated endocytosis and the cholesterol-dependent endocytosis (Lajoie \& Nabi, 2010). During internalization, small GTPases (e.g., Rab5), guide the GLUT4-containing vesicles towards the cell interior (Huang et al., 2001). Upon the stimulation of insulin, several intracellular signaling cascades are initiated, including the extracellular signal regulated kinase (Erk)1/2 signaling cascade, and the phosphatidylinositide 3-kinase (PI3K)/Akt signaling cascade (Zarich et al., 2006). However, the former cascade has been found to be unimportant for glucose transportation (Lazar et al., 1995). Instead, the insulin signaling pathway significantly increases the exocytosis of GSVs by controlling the activation states of small GTPases via activating the PI3K/Akt signaling cascade (Leto \& Saltiel, 2012). Once is recruited and activated, Akt phosphorylates and inactivates two 
GAPs, the AS160 - for vesicle translocation, and the RAL-GAP complex (RGC) for vesicle targeting (Leto \& Saltiel, 2012). Thus, insulin is able to regulate glucose uptake by increasing the GLUT4 level and the duration of GLUT4 remains on the plasma membrane. Besides, studies also show that the 3T3-L1 pre-adipocytes, once they reach confluence, become more sensitive to insulin stimulation. Under the pre-confluent state, the cell surface GLUT4 level of 3T3-L1 cells was increased by $70 \%$ upon insulin stimulation; while under confluent state, the surface transporter level of 3T3-L1 cells was increased by $270 \%$ upon insulin stimulation (Govers et al., 2004).

Dexamethasone is a synthetic glucocorticoid that performs an antiinflammatory role in the body. It triggers the differentiation of primary MSCs into osteocytes and adipocytes in vitro. With either an increased concentration of DEX in media or an extended incubation time with DEX, the MSCs prefer adipogenic differentiation than osteogenic differentiation (Yin et al., 2006). 3-isobutyl-1methylxanthine (IBMX) is one of the most potent and competitive, non-specific inhibitor of phosphodiesterases that enhance the intracellular cyclic adenosine monophosphate (CAMP) and activate protein kinase A (PKA) (Schroeder et al., 2012). Since the PKA signaling pathway is required for the transcriptional activation of PPARY, IBMX performs a regulatory role in the gene expression during differentiation. A study has shown that treatment of IBMX on the 3T3-L1 cells does not drive the pre-adipocytes towards adipogenic differentiation. But that did not represent a final fate of the pre-adipocytes. Indeed, treatment of DEX on 
IBMX pre-treated cells followed by an additional 48 hours of IBMX treatment triggered the differentiation process (Pantoja et al., 2008).

In conclusion, the three hormones, insulin, DEX, and IBMX, ensure the 3T3L1 pre-adipocytes to enter and complete the differentiation process properly. Insulin promotes the adipogenesis process by regulating the GLUT4 levels on the plasma membrane and the sensitivity of the cells to respond to insulin stimulation. Dexamethasone, in combination with IBMX, increase the expression of PPARY, C/EBPס, and C/EBP $\beta$, which are important adipogenic transcription factors for adipocyte differentiation (Cao et al., 1991).

\section{I.1.2.3 Adipogenesis in vitro: the mitotic clonal expansion phase and the morphological change/terminal differentiation phase}

As is mentioned above, two different kinds of in vitro models are used in the study of adipocyte differentiation: the pre-adipocyte cell lines and the multipotent stem cell lines. Some cell types undergo a proliferative phase called the mitotic clonal expansion (MCE) phase before terminal differentiation, while some other cell types directly enter the differentiation phase. Here, I will discuss the 3T3-L1 (pre-adipocyte cell line) adipogenesis process.

In the process of 3T3-L1 pre-adipocytes differentiation, insulin action, glucose uptake, lipid transportation and synthesis, transcription factors (e.g., PPARy and C/EBPa), cell cycle proteins (e.g., CDK2 (Cyclin-dependent kinase 2), cyclin D1 and retinoblastoma (Rb)), adipocyte-associated proteins (e.g., ACC and FAS), and activation of signaling cascades (e.g., the insulin signaling pathway) are 
required (Koppen \& Kalkhoven, 2010). Before hormone activation, the preadipocytes stop proliferation once they reach cell confluence. The treatment of hormone cocktail (combination of insulin, DEX, and IBMX) will trigger the cells to enter the fate of differentiation, which includes two phases: the MCE phase and the morphological change/terminal differentiation phase (Figure 3). The former phase consists of two rounds of post-confluence mitosis, and the latter phase, including the transition to a round cell shape from an elongated cell shape and to contain large globules of fat in the cytoplasm, is the morphological change of preadipocytes into adipocytes, (Figure 3).

In the MCE phase (usually occupies the first 48 hours after hormone treatment), a group of cell cycle proteins are periodically expressed and degraded to ensure proliferation through mitosis. Cyclin D1 is a protein expressed periodically in the G1 phase of the cell cycle, and it is required for the transition from $\mathrm{G} 1$ phase to S phase. cAMP elevates the expression of cyclin D1 during the first few hours of adipogenesis, which is induced by IBMX and insulin (Fox et al., 2008). CDK2 belongs to a family of protein kinases that regulated the cell cycle. The expression of CDK2 is required during the G1/S transition because of its catalytic role in the cyclin-dependent protein kinase complex (Peng et al., 2016). Retinoblastoma is phosphorylated by the cyclin-dependent protein kinase complex, which promotes transcriptional activation of the cell cycle required genes to drive the cells enter S phase (Berthet et al., 2006).

Meanwhile, adipogenic specific proteins (e.g., C/EBPs and PPARY) are regulated transcriptionally, which will be discussed in the next section. 


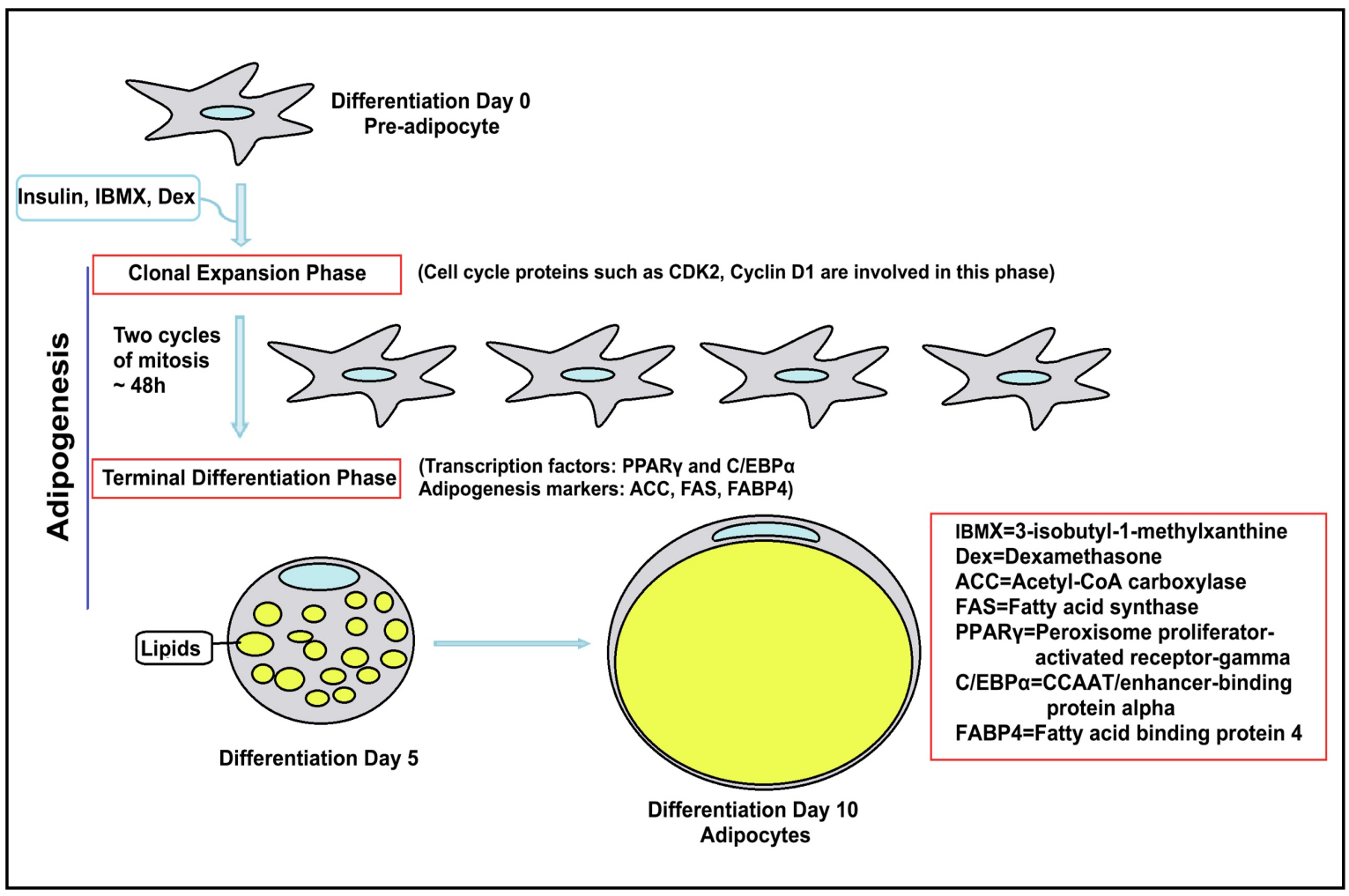

\section{Figure 3. The process of adipogenesis.}

Pre-adipocytes are fibroblast-like elongate-shaped cells with a round, centrally located nucleus. Upon the stimulation of hormone cocktail (combination of insulin, IBMX and DEX), pre-adipocytes undergo a ten-day process of differentiation named adipogenesis. Two phases are involved in this process. The clonal expansion phase, which happens in the first 48hs of adipogenesis, allows preadipocytes to go through two cycles of mitosis to quadruple the cell. In the latter terminal differentiation phase, lipid droplets will be generated, accumulated, and fused in the cytoplasm and eventually form a large lipid vacuole. (Rosen \& Spiegelman, 2000)

\section{I.1.2.4 The adipogenic markers: C/EBPs (C/EBPa, C/EBP $\beta$, and C/EBPס) and PPARY}

A series of changes happen simultaneously and successively in transcriptional level during adipogenesis (Figure 4). The C/EBP family members share the characteristics of C-terminal leucine zipper domain for dimerization and a DNA-binding domain for transactivation activity. Three of the family members, $\mathrm{C} / \mathrm{EBP} \alpha / \beta / \delta$, have established roles in adipogenesis. During the first 24 hours after 
hormone treatment, a transient, fast, and dramatic accumulation of C/EBP $\beta$ and C/EBP $\delta$ will appear within the MCE phase (Figure 4). The expression of C/EBP $\beta$ is critical for adipogenesis, which is supported by a study showing that mouse embryo fibroblasts from C/EBP $\beta(-/-)$ mice never enter the MCE phase and cannot differentiate into adipocytes (Tang et al., 2003). Once is hyperphosphorylated by the mitogen-activating protein kinase (MAPK) and glycogen synthase kinase $3 \beta$ (GSK-3 $\beta$ ), C/EBP $\beta$ acquires its DNA-binding activity and transactivate both C/EBPa and PPARY (Tang et al., 2005). Though C/EBP $\beta$ appears within 2 hours after hormone induction, it only gains DNA-binding activity after a long lag when the cells enter S phase during the mitotic clonal expansion phase (MCE) (Figure 4). An in vivo study shows that newborn C/EBP $\beta(-/-) \cdot \delta(-I-)$ mice does not accumulate droplets, and ependymal fat pad weight of adult C/EBP $\beta(-/-) \cdot \delta(-/-)$ mice is significantly reduced (Tanaka et al., 1997). The growth of C/EBPס deficient pre-adipocytes are dramatically depressed under hormone induction (Hishida et al., 2009). However, the overexpression of C/EBP $\beta$, not C/EBPD, is sufficient to induce adipogenesis, which indicates a regulatory, but less important role of C/EBPD in adipogenesis (Yeh et al., 1995). The expression of C/EBP $\beta$ and C/EBP $\delta$ both peak shortly after hormone induction and experience a sudden decrease together with the expression of low levels of C/EBPa and PPARY. C/EBPa and PPARy can then initiate the expression of each other in a positive feedback loop, perform proliferation inhibition activity, regulate adipogenic genes and proteins, and remain continuously elevated during adipogenesis (Figure 4). 


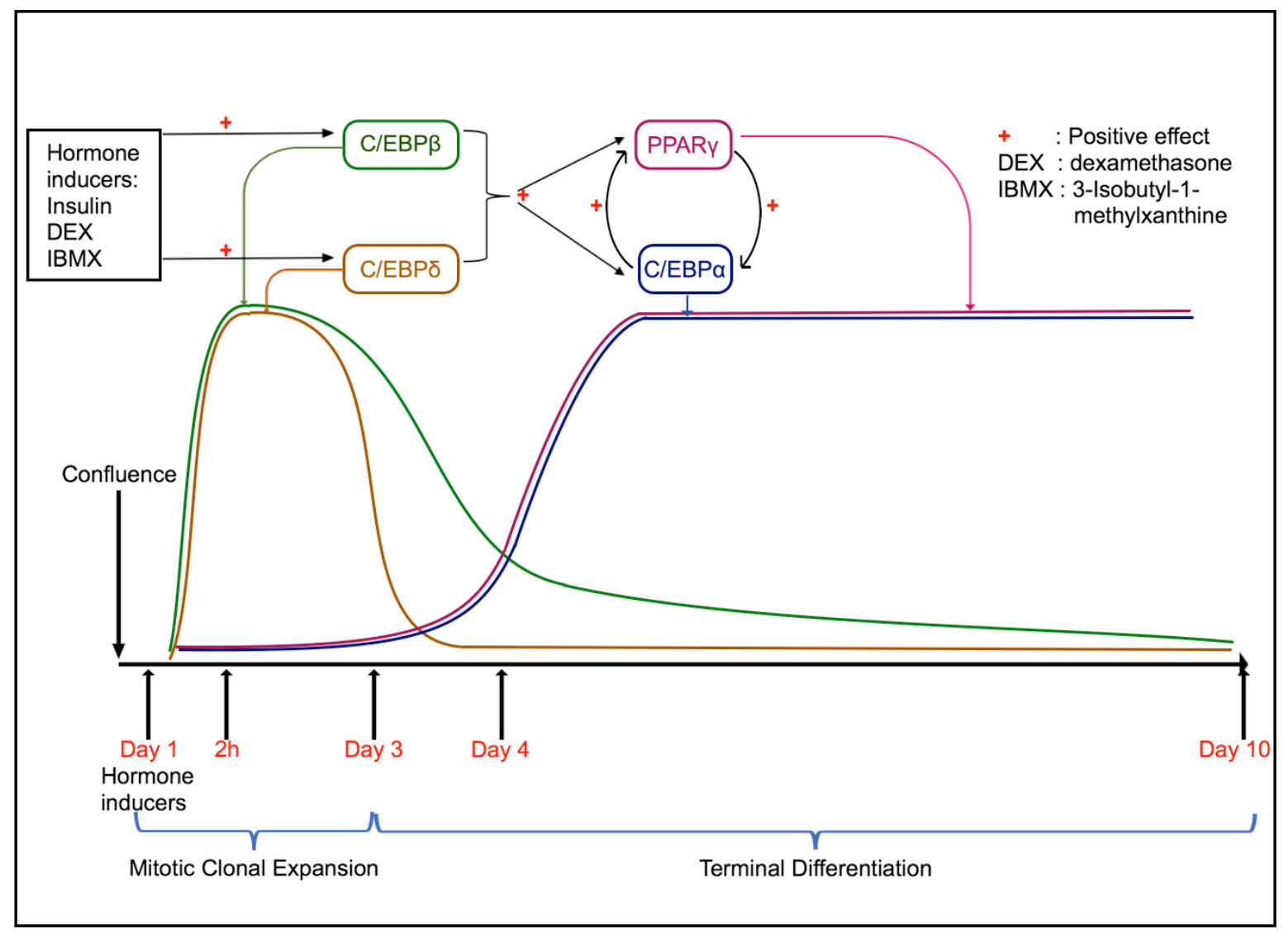

Figure 4. The regulation of transcription factors during adipogenesis.

A transient and dramatic increase of C/EBP $\beta$ and C/EBP $\delta$ takes place within the first 2 hours after hormone treatment and experience a sudden decrease at the end of the mitotic clonal expansion (MCE) phase. The expression of these two transcription factors transactivates both C/EBPa and PPARY, which initiate the expression of each other in a positive feedback loop, when the cells cease the MCE phase. (Ramji \& Foka, 2002; Rosen et al., 2002).

The two key transcription factors, C/EBPa and PPARy, emerge and dramatically increase in the second wave (the C/EBP $\beta$ and C/EBP $\delta$ are the first wave) of adipogenic transcription factors during the development of all types of adipose cells. A genomic study shows that PPARy binds to 5299 genomic regions, where over $60 \%$ are also found to be bound by C/EBPa in the 3T3-L1 preadipocytes (Lefterova et al., 2008). Another study reports C/EBPa to be 
responsible for insulin-sensitive glucose transport and the regulation of several adipogenic related proteins, such as diacylglycerol acyltransferase 1 and 2 (DGAT1/2) and ACC (Olofsson et al., 2008; Z Wu et al., 1999). Interestingly, PPARy expression is necessary and sufficient to induce adipogenesis even in the lack of C/EBPa in mouse embryonic fibroblasts. In concordance, $\mathrm{C} / \mathrm{EBPa}$ itself is not able to induce adipogenesis in the absence of PPARY (Rosen \& MacDougald, 2006). The expression of the dominant negative mutant of PPARy reduced the mRNAs of several adipogenic key enzymes - GLUT4, insulin receptor, and $\mathrm{C} / \mathrm{EBP} \alpha$ - in mature adipocytes (Tamori et al., 2002). So far, no other transcription factors have been found to successively induce adipogenesis in the absence of PPARy, which indicates the importance and unique role of PPARy in this process. Peroxisome proliferator-activated receptor gamma (PPARY) exists in two isoforms, PPARY1 and PPARY2. The former one is more ubiquitously expressed while the latter one is exclusively expressed in adipocytes. Nevertheless, both isoforms are highly induced during adipogenesis (Siersbaek et al., 2010).

In summary, the expression of PPARy and C/EBPa is induced by C/EBP $\beta$ and C/EBP $\delta$ when the hormone-treated pre-adipocytes cease the MCE phase. Both PPARy and C/EBPa are essential for the differentiation of pre-adipocytes. However, only PPARy plays a unique and indispensable role in the differentiation process. 


\section{I.2 The receptor-mediated endocytosis}

\section{I.2.1 Endocytosis}

All types of cells require fuel for metabolism. Eukaryotic cells, including the adipocytes, have the most complicated systems to communicate with the environment around them. Cells respond to changes and stimuli in the extracellular environment to mediate signal transduction, build interior trafficking structures, and secrete hormones to the extracellular environment (Alberts et al., 2007). To complete these missions, eukaryotic cells developed a high-efficient internal membrane trafficking system to transfer proteins (such as cell-surface receptors) between different membrane structures and to take up solutes, particles, or macromolecules from the external environment. By the process of exocytosis, the cells deliver proteins, hormones, and lipids either to the plasma membrane or the extracellular environment. Through the contrary process named endocytosis, the cells internalize certain particles/macromolecules by surrounding them with an area of the plasma membrane, removing the plasma membrane from the cell surface to form a vesicle structure, and delivering the vesicle structure to different intracellular compartments in an energy-consuming manner (Cooper, 2000). Compartments, such as the ER and Golgi apparatus, in the exocytosis process have recognizable shapes and certain localizations. In contrast, compartments in endocytosis process exist as vesicles that are usually isolated from large cellular structures. As a result, two endocytic compartments, the early endosomes and the late endosomes, are distinguished by their localization and time of formation during the endocytic process (Kornilova, 2014). Endocytosis can generally be divided into 
three stages. First, the cargos (solutes, particles, and macromolecules) are internalized into the cell with part of the plasma membrane as intracellular vesicles. Second, the internalized vesicles are sorted and delivered to the early endosomes and then to different intracellular membrane compartments. At last, the cargos will reach the final destination, either the lysosome to be degraded or the plasma membrane to be reused (Sahay et al., 2010).

There are multiple pathways for the solutes, particles, and macromolecules to enter the cells. Endocytosis has been broadly classified as phagocytosis and pinocytosis (Cooper, 2000). These two categories can be distinguished by the size of material been internalized and also by the dependence of phagocytosis on actin polymerization as a key step in particle ingestion (J Liu \& Shapiro, 2003). The process of taking large particles (generally larger than $250 \mathrm{~nm}$ in diameter), such as cell debris, bacteria or even another cell, is named phagocytosis (Doherty \& McMahon, 2009). Specific cell types, such as macrophages, monocytes, and neutrophils are well-known "professional phagocytes" that wipe out foreign material (bacteria and pathogens) as part of the immune system. The uptake of fluids and solutes (such as vitamins, some ions, and cholesterol, which are generally less than $150 \mathrm{~nm}$ in diameter), together with the macromolecules (such as transmembrane receptors, ion-channels, and cell-surface transporters) that they bind to, is called pinocytosis (Cooper, 2000). Different from phagocytosis that usually occurs in phagocytotic cells, pinocytosis exists in all cell types. At least two classifications of pinocytosis have been proposed: one considers the material been engulfed into the cell; the other one emphasizes on the proteins that participate in 
the process of endocytosis (Sahay et al., 2010). The former one classified pinocytosis as receptor-mediated endocytosis, adsorptive endocytosis, and fluidphase endocytosis (Khalil et al., 2006). The fluid-phase endocytosis can occur by either micropinocytosis (vesicles less than $0.1 \mu \mathrm{m}$ in diameter) or macropinocytosis (vesicles between $0.5 \mu \mathrm{m}$ to $5 \mu \mathrm{m}$ in diameter) (Kruth et al., 2005). The latter one can further classify pinocytosis into two types: clathrindependent endocytosis, also known as clathrin-mediated endocytosis (CME), and clathrin-independent endocytosis (Sahay et al., 2010).

\subsubsection{Mechanism of receptor-mediated endocytosis: how the initial signal is implemented - magnification V.S. quenching.}

\section{I.2.2.1 The ligands and the receptor tyrosine kinases: the soulmates}

Receptor-mediated endocytosis (RME), which is characterized by selective uptake of specific macromolecules followed by internalization of ligand-receptor complexes, generally occur through a clathrin-dependent process (Lodish et al., 2016). The categories of macromolecules been internalized through RME are 1) peptide signaling growth factors, cytokines, and hormones, such as EGF, FGF, and insulin; 2) cell metabolism-related macromolecules, such as transferrin and low-density lipoprotein (LDL); 3) toxins, such as Clostridium perfringens lota and Clostridium botulinum C2; 4) viruses, such as measles virus (through Nectin 4 receptor) and Rubella virus (through myelin oligodendrocyte glycoprotein, MOG);

5) bacteria, such as Listeria monocytogenes (through E-cadherin and Met) and Yersinia pseudotuberculosis ( $\beta 1$-integrins) (Backovic \& Rey, 2012; Cossart \& 
Helenius, 2014; Gibert et al., 2011; Kornilova, 2014). I will only discuss the entry of macromolecules from the first category in this chapter.

Receptor-mediated endocytosis is controlled and regulated by a large number of specialized proteins to mediate fission and fusion of phospholipid membranes, engulfment of ligands and ligands binding proteins (the receptor tyrosine kinases, RTKs), movement and directing of ligand-receptor complexes containing vesicles towards different cellular structures (Doherty \& McMahon, 2009). The process of RME starts with the binding of the macromolecules and specific RTKs, which are a group of cell-surface receptors that consist of 58 receptors divided into 20 subfamilies (Critchley et al., 2018). Receptors and ligands come in matched pairs. Each RTK only recognizes one or a few specific ligand(s), for instance, the insulin receptor (IR) specifically identifies insulin and insulin-like growth factors (IGFs), the epidermal growth factor receptor (EGFR) binds to EGF and transforming growth factor $\alpha$ (TGF- $\alpha$ ), and fibroblast growth factor receptor 4 (FGFR4, from the FGFR family) has high affinity to several ligands, including FGF1, 2, 4, 6, 8, 9, 16, 17, 18, and 19 (Lodish et al., 2016; Tiong et al., 2013). Meanwhile, a ligand can be picked up by only one or a few receptor(s), e. g., insulin can be recognized by both the IRs and the IGF receptors (IGFRs), FGF-1 can binds to FGFR1/2/3/4 (Sorkin \& Puthenveedu, 2014; Tiong et al., 2013).

However, the binding affinities between different ligands towards the same receptor or different receptors with the same ligand are quite diverse. In summary, despite the fact that one RTK can recognize one or several ligand(s) and one 
ligand can bind to different RTKs with vary affinities, the bindings between ligands and RTKs are of high specificity and precision.

\section{I.2.2.2 The internalization of ligand-receptor complexes: engulfment does not mean suppression}

The binding of RTKs with specific ligand(s) will form the ligand-receptor complexes, which will be internalized into the cell with part of the plasma membrane where the RTKs locate through RME (Figure 5.B). The responsiveness of cells to the extracellular signal molecules depends on the number of ligandreceptor complexes formed on the plasma membrane. Thus, the endocytosis of these complexes, which alters the distribution and concentration of RTKs on the plasma membrane, regulates the long-term homeostasis and sensitivity of the cell to specific ligands(s) (Lodish et al., 2016).

Once the RTKs recognize the extracellular signal and form the ligandreceptor complexes, the area of the plasma membrane that contains these complexes will be pinched off as clathrin-coated pits (Figure 5). The internalization process requires the participation of two proteins, the adaptor protein 2 (AP2) and clathrin. The former one, AP2 complex, which is formed by 4 subunits (the large $\alpha$ and $\beta 2$ subunits, the medium-sized $\mu 2$ subunit, and the small-sized $\sigma 2$ subunit) as a heterotetrameric structure, serves as bridges between the plasma membrane, RTK, and clathrin (Higgins \& McMahon, 2002) Park, 2014 \#1013). Knockout of AP2 in mice is embryonic lethal, indicating the crucial role of AP2 in embryonic development and cell homeostasis (Park \& Guo, 2014). The latter one, clathrin, 
has a triskelion structure with three clathrin heavy chains $(\mathrm{CHC})$ stretched out from a central vertex that is made up by three tightly associated clathrin light chains (CLC) (Conner \& Schmid, 2003; Royle, 2006). Knockout of the CHC in Hela cells results in diminished growth rate and impaired endocytosis (Hinrichsen et al., 2003). To form the clathrin-coated pits, the first step is to "mark" the transmembrane receptors - the majority of which are RTKs - to be internalized. The marking is accomplished when cytoplasmic-located specific motifs of RTKs become exposed because of structural change under ligand binding (Pearse et al., 2000). The well-characterized motifs include the tyrosine-based $Y X X \Phi / N P X Y$ motif and the dileucine-based [D/E]XXXL[L/l] motif ( $\mathrm{X}$ is any amino acid, and $\Phi$ is a bulky hydrophobic amino acid, e.g., leucine, isoleucine, methionine, valine, and phenylalanine) (Bonifacino \& Traub, 2003). The AP2 complex interacts with phosphatidylinositol-4,5-bisphosphate (PIP2) and phosphatidylinositol-3,4,5triphosphate (PIP3) through its $\alpha$ subunit and $\mu 2$ subunit. The interactions between the AP2 complex and PIP2/PIP3 are responsible for its localization on the plasma membrane (BM Collins et al., 2002). The AP2 complex also recognizes the exposed $Y X X \Phi / N P X Y$ motif through the $\mu 2$ subunit and the $[D / E] X X X L[L / I]$ motif through $\mu 2$ and/or $\beta 2$ subunit (Bonifacino \& Traub, 2003). After binding to motifs located on the RTK, the AP2 complex undergoes a large conformational change from a locked state to an open state (Park \& Guo, 2014). In the open state, AP2 complex recruits clathrin to the plasma membrane through the "hinge" domains of its large $\alpha$ and $\beta 2$ subunits and promotes the self-assembles of clathrin to build cage-like structures/lattice (Park \& Guo, 2014). Hence, the curvature of the 
membrane region that contains ligand-receptor complexes, the AP2 complexes, and the recruited clathrin is called the clathrin-coated pit. Through the action of other factors, such as endophilin and dynamin, the clathrin-coated pit further curves into the cell and finally will pinch off from the cell membrane (Figure 5.B).

The mature pits - the pits dissociate entirely from the cell membrane - will be uncoated and fuse to an early endosome where the ligand-receptor complexes are sorted to lysosomes to be degraded or recycled back to the plasma membrane to be reused (Figure 5.B). The ratio between the recycled receptors and degraded receptors varies. For instance, the insulin receptors in the 3T3-L1 pre-adipocytes are efficiently recycled upon insulin stimulation at a concentration of $100 \mathrm{ng} / \mathrm{ml}$ (Marshall, 1985). High concentration of EGF (over 100ng/ml) promotes the degradation of EGFR while low concentration of EGF (lower than $50 \mathrm{ng} / \mathrm{ml}$ ) favors recycling of EGFR (Sigismund et al. 2008).

The role of RME involves both the rapid internalization of receptors following ligand binding and the subsequent sorting of the internalized ligand-receptor complexes (Goh \& Sorkin, 2013). Thus, RME plays an essential role in controlling the functional activities of the RTKs. 


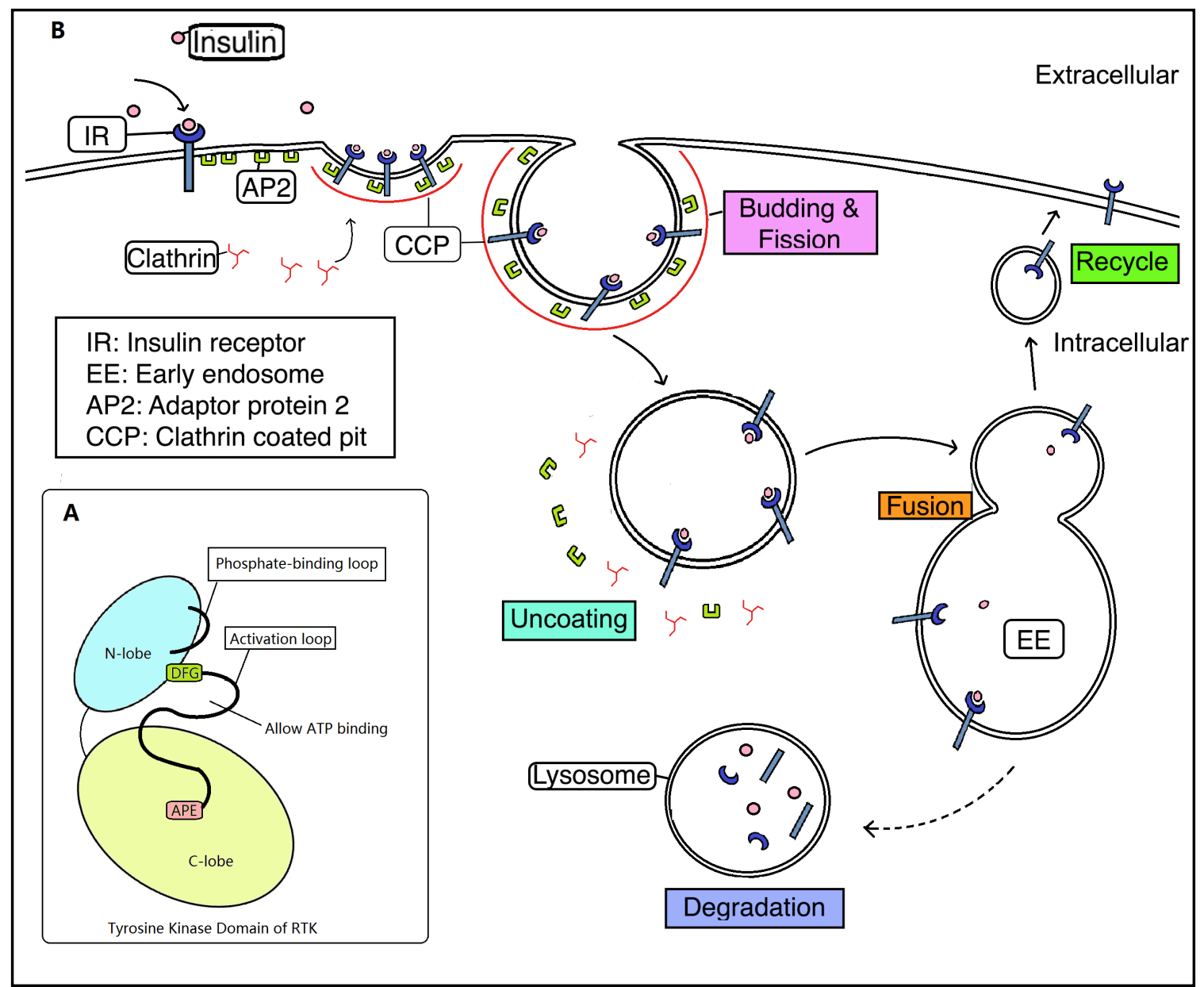

Figure 5. The tyrosine kinase domain of RTKs and receptor-mediated endocytosis.

A. The tyrosine kinase domain of RTKs contains a smaller N-lobe and a bigger Clobe. The cleft between the two lobes permits a specific site for ATP binding. B. Receptor tyrosine kinases are activated by binding with specific ligands followed by the formation of ligand-receptor complexes. The activated RTKs interact with AP2, which links to the plasma membrane and recruits clathrin. The ligandreceptor complexes then clustered on the plasma membrane to form a growing curved clathrin-coated pit. The mature pit then buds off from the plasma membrane and becomes the clathrin-coated pit (CCP). The CCP will be uncoated in the cytosol and the uncoated vesicle will be delivered to early endosomes (EEs) to fuse with them. Some ligand-receptor complexes remain intact while some ligands dissociate from the receptors when reaching the early endosomes. The ligands and some of the receptors will be sorted to late endosomes and eventually, lysosomes to be degraded. However, some of the receptors will be recycled to the plasma membrane. (Sorkin \& Puthenveedu, 2014; Casem, 2016; Kirchhausen et al., 2014; Cooper, 2000; Lemmon and Schlessinger, 2010). 
As is mentioned above, the RME mediates the internalization and sorting of the RTKs. It is believed that the primary role of RME is to terminate the RTK signaling through ubiquitination and degradation upon vesicle sorting. However, several studies showed that the internalized ligand-receptor complexes continue functioning and mediate the full biological functions of the RTK signaling (von Zastrow \& Sorkin, 2007). In other words, instead of just functioning as a delivery station, the endosomes that contain ligand-receptor complexes may also function as active signaling sites (Irannejad et al., 2015). For instance, activated EGFR has been found to co-localize with endosomes and downstream signaling molecules, including the adaptor protein - Src homology and collagen protein (Shc, Src stands for Rous sarcoma oncogene cellular homolog), the Ras guanine nucleotide exchange factor (GEF) - son of sevenless (SOS), and the docking protein - growth factor receptor-bound protein 2 (Grb2) - in vivo (Di Guglielmo et al., 1994). Besides, the internalized non-phosphorylated EGFR-ligand complex, which is induced by reversible inhibitors, could be activated in endosomes upon inhibitor wash-out and were able to perform its biological function by recruiting downstream signaling molecules (Pennock \& Wang, 2003). Furthermore, the tropomyosin receptor kinase A (TrkA) receptors, once internalized upon nerve growth factor (NGF) binding, localize on the endocytic vesicles, remain phosphorylated, and are associated with phosphoinositide phospholipase C (PLC- $\gamma 1)$, which acts as an essential intracellular signaling transduction enzyme that catalyzes the formation of inositol 1,4,5-trisphosphate $\left(\mathrm{IP}_{3}\right)$ and diacylglycerol (Grimes et al., 1996). The TrkA-NGF complexes were also shown to move from the distal axon to the 
neuronal cell body to carry the signal from the cell periphery to the nucleus (Cosker \& Segal, 2014). Researchers also observed an accumulation of activated insulin receptors in the intracellular compartments in the presence of insulin (Kublaoui et al., 1995).

In summary, the RTKs are internalized into the cell in the form of ligandreceptor complexes through clathrin-mediated endocytosis. The engulfed receptors, in some cases, are not degraded immediately. Instead, these receptors appear to remain activated and functional in endosomal compartments after internalization.

\section{I.2.2.3 The small GTPase Rab proteins in the receptor-mediated endocytosis: the logistic company to control the delivery}

As is mentioned above, common procedures of RME include the budding of clathrin-coated pits from the plasma membrane into the cell, movement of vesicles in the cytosol, targeting of the vesicles to specific destinations, and eventually the fusion of vesicles to subcellular structures (Gonzalez \& Scheller, 1999). Numerous of proteins, including the Rab (Ras-related GTP-binding protein) family proteins, participate and act in the RME process to ensure the internalization, targeting, and fusion to take place precisely. The Rab proteins are a group of small GTPases ( 20-30 kDa) belonging to the Ras superfamily and take part in the process of membrane trafficking (Grosshans et al., 2006). Over 70 Rab proteins are found to function in intracellular transport and are classified into 6 groups based on their function in different components of intracellular membrane 
trafficking, such as vesicle budding, delivery, fusion, and localization of certain proteins on different membrane domains (Stenmark, 2009). Mutations and abnormal expression of Rabs have been found to relate with many diseases. For instance, mutations on the Rab27a gene are responsible for the Griscelli syndrome (Menasche et al., 2000). The G19V mutation of Rab38 leads to the HermanskyPudlak syndrome (Loftus et al., 2002). Rab25, which belongs to the Rab11 subfamily, is elevated expressed and has an oncogenic function in ovarian, breast, prostate, bladder, and gastric cancer (S Wang et al., 2017). Rab23, a negative regulator of the hedgehog signaling pathway that predominantly locates on the plasma membrane, has increased expression in hepatocellular carcinomas, diffuse-type gastric cancer, and follicular adenoma type of thyroid tumors (Evans et al., 2003; Lim \& Tang, 2015).

The Rab proteins function as molecular switches as they can be "turned off" to their GDP-bound form (inactive form) by GTPase activating proteins (GAPs) and "turned on" to their GTP-bound form (active form) by guanine-nucleotide exchange factors (GEFs) (G Li, 2015). By recycling between the two forms, the Rab proteins govern the receptor-mediated endocytosis by regulating membrane trafficking system, specifically, by recruiting Rab effector proteins to specific sites of the intracellular membrane structures. Every Rab protein has its unique localization on distinct membrane compartments to control the specificity of membrane structures and directionality of membrane trafficking (Zhen \& Stenmark, 2015).

The Rab proteins can be found both in the cytosol and on membrane structures. The Rab GDP dissociation inhibitor (GDI) specifically recognizes the 
GDP-bound Rabs. Thus, GDI solubilizes the Rabs and removes inactive Rabs from membrane structures (Figure 6). The GDI displacement factor (GDF), which locates on the donor membrane, initiates the recruitment of Rabs by dissociating the GDI from Rabs and inserting the Rabs into the membrane of intracellular compartments (Figure 6). To gain the membrane association ability, Rabs require post-translational modification of two cysteine residues located on or near the Cterminal (Leung et al., 2006). The Rab proteins are then activated by a group of membrane-bound proteins named guanine nucleotide exchange factors (GEFs) (Figure 6). The activated GTP-bound Rabs then recruit several specific Rab effectors to facilitate vesicle budding, vesicle movement/delivery, and vesicle tethering (Muller \& Goody, 2018). For instance, Rab1 and Rab2 are found on ER and cis-Golgi to regulate ER-Golgi and Golgi-ER trafficking, respectively; Rab5 is found to locate on early endosomes, clathrin-coated vesicles, and the plasma membrane to mediate vesicle budding and early endosome fusion; Rab7 is found on late endosomes to regulate late endosome trafficking (Stenmark \& Olkkonen, 2001). Then the activated GTP-bound Rabs are converted to the inactive forms through hydrolysis of GTP, which is mediated by another group of proteins termed GTPase activating proteins (GAPs). As an end, the inactivated Rabs will be removed from the acceptor membrane by the GDIs to enter the cytosol. 


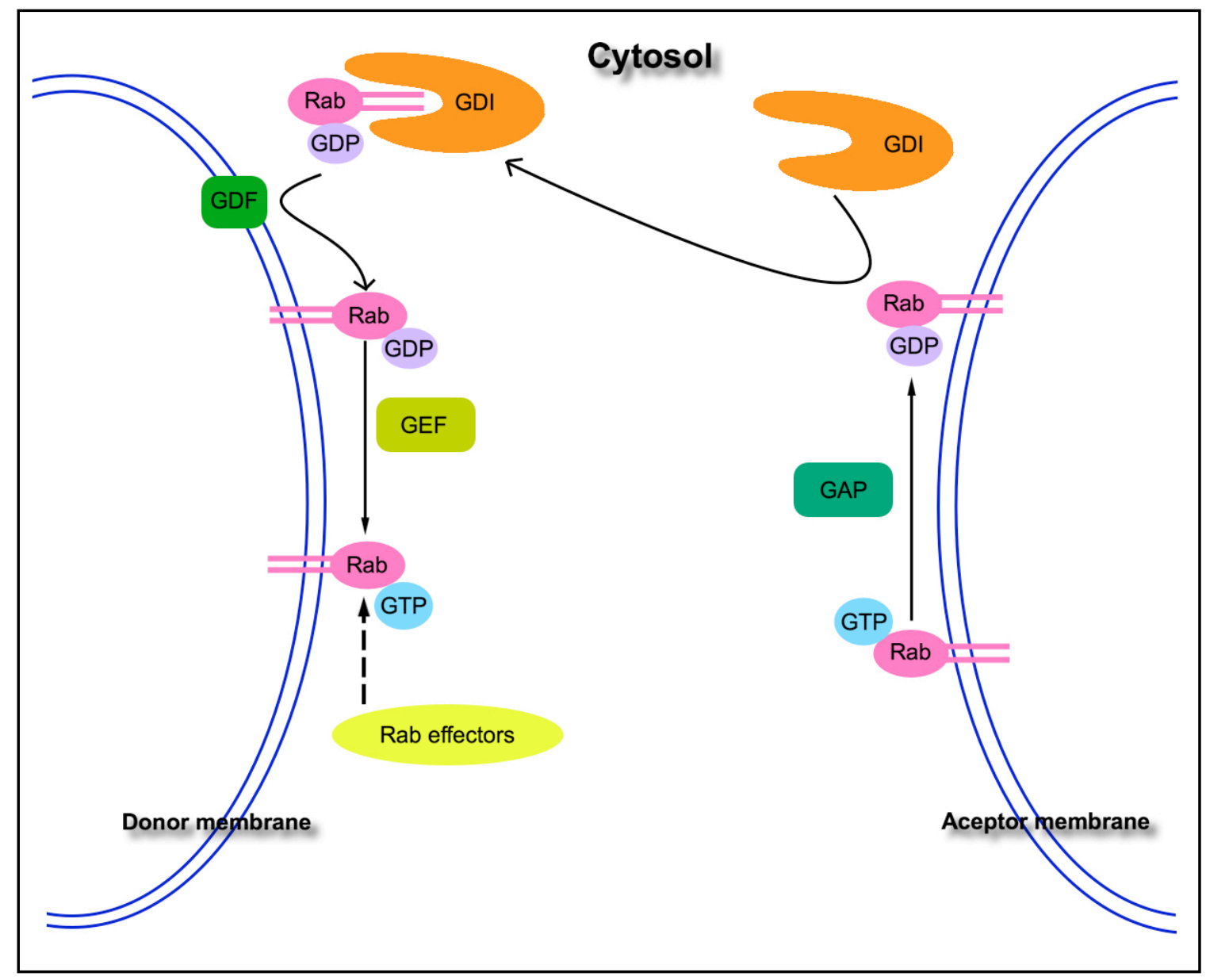

Figure 6. Rab GTPases cycle.

Rab GTPases exist both in cytosol and on membrane. GDF, which locates on the donor membrane, displaces GDI and inserts Rabs onto the donor membrane. GEFs, which also locate on the donor membrane, replace the GDP to GTP to activate Rabs. Activated Rabs can recruit specific Rab effectors to mediate different membrane trafficking processes. The activated GTP-bound Rabs are converted to the inactive forms through hydrolysis of GTP, which is mediated by GAPs. Then GDIs specifically recognize the GDP-bound Rabs and thus solubilize the Rabs and remove inactive Rabs from the acceptor membrane. (GDI: Rab GDP dissociation inhibitor; GEF: guanine nucleotide exchange factor; GAP: GTPaseactivating protein; GDF: GDI displacement factor). (G Li, 2015; Zhen \& Stenmark, 2015) 
In conclusion, the small GTPase Rab proteins perform their functions in the RME process by switching between their active and inactive forms and recruiting specific Rab effectors to certain membrane compartments.

\section{I.2.3 Structure of the receptor tyrosine kinases}

The human genome encodes 58 RTKs divided into 20 subfamilies, and the majority of RTKs share similar structures (Karpov et al., 2015). Generally, an RTK is comprised of an extracellular domain for ligand binding, a single a-helix transmembrane domain, and an intracellular region that contains a juxtamembrane domain, a tyrosine kinase domain (TKD), and a C-terminal (Lemmon \& Schlessinger, 2010). The extracellular domains of RTKs are quite diverse between different subfamilies, which ensures the high specificity of each RTK to recognize unique ligand(s) (Karpov et al., 2015). On the contrary, the intracellular regions are relatively conserved between different subfamilies. The tyrosine kinase domain of RTKs has an N-lobe and a C-lobe (Figure 5.A). The smaller N-lobe consists of a five-stranded $\beta$-sheet and one $\alpha$-helix, while the bigger C-lobe mainly consists of a-helices (Huse \& Kuriyan, 2002). Besides the big cleft between the two lobes that forms a specific site for ATP binding, a phosphate-binding loop, which contains a highly conserved Gly-rich (GXGXXG) motif, poses the y-phosphate of ATP and

allows ATP to fit beneath the loop (Taylor \& Kornev, 2011). Another highly conserved construction, the activation loop, which usually contains around 20 to 35 residues and is the primary site of regulatory phosphorylation, starts at the tripeptide Asp-Phe-Gly (DFG) motif and ends at another tripeptide Ala-Pro-Glu 
motif (Svensson et al., 2016; Bayliss et al., 2015). The capacity of undergoing large conformational change allows the activation loop to switch between inactive and active states. In the inactive state, each TKD is stabilized in a unique auto-inhibition configuration by several particular intramolecular interactions between the juxtamembrane domain/C-terminal and the TKD (Lemmon \& Schlessinger, 2010). Though the structures of inactive TKDs differ from receptor to receptor, which determines the diverse functions of RTKs, the active structures of all TKDs are very similar to each other (Nolen et al., 2004). Upon activation of TKD by specific ligands, the phosphorylated tyrosine residues in the activation loop then serve as sites for assembly of signaling molecules that contain Src homology 2 (SH2) or phosphor-tyrosine-binding (PTB) domains (Axel Ullrich \& Schlessinger, 1990). The phosphorylation of these signaling molecules can be triggered either directly by phosphorylated RTKs themselves, or indirectly by docking proteins, which are recruited and phosphorylated by activated RTKs (Schlessinger \& Lemmon, 2003). Then the recruited signaling molecules pass down the initial signal and regulate cell survival, proliferation, and differentiation.

\section{I.3 The insulin signaling pathways: the essential determinant of adipogenesis}

The insulin receptor (IR) and insulin-like growth factor receptor 1 (IGF-1R) belong to the IR subfamily of RTKs. Both IR and IGF-1R have differ affinities to insulin and IGFs (IGF-1/-2), which are from the same structural-related insulinpeptide superfamily (De Meyts et al., 2000-2013). The insulin signaling pathways 
that are triggered by the activation of the IR and IGF-1R integrate the storage and release of nutrients through human lives. The outlines of the insulins signaling pathways have been well described, but many details of signal transduction still need to be elucidated. The two well-established and most essential signaling pathways been initiated by insulin/IGFs are the Erk1/2 signaling pathway and the PI3K/Akt signaling pathway (Zarich et al., 2006). The effects of insulin signaling pathways activation on adipocytes can be divided into three types: immediate effects, mid-term effects, and long-term effects. Immediate effects, such as the phosphorylation and dephosphorylation of specific enzymes and proteins, take place within several seconds after IR activation. Mid-term effects include the upand down-regulated expression of specific proteins within 5-60 minutes after insulin stimulation. Long-term effects, e.g., cell proliferation and cell differentiation, will be detected from several hours to several days after insulin stimulation. Details of the effects of the insulin signaling pathways on adipocytes will be discussed later in this section.

\section{I.3.1 Insulin receptor and its structure}

The initiation of the insulin signaling pathways start with the binding of insulin or IGFs to the IR or the IGF-1R. Between the two receptors, IR is the primary site for insulin binding. The IR was first identified in 1971 by Cuatrecasas on adipocytes (Cuatrecasas, 1971). Through decades of research, the IR is proved to exist on the membrane of all types of mammalian cells with vary numbers from $\sim 40$ on erythrocytes to $\sim 200 \sim 300 \times 10^{3}$ on adipocytes (Watanabe et al., 1998). 
Thus, dysregulation of cell metabolism happens when the IR is abnormally expressed on the cell surface. For instance, increased expression of the IR is often overserved in malignant cells. About $80 \%$ of the breast cancer cells have a significant higher IR content than the normal breast tissue cells. Besides, a higher level of IR expression predicts a poor survival in breast cancer patients (Vigneri et al., 2016). The IR knockout mice only survived a few days after birth. The "fatspecific" IR knockout mice and adipocyte-specific IR knockout mice, though had a reduced fat mass and were protected from obesity-associated glucose intolerance, both suffered increased TAG accumulation in liver, hepatomegaly, and decreased lifespan (M. Bluher et al., 2002; Eguchi et al., 2011; Joshi et al., 1996).

As a member of the RTKs, the IR contains an extracellular domain for ligand binding, a transmembrane domain, and an intracellular region which includes a juxtamembrane domain, a tyrosine kinase domain, and a C-terminal (Figure 7). However, unlike the prototypical RTKs that exist as single-chain polypeptides, IR exists as a covalently-linked tetramer consists of two $\alpha$-subunits and two $\beta$ subunits (Weiss et al., 2014). The four subunits are disulfide-linked to form a $\sim 350$ $\mathrm{kDa}$ structure. The $\alpha$-subunit and 194 residues of the $\beta$-subunit together form the extracellular portion of the IR, while the rest of the $\beta$-subunit, which contains a single transmembrane part and a cytoplasmic portion (IR- $\beta$-tail) that permits the tyrosine kinase activity of the IR, is the intracellular portion (Belfiore et al., 2009). Upon ligand binding, the $\alpha$-subunits of the IR will inhibit the kinase activity of the $\beta$-subunits by inducing a structural change of the IR molecule at first. Then, this conformational change of the IR molecule will bring the two $\beta$-subunits close 
enough to each other to permit the kinase activity of the $\beta$-subunits (Boucher et al., 2014). The activation of tyrosine kinase activity of the IR includes the autophosphorylation of three tyrosine residues, which are Y1158, Y1162 and Y1163 in the activation loop of the kinase domain (contains $\sim 300$ residues) (Figure 7). Among the three tyrosine residues, the $\mathrm{Y} 1162$ is hydrogen-bonded to the catalytic loop that occludes the ATP-binding site in the absence of $\mathrm{Mg}^{2+}$-ATP and will be the first to undergo autophosphorylation during IR activation, followed by autophosphorylation of the other two residues (Wei et al., 1995). Mutations in these three residues not only affected the kinase activity of the IR but also impaired the biological function of the IR (Wilden et al., 1992). Besides the three tyrosine residues that permit the catalytic kinase activity, some other tyrosine residues, such as Y965 and Y972 in the juxtamembrane region ( 35 residues; between the transmembrane helix and the tyrosine kinase domain) and Y1328 and Y1334 in the C-terminal ( $\sim 70$ residues) of the $\beta$-subunit, are also autophosphorylated upon ligand binding (Figure 7). Mutations on the tyrosine sites leads to decreased signaling transduction and/or diminished insulin sensitivity, glycogen synthesis, and nutrients uptake (Table 2).

The IR has two isoforms: the IR isoform A (IR-A) without the exon 11, which codes a 12-amino acid segment at the C-terminal of $\alpha$-subunit, and the IR isoform B (IR-B) with the exon 11 (Ebina et al., 1985; A. Ullrich et al., 1985). The two isoforms exhibit vary distribution in a tissue-specific manner and distinct cellular functional properties (Figure 7). 


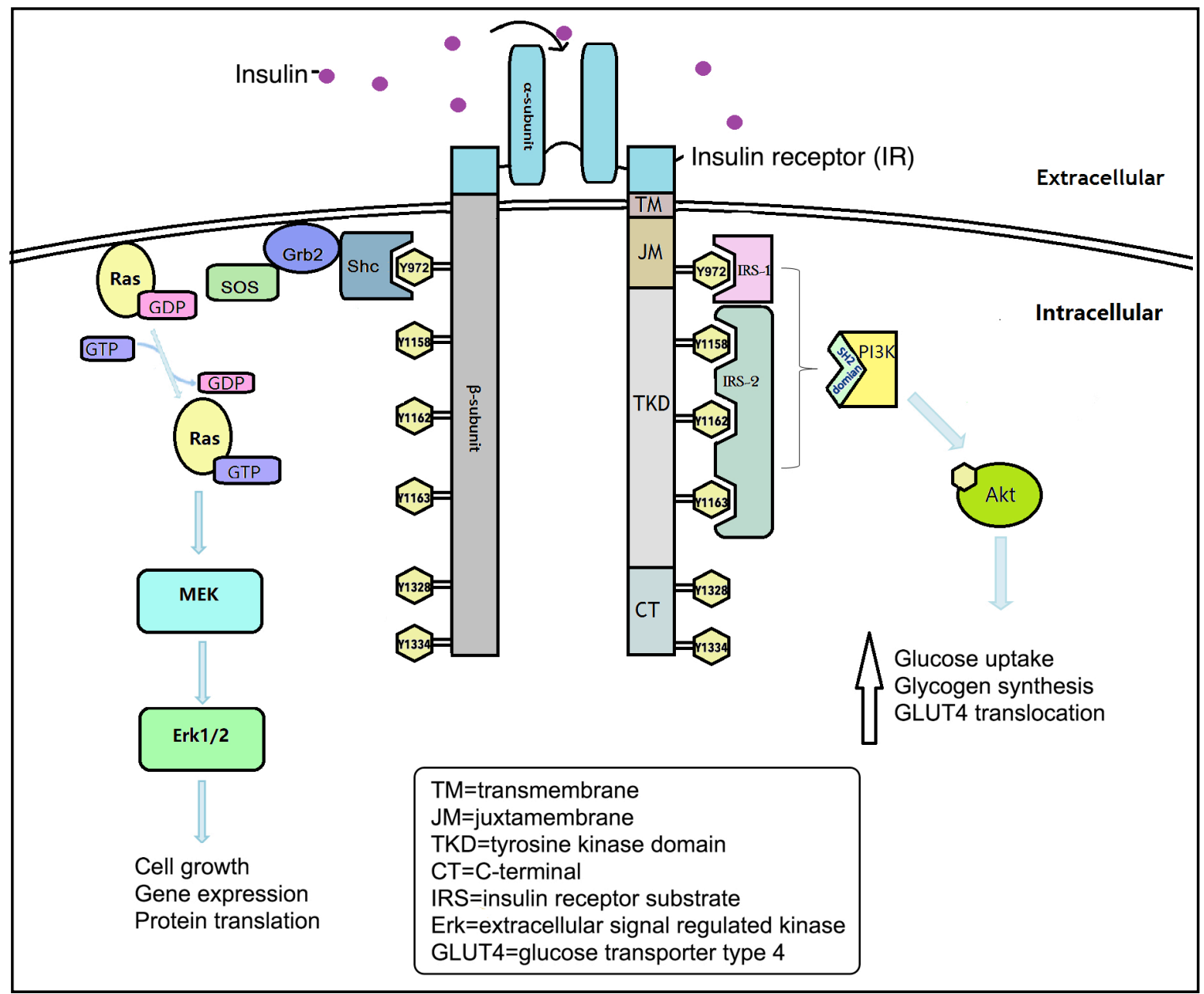

Figure 7 The insulin signaling pathway.

Insulin receptor (IR) is activated upon insulin binding. The activation of IR leads to the phosphorylation of several tyrosine kinases in the intracellular region of IR, including Y972 in the juxtamembrane region, Y1158, Y1162 and Y1163 in the tyrosine kinase domain and Y1328 and Y1334 in the C-terminal. The pY972 is responsible for the activation of IRS-1 and Shc through the phosphotyrosinebinding domain (PTB domain), while Y1158, Y1162 and Y1163 activate IRS-2 after phosphorylation. In the PI3K/Akt pathway showing on the right of the figure, the activated IRS-1/2 can directly recruit the PI3K and eventually lead to the activation of Akt. Glucose uptake, glycogen synthesis and Glut4 translocation are upregulated upon Akt activation. In the Erk1/2 signaling pathway showing on the left, activated Shc recruits the Grb2-SOS complex, which mediates the GDP/GTP exchange of Ras. At the end, Erk1/2 will be activated and anticipates in the regulation of cell growth, gene expression and protein translation. (Cieniewicz et al., 2016; Papich \& Riviere, 2009; Youngren, 2007; Taguchi \& White, 2008; Boucher et al.; Hubbard, 2013). 
The IR-B has high affinity to insulin and is predominantly expressed in differentiated tissues that contain a higher number of IRs on the cell surface and have an inadequate response to IGF-2, such as liver, kidney, adipose tissue, and muscle. In contrast, though the IR-A has similar affinity to insulin as the IR-B, it exhibits high affinity to IGF-2. Besides, the IR-A is primarily expressed in fetal and tumor tissues with comparatively greater rates of internalization and recycling than the IR-B (Escribano et al., 2017). Because of these differences, the IR-A activation is mainly associated with cell growth, cell proliferation, and cell survival, whereas the IR-B activation favors regulation of metabolism and differentiation. In the 32D cells, the IR-A preferentially sends mitogenic, antiapoptotic signals and translocate insulin receptor substrates (IRS-1) to the nucleus more effectively while the IR-B tends to send differentiation signals (Sciacca et al., 2003). In vascular smooth muscle cells, the overexpression of IR-A confers a stronger migratory capability (Beneit et al., 2016). The IR-A is also proved to be more efficient at increasing glycogen synthesis and storage and promoting glucose uptake than the IR-B (Diaz-Castroverde et al., 2016).

The activation of the IR will induce the recruitment of downstream proteins that contain either a phosphotyrosine-binding domain (PTB domain) or an SH2 domain (Figure 7). E.g., IRS-1/-2 and Shc (Src homology and collagen protein) have a PTB domain, while Shc and APS (adaptor protein with pleckstrin homology and Src homology 2 domains) contain an SH2 domain (Boucher et al., 2014; Taguchi \& White, 2008). The PTB domain-containing proteins bind to pY972 (phosphorylated-Y972), which creates a lower affinity docking site for the PTB 
domain of IRS-1, but a much higher affinity docking site for the same domain of Shc (Chaika et al., 1999; SawkaVerhelle et al., 1996). Interestingly, the Y972 belongs to the NPXY motif where the phosphorylation on the tyrosine site recruits the AP2 complex. In addition, pY972 is also the recruiting site for IRS-2. However, different from the IRS-1 that only interacts with the IR through one phosphorylated tyrosine (the pY972), the IRS-2 also interacts with the three tyrosines that located in the activation loop (Jensen \& De Meyts, 2009; He et al., 1996). As consequences of IR activation, two major signaling pathways are activated: the Erk1/2 signaling pathway and the PI3K/Akt signaling pathway (Figure 7). The specific function and regulation of the two pathways will be discussed later.

\section{I.3.2 Insulin-like growth factor receptor 1 and its structure}

The complementary DNA for human IGF-1R was cloned and sequenced in 1986 (A. Ullrich et al., 1986). It binds to IGF-1 with higher affinity than IGF-2 but does not recognize insulin efficiently. The IGF-1R is widely expressed in many cell types in fetal and postnatal tissues and plays a role in essential cellular processes, including cell growth, cell differentiation, and apoptosis (Arcaro, 2013). Mice with null mutants for the IGF-1R exhibit a severe growth deficiency (only $45 \%$ of normal size) and die invariably at birth because of respiratory failure (JP Liu et al., 1993). Non-malignant cells treated with IGF-1R nuclear translocation inhibitor or IGF-1R inhibitor display a decreased proliferation and migration rate than the untreated cells (Solomon-Zemler et al., 2017). In addition to the role of the IGF-1R during development and cell proliferation, evidence also suggests a vital role of it in 
malignant transformation (Sachdev \& Yee, 2007). For instance, data show that the increased expression of the IGR-1R is associated with malignancy behavior in familial pheochromocytomas and paragangliomas regardless of the age at diagnosis and the genetic aetiology (Fernandez et al., 2013). Evidence also shows that a disrupted activation of the IGF-1R results in inhibited growth and motility of a wide range of cancer cells in vitro and in mouse models (Sachdev \& Yee, 2007).

The IGF-1R and the IR are from the same subfamily of RTKs. Thus, the IGF-1R is highly structural homologous to the IR, sharing $45 \%$ to $65 \%$ amino acid identity in the ligand-binding domain, $65 \%$ to $85 \%$ identity in the tyrosine kinase and substrate recruitment domains, and nearly absolute conservation in the ATP binding pocket (Escribano et al., 2017). However, unlike the IR gene that is alternatively spliced to produce two isoforms, the IGF-1R gene is assembled without alternative splicing (Morris F. White, 2012). Similar to the IR, the IGF-1R is a tetramer consists of two $\alpha$-subunits and two $\beta$-subunits. One $\alpha$ subunit and one $\beta$ subunit form an $\alpha \beta$ half-receptor monomer. Two monomers are assembled into heterotetramer complex through disulfide bonds, which can be induced by treatment of IGF-1 or Mn/MgATP in vitro (Treadway et al., 1989). Activation and signaling transduction of the IGR-1R is also quite similar to those of the IR. The three tyrosine residues locate on the activation loop of the tyrosine domain of IGF$1 R$ are $Y 1131, Y 1135$, and $Y 1136$ (these three tyrosine residues resemble the functions of $\mathrm{Y} 1158, \mathrm{Y} 1162$, and $\mathrm{Y} 1163$ on the IR). The Y950 locates on the NYXP motif of the juxtamembrane domain of the IGF-1R has similar function as the Y972 of the IR (Table 2). 
Table 2. Locations and functions of essential amino acids on the $\beta$-subunit of the IR and the IGF-1R.

A. Locations of essential amino acid residues on the $\beta$-subunit.

\begin{tabular}{|c|c|c|c|c|}
\hline Receptor & $\begin{array}{c}\text { Full } \\
\text { Length }\end{array}$ & $\begin{array}{c}\text { Juxtamembrane } \\
\text { Domain }\end{array}$ & $\begin{array}{c}\text { Tyrosine Kinase } \\
\text { Domain }\end{array}$ & C-Terminal \\
\hline 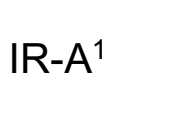 & 1343 & Y953, Y960 & $\begin{array}{l}\text { K1018, Y1146, } \\
\text { Y1150, Y1151 }\end{array}$ & $\begin{array}{l}\text { Y1316, } \\
\text { Y1322 }\end{array}$ \\
\hline IR-B ${ }^{2}$ & 1355 & Y965, Y972 & $\begin{array}{l}\text { K1030, Y1158, } \\
\text { Y1162, Y1163 }\end{array}$ & $\begin{array}{l}\text { Y1328, } \\
\text { Y1334 }\end{array}$ \\
\hline IGF-1R ${ }^{3}$ & 1337 & Y943, Y950 & $\begin{array}{l}\text { K1003, Y1131, } \\
\text { Y1135, Y1136 }\end{array}$ & Y1316 \\
\hline
\end{tabular}

1 The numbering of amino acids of IR-A corresponds to the receptor of Ullrich et al. (A. Ullich et al., 1985).

2 The numbering of amino acids of IR-B corresponds to the receptor of Ebina et al. (Ebina et al., 1985).

${ }^{3}$ The numbering of amino acids of IGF-1R corresponds to the receptor of Ullrich et al. (A. Ullrich et al., 1986).

\section{B. Functions of essential amino acid residues on the $\beta$-subunit of the IR-B.}

\begin{tabular}{ll}
\hline \hline Amino acid & Function \\
\hline Y965 & IR autophosphorylation site \\
& AP2 complex binding site ${ }^{15}$ \\
& IR autophosphorylation site \\
Y972 & AP2 complex binding site ${ }^{9}$ \\
& PTB domain-containing protein binding site ${ }^{12}$ \\
& IRS-1/2 binding site \\
K1030 & ATP binding site \\
& IR autophosphorylation sites \\
Y1158, Y1162, Y1163 & Essential tyrosine residues on the activation \\
& loop ${ }^{14}$ \\
IRS-2 binding site & \\
Y1328, Y1334 & IR autophosphorylation sites
\end{tabular}

${ }^{5}$ (He et al., 1996); ${ }^{6}\left(\mathrm{M}\right.$. F. White et al., 1988); ${ }^{9}$ (Bonifacino \& Traub, 2003); ${ }^{12}$ (Chaika et al., 1999); ${ }^{14}$ (Cieniewicz et al., 2016); ${ }^{15}$ (Y Xu et al., 2011). 


\section{Effects of essential amino acid residue mutants on the $\beta$-subunit of the IR-B.}

\begin{tabular}{|c|c|}
\hline Mutant & Effects of Mutant \\
\hline Y965F & No effect on IR internalization or IR auto-phosphorylation ${ }^{11}$ \\
\hline Y972F & $\begin{array}{l}\text { No interaction with IRS-14,5 } \\
\text { No effect on IRS-2 } \text { binding }^{5} \\
\text { No effect on IR auto-phosphorylation }{ }^{11} \\
\text { Decreased insulin sensitivity }{ }^{6} \text { and rate of glucose } \\
\text { transport }^{12} \\
\text { Diminished glycogen synthesis and internalization }\end{array}$ \\
\hline Y965A & $\begin{array}{l}\text { No effect on IRS-2 binding }{ }^{5} \\
\text { No effect on IR auto-phosphorylation }{ }^{11} \\
\text { Decreased IR internalization }\end{array}$ \\
\hline Y972A & $\begin{array}{l}\text { No effect on IR auto-phosphorylation }{ }^{11} \\
\text { Decreased IR internalization }\end{array}$ \\
\hline$\triangle 966-977$ & $\begin{array}{l}\text { No effect on auto-phosphorylation of } \beta \text {-subunit }{ }^{8} \\
\text { Diminished downstream signaling, glycogen synthesis, } \\
\text { and IR internalization }\end{array}$ \\
\hline K1030A & $\begin{array}{l}\text { No interaction with IRS-1/24,5 } \\
\text { Decreased IR internalization }{ }^{13}\end{array}$ \\
\hline K1030R & $\begin{array}{l}\text { Diminished glycogen synthesis, insulin sensitivity, MAP } \\
\text { kinase activity, }\end{array}$ \\
\hline Y1158F & $\begin{array}{l}\text { No effect on IRS-2 binding } \\
\text { Decreased IR internalization }{ }^{13}\end{array}$ \\
\hline $\begin{array}{l}\text { Y1158, } \\
\text { Y1162F, } \\
\text { Y1163F }\end{array}$ & $\begin{array}{l}\text { Deduction of insulin-activated auto-phosphorylation }{ }^{16} \\
\text { Decreased IR internalization }{ }^{13} \\
\text { Diminished glucose uptake }\end{array}$ \\
\hline$\Delta 1312-1355$ & $\begin{array}{l}\text { No significant influence on kinase activities }{ }^{7,10} \\
\text { No significant effect on IR internalization }{ }^{13}\end{array}$ \\
\hline
\end{tabular}

${ }^{4}$ (O'Neill et al., 1994); ${ }^{5}$ (He et al., 1996); ${ }^{6}\left(\mathrm{M}\right.$. F. White et al., 1988); ${ }^{7}$ (Backer, Schroeder, et al., 1992); ${ }^{8}$ (Backer et al., 1990); ${ }^{9}$ (Bonifacino \& Traub, 2003); ${ }^{10}$ (Myers et al., 1991); ${ }^{11}$ (Backer, Shoelson, et al., 1992); ${ }^{12}$ (Chaika et al., 1999); ${ }^{13}$ (Carpentier et al., 1993); ${ }^{14}$ (Cieniewicz et al., 2016); ${ }^{15}$ (Y Xu et al., 2011); ${ }^{16}$ (Ellis et al., 1986). 


\section{I.3.3 Signaling transduction in adipocyte differentiation}

Because of the important function in cellular signaling transduction, the RTKs regulate several essential cellular processes such as proliferation, differentiation, and tissue homeostasis (Lemmon \& Schlessinger, 2010; F Liu \& Zhuang, 2016). For instance, RTKs regulate the liver regeneration through the Erk1/2 signaling pathway (J Li et al., 2011). In liver, the proliferation of hepatocytes (hepatocytes undergo two cell cycles) occur in the early 66 hours after partial hepatectomy (L Xu et al., 2010). The RTK $\rightarrow$ SHC $\rightarrow$ GRB2/SOS $\rightarrow$ RAS $\rightarrow$ RAF pathway is found to promote the progression of $\mathrm{G}_{1}$ phase during the proliferation, while the RTK $\rightarrow$ PLCY $\rightarrow$ PKC $\rightarrow$ SRC/PYK2 $\rightarrow$ GRB2/SOS $\rightarrow$ RAS $\rightarrow$ RAF pathway participates in advancing the $S$ phase and $\mathrm{G}_{2} / \mathrm{M}$ phase checkpoint ( $\mathrm{J} \mathrm{Li}$ et al., 2011). RTKs also regulate the differentiation of mesenchymal stem cells (MSCs) into neuronal cells (Tzeng et al., 2015). Upon the stimulation of growth factors such as FGF-8 (fibroblast growth factor 8) and FGF-2 (fibroblast growth factor 2), RTKs induce activation of both the Erk1/2 signaling pathway and the PI3K/Akt signaling pathway in MSCs (Trzaska et al., 2007). On the one hand, the phosphorylation of Erk in the former pathway phosphorylates the downstream protein GREB (cAMP response element-binding protein) and then leads to the upregulation of TrkB (tyrosine receptor kinase $\mathrm{B}$, the receptor of BDNF) and the secretion of BDNF (brain-derived neurotrophic factor) (Tzeng et al., 2015). On the other hand, the activation of the later pathway plays a critical role in cell survival (Tzeng et al., 2015). Therefore, the importance of RTKs on intracellular trafficking 
and cellular signaling, and how these receptors regulate proliferation and differentiation will allow us to understand the critical role of these receptors in the process of adipogenesis.

Following up the functions of RTKs, the IR specifically activates two essential signaling pathways: the Erk1/2 signaling pathway and the PI3K/Akt signaling pathway (Figure 7). Through the two pathways, the activation of the IR regulates multiple biological processes: gene expression, protein translation, and cell growth via the Erk1/2 signaling pathway; and changes in metabolic function, such as glucose uptake, glycogen synthesis, and expression of necessary enzymes/proteins as acute metabolic response, through the PI3K/Akt signaling pathway (Taniguchi et al., 2006; Jensen \& De Meyts, 2009). On the one hand, Shc is recruited and activated through the pY972 on the juxtamembrane domain of the IR. Then Grb2 will be recruited via the interaction between its $\mathrm{SH} 2$ domain and tyrosine phosphorylated Shc (Jameson et al., 2016). At last, SOS will be recruited and interacts with the two SH3 domains of Grb2 to form the Grb2-SOS complex, following the activation of RAS $\rightarrow$ RAF $\rightarrow$ MEK $\rightarrow$ Erk1/2 cascade (Zarich et al., 2006). On the other hand, the phosphorylation on the $Y 972$ recruits and activates both IRS-1 and IRS-2 whereas the Y1158, Y1162, and Y1163 on the activation loop of the IR are only responsible for IRS-2 recruitment and activation. Then PI3K will be recruited and activated based on its SH2 domains following IRS-1/2 activation (Youngren, 2007). The activated PI3K finally leads to activation of Akt, which ensures the IRS-1/2 $\rightarrow \mathrm{PI} 3 \mathrm{~K} \rightarrow$ Akt cascade. 
Besides the effects on normal cell processes, the IR signaling pathways are essential for the differentiation of the pre-adipocytes in specific aspects. First, the signaling pathway is triggered by activation of the IR and regulates the differentiation, proliferation, and growth of the fat cells (adipocytes) by stimulating the formation and storage of lipids in both pre-adipocytes and adipocytes (Saltiel \& Kahn, 2001). Second, the invagination of the IR complexes is activated through the RME, which regulates the IR distribution on the plasma membrane, insulin sensitivity, and density of the IR biological activities (Morcavallo et al., 2014). Interestingly, the receptor signaling of IR complexes is not terminated after invagination, on the opposite, it can be magnified (Vieira et al., 1996). Since the internalized IR complexes are still active and continue triggering the downstream signaling, the process of internalization is essential for the regulation of signal transduction (Sorkin \& Von Zastrow, 2002). As is discussed above, there are two fates for these internalized vesicles: 1) to merge with lysosomes and be degraded; 2) to proceed to the recycling endosomes from where the IR is brought back to the cell surface to be used again (Marsh, 2001). The transport and sorting of early endosomes require the participation of Rab5 (Hunker et al., 2006).

\section{I.4 Regulating the function of Rab5}

\section{I.4.1 The small GTPase Rab5: small but essential}

Rab5 is a Ras-like small GTPase (small GTP-binding protein) that not only shows a crucial regulatory role in controlling the RME of the IR but also plays a rate-limited role in early endosome fusion (Barbieri et al., 2004). Like the other 
GTPases, Rab5 has two forms: the active form and the inactive form. The active form is also the Rab5 GTP-bound form, while the inactive form is also the Rab5GDP-bound form (Figure 8). The converting of the Rab5 GTP-bound form to the Rab5 GDP-bound form (inactivation of Rab5) is triggered by Rab5 GAPs while the activation of Rab5 is catalyzed by Rab5 GEFs (Figure 8).

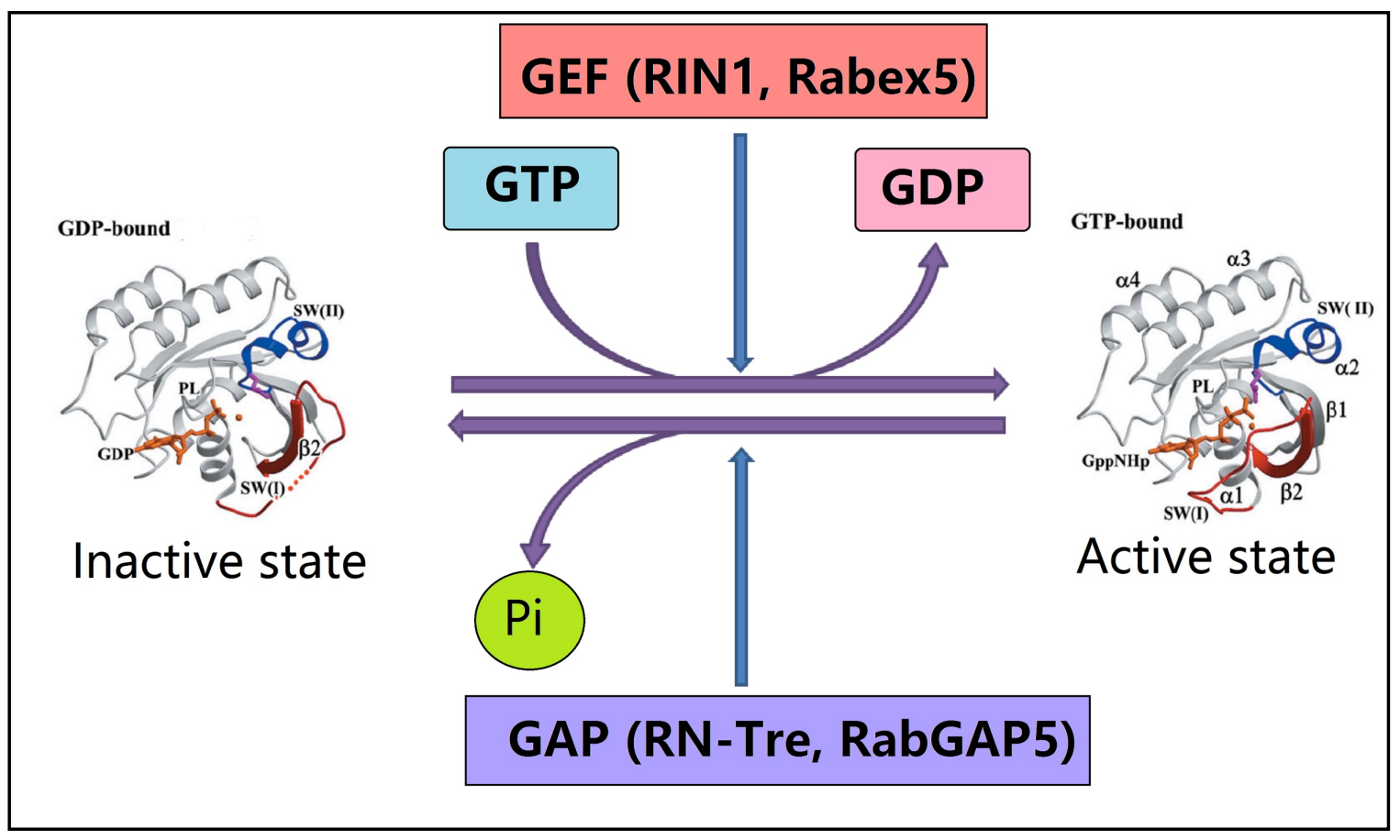

\section{Figure 8. Rab5 regulation.}

As other GTPases, Rab5 has two forms: the active form and the inactive form. The active form is the Rab5 GTP-bound form while the inactive form is the Rab5 GDPbound form. The converting of the GTP-bound form to the GDP-bound form (inactivation of Rab5) is triggered by GAPs while the converse activation process of Rab5 is catalyzed by GEFs (Lundquist, 2006). The ribbon diagrams of GTP/GDP-bound form of Rab5 are modified from Zhu et al. (Zhu et al., 2004). The switch I/II (SW (I)/(II)) regions are shown in red and blue, respectively. GppNHp (a nonhydrolyzable GTP analog), GDP, and metal ions are shown in brown sticks and dots, respectively. (PL: phosphate-binding loop; GAP: GTPase activating protein; GEF: guanine exchange factor; GppNHp: guanosine-5'( $\beta, \gamma)$-imidotriphosphate.) 
As the primary Rab protein to function in early endosome dynamics and probably the one that has the best-characterized effectors in mammalian studies, Rab5 presents on the plasma membrane and endocytic vesicles, but mainly locates on sorting endosomes (Woodman, 2000). Rab5 is also a membraneassociated protein that undergoes a hydrophobic modification at the C-terminal (Woodman, 2000). The isoprenylation of C-terminal cysteines allow Rab5 to associate with the membrane of an organelle or transport vesicles in its GTPbound form (Pechlivanis \& Kuhlmann, 2006). When in the Rab5-GDP binding form, Rab5 can be maintained in a soluble state, transferred, and efficiently recruited in the cytosol by forming a cytosolic complex with guanine nucleotide dissociation inhibitor (GDI) (Woodman, 2000). The GDI displacement factors (GDFs), which present on the membrane of the endocytic vesicles or the early endosome, then catalyze the localization of Rab5 to these membrane compartments and mediate the replacement of GDI (Blumer et al., 2013). A Rab5 GEF in the endosome membrane will then activate Rab5 by exchanging GDP to GTP (Alberts et al., 2007). The activated Rab5 can activate PI3K, which synthesizes PI3P (phosphatidylinositol 3-phosphate). Together with PI3P, the activated Rab5 binds to a variety of Rab5 effectors to perform the biological effects of Rab5 on endosome fusion (Woodman, 2000). In addition, the activated Rab5 can recruit more Rab5 GEFs, thus creating a positive feedback loop to further enhancing Rab5 assembly. Interestingly, Rab5 is also reported to be required for the interaction between IRS-1 and p85a and the activation of Akt upon insulin stimulation (Su et al., 2006). 
In summary, Rab5 activity is regulated by several Rab5 specific GEFs and GAPs, and more importantly, different Rab5 effectors are recruited by the GTPbound Rab5 to modulate particular intracellular pathways (Table 3).

Table 3. Rab5 regulators and effectors.

\begin{tabular}{ll}
\hline \hline & Regulator/Effector \\
\hline Rab5 GEF & RIN1/2/3 \\
& Rabex-5 \\
& ALS2/Alsin \\
& RAP6/GAPex-5/RME-6 \\
Rab5 GAP & RN-Tre \\
& RabGAP-5 \\
& Rabaptin-5 \\
& Vps34 \\
& Rabenosyn-5 \\
& EEA1 \\
& APPL1/2 \\
& PI3K \\
& Rabankyrin-5 \\
& Huntingtin \\
\hline \hline
\end{tabular}

1.4.2 Guanine nucleotide exchange factors, GTPase-activating proteins, and effectors of Rab5: working cooperatively

Rab5 GEFs, including Ras interference 1/2/3 (RIN1/2/3), Rabaptin-5 associated exchange factor for Rab5 (Rabex-5), , amyotrophic lateral sclerosis 2 (ALS2/Alsin), GTPase activating protein and exchange factor for Rab5 (GAPex-5), 
and Ras interference-like (Rinl) are specialized by the highly conserved vacuolar protein sorting-associated protein 9 (VPS9) domain through which the inactivated Rab5 interacts with (Carney et al., 2006). The VPS9 domain-containing proteins are widely conserved in eukaryotic cells of different species, such as Vps9p and Muk1p from S. cerevisiae, RME-6, RABX-5, and CE23604 from Caenorhabditis elegans (C. elegans) and at least nine proteins from the human beings (Carney et al., 2006).

Functions of the Rab5 GEFs have been extensively studied in the past four decades. The RIN family is composed of RIN1, RIN2, and RIN3. They are multifunctional proteins that, besides the VPS9 domain, contain another three domains: the RA (Ras association) domain, the PR (proline rich) domain, and the $\mathrm{SH} 2$ domain. The RIN proteins share similar structure of all the domains but are distinguished by the containing of a different number of the $\mathrm{PH}$ domain, which has one/two/three repeats in RIN1, RIN2 and RIN3, respectively. The RIN proteins can be activated by the IR through the $\mathrm{SH} 2$ domain and activate Rab5 through the VPS9 domain upon IR activation. Activation of RIN proteins leads to the activation of Rab5, thus promotes the early endosome fusion (Barbieri et al., 2004). The RA domain of the RIN proteins is responsible for the interaction with Ras, indicating RIN proteins to be Ras effectors that promote Rab5 activity. RIN1 is the most wellcharacterized protein in the RIN family, existing in both the cytoplasm and the plasma membrane (Colicelli et al., 2012). Previous studies show that RIN1 promotes EGFR and TGF- $\beta$ receptor internalization through Rab5 activation (Barbieri et al., 2003; Colicelli et al., 2012). The expression of RIN1-SH2 domain, 
however, impairs the EGFR internalization without affecting cargo endocytic receptors, such as transferrin (Barbieri et al., 2003). RIN1 also binds to 14-3-3 proteins through a sequence containing serine 351 . The binding with 14-3-3 locates RIN1 to the cytoplasm and intracellular compartments whereas the mutation S351A shifts RIN1 localization to the plasma membrane (Y Wang et al., 2002). RIN1:R94A mutant, which locates in the SH2 domain, showed a decreased interaction with EGFR upon EGFR activation (Barbieri et al., 2003). The RIN1:Y561F mutant, which locates in the VPS9 domain of RIN1, showed defective function in activation of Rab5 and dramatic inhibition of Rab5 function (Galvis et al., 2009). In addition, RIN1 has been found to be a breast tumor suppressor gene and undergoes a regulated expression in forebrain neurons and epithelial cells (Dzudzor et al., 2010; Milstein et al., 2007). RIN2 and RIN3 display same biochemical property as RIN1 that perform the guanine nucleotide exchange activity. However, both RIN2 and RIN3 can bind to amphiphysin II, whereas RIN1 cannot. Besides this distinct interaction, RIN1 is dominantly expressed in brain and pancreas, RIN2 has its highest expression in heart and kidney, and RIN3 exhibits higher expression in human mast cells (Carney et al., 2006; Janson et al., 2012). RIN3 also exhibits a unique intracellular localization as it locates on Rab5-positive vesicles in the cytoplasm but does not colocalize with the essential early endosome marker early endosome antigen 1 (EEA1) (Kajiho et al., 2003).

The Rinl was recently identified as a Rab5 GEF with high similarity to the RIN proteins but without an RA domain (Kajiho et al., 2012). It is ubiquitously expressed in all types of cells but with higher expression in lymphoid organs, such 
as thymus and spleen, and specifically accumulates at neuromuscular synapses (Woller et al., 2011). It colocalizes with Rab5 in actin-rich membrane ruffles, which indicates a novel role of Rinl to recruit Rab5 to the cytoskeleton (Woller et al., 2011). Interestingly, the Rinl also activates Rab22 and even shows a higher catalytic activity for Rab22 compared to Rab5.

The Rabex-5 protein structure is identified to be made up of an N-terminal domain, a membrane binding domain, a helical bundle (HB) domain, a VPS9 domain, a coiled-coil (CC) domain, and a PR domain (Shin et al., 2012). The Rabex-5 activates Rab5 and thus recruits Rabaptin-5 (a Rab5 effector), which then binds to the GTP-bound Rab5 and recruits Rabex-5 in a positive loop. Interestingly, the GTP exchange activity of Rabex-5 is much higher when in the Rabex-5Rabaptin5 complex (Delprato et al., 2004). Besides, the VPS9 domain of Rabex-5 alone shows a higher GTP exchange activity than the full-length Rabex-5 (Delprato et al., 2004).

Alsin is a $183 \mathrm{kDa}$ protein that mainly expresses in brain. It is a multifunctional protein that contains a Ran GEF RCC1 (RCC1-like) domain, a tandem $\mathrm{Dbl}$ homology $(\mathrm{DH})$ domain, a pleckstrin homology domain, several membrane occupation and recognition nexus (MORN) motifs, and a VPS9 domain (Carney et al., 2006). Alsin exhibits colocalization with Rab5 and its effector EEA1 on the early endosomes in Hela cells (Otomo et al., 2003). Overexpression of the wild-type Alsin and the constitutive active form of Alsin both results in enlarged endosomes in cultured neuronal cells through the activation of Rab5 (Otomo et al., 2003). Besides, Alsin-deficient mice exhibit a disturbance in endosome 
transportation of IGF-1R but unaltered endocytosis of transferrin and dextran (Devon et al., 2006).

Rab5-activating protein 6 (RAP6) is the human homolog of GAPex-5, which is also known as receptor-mediated endocytosis protein 6 (RME-6) as the C. elegans homolog, contains an N-terminal RasGAP domain and a C-terminal VPS9 domain. Unlike the other Rab5 GEF proteins that colocalize with Rab5 on the early endosomes, RAP6 is primarily found on clathrin-coated pits (CCPs). In vivo, the expression of the dominant-negative form of Rab5 (Rab5-S34N, this mutant will be discussed later in other chapters) or small interfering RNA (siRNA)-mediated depletion of RAP6, reduced the uncoating efficiency of AP2 complex on the CCPs by increasing the steady-state levels of AP2 (Semerdjieva et al., 2008).

Another group of proteins that regulate the Rab5 function are the GAPs, including the Rab5-specific GAP protein (RabGAP-5) and related to the $\mathrm{N}$ terminus of tre oncogene (RN-tre), which solubilize Rab5 by inactivating Rab5 from the acceptor membrane (Figure 6). The rate of GTP hydrolysis mediated by GAPs is relatively high since the basal rate is intrinsically slow ( 1 $\mathrm{min})$ (Scheffzek et al., 1998).

RN-tre localizes to Rab5-positive vesicles. Overexpression of RN-tre inhibits the Rab5-dependent internalization of transferrin and EGF but does not affect the membrane association of EEA1 (Haas et al., 2005; Palamidessi et al., 2013). Removal of RN-tre increases the level of active Rab5 and significantly improves the cell migration of mouse embryo fibroblasts in vitro (Palamidessi et al., 2013). 
The overexpression of RabGAP-5 results in a loss of Rab5 effector EEA1 from early endosomes and impaired endocytosis (Haas et al., 2005). However, depletion of RabGAP-5 leads to similar phenotype as the expression of the constitutive active mutant of Rab5 (Rab5-S34N): level of endosome-localized EEA1 is increased, endosomes become larger, and trafficking of EGF is disrupted (Haas et al., 2005).

In the processes of vesicle formation and delivery, Rab5 is also regulated by multiple Rab5 effectors. As one of the best studied Rab proteins to date, Rab5 has been found to interacts with as many as 30 different effector proteins (Pfeffer, 2005). For instance, EEA1, an important Rab5 effector that binds to Rab5-GTP form, is the only effector that is necessarily required by minimal fusion and mediates endosome docking (Christoforidis et al., 1999). Another Rab5 effector, Rabaptin-5, is initially identified as an GTP-bound Rab5 effector through a yeast 2-hybrid screen (Stenmark et al., 1995). Rabaptin-5 is mostly found as a complex with Rabex-5 in the cell (Horiuchi et al., 1997). Rabex-5 and Rabaptin-5 recruit each other in a positive loop upon Rab5 activation and thus keep the membrane Rab5-postive until the loop is interrupted by other recruited compartments (Kalin et al., 2015). Deletion of the Rab5-binding domain of Rabaptin-5 results in giant endosomes as well as impaired endocytosis process (Kalin et al., 2015).

In summary, the movement of intracellular vesicles mediated by RME is related with Rab5 and its effectors due to their roles in regulating vesicle formation and delivery. 


\section{5 References}

Alberts, B., Johnson, A., Lewis, J., Raff, M., Roberts, K., \& Walter, P. (2007). Molecular Biology of the Cell (5 ed.): Garland Science.

Ali, A. T., Hochfeld, W. E., Myburgh, R., \& Pepper, M. S. (2013). Adipocyte and adipogenesis. Eur J Cell Biol, 92(6-7), 229-236. doi:10.1016/j.ejcb.2013.06.001

Arcaro, A. (2013). Targeting the insulin-like growth factor-1 receptor in human cancer. Front Pharmacol, 4, 30. doi:10.3389/fphar.2013.00030

Ariotti, N., Murphy, S., Hamilton, N. A., Wu, L., Green, K., Schieber, N. L., Li, P., Martin, S., \& Parton, R. G. (2012). Postlipolytic insulin-dependent remodeling of micro lipid droplets in adipocytes. Mol Biol Cell, 23(10), 1826-1837. doi:10.1091/mbc.E11-10-0847

Arner, P., Bernard, S., Salehpour, M., Possnert, G., Liebl, J., Steier, P., Buchholz, B. A., Eriksson, M., Arner, E., Hauner, H., Skurk, T., Ryden, M., Frayn, K. N., \& Spalding, K. L. (2011). Dynamics of human adipose lipid turnover in health and metabolic disease. Nature, 478(7367), 110-113. doi:10.1038/nature10426

Backer, J. M., Kahn, C. R., Cahill, D. A., Ullrich, A., \& White, M. F. (1990). Receptor-mediated internalization of insulin requires a 12-amino acid sequence in the juxatamembrane region of the insulin receptor beta-subunit. J Biol Chem, 265(27), 16450-16454.

Backer, J. M., Schroeder, G. G., Kahn, C. R., Myers, M. G., Jr., Wilden, P. A., Cahill, D. A., \& White, M. F. (1992). Insulin stimulation of phosphatidylinositol 3kinase activity maps to insulin receptor regions required for endogenous substrate phosphorylation. J Biol Chem, 267(2), 1367-1374.

Backer, J. M., Shoelson, S. E., Weiss, M. A., Hua, Q. X., Cheatham, R. B., Haring, E., Cahill, D. C., \& White, M. F. (1992). The insulin receptor juxtamembrane region contains two independent tyrosine/beta-turn internalization signals. J Cell Biol, 118(4), 831-839. doi:10.1083/jcb.118.4.831

Backovic, M., \& Rey, F. A. (2012). Virus entry: old viruses, new receptors. Curr Opin Virol, 2(1), 4-13. doi:10.1016/j.coviro.2011.12.005

Barbatelli, G., Murano, I., Madsen, L., Hao, Q., Jimenez, M., Kristiansen, K., Giacobino, J. P., De Matteis, R., \& Cinti, S. (2010). The emergence of cold-induced brown adipocytes in mouse white fat depots is determined predominantly by white to brown adipocyte transdifferentiation. Am J Physiol Endocrinol Metab, 298(6), E1244-1253. doi:10.1152/ajpendo.00600.2009 
Barbieri, M. A., Fernandez-Pol, S., Hunker, C., Horazdovsky, B. H., \& Stahl, P. D. (2004). Role of rab5 in EGF receptor-mediated signal transduction. Eur J Cell Biol, 83(6), 305-314. doi:10.1078/0171-9335-00381

Barbieri, M. A., Kong, C., Chen, P. I., Horazdovsky, B. F., \& Stahl, P. D. (2003). The SRC homology 2 domain of Rin 1 mediates its binding to the epidermal growth factor receptor and regulates receptor endocytosis. J Biol Chem, 278(34), 3202732036. doi:10.1074/jbc.M304324200

Barneda, D., Frontini, A., Cinti, S., \& Christian, M. (2013). Dynamic changes in lipid droplet-associated proteins in the "browning" of white adipose tissues. Biochim Biophys Acta, 1831(5), 924-933. doi:10.1016/j.bbalip.2013.01.015

Bartness, T. J., \& Ryu, V. (2015). Neural control of white, beige and brown adipocytes. Int J Obes Suppl, 5(Suppl 1), S35-39. doi:10.1038/ijosup.2015.9

Bayliss, R., Haq, T., \& Yeoh, S. (2015). The Ys and wherefores of protein kinase autoinhibition. Biochim Biophys Acta, $1854(10$ Pt $\quad$ B), 1586-1594. doi:10.1016/j.bbapap.2015.04.025

Belfiore, A., Frasca, F., Pandini, G., Sciacca, L., \& Vigneri, R. (2009). Insulin receptor isoforms and insulin receptor/insulin-like growth factor receptor hybrids in physiology and disease. Endocr Rev, 30(6), 586-623. doi:10.1210/er.2008-0047

Beneit, N., Fernandez-Garcia, C. E., Martin-Ventura, J. L., Perdomo, L., Escribano, O., Michel, J. B., Garcia-Gomez, G., Fernandez, S., Diaz-Castroverde, S., Egido, J., Gomez-Hernandez, A., \& Benito, M. (2016). Expression of insulin receptor (IR) $A$ and $B$ isoforms, IGF-IR, and IR/IGF-IR hybrid receptors in vascular smooth muscle cells and their role in cell migration in atherosclerosis. Cardiovasc Diabetol, 15(1), 161. doi:10.1186/s12933-016-0477-3

Berg, J. M., Gatto, G. J., Stryer, L., \& Tymoczko, J. L. (2015). Biochemistry (8 ed.). New York: W H Freeman: Kate Ahr Parker.

Berthet, C., Klarmann, K. D., Hilton, M. B., Suh, H. C., Keller, J. R., Kiyokawa, H., \& Kaldis, P. (2006). Combined loss of Cdk2 and Cdk4 results in embryonic lethality and Rb hypophosphorylation. Dev Cell, 10(5), 563-573. doi:10.1016/j.devcel.2006.03.004

Bloomgarden, Z. T. (2003). Prevention of Obesity and Diabetes. Diabetes Care, 26(11), 3172-3178.

Bluher, M. (2013). Adipose tissue dysfunction contributes to obesity related metabolic diseases. Best Pract Res Clin Endocrinol Metab, 27(2), 163-177. doi:10.1016/j.beem.2013.02.005 
Bluher, M., Michael, M. D., Peroni, O. D., Ueki, K., Carter, N., Kahn, B. B., \& Kahn, C. R. (2002). Adipose Tissue Selective Insulin Receptor Knockout Protects against Obesity and Obesity-Related Glucose Intolerance. Developmental Cell, 3, 25-38.

Blumer, J., Rey, J., Dehmelt, L., Mazel, T., Wu, Y. W., Bastiaens, P., Goody, R. S., \& Itzen, A. (2013). RabGEFs are a major determinant for specific Rab membrane targeting. J Cell Biol, 200(3), 287-300. doi:10.1083/jcb.201209113

Bonifacino, J. S., \& Traub, L. M. (2003). Signals for sorting of transmembrane proteins to endosomes and lysosomes. Annu Rev Biochem, 72, 395-447. doi:10.1146/annurev.biochem.72.121801.161800

Boucher, J., Kleinridders, A., \& Kahn, C. R. (2014). Insulin receptor signaling in normal and insulin-resistant states. Cold Spring Harb Perspect Biol, 6(1). doi:10.1101/cshperspect.a009191

Caballero, B. (2007). The global epidemic of obesity: an overview. Epidemiologic Reviews, 29(1), 1-5. doi:10.1093/epirev/mxm012

Cao, Z., Umek, R. M., \& McKnight, S. L. (1991). Regulated expression of three C/EBP isoforms during adipose conversion of 3T3-L1 cells.pdf. Genes \& Development, 5, 1538-1552.

Carney, D. S., Davies, B. A., \& Horazdovsky, B. F. (2006). Vps9 domain-containing proteins: activators of Rab5 GTPases from yeast to neurons. Trends Cell Biol, 16(1), 27-35. doi:10.1016/j.tcb.2005.11.001

Carpentier, J. L., Paccaud, J. P., Backer, J., Gilbert, A., Orci, L., Kahn, C. R., \& Baecker, J. (1993). Two steps of insulin receptor internalization depend on different domains of the beta-subunit. $J$ Cell Biol, 122(6), 1243-1252. doi:10.1083/jcb.122.6.1243

Casem, M. L. (2016). Endocytosis Case Studies in Cell Biology (pp. 217-240).

Cawthorn, W. P., \& Sethi, J. K. (2008). TNF-alpha and adipocyte biology. FEBS Lett, 582(1), 117-131. doi:10.1016/j.febslet.2007.11.051

Cedikova, M., Kripnerova, M., Dvorakova, J., Pitule, P., Grundmanova, M., Babuska, V., Mullerova, D., \& Kuncova, J. (2016). Mitochondria in White, Brown, and Beige Adipocytes. Stem Cells Int, 2016, 6067349. doi:10.1155/2016/6067349

Chaika, O. V., Chaika, N., Volle, D. J., Hayashi, H., Ebina, Y., Wang, L. M., Pierce, J. H., \& Lewis, R. E. (1999). Mutation of tyrosine 960 within the insulin receptor juxtamembran domain impairs glucose transport but does not inhibit ligandmediate phosphorylation of insulin receptor substrate-2 in 3T3-L1 adipocytes. $J$ Biol Chem, 274(17), 12075-12080. 
Chirala, S. S., \& Wakil, S. J. (2004). Structure and Function of Animal Fatty Acid Synthase. Lipids, 39(11), 1045-1053.

Christoforidis, S., McBride, H. M., Burgoyne, R. D., \& Zerial, M. (1999). The Rab5 effector EEA1 is a core component of endosome docking. Nature, 397(6720), 621625. doi:10.1038/17618

Cieniewicz, A. M., Cooper, P. R., McGehee, J., Lingham, R. B., \& Kihm, A. J. (2016). Novel method demonstrates differential ligand activation and phosphatase-mediated deactivation of insulin receptor tyrosine-specific phosphorylation. Cell Signal, 28(8), 1037-1047. doi:10.1016/j.cellsig.2016.05.001

Cildir, G., Akincilar, S. C., \& Tergaonkar, V. (2013). Chronic adipose tissue inflammation: all immune cells on the stage. Trends Mol Med, 19(8), 487-500. doi:10.1016/j.molmed.2013.05.001

Colicelli, J., Ting, P. Y., \& Janson, C. (2012). RIN Family Proteins (RIN1, RIN2, and RIN3). Encyclopedia of Signaling Molecules.

Collins, B. M., McCoy, A. J., Kent, H. M., Evans, P. R., \& Owen, D. J. (2002). Molecular Architecture and Functional Model of the Endocytic AP2 Complex. Cell, 109(4), 523-535. doi:10.1016/s0092-8674(02)00735-3

Collins, J. M., Neville, M. J., Pinnick, K. E., Hodson, L., Ruyter, B., van Dijk, T. H., Reijngoud, D. J., Fielding, M. D., \& Frayn, K. N. (2011). De novo lipogenesis in the differentiating human adipocyte can provide all fatty acids necessary for maturation. J Lipid Res, 52(9), 1683-1692. doi:10.1194/jIr.M012195

Conner, S. D., \& Schmid, S. L. (2003). Regulated portals of entry into the cell. Nature, 422(6927), 37-44. doi:10.1038/nature01451

Cooper, G. M. (2000). The cell: A Molecular Approach. (2 ed.): Sunderland (MA): Sinauer Associates.

Coppack, S. W. (2005). Adipose tissue changes in obesity. Biochem Soc Trans, 33(Pt 5), 1049-1052. doi:10.1042/BST20051049

Cosker, K. E., \& Segal, R. A. (2014). Neuronal Signaling through Endocytosis. Cold Spring Harbor Perspectives in Biology, 6(2). doi:ARTN a020669

10.1101/cshperspect.a020669

Cossart, P., \& Helenius, A. (2014). Endocytosis of viruses and bacteria. Cold Spring Harb Perspect Biol, 6(8). doi:10.1101/cshperspect.a016972

Critchley, W. R., Pellet-Many, C., Ringham-Terry, B., Harrison, M. A., Zachary, I. C., \& Ponnambalam, S. (2018). Receptor Tyrosine Kinase Ubiquitination and De- 
Ubiquitination in Signal Transduction and Receptor Trafficking. Cells, 7(3). doi:10.3390/cells7030022

Cuatrecasas, P. (1971). Insulin--receptor interactions in adipose tissue cells: direct measurement and properties. Proc Natl Acad Sci U S A, 68(6), 1264-1268.

Currie, E., Schulze, A., Zechner, R., Walther, T. C., \& V., F. J. R. (2013). Cellular Fatty Acid Metabolism and Cancer. Cell Metabolism, 18(2), 153-161. doi:10.1016/j.cmet.2013.05.017

Czech, M. P., \& Buxton, J. M. (1993). Insulin action on the internalization of the GLUT4 glucose transporter in isolated rat adipocytes.pdf. J. Biol. Chem., 268, 9187-9190.

de Jong, J. M. A., Wouters, R. T. F., Boulet, N., Cannon, B., Nedergaard, J., \& Petrovic, N. (2017). The beta3-adrenergic receptor is dispensable for browning of adipose tissues. Am J Physiol Endocrinol Metab, 312(6), E508-E518. doi:10.1152/ajpendo.00437.2016

De Meyts, P. (2004). Insulin and its receptor: structure, function and evolution. Bioessays, 26(12), 1351-1362. doi:10.1002/bies.20151

De Meyts, P., S., W., Palsgaard, J., Theede, A. M., Gauguin, L., Aladdin, H., \& Whittaker, J. (2000-2013). Insulin and IGF-I Receptor Structure and Binding Mechanism.

Delprato, A., Merithew, E., \& Lambright, D. G. (2004). Structure, exchange determinants, and family-wide rab specificity of the tandem helical bundle and Vps9 domains of Rabex-5. Cell, 118(5), 607-617. doi:10.1016/j.cell.2004.08.009

Devon, R. S., Orban, P. C., Gerrow, K., Barbieri, M. A., Schwab, C., Cao, L. P., Helm, J. R., Bissada, N., Cruz-Aguado, R., Davidson, T. L., Witmer, J., Metzler, M., Lam, C. K., Tetzlaff, W., Simpson, E. M., McCaffery, J. M., El-Husseini, A. E., Leavitt, B. R., \& Hayden, M. R. (2006). Als2-deficient mice exhibit disturbances in endosome trafficking associated with motor behavioral abnormalities. Proc Natl Acad Sci U S A, 103(25), 9595-9600. doi:10.1073/pnas.0510197103

Di Guglielmo, G. M., Baass, P. C., Ou, W. J., Posner, B. I., \& Bergeron, J. J. (1994). Compartmentalization of SHC, GRB2 and mSOS, and hyperphosphorylation of Raf-1 by EGF but not insulin in liver parenchyma. The EMBO Journal, 13(18), 4269-4277.

Diaz-Castroverde, S., Baos, S., Luque, M., Di Scala, M., Gonzalez-Aseguinolaza, G., Gomez-Hernandez, A., Beneit, N., Escribano, O., \& Benito, M. (2016). Prevalent role of the insulin receptor isoform $A$ in the regulation of hepatic glycogen 
metabolism in hepatocytes and in mice. Diabetologia, 59(12), 2702-2710. doi:10.1007/s00125-016-4088-z

Dimitriadis, G., Mitrou, P., Lambadiari, V., Maratou, E., \& Raptis, S. A. (2011). Insulin effects in muscle and adipose tissue. Diabetes Research and Clinical Practice, 93, S52-S59. doi:10.1016/s0168-8227(11)70014-6

Doherty, G. J., \& McMahon, H. T. (2009). Mechanisms of endocytosis. Annu Rev Biochem, 78, 857-902. doi:10.1146/annurev.biochem.78.081307.110540

Dwivedi, G., \& Dwivedi, S. (2007). Sushruta - the Clinician - Teacher par Excellence. Indian J Chest Dis Allied Sci, 49, 243-244.

Dzudzor, B., Huynh, L., Thai, M., Bliss, J. M., Nagaoka, Y., Wang, Y., Ch'ng, T. H., Jiang, M., Martin, K. C., \& Colicelli, J. (2010). Regulated expression of the Ras effector Rin1 in forebrain neurons. Mol Cell Neurosci, 43(1), 108-116. doi:10.1016/j.mcn.2009.09.012

Ebina, Y., Ellis, L., Jarnagin, K., Edery, M., Graf, L., Clauser, E., Ou, J. H., Masiarz, F., Kan, Y. W., Goldfine, I. D., \& et al. (1985). The human insulin receptor cDNA: the structural basis for hormone-activated transmembrane signalling. Cell, 40(4), 747-758.

Eguchi, J., Wang, X., Yu, S., Kershaw, E. E., Chiu, P. C., Dushay, J., Estall, J. L., Klein, U., Maratos-Flier, E., \& Rosen, E. D. (2011). Transcriptional control of adipose lipid handling by IRF4. Cell Metab, 13(3), 249-259. doi:10.1016/j.cmet.2011.02.005

Ehehalt, R., Fullekrug, J., Pohl, J., Ring, A., Herrmann, T., \& Stremmel, W. (2006). Translocation of long chain fatty acids across the plasma membrane--lipid rafts and fatty acid transport proteins. Mol Cell Biochem, 284(1-2), 135-140. doi:10.1007/s11010-005-9034-1

Eknoyan, G. (2006). A history of obesity, or how what was good became ugly and then bad. Advances in Chronic Kidney Disease. Adv Chronic Kidney Dis, 13(4), 421-427. doi:10.1053/j.ackd.2006.07.002

Ellis, L., Clauser, E., Morgan, D. O., Edery, M., Roth, R. A., \& Rutter, W. J. (1986). Replacement of insulin receptor tyrosine residues 1162 and 1163 compromises insulin-stimulated kinase activity and uptake of 2-deoxyglucose. Cell, 45(5), 721732.

Enerback, S. (2009). The origins of brown adipose tissue. N Engl J Med, 360(19), 2021-2023. doi:10.1056/NEJMcibr0809610

Escribano, O., Beneit, N., Rubio-Longas, C., Lopez-Pastor, A. R., \& GomezHernandez, A. (2017). The Role of Insulin Receptor Isoforms in Diabetes and Its 
Metabolic and Vascular Complications. J Diabetes Res, 2017, 1403206. doi:10.1155/2017/1403206

Esters, H., Alexandrov, K., lakovenko, A., Ivanova, T., Thoma, N., Rybin, V., Zerial, M., Scheidig, A. J., \& Goody, R. S. (2001). Vps9, Rabex-5 and DSS4: proteins with weak but distinct nucleotide-exchange activities for Rab proteins. J Mol Biol, 310(1), 141-156. doi:10.1006/jmbi.2001.4735

Evans, T. M., Ferguson, C., Wainwright, B. J., Parton, R. G., \& Wicking, C. (2003). Rab23, a Negative Regulator of Hedgehog Signaling, Localizes to the Plasma Membrane and the Endocytic Pathway. Traffic, 4(12), 869-884. doi:10.1046/j.1600-0854.2003.00141.x

Ezzati, M., Lopez, A. D., Rodgers, A., \& Murray, C. J. L. (2004). Comparative quantification of health risks: global and regional burden of disease attributable to selected major risk factors. Retrieved from

Fernandez, M. C., Martin, A., Venara, M., Calcagno Mde, L., Sanso, G., Quintana, S., Chemes, H. E., Barontini, M., \& Pennisi, P. A. (2013). Overexpression of the insulin-like growth factor 1 receptor (IGF-1R) is associated with malignancy in familial pheochromocytomas and paragangliomas. Clin Endocrinol (Oxf), 79(5), 623-630. doi:10.1111/cen.12205

Ferrucci, L., Studenski, S. A., Alley, D. E., Barbagallo, M., \& Harris, T. B. (2010). Obesity in aging and art. J Gerontol A Biol Sci Med Sci, 65(1), 53-56. doi:10.1093/gerona/glp166

Finkelstein, E. A., Khavjou, O. A., Thomspson, H., Trogdon, J. G., Pan, L., Sherry, B., \& Dietz, W. (2011). Obesity and Severe Obesity Forecasts Through 2030. American Journal of Preventive Medicine, 42(6), 563-570.

Fox, K. E., Colton, L. A., Erickson, P. F., Friedman, J. E., Cha, H. C., Keller, P., MacDougald, O. A., \& Klemm, D. J. (2008). Regulation of cyclin D1 and Wnt10b gene expression by cAMP-responsive element-binding protein during early adipogenesis involves differential promoter methylation. J Biol Chem, 283(50), 35096-35105. doi:10.1074/jbc.M806423200

Fujimoto, T., \& Parton, R. G. (2011). Not just fat: the structure and function of the lipid droplet. Cold Spring Harb Perspect Biol, 3(3). doi:10.1101/cshperspect.a004838

Furuhashi, M., Saitoh, S., Shimamoto, K., \& Miura, T. (2014). Fatty Acid-Binding Protein 4 (FABP4): Pathophysiological Insights and Potent Clinical Biomarker of Metabolic and Cardiovascular Diseases. Clin Med Insights Cardiol, 8(Suppl 3), 2333. doi:10.4137/CMC.S17067 
Galvis, A., Balmaceda, V., Giambini, H., Conde, A., Villasana, Z., Fornes, M. W., \& Barbieri, M. A. (2009). Inhibition of early endosome fusion by Rab5-binding defective Ras interference 1 mutants. Arch Biochem Biophys, 482(1-2), 83-95. doi:10.1016/j.abb.2008.11.009

Garrett, R., \& Grisham, C. (2017). Biochemistry (6 ed.).

Geerling, J. J., Boon, M. R., Kooijman, S., Parlevliet, E. T., Havekes, L. M., Romijn, J. A., Meurs, I. M., \& Rensen, P. C. (2014). Sympathetic nervous system control of triglyceride metabolism: novel concepts derived from recent studies. J Lipid Res, 55(2), 180-189. doi:10.1194/jlr.R045013

Gibert, M., Monier, M. N., Ruez, R., Hale, M. L., Stiles, B. G., Benmerah, A., Johannes, L., Lamaze, C., \& Popoff, M. R. (2011). Endocytosis and toxicity of clostridial binary toxins depend on a clathrin-independent pathway regulated by Rho-GDI. Cell Microbiol, 13(1), 154-170. doi:10.1111/j.1462-5822.2010.01527.x

Giovannucci, E., Harlan, D. M., Archer, M. C., Bergenstal, R. M., Gapstur, S. M., Habel, L. A., Pollak, M., Regensteiner, J. G., \& Yee, D. (2010). Diabetes and cancer: a consensus report. CA Cancer J Clin, 60(4), 207-221. doi:10.3322/caac.20078

Goh, L. K., \& Sorkin, A. (2013). Endocytosis of receptor tyrosine kinases. Cold Spring Harb Perspect Biol, 5(5), a017459. doi:10.1101/cshperspect.a017459

Gonzalez, L., \& Scheller, R. H. (1999). Regulation of Membrane Trafficking. Cell, 96(6), 755-758. doi:10.1016/s0092-8674(00)80585-1

Govers, R., Coster, A. C., \& James, D. E. (2004). Insulin increases cell surface GLUT4 levels by dose dependently discharging GLUT4 into a cell surface recycling pathway. Mol Cell Biol, 24(14), 6456-6466. doi:10.1128/MCB.24.14.64566466.2004

Grant, B. D., \& Donaldson, J. G. (2009). Pathways and mechanisms of endocytic recycling. Nat Rev Mol Cell Biol, 10(9), 597-608. doi:10.1038/nrm2755

Grimes, M. L., Zhou, J., Beattie, E. C., Yuen, E. C., Hall, D. E., Valletta, J. S., Topp, K. S., LaVail, J. H., Bunnett, N. W., \& Mobley, W. C. (1996). Endocytosis of activated TrkA: evidence that nerve growth factor induces formation of signaling endosomes. J Neurosci, 16(24), 7950-7964.

Grosshans, B. L., Ortiz, D., \& Novick, P. (2006). Rabs and their effectors: achieving specificity in membrane traffic. Proc Natl Acad Sci U S A, 103(32), 11821-11827. doi:10.1073/pnas.0601617103 
Guan, H. P., Li, Y., Jensen, M. V., Newgard, C. B., Steppan, C. M., \& Lazar, M. A. (2002). A futile metabolic cycle activated in adipocytes by antidiabetic agents. Nat Med, 8(10), 1122-1128. doi: $10.1038 / \mathrm{nm} 780$

Guo, Y., Cordes, K. R., Farese, R. V., Jr., \& Walther, T. C. (2009). Lipid droplets at a glance. J Cell Sci, 122(Pt 6), 749-752. doi:10.1242/jcs.037630

Guo, Y., Walther, T. C., Rao, M., Stuurman, N., Goshima, G., Terayama, K., Wong, J. S., Vale, R. D., Walter, P., \& Farese, R. V. (2008). Functional genomic screen reveals genes involved in lipid-droplet formation and utilization.pdf. Nature, 453(7195), 657-661. doi:10.1038/nature06928

Gurr, M. I., Harwood, J. L., Frayn, K. N., Murphy, D. J., \& Michell, R. H. (2016). Lipids Biochemistry, Biotechnology and Health (6 ed.): Wiley-Blackwell.

Gustafson, B., Hedjazifar, S., Gogg, S., Hammarstedt, A., \& Smith, U. (2015). Insulin resistance and impaired adipogenesis. Trends Endocrinol Metab, 26(4), 193-200. doi:10.1016/j.tem.2015.01.006

Haas, A. K., Fuchs, E., Kopajtich, R., \& Barr, F. A. (2005). A GTPase-activating protein controls Rab5 function in endocytic trafficking. Nat Cell Biol, 7(9), 887-893. doi:10.1038/ncb1290

Hamann, A., Filer, J. S., \& Lowell, B. B. (1988). Obesity after genetic ablation of brown adipose tissue. Z. Ernahrungswiss, 37, 1-7.

Harris, C. A., Haas, J. T., Streeper, R. S., Stone, S. J., Kumari, M., Yang, K., Han, X., Brownell, N., Gross, R. W., Zechner, R., \& Farese, R. V., Jr. (2011). DGAT enzymes are required for triacylglycerol synthesis and lipid droplets in adipocytes. J Lipid Res, 52(4), 657-667. doi:10.1194/jlr.M013003

Hashemi, H. F., \& Goodman, J. M. (2015). The life cycle of lipid droplets. Curr Opin Cell Biol, 33, 119-124. doi:10.1016/j.ceb.2015.02.002

Haslam, D. W., \& James, W. P. T. (2005). Obesity. The Lancet, 366(9492), 11971209. doi:10.1016/s0140-6736(05)67483-1

He, W. M., Craparo, A., Zhu, Y. Y., ONeill, T. J., Wang, L. M., Pierce, J. H., \& Gustafson, T. A. (1996). Interaction of insulin receptor substrate-2 (IRS-2) with the insulin and insulin-like growth factor I receptors - Evidence for two distinct phosphotyrosine-dependent interaction domains within IRS-2. Journal of Biological Chemistry, 271(20), 11641-11645. doi:DOI 10.1074/jbc.271.20.11641

Heid, H., Rickelt, S., Zimbelmann, R., Winter, S., Schumacher, H., Dorflinger, Y., Kuhn, C., \& Franke, W. W. (2014). On the formation of lipid droplets in human adipocytes: the organization of the perilipin-vimentin cortex. PLoS One, 9(2), e90386. doi:10.1371/journal.pone.0090386 
Heitmann, B. L., Westerterp, K. R., Loos, R. J., Sorensen, T. I., O'Dea, K., McLean, P., Jensen, T. K., Eisenmann, J., Speakman, J. R., Simpson, S. J., Reed, D. R., \& Westerterp-Plantenga, M. S. (2012). Obesity: lessons from evolution and the environment. Obes Rev, 13(10), 910-922. doi:10.1111/j.1467-789X.2012.01007.x

Higgins, M. K., \& McMahon, H. T. (2002). Snap-shots of clathrin-mediated endocytosis.pdf. TRENDS in Biochemical Sciences, 27(5), 257-263.

Hinrichsen, L., Harborth, J., Andrees, L., Weber, K., \& Ungewickell, E. J. (2003). Effect of clathrin heavy chain- and alpha-adaptin-specific small inhibitory RNAs on endocytic accessory proteins and receptor trafficking in HeLa cells. J Biol Chem, 278(46), 45160-45170. doi:10.1074/jbc.M307290200

Hishida, T., Nishizuka, M., Osada, S., \& Imagawa, M. (2009). The role of C/EBPdelta in the early stages of adipogenesis. Biochimie, 91(5), 654-657. doi:10.1016/j.biochi.2009.02.002

Huang, J., Imamura, T., \& Olefsky, J. M. (2001). Insulin can regulate GLUT4 internalization by signaling to Rab5 and the motor protein dynein. PNAS, 98. doi:10.1073/pnas.241368698

Hubbard, S. R. (2013). The insulin receptor: both a prototypical and atypical receptor tyrosine kinase. Cold Spring Harb Perspect Biol, 5(3), a008946. doi:10.1101/cshperspect.a008946

Hunker, C. M., Kruk, I., Hall, J., Giambini, H., Veisaga, M. L., \& Barbieri, M. A. (2006). Role of Rab5 in insulin receptor-mediated endocytosis and signaling. Arch Biochem Biophys, 449(1-2), 130-142. doi:10.1016/j.abb.2006.01.020

Huse, M., \& Kuriyan, J. (2002). The Conformational Plasticity of Protein Kinases. Cell, 109(3), 275-282. doi:10.1016/s0092-8674(02)00741-9

Irannejad, R., Tsvetanova, N. G., Lobingier, B. T., \& von Zastrow, M. (2015). Effects of endocytosis on receptor-mediated signaling. Curr Opin Cell Biol, 35, 137-143. doi:10.1016/j.ceb.2015.05.005

Ishibashi, J., \& Seale, P. (2010). Beige Can Be Slimming. Science, 328(5982), 1113-1114. doi:10.1126/science.1190816

James, D. E., Brown, R., Navarro, J., \& Pilch, P. F. (1988). Insulin-regulatable tissues express a unique insulin-sensitive glucose transport protein. Nature, 333(6169), 183-185. doi:10.1038/333183a0

Jameson, J. L., De Groot, L. J., Kretser, D., Giudice, L. C., Grossman, A., Melmed, S., Potts, J. T., Jr., \& Weir, G. C. (2016). Endocrinology: Adult and Pediatric (7 ed.). 
Jang, M. K., Yun, Y. R., Kim, J. H., Park, M. H., \& Jung, M. H. (2017). Gomisin N inhibits adipogenesis and prevents high-fat diet-induced obesity. Sci Rep, 7, 40345. doi:10.1038/srep40345

Janson, C., Kasahara, N., Prendergast, G. C., \& Colicelli, J. (2012). RIN3 is a negative regulator of mast cell responses to SCF. PLoS One, 7(11), e49615. doi:10.1371/journal.pone.0049615

Jensen, M., \& De Meyts, P. (2009). Chapter 3 Molecular Mechanisms of Differential Intracellular Signaling From the Insulin Receptor Insulin and IGFs (pp. 51-75).

Jhun, B. H., Rampal, A. L., Liu, H., Lachaal, M., \& Jung, C. Y. (1992). Effects of insulin on steady state kinetics of GLUT4 subcellular distribution in rat adipocytes. Evidence of constitutive GLUT4 recycling.pdf. J. Biol. Chem, 267, 17710-17715.

Joshi, R. L., Lamothe, B., Cordonnier, N., Mesbah, K., Monthioux, E., Jami, J., \& Bucchini, D. (1996). Targeted disruption of the insulin receptor gene in the mouse results in neonatal lethality. EMBO J, 15(7), 1542-1547.

Kajiho, H., Fukushima, S., Kontani, K., \& Katada, T. (2012). RINL, guanine nucleotide exchange factor Rab5-subfamily, is involved in the EphA8-degradation pathway with odin. PLoS One, 7(1), e30575. doi:10.1371/journal.pone.0030575

Kajiho, H., Saito, K., Tsujita, K., Kontani, K., Araki, Y., Kurosu, H., \& Katada, T. (2003). RIN3: a novel Rab5 GEF interacting with amphiphysin II involved in the early endocytic pathway. J Cell Sci, 116(Pt 20), 4159-4168. doi:10.1242/jcs.00718

Kajimura, S., Spiegelman, B. M., \& Seale, P. (2015). Brown and Beige Fat: Physiological Roles beyond Heat Generation. Cell Metab, 22(4), 546-559. doi:10.1016/j.cmet.2015.09.007

Karpov, O. A., Fearnley, G. W., Smith, G. A., Kankanala, J., McPherson, M. J., Tomlinson, D. C., Harrison, M. A., \& Ponnambalam, S. (2015). Receptor tyrosine kinase structure and function in health and disease. AIMS Biophysics, 2(4), 476502. doi:10.3934/biophy.2015.4.476

Khalil, I. A., Kogure, K., Akita, H., \& Harashima, H. (2006). Uptake pathways and subsequent intracellular trafficking in nonviral gene delivery. Pharmacol Rev, 58(1), 32-45. doi:10.1124/pr.58.1.8

Kirchhausen, T., Owen, D., \& Harrison, S. C. (2014). Molecular structure, function, and dynamics of clathrin-mediated membrane traffic. Cold Spring Harb Perspect Biol, 6(5), a016725. doi:10.1101/cshperspect.a016725

Klemm, D. J., Leitner, J. W., Watson, P., Nesterova, A., Reusch, J. E., Goalstone, M. L., \& Draznin, B. (2001). Insulin-induced adipocyte differentiation. Activation of 
CREB rescues adipogenesis from the arrest caused by inhibition of prenylation. $J$ Biol Chem, 276(30), 28430-28435. doi:10.1074/jbc.M103382200

Kohlwein, S. D., Veenhuis, M., \& van der Klei, I. J. (2013). Lipid droplets and peroxisomes: key players in cellular lipid homeostasis or a matter of fat--store 'em up or burn 'em down. Genetics, 193(1), 1-50. doi:10.1534/genetics.112.143362

Koppen, A., \& Kalkhoven, E. (2010). Brown vs white adipocytes: the PPARgamma coregulator story. FEBS Lett, 584(15), 3250-3259. doi:10.1016/j.febslet.2010.06.035

Kornilova, E. S. (2014). Receptor-mediated endocytosis and cytoskeleton. Biochemistry (Mosc), 79(9), 865-878. doi:10.1134/S0006297914090041

Kralisch, S., \& Fasshauer, M. (2013). Adipocyte fatty acid binding protein: a novel adipokine involved in the pathogenesis of metabolic and vascular disease? Diabetologia, 56(1), 10-21. doi:10.1007/s00125-012-2737-4

Kruth, H. S., Jones, N. L., Huang, W., Zhao, B., Ishii, I., Chang, J., Combs, C. A., Malide, D., \& Zhang, W. Y. (2005). Macropinocytosis is the endocytic pathway that mediates macrophage foam cell formation with native low density lipoprotein. $J$ Biol Chem, 280(3), 2352-2360. doi:10.1074/jbc.M407167200

Kublaoui, B., Lee, J., \& Pilch, P. F. (1995). Dynamics of signaling during insulinstimulated endocytosis of its receptor in adipocytes. J Biol Chem, 270(1), 59-65.

Kushner, R. F. (2014). Weight loss strategies for treatment of obesity. Prog Cardiovasc Dis, 56(4), 465-472. doi:10.1016/j.pcad.2013.09.005

Lajoie, P., \& Nabi, I. R. (2010). International Review of Cell and Molecular Biology (Vol. 282): Elsevier.

Lazar, D. F., Wiese, R. J., Brady, M. J., Mastick, C. C., Waters, S. B., Yamauchi, K., Pessin, J. E., Cuatrecasas, P., \& Saltiel, A. R. (1995). Mitogen-Activated Protein-Kinase Kinase Inhibition Does Not Block the Stimulation of GlucoseUtilization by Insulin. Journal of Biological Chemistry, 270(35), 20801-20807.

Lefterova, M. I., Zhang, Y., Steger, D. J., Schupp, M., Schug, J., Cristancho, A., Feng, D., Zhuo, D., Stoeckert, C. J., Jr., Liu, X. S., \& Lazar, M. A. (2008). PPARgamma and C/EBP factors orchestrate adipocyte biology via adjacent binding on a genome-wide scale. Genes Dev, 22(21), 2941-2952. doi:10.1101/gad.1709008

Lemmon, M. A., \& Schlessinger, J. (2010). Cell signaling by receptor tyrosine kinases. Cell, 141(7), 1117-1134. doi:10.1016/j.cell.2010.06.011 
Leto, D., \& Saltiel, A. R. (2012). Regulation of glucose transport by insulin: traffic control of GLUT4. Nat Rev Mol Cell Biol, 13(6), 383-396. doi:10.1038/nrm3351

Leung, K. F., Baron, R., \& Seabra, M. C. (2006). Thematic review series: lipid posttranslational modifications. geranylgeranylation of Rab GTPases. J Lipid Res, 47(3), 467-475. doi:10.1194/jIr.R500017-JLR200

Li, G. (2015). Rab GTPases.

Li, J., Wang, G., Fan, J., Chang, C., \& Xu, C. (2011). Eight paths of ERK1/2 signalling pathway regulating hepatocyte proliferation in rat liver regeneration. Journal of Genetics. J Genet, 90(3), 435-442.

Lim, Y. S., \& Tang, B. L. (2015). A role for Rab23 in the trafficking of Kif17 to the primary cilium. J Cell Sci, 128(16), 2996-3008. doi:10.1242/jcs.163964

Liu, F., \& Zhuang, S. (2016). Role of Receptor Tyrosine Kinase Signaling in Renal Fibrosis. Int J Mol Sci, 17(5). doi:10.3390/ijms17060972

Liu, J., \& Shapiro, J. I. (2003). Endocytosis and signal transduction: basic science update. Biol Res Nurs, 5(2), 117-128. doi:10.1177/1099800403256860

Liu, J. P., Baker, J., Perkins, A. S., Robertson, E. J., \& Efstratiadis, A. (1993). Mice carrying null mutations of the genes encoding insulin-like growth factor I (Igf-1) and type 1 IGF receptor (Igf1r). Cell, 75(1), 59-72.

Lodish, H., Berk, A., Kaiser, C. A., Karieger, M., Bretscher, A., Ploegh, H., Amon, A., \& Martin, K. C. (2016). Molecular Cell Biology.pdf (8 ed.): Katherine Ahr Parker.

Loftus, S. K., Larson, D. M., Baxter, L. L., Antonellis, A., Chen, Y., Wu, X., Jiang, Y., Bittner, M., Hammer, J. A., 3rd, \& Pavan, W. J. (2002). Mutation of melanosome protein RAB38 in chocolate mice. Proc Natl Acad Sci U S A, 99(7), 4471-4476. doi:10.1073/pnas.072087599

Lowe, C. E., O'Rahilly, S., \& Rochford, J. J. (2011). Adipogenesis at a glance. J Cell Sci, 124(Pt 16), 2681-2686. doi:10.1242/jcs.079699

Lundquist, E. A. (2006). Small GTPases. WormBook, 1-18. doi:10.1895/wormbook.1.67.1

MacDougald, O. A., \& Mandrup, S. (2002). Adipogenesis: forces that tip the scales. Trends in Endocrinology and Metabolism, 13(1), 5-11. doi:Doi 10.1016/S10432760(01)00517-3

Marsh, M. (2001). Endocytosis: Oxford University Press. 
Marshall, S. (1985). Kinetics of insulin receptor internalization and recycling in adipocytes. Shunting of receptors to a degradative pathway by inhibitors of recycling. J Biol Chem, 260(7), 4136-4144.

Mckay, B. (2014, May 29, 2014). Study finds $29 \%$ of world population is overweight or obese, $2 / 3$ rds live in developing countries. The Wall Street Journal.

Mechanick, J. I., Youdim, A., Jones, D. B., Timothy Garvey, W., Hurley, D. L., Molly McMahon, M., Heinberg, L. J., Kushner, R., Adams, T. D., Shikora, S., Dixon, J. B., \& Brethauer, S. (2013). Clinical practice guidelines for the perioperative nutritional, metabolic, and nonsurgical support of the bariatric surgery patient-2013 update: cosponsored by American Association of Clinical Endocrinologists, the Obesity Society, and American Society for Metabolic \& Bariatric Surgery. Surg Obes Relat Dis, 9(2), 159-191. doi:10.1016/j.soard.2012.12.010

Medzhitov, R. (2008). Origin and physiological roles of inflammation. Nature, 454(7203), 428-435. doi:10.1038/nature07201

Meegalla, R. L., Billheimer, J. T., \& Cheng, D. (2002). Concerted elevation of acylcoenzyme A: diacylglycerol acyltransferase (DGAT) activity through independent stimulation of mRNA expression of DGAT1 and DGAT2 by carbohydrate and insulin.pdf. Biochemical and Biophysical Research Communications, 298, 317-323. doi:S0006-291X(02)02466-X

Menasche, G., Pastural, E., Feldmann, J., Certain, S., Ersoy, F., Dupuis, S., Wulffraat, N., Bianchi, D., Fischer, A., Le Deist, F., \& de Saint Basile, G. (2000). Mutations in RAB27A cause Griscelli syndrome associated with haemophagocytic syndrome. Nat Genet, 25(2), 173-176. doi:10.1038/76024

Milstein, M., Mooser, C. K., Hu, H., Fejzo, M., Slamon, D., Goodglick, L., Dry, S., \& Colicelli, J. (2007). RIN1 is a breast tumor suppressor gene. Cancer Res, 67(24), 11510-11516. doi:10.1158/0008-5472.CAN-07-1147

Morcavallo, A., Stefanello, M., lozzo, R. V., Belfiore, A., \& Morrione, A. (2014). Ligand-mediated endocytosis and trafficking of the insulin-like growth factor receptor I and insulin receptor modulate receptor function. Front Endocrinol (Lausanne), 5, 220. doi:10.3389/fendo.2014.00220

Moreno-Navarrete, J. M., \& Fernández-Real, J. M. (2012). Adipocyte Differentiation Adipose Tissue Biology (pp. 17-38).

Morris, M. J., Beilharz, J. E., Maniam, J., Reichelt, A. C., \& Westbrook, R. F. (2015). Why is obesity such a problem in the 21st century? The intersection of palatable food, cues and reward pathways, stress, and cognition. Neurosci Biobehav Rev, 58, 36-45. doi:10.1016/j.neubiorev.2014.12.002 
Mraz, M., \& Haluzik, M. (2014). The role of adipose tissue immune cells in obesity and low-grade inflammation. J Endocrinol, 222(3), R113-127. doi:10.1530/JOE14-0283

Muller, M. P., \& Goody, R. S. (2018). Molecular control of Rab activity by GEFs, GAPs and GDI. Small GTPases, 9(1-2), 5-21. doi:10.1080/21541248.2016.1276999

Myers, M. G., Backer, J. M., Siddle, K., \& White, M. F. (1991). The insulin receptor functions normally in Chinese hamster ovary cells after truncation of the $C$ terminus. J Biol Chem, 266(16), 10616-10623.

Nolen, B., Taylor, S., \& Ghosh, G. (2004). Regulation of protein kinases; controlling activity through activation segment conformation. Mol Cell, 15(5), 661-675. doi:10.1016/j.molcel.2004.08.024

Nye, C. K., Hanson, R. W., \& Kalhan, S. C. (2008). Glyceroneogenesis is the dominant pathway for triglyceride glycerol synthesis in vivo in the rat. $\mathrm{J} \mathrm{Biol} \mathrm{Chem,}$ 283(41), 27565-27574. doi:10.1074/jbc.M804393200

O'Neill, T. J., Craparo, A., \& Gustafson, T. A. (1994). Characterization of an interaction between insulin receptor substrate 1 and the insulin receptor by using the two-hybrid system. Mol Cell Biol, 14(10), 6433-6442.

Oliver, E., McGillicuddy, F., Phillips, C., Toomey, S., \& Roche, H. M. (2010). The role of inflammation and macrophage accumulation in the development of obesityinduced type 2 diabetes mellitus and the possible therapeutic effects of long-chain n-3 PUFA. Proc Nutr Soc, 69(2), 232-243. doi:10.1017/S0029665110000042

Olofsson, L. E., Orho-Melander, M., William-Olsson, L., Sjöholm, K., Sjöström, L., Groop, L., Carlsson, B., Carlsson, L. M. S., \& Olsson, B. (2008). CCAAT/Enhancer Binding Protein a $(\mathrm{C} / \mathrm{EBP} \alpha)$ in Adipose Tissue Regulates Genes in Lipid and Glucose Metabolism and a Genetic Variation in C/EBPa Is Associated with Serum Levels of Triglycerides. The Journal of Clinical Endocrinology \& Metabolism, 93(12), 4880-4886. doi:10.1210/jc.2008-0574

Otomo, A., Hadano, S., Okada, T., Mizumura, H., Kunita, R., Nishijima, H., Showguchi-Miyata, J., Yanagisawa, Y., Kohiki, E., Suga, E., Yasuda, M., Osuga, H., Nishimoto, T., Narumiya, S., \& Ikeda, J. E. (2003). ALS2, a novel guanine nucleotide exchange factor for the small GTPase Rab5, is implicated in endosomal dynamics. Human Molecular Genetics, 12(14), 1671-1687. doi:10.1093/hmg/ddg184

Palamidessi, A., Frittoli, E., Ducano, N., Offenhauser, N., Sigismund, S., Kajiho, H., Parazzoli, D., Oldani, A., Gobbi, M., Serini, G., Di Fiore, P. P., Scita, G., \& Lanzetti, L. (2013). The GTPase-activating protein RN-tre controls focal adhesion 
turnover and cell migration. Curr Biol, 23(23), 2355-2364. doi:10.1016/j.cub.2013.09.060

Pantoja, C., Huff, J. T., \& Yamamoto, K. R. (2008). Glucocorticoid signaling defines a novel commitment state during adipogenesis in vitro. Mol Biol Cell, 19(10), 40324041. doi:10.1091/mbc.E08-04-0420

Papich, M. G., \& Riviere, J. E. (2009). Veterinary pharmacology and therapeutics (9 ed.): Wiley-Blackwell.

Park, S. Y., \& Guo, X. (2014). Adaptor protein complexes and intracellular transport. Biosci Rep, 34(4). doi:10.1042/BSR20140069

Pearse, B. M. F., Smith, C. J., \& Owen, D. J. (2000). Clathrin coat construction in endocytosis.pdf. Current Opinion in Structural Biology, 10, 220-228.

Pechlivanis, M., \& Kuhlmann, J. (2006). Hydrophobic modifications of Ras proteins by isoprenoid groups and fatty acids--More than just membrane anchoring. Biochim Biophys Acta, 1764(12), 1914-1931. doi:10.1016/j.bbapap.2006.09.017

Peng, C., Zeng, W., Su, J., Kuang, Y., He, Y., Zhao, S., Zhang, J., Ma, W., Bode, A. M., Dong, Z., \& Chen, X. (2016). Cyclin-dependent kinase 2 (CDK2) is a key mediator for EGF-induced cell transformation mediated through the ELK4/c-Fos signaling pathway. Oncogene, 35(9), 1170-1179. doi:10.1038/onc.2015.175

Pennock, S., \& Wang, Z. (2003). Stimulation of cell proliferation by endosomal epidermal growth factor receptor as revealed through two distinct phases of signaling. Mol Cell Biol, 23(16), 5803-5815.

Pfeffer, S. (2005). Filling the Rab GAP. Nat Cell Biol, 7(9), 856-857. doi:10.1038/ncb0905-856

Plomgaard, P., Bouzakri, K., Krogh-Madsen, R., Mittendorfer, B., Zierath, J. R., \& Pedersen, B. K. (2005). Tumor necrosis factor-alpha induces skeletal muscle insulin resistance in healthy human subjects via inhibition of Akt substrate 160 phosphorylation. Diabetes, 54(10), 2939-2945.

Poekes, L., Lanthier, N., \& Leclercq, I. A. (2015). Brown adipose tissue: a potential target in the fight against obesity and the metabolic syndrome. Clin Sci (Lond), 129(11), 933-949. doi:10.1042/CS20150339

Pol, A., Gross, S. P., \& Parton, R. G. (2014). Biogenesis of the multifunctional lipid droplet: lipids, proteins, and sites. J Cell Biol, 204(5), 635-646. doi:10.1083/jcb.201311051 
Qian, S., Huang, H., \& Tang, Q. (2015). Brown and beige fat: the metabolic function, induction, and therapeutic potential. Front Med, 9(2), 162-172. doi:10.1007/s11684-015-0382-2

Qian, S. W., Tang, Y., Li, X., Liu, Y., Zhang, Y. Y., Huang, H. Y., Xue, R. D., Yu, H. Y., Guo, L., Gao, H. D., Liu, Y., Sun, X., Li, Y. M., Jia, W. P., \& Tang, Q. Q. (2013). BMP4-mediated brown fat-like changes in white adipose tissue alter glucose and energy homeostasis. Proc Natl Acad Sci U S A, 110(9), E798-807. doi:10.1073/pnas.1215236110

Ramji, D. P., \& Foka, P. (2002). CCAAT/enhancer-binding proteins: structure, function and regulation.pdf. Biochem J, 365, 561-575.

Rehman, J., Traktuev, D., Li, J., Merfeld-Clauss, S., Temm-Grove, C. J., Bovenkerk, J. E., Pell, C. L., Johnstone, B. H., Considine, R. V., \& March, K. L. (2004). Secretion of angiogenic and antiapoptotic factors by human adipose stromal cells. Circulation, 109(10), 1292-1298. doi:10.1161/01.CIR.0000121425.42966.F1

Report, M. a. M. W. (2004). Prevalence of Overweight and Obesity Among Adults with Diagnosed Diabetes - United States, 1988-1994 and 1999-2002. Centers for Disease Control and Prevention (CDC).

Reshef, L., Olswang, Y., Cassuto, H., Blum, B., Croniger, C. M., Kalhan, S. C., Tilghman, S. M., \& Hanson, R. W. (2003). Glyceroneogenesis and the triglyceride/fatty acid cycle. J Biol Chem, 278(33), 30413-30416. doi:10.1074/jbc.R300017200

Riordan, N. H., Ichim, T. E., Min, W. P., Wang, H., Solano, F., Lara, F., Alfaro, M., Rodriguez, J. P., Harman, R. J., Patel, A. N., Murphy, M. P., Lee, R. R., \& Minev, B. (2009). Non-expanded adipose stromal vascular fraction cell therapy for multiple sclerosis. J Transl Med, 7, 29. doi:10.1186/1479-5876-7-29

Rosen, E. D., Hsu, C. H., Wang, X., Sakai, S., Freeman, M. W., Gonzalez, F. J., \& Spiegelman, B. M. (2002). C/EBPalpha induces adipogenesis through PPARgamma: a unified pathway. Genes Dev, 16(1), 22-26. doi:10.1101/gad.948702

Rosen, E. D., \& MacDougald, O. A. (2006). Adipocyte differentiation from the inside out. Nat Rev Mol Cell Biol, 7(12), 885-896. doi:10.1038/nrm2066

Rosen, E. D., \& Spiegelman, B. M. (2000). Molecular regulation of adipogenesis. Annu Rev Cell Dev Biol, 16, 145-171. doi:10.1146/annurev.cellbio.16.1.145

Rothwell, N. J., \& Stock, M. J. (1979). A role for brown adipose tissue in dietinduced thermogene. Nature, 281, 31-35. 
Royle, S. J. (2006). The cellular functions of clathrin. Cell Mol Life Sci, 63(16), 1823-1832. doi:10.1007/s00018-005-5587-0

Rubinstein, S., \& Caballero, B. (2000). Is Miss America an Undernourished Role Model? Journal of the American Medical Association, 283(12), 53-36.

Sachdev, D., \& Yee, D. (2007). Disrupting insulin-like growth factor signaling as a potential cancer therapy. Mol Cancer Ther, 6(1), 1-12. doi:10.1158/15357163.MCT-06-0080

Saely, C. H., Geiger, K., \& Drexel, H. (2012). Brown versus white adipose tissue: a mini-review. Gerontology, 58(1), 15-23. doi:10.1159/000321319

Sahay, G., Alakhova, D. Y., \& Kabanov, A. V. (2010). Endocytosis of nanomedicines. J Control Release, 145(3), 182-195. doi:10.1016/j.jconrel.2010.01.036

Saltiel, A. R., \& Kahn, C. R. (2001). Insulin signalling and the regulation of glucose and lipid metabolism. Nature, 414(6865), 799-806. doi:10.1038/414799a

Sanchez-Gurmaches, J., Hung, C. M., Sparks, C. A., Tang, Y. F., Li, H. W., \& Guertin, D. A. (2012). PTEN Loss in the Myf5 Lineage Redistributes Body Fat and Reveals Subsets of White Adipocytes that Arise from Myf5 Precursors. Cell Metabolism, 16(3), 348-362. doi:10.1016/j.cmet.2012.08.003

Saponaro, C., Gaggini, M., Carli, F., \& Gastaldelli, A. (2015). The Subtle Balance between Lipolysis and Lipogenesis: A Critical Point in Metabolic Homeostasis. Nutrients, 7(11), 9453-9474. doi:10.3390/nu7115475

SawkaVerhelle, D., TartareDeckert, S., White, M. F., \& vanObberghen, E. (1996). Insulin receptor substrate-2 binds to the insulin receptor through its phosphotyrosine-binding domain and through a newly identified domain comprising amino acids 591-786. Journal of Biological Chemistry, 271(11), 59805983. doi:DOI 10.1074/jbc.271.11.5980

Schaffer, J. E., \& Lodish, H. F. (1994). Expression cloning and characterization of a novel adipocyte long chain fatty acid transport protein.pdf. Cell, 79, 427-436.

Scheffzek, K., Ahmadian, M. R., \& Wittinghofer, A. (1998). GTPase-activating proteins: helping hands to complement an active site. Trends Biochem Sci, 23(7), 257-262.

Schlessinger, J., \& Lemmon, M. A. (2003). SH2 and PTB domains in tyrosine kinase signaling. Sci STKE, 2003(191), RE12. doi:10.1126/stke.2003.191.re12

Schroeder, J. A., Ruta, J. D., Gordon, J. S., Rodrigues, A. S., \& Foote, C. C. (2012). The phosphodiesterase inhibitor isobutylmethylxanthine attenuates behavioral 
sensitization to cocaine. Behav Pharmacol, 23(3), 310-314. doi:10.1097/FBP.0b013e3283536d04

Sciacca, L., Prisco, M., Wu, A., Belfiore, A., Vigneri, R., \& Baserga, R. (2003). Signaling differences from the $A$ and $B$ isoforms of the insulin receptor (IR) in 32D cells in the presence or absence of IR substrate-1. Endocrinology, 144(6), 26502658. doi:10.1210/en.2002-0136

Seale, P., Bjork, B., Yang, W., Kajimura, S., Chin, S., Kuang, S., Scime, A., Devarakonda, S., Conroe, H. M., Erdjument-Bromage, H., Tempst, P., Rudnicki, M. A., Beier, D. R., \& Spiegelman, B. M. (2008). PRDM16 controls a brown fat/skeletal muscle switch. Nature, 454(7207), 961-967. doi:10.1038/nature07182

Semerdjieva, S., Shortt, B., Maxwell, E., Singh, S., Fonarev, P., Hansen, J., Schiavo, G., Grant, B. D., \& Smythe, E. (2008). Coordinated regulation of AP2 uncoating from clathrin-coated vesicles by rab5 and hRME-6. J Cell Biol, 183(3), 499-511. doi:10.1083/jcb.200806016

Shin, D., Lee, S. Y., Han, S., Ren, S., Kim, S., Aikawa, Y., \& Lee, S. (2012). Differential polyubiquitin recognition by tandem ubiquitin binding domains of Rabex-5. Biochem Biophys Res Commun, 423(4), 757-762. doi:10.1016/j.bbrc.2012.06.032

Siersbaek, R., Nielsen, R., \& Mandrup, S. (2010). PPARgamma in adipocyte differentiation and metabolism--novel insights from genome-wide studies. FEBS Lett, 584(15), 3242-3249. doi:10.1016/j.febslet.2010.06.010

Sigismund, S., Argenzio, E., Tosoni, D., Cavallaro, E., Polo, S., \& Di Fiore, P. P. (2008). Clathrin-mediated internalization is essential for sustained EGFR signaling but dispensable for degradation. Dev Cell, 15(2), 209-219. doi:10.1016/j.devcel.2008.06.012

Solomon-Zemler, R., Sarfstein, R., \& Werner, H. (2017). Nuclear insulin-like growth factor-1 receptor (IGF1R) displays proliferative and regulatory activities in non-malignant cells. PLoS One, 12(9), e0185164. doi:10.1371/journal.pone.0185164

Sorkin, A., \& Puthenveedu, M. A. (2014). Clathrin-mediated endocytosis. Vesicle Trafficking in Cancer, 1-31. doi:10.1007/978-1-4614-6528-7_1

Sorkin, A., \& Von Zastrow, M. (2002). Signal transduction and endocytosis: close encounters of many kinds. Nat Rev Mol Cell Biol, 3(8), 600-614. doi:10.1038/nrm883 
Stahl, A., Evans, J. G., Pattel, S., Hirsch, D., \& Lodish, H. F. (2002). Insulin Causes Fatty Acid Transport Protein Translocation and Enhanced Fatty Acid Uptake in Adipocytes.pdf. Developmental Cell, 2, 477-488.

Stenmark, H. (2009). Rab GTPases as coordinators of vesicle traffic. Nat Rev Mol Cell Biol, 10(8), 513-525. doi:10.1038/nrm2728

Stenmark, H., Vitale, G., Ullrich, O., \& Zerial, M. (1995). Rabaptin-5 Is a Direct Effector of the Small Gtpase Rab5 in Endocytic Membrane-Fusion. Cell, 83(3), 423-432. doi:Doi 10.1016/0092-8674(95)90120-5

Stenmark, H., \& Olkkonen, V. M. (2001). The Rab GTPase family.pdf. Genome Biology, 2(5), 3007.3001-3007.3007.

Strawford, A., Antelo, F., Christiansen, M., \& Hellerstein, M. K. (2004). Adipose tissue triglyceride turnover, de novo lipogenesis, and cell proliferation in humans measured with 2H2O. Am J Physiol Endocrinol Metab, 286(4), E577-588. doi:10.1152/ajpendo.00093.2003

Su, X., Lodhi, I. J., Saltiel, A. R., \& Stahl, P. D. (2006). Insulin-stimulated Interaction between insulin receptor substrate 1 and p85alpha and activation of protein kinase B/Akt require Rab5. J Biol Chem, 281(38), 27982-27990. doi:10.1074/jbc.M602873200

Sumi, M., Sata, M., Toya, N., Yanaga, K., Ohki, T., \& Nagai, R. (2007). Transplantation of adipose stromal cells, but not mature adipocytes, augments ischemia-induced angiogenesis. Life Sci., 80, 559-565.

Suzuki, M., Shinohara, Y., Ohsaki, Y., \& Fujimoto, T. (2011). Lipid droplets: size matters. $J$ Electron Microsc (Tokyo), 60 Suppl 1, S101-116. doi:10.1093/jmicro/dfr016

Svensson, R. U., Parker, S. J., Eichner, L. J., Kolar, M. J., Wallace, M., Brun, S. N., Lombardo, P. S., Van Nostrand, J. L., Hutchins, A., Vera, L., Gerken, L., Greenwood, J., Bhat, S., Harriman, G., Westlin, W. F., Harwood, H. J., Jr., Saghatelian, A., Kapeller, R., Metallo, C. M., \& Shaw, R. J. (2016). Inhibition of acetyl-CoA carboxylase suppresses fatty acid synthesis and tumor growth of nonsmall-cell lung cancer in preclinical models. Nat Med, 22(10), 1108-1119. doi: $10.1038 / \mathrm{nm} .4181$

Swierczynski, J., Zabrocka, L., Goyke, E., Raczynska, S., Adamonis, W., \& Sledzinski, Z. (2003). Enhanced glycerol 3-phosphate dehydrogenase activity in adipose tissue of obese humans.pdf. Mol and Cell Biochem, 254, 55-59.

Symonds, M. E. (2012). Adipose Tissue Biology: Springer Science + Business Media, LLC. 
Szentirmai, E., \& Kapas, L. (2017). The role of the brown adipose tissue in beta3adrenergic receptor activation-induced sleep, metabolic and feeding responses. Sci Rep, 7(1), 958. doi:10.1038/s41598-017-01047-1

Taguchi, A., \& White, M. F. (2008). Insulin-like signaling, nutrient homeostasis, and life span. Annu Rev Physiol, 70, 191-212. doi:10.1146/annurev.physiol.70.113006.100533

Tamori, Y., Masugi, J., Nishino, N., \& Kasuga, M. (2002). Role of Peroxisome Proliferator-Activated Receptor- $\gamma$ in Maintenance of the Characteristics of Mature 3T3-L1 Adipocytes.pdf. Diabetes, 51, 2045-2055.

Tanaka, T., Yoshida, N., Kishimoto, T., \& Akira, S. (1997). Defective adipocyte differentiation in mice lacking the C/EBPbeta and/or C/EBPdelta gene.pdf. The EMBO Journal, 16(24), 7432-7443.

Tang, Q. Q., Gronborg, M., Huang, H., Kim, J. W., Otto, T. C., Pandey, A., \& Lane, M. D. (2005). Sequential phosphorylation of CCAAT enhancer-binding protein beta by MAPK and glycogen synthase kinase 3beta is required for adipogenesis. Proc Natl Acad Sci U S A, 102(28), 9766-9771. doi:10.1073/pnas.0503891102

Tang, Q. Q., Otto, T. C., \& Lane, M. D. (2003). CCAAT/enhancer-binding protein is required for mitotic clonal expansion during adipogenesis.pdf. PNAS, 100(3), 850-855.

Taniguchi, C. M., Emanuelli, B., \& Kahn, C. R. (2006). Critical nodes in signalling pathways: insights into insulin action. Nat Rev Mol Cell Biol, 7(2), 85-96. doi:10.1038/nrm1837

Taylor, S. S., \& Kornev, A. P. (2011). Protein kinases: evolution of dynamic regulatory proteins. Trends Biochem Sci, 36(2), 65-77. doi:10.1016/j.tibs.2010.09.006

Timmons, J. A., Wennmalm, K., Larsson, O., Walden, T. B., Lassmann, T., Petrovic, N., Hamilton, D. L., Gimeno, R. E., Wahlestedt, C., Baar, K., Nedergaard, J., \& Cannon, B. (2007). Myogenic gene expression signature establishes that brown and white adipocytes originate from distinct cell lineages. Proceedings of the National Academy of Sciences of the United States of America, 104(11), 44014406. doi:10.1073/pnas.0610615104

Tiong, K. H., Mah, L. Y., \& Leong, C. O. (2013). Functional roles of fibroblast growth factor receptors (FGFRs) signaling in human cancers. Apoptosis, 18(12), 1447-1468. doi:10.1007/s10495-013-0886-7 
Treadway, J. L., Morrison, B. D., Goldfine, I. D., \& Pessin, J. E. (1989). Assembly of insulin/insulin-like growth factor-1 hybrid receptors in vitro. J Biol Chem, 264(36), 21450-21453.

Trzaska, K. A., Kuzhikandathil, E. V., \& Rameshwar, P. (2007). Specification of a dopaminergic phenotype from adult human mesenchymal stem cells. Stem Cells, 25(11), 2797-2808. doi:10.1634/stemcells.2007-0212

Tzeng, H. H., Hsu, C. H., Chung, T. H., Lee, W. C., Lin, C. H., Wang, W. C., Hsiao, C. Y., Leu, Y. W., \& Wang, T. H. (2015). Cell Signaling and Differential Protein Expression in Neuronal Differentiation of Bone Marrow Mesenchymal Stem Cells with Hypermethylated Salvador/Warts/Hippo (SWH) Pathway Genes. PLoS One, 10(12), e0145542. doi:10.1371/journal.pone.0145542

Ullrich, A., Bell, J. R., Chen, E. Y., Herrera, R., Petruzzelli, L. M., Dull, T. J., Gray, A., Coussens, L., Liao, Y. C., Tsubokawa, M., Mason, A., Seeburg, P. H., Grunfeld, C., Rosen, O. M., \& Ramachandran, J. (1985). Human insulin receptor and its relationship to the tyrosine kinase family of oncogenes. Nature, 313(6005), 756761. doi:10.1038/313756a0

Ullrich, A., Gray, A., Tam, A. W., Yang-Feng, T., Tsubokawa, M., Collins, C., Henzel, W., Le Bon, T., Kathuria, S., \& Chen, E. (1986). Insulin-like growth factor I receptor primary structure: comparison with insulin receptor suggests structural determinants that define functional specificity. EMBO J, 5(10), 2503-2512.

Ullrich, A., \& Schlessinger, J. (1990). Signal transduction by receptors with tyrosine kinase activity. Cell, 61(2), 203-212. doi:10.1016/0092-8674(90)90801-k

van Marken Lichtenbelt, W. D., \& Daanen, H. A. (2003). Cold-induced metabolism. Curr Opin Clin Nutr Metab Care, 6(4), 469-475. doi:10.1097/01.mco.0000078992.96795.5f

Vargas, D., Rosales, W., \& Lizcano, F. (2015). Modifications of Human Subcutaneous ADMSC after PPARgamma Activation and Cold Exposition. Stem Cells Int, 2015, 196348. doi:10.1155/2015/196348

Vazquez-Vela, M. E., Torres, N., \& Tovar, A. R. (2008). White adipose tissue as endocrine organ and its role in obesity. Arch Med Res, 39(8), 715-728. doi:10.1016/j.arcmed.2008.09.005

Vegiopoulos, A., Muller-Decker, K., Strzoda, D., Schmitt, I., Chichelnitskiy, E., Ostertag, A., Berriel Diaz, M., Rozman, J., Hrabe de Angelis, M., Nusing, R. M., Meyer, C. W., Wahli, W., Klingenspor, M., \& Herzig, S. (2010). Cyclooxygenase-2 controls energy homeostasis in mice by de novo recruitment of brown adipocytes. Science, 328(5982), 1158-1161. doi:10.1126/science.1186034 
Vegiopoulos, A., Rohm, M., \& Herzig, S. (2017). Adipose tissue: between the extremes. EMBO J, 36(14), 1999-2017. doi:10.15252/embj.201696206

Vieira, A. V., Lamaze, C., \& Schmid, S. L. (1996). Control of EGF receptor signaling by clathrin-mediated endocytosis. Science, 274(5295), 2086-2089.

Vigneri, R., Goldfine, I. D., \& Frittitta, L. (2016). Insulin, insulin receptors, and cancer. J Endocrinol Invest, 39(12), 1365-1376. doi:10.1007/s40618-016-0508-7

Vijgen, G. H., Bouvy, N. D., Teule, G. J., Brans, B., Schrauwen, P., \& van Marken Lichtenbelt, W. D. (2011). Brown adipose tissue in morbidly obese subjects. PLoS One, 6(2), e17247. doi:10.1371/journal.pone.0017247

von Zastrow, M., \& Sorkin, A. (2007). Signaling on the endocytic pathway. Curr Opin Cell Biol, 19(4), 436-445. doi:10.1016/j.ceb.2007.04.021

Wakil, S. J., \& Abu-Elheiga, L. A. (2009). Fatty acid metabolism: target for metabolic syndrome. J Lipid Res, 50 Suppl, S138-143. doi:10.1194/jlr.R800079JLR200

Wang, S., Hu, C., Wu, F., \& He, S. (2017). Rab25 GTPase- Functional roles in cancer.pdf. Oncotarget, 8(38), 64591-64599.

Wang, Y., Waldron, R. T., Dhaka, A., Patel, A., Riley, M. M., Rozengurt, E., \& Colicelli, J. (2002). The RAS Effector RIN1 Directly Competes with RAF and Is Regulated by 14-3-3 Proteins. Molecular and Cellular Biology, 22(3), 916-926. doi:10.1128/mcb.22.3.916-926.2001

Watanabe, M., Hayasaki, H., Tamayama, T., \& Shimada, M. (1998). Histologic distribution of insulin and glucagon receptors.pdf. Braz J Med Biol Res, 31(2), 243256.

Wei, L., Hubbard, S. R., Hendrickson, W. A., \& Ellis, L. (1995). Expression, characterization, and crystallization of the catalytic core of the human insulin receptor protein-tyrosine kinase domain. J Biol Chem, 270(14), 8122-8130.

Weiss, M., Steiner, D. F., \& Philipson, L. H. (2014). Insulin Biosynthesis, Secretion, Structure, and Structure-Activity Relationships: South Dartmouth (MA): MDText.com, Inc.

White, M. F. (2012). Mechanisms of Insulin Action Atlas of Diabetes (pp. 19-38).

White, M. F., Livingston, J. N., Backer, J. M., Lauris, V., Dull, T. J., Ullrich, A., \& Kahn, C. R. (1988). Mutation of the insulin receptor at tyrosine 960 inhibits signal transmission but does not affect its tyrosine kinase activity. Cell, 54(5), 641-659. 
Wilden, P. A., Siddle, K., Haring, E., Backer, J. M., White, M. F., \& Kahn, C. R. (1992). The role of insulin receptor kinase domain autophosphorylation in receptormediated activities. Analysis with insulin and anti-receptor antibodies. J Biol Chem, 267(19), 13719-13727.

Wilfling, F., Wang, H., Haas, J. T., Krahmer, N., Gould, T. J., Uchida, A., Cheng, J. X., Graham, M., Christiano, R., Frohlich, F., Liu, X., Buhman, K. K., Coleman, R. A., Bewersdorf, J., Farese, R. V., Jr., \& Walther, T. C. (2013). Triacylglycerol synthesis enzymes mediate lipid droplet growth by relocalizing from the ER to lipid droplets. Dev Cell, 24(4), 384-399. doi:10.1016/j.devcel.2013.01.013

Woller, B., Luiskandl, S., Popovic, M., Prieler, B. E. M., Ikonge, G., Mutzl, M., Rehmann, H., \& Herbst, R. (2011). Rin-like, a novel regulator of endocytosis, acts as guanine nucleotide exchange factor for Rab5a and Rab22. Biochimica Et Biophysica Acta-Molecular Cell Research, 1813(6), 1198-1210. doi:10.1016/j.bbamcr.2011.03.005

Woodman, P. G. (2000). Biogenesis of the Sorting Endosome: The Role of Rab5. Traffic, 1(9), 695-701. doi:10.1034/j.1600-0854.2000.010902.x

Wu, J., Bostrom, P., Sparks, L. M., Ye, L., Choi, J. H., Giang, A. H., Khandekar, M., Virtanen, K. A., Nuutila, P., Schaart, G., Huang, K., Tu, H., van Marken Lichtenbelt, W. D., Hoeks, J., Enerback, S., Schrauwen, P., \& Spiegelman, B. M. (2012). Beige adipocytes are a distinct type of thermogenic fat cell in mouse and human. Cell, 150(2), 366-376. doi:10.1016/j.cell.2012.05.016

Wu, Z., Rosen, E. D., Brun, R., Hauser, S., Adelmant, G., Troy, A. E., McKeon, C., Darlington, G. J., \& Spiegelman, B. M. (1999). Cross-Regulation of C/EBPa and PPARy Controls the Transcriptional Pathway of Adipogenesis and Insulin Sensitivity. Molecular Cell, 3(2), 151-158. doi:10.1016/s1097-2765(00)80306-8

Xu, L., Lubkov, V., Taylor, L. J., \& Bar-Sagi, D. (2010). Feedback regulation of Ras signaling by Rabex-5-mediated ubiquitination. Curr Biol, 20(15), 1372-1377. doi:10.1016/j.cub.2010.06.051

Xu, Y., Rubin, B. R., Orme, C. M., Karpikov, A., Yu, C., Bogan, J. S., \& Toomre, D. K. (2011). Dual-mode of insulin action controls GLUT4 vesicle exocytosis. J Cell Biol, 193(4), 643-653. doi:10.1083/jcb.201008135

Yan, H., Jahanshahi, M., Horvath, E. A., Liu, H. Y., \& Pfleger, C. M. (2010). Rabex5 ubiquitin ligase activity restricts Ras signaling to establish pathway homeostasis in Drosophila. Curr Biol, 20(15), 1378-1382. doi:10.1016/j.cub.2010.06.058

Yang, H., Galea, A., Sytnyk, V., \& Crossley, M. (2012). Controlling the size of lipid droplets: lipid and protein factors. Curr Opin Cell Biol, 24(4), 509-516. doi:10.1016/j.ceb.2012.05.012 
Yeh, W. C., Cao, Z., Classon, M., \& McKnight, S. L. (1995). Cascade regulation of terminal adipocyte differentiation by three members of the C/EBP family of leucine zipper proteins. Genes \& Development, 9(2), 168-181. doi:10.1101/gad.9.2.168

Yin, L., LI, Y. B., \& Wang, Y. S. (2006). Dexamethasone-induced adipogenesis in primary marrow stromal cell cultures: mechanism of steroid-induced osteonecrosis. Chin Med J (Engl), 119(7), 581-588.

Youngren, J. F. (2007). Regulation of insulin receptor function. Cell Mol Life Sci, 64(7-8), 873-891. doi:10.1007/s00018-007-6359-9

Zarich, N., Oliva, J. L., Martinez, N., Jorge, R., Ballester, A., Gutierrez-Eisman, S., Garcia-Vargas, S., \& Rojas, J. M. (2006). Grb2 is a negative modulator of the intrinsic Ras-GEF activity of hSos1. Mol Biol Cell, 17(8), 3591-3597. doi:10.1091/mbc.E05-12-1104

Zhen, Y., \& Stenmark, H. (2015). Cellular functions of Rab GTPases at a glance. Journal of Cell Science, 128(17), 3171-3176. doi:10.1242/jcs.166074

Zhu, G., Zhai, P., Liu, J., Terzyan, S., Li, G., \& Zhang, X. C. (2004). Structural basis of Rab5-Rabaptin5 interaction in endocytosis. Nat Struct Mol Biol, 11(10), 975-983. doi:10.1038/nsmb832

Zuk, P. A., Zhu, M., Mizuno, H., Huang, J., Futrell, J. W., Katz, A. J., Benhaim, P., Lorenz, H. P., \& Hedrick, M. H. (2001). Multilineage cells from human adipose tissue: implications for cell-based therapies. Tissue Eng, 7(2), 211-228. doi:10.1089/107632701300062859 


\section{CHAPTER II}

\section{Role of Rab5 in the process of adipogenesis}

\section{1 Introduction}

As described in Chapter I, the in vitro differentiation of the mouse 3T3-L1 pre-adipocytes into mature adipocytes is an insulin-dependent ten-days process that can be divided into a mitotic clonal expansion (MCE) phase and a terminal differentiation phase (Tang \& Lane, 2012). The pre-adipocytes undergo two cycles of mitosis during the MCE phase maintaining their fibroblast-like cell characteristics. However, the cells exhibit distinct morphological changes in the terminal differentiation phase. Besides the alterations in the cell shape and size, the most noticeable feature of the mature adipocytes is the formation and accumulation of a large number of lipid droplets in the cytosol (Suzuki et al., 2011). The conversion from pre-adipocytes into adipocytes, along with the remarkable changes in cell morphology, is controlled by the insulin and IGF-1 signaling pathways and numerous transcription factors. Much of what is known about the adipogenic factors required for adipogenesis process is based on the in vitro studies of adipogenic cell lines, such as the mouse 3T3-L1 and 3T3-F442A cell lines. The essential transcription factors promoting the adipogenesis process are the peroxisome proliferator-activated receptor y (PPARY) and the CCAAT/enhancerbinding protein (C/EBP) family (Rosen et al., 2002). These transcription factors regulate the expression of most genes that define mature adipocytes, including the insulin-sensitive glucose transporter isoform 4 (GLUT4), which is primarily 
expressed on the plasma membrane of adipocytes (James et al., 1988; Tamori et al., 2002). The expression level of GLUT4 and the number of GLUT4 existing on the plasma membrane is regulated through the insulin and IGF-1R signaling pathways (Bryant et al., 2002; Czech \& Buxton, 1993). Several Rab proteins are involved in the trafficking of GLUT4 by participating in the insulin signaling transduction process and the transportation of GLUT4 from intracellular GLUT4 storage vesicles (GSVs) to the plasma membrane (Sadacca et al., 2013). In particular, three Rab proteins of the endosomal system (e.g., Rab5, Rab4, and Rab11) participate at different steps of the GLUT4 trafficking process.

Rab5 is a key regulatory molecule directing in the early endocytic pathway (Barbieri et al., 2004; Barbieri et al., 2000; Hoffenberg et al., 2000). Rab5 is encoded as three differentially expressed isoforms, Rab5a, Rab5b, and Rab5c (Chen et al., 2009). The mRNA expression profiling study shows distinct tissue distributions of the Rab5 isoforms (Gurkan et al., 2005). A study shows that the suppression of Rab5a or Rab5b undermines the degradation of EGFR, whereas Rab5c shows limited effect (Chen et al., 2009). Another study suggested the silencing of Rab5c, but not the other two isoforms, significantly reduced the focal adhesion foci of Hela cells, indicating a particular role of Rab5c in cell migration (Chen et al., 2014). However, the functional redundancy of the isoforms is suggested as only the simultaneous knockdown of all three isoforms results in an inhibition of the insulin-dependent Akt activation, whereas individual knockdown of any single isoform does not affect Akt activation (Su et al., 2006). 
Mutational studies have shown that the Rab5:S34N, a Rab5 GTP-binding defective mutant, inhibits transferrin and EGF endocytosis displaying a dominantnegative effect; whereas the Rab5:Q79L, a mutant with reduced GTPase activity, behaves as a constitutively active Rab5 mutant stimulating internalization of several ligands, such as EGF and insulin (Dinneen \& Ceresa, 2004; Hunker et al., 2006; Jozic et al., 2011; Jozic et al., 2012; Mendoza et al., 2013). The Q79 residue of Rab5 locates on the GTPase domain (residues 15-184) of Rab5. Structural study of Rab5 reveals that each GTPase domain of Rab5 binds to one GTP and one $\mathrm{Mg}^{2+}$ ion and contains a central six-strand $\beta$-sheet $(\beta 1-\beta 6)$ flanked by five $\alpha$ helices (a1- a5) (Terzyan et al., 2003). Two switch regions, switch I (residues 4464) and switch II (residues 76-94) undergo structural changes between the GTPbound and GDP-bound forms (G Zhu et al., 2004). Several residues on Rab5 have been reported to be responsible for the interaction and recruitment of specific Rab5 effectors. For instance, Y57A, W74A, Y82A, and Y89A based on the Rab5:Q79L mutant showed significant decreased binding affinity with Rabaptin-5, whereas K116E and R120E based on the Rab5:Q79L mutant had no effect on Rab5Rabaptin-5 binding (G Zhu et al., 2004). Moreover, Y57A, W74A, Y82A, and Y89A are also found to be effector binding epitopes for EEA 1 and Rabenosyn- 5 based on structural studies (Mishra et al., 2010).

Like the other small GTPases, the Rab5 cycle is regulated by several Rab5 GEFs (e.g., RIN1, Rabex-5, and Rinl) and Rab5 GAPs (e.g., RN-tre and RabGap5). Rab5 in its active form (the GTP-bound form) recruits several downstream effectors onto the endosome membrane to support the endosomal fusion in the 
early endocytic pathway and the interaction of endosomes with microtubule networks (Balaji et al., 2012; Sandri et al., 2012). Rab5 is also implicated in other cellular processes such as receptor cell signaling and phagosome maturation (Mustafi et al., 2013). Recently, Rab5 is also proved to participate in several cellular functions, including endoplasmic reticulum (ER) reorganization, nuclear Lamin disassembly, spindle assembly and stability during mitosis (Audhya et al., 2007; Capalbo et al., 2011; Das et al., 2014). Furthermore, up-regulation of the Rab5-GTP level upon addition of EGF requires the participation of one or more Rab5 GEFs (Hunker et al., 2006; Jozic et al., 2011; Jozic et al., 2012). Interesting, the addition of insulin to 3T3-L1 pre-adipocytes, but not the NIH-3T3 or the HepG2 cell lines, induced inactivation of Rab5 (Huang et al., 2001; Tessneer et al., 2014). Thus, evidence regarding the regulation of Rab5 activity during adipogenesis process and the understanding of the cellular mechanisms by which Rab5 modulates the differentiation of 3T3-L1 pre-adipocytes are lacking.

Besides Rab5, several Rab proteins (e.g., Rab4, Rab7, Rab22, and Rab31) also have their particular roles in the endocytosis process. In vitro study of 3T3-L1 cells reveals an increased cytosolic Rab4 level upon insulin stimulation (Shisheva \& Czech, 1997). Rab4 is also proved to play a role in determining directional vesicle mobility (Potokar et al., 2012). Similar as Rab5, the overexpression of the dominant-negative mutant of Rab4 (Rab4:Q67L) results in enlarged endosomes and diminished vesicle mobility in terms of vesicle track length (the total length that the vesicle traveled during analysis), maximal displacement (maximal distance between two positions in the track that the vesicle traveled during analysis), and 
speed (Potokar et al., 2012). Consistently, the overexpression of the dominantpositive mutant of Rab4 (Rab4:S22N), leads to dysfunctional vesicle directionality (Potokar et al., 2012). If Rab5 is the key for homotypical early endosome fusion, then Rab7, which controls the net movement of late endocytic elements, is the star to govern the early to late endosome fusion (Lebrand et al., 2002). It is reported that Rab7 colocalizes with the insulin-responsive GLUT4-containing intracellular compartments, but its localization is not affected by the stimulation of insulin (Millar et al., 1999). The deletion of Rab7 in Hela cells does not affect the trafficking of the EGF-EGFR complex through the early endosome to the late endosome upon EGF stimulation. However, the EGF-EGFR complex is sequestrated in the late endosomes indicating a regulatory role of Rab7 in the receptor trafficking (Vanlandingham \& Ceresa, 2009). Rab11 is a master regulator to mediate the transportation of intracellular vesicles towards the cell surface in the exocytosis process (Takahashi et al., 2012). Depletion of Rab11 results in tubulated recycling endosomes as well as the accumulation of recycling compartments containing endocytosed transferrin and transferrin receptor beneath the plasma membrane (Takahashi et al., 2012). Rab22 is from the same subfamily of small GTPases as Rab5 and thus displays high sequence homology to Rab5 (Kauppi et al., 2002). A previous study showed that Rab22 even perform a higher affinity to the Rab5 GEF, Rabex-5, interacted with Rabex-5 to recruit the Rab5 effector, EEA1, and promoted early endosome fusion (HP Zhu et al., 2009). The knockdown of Rab22 abrogates the membrane targeting of Rabex-5 in the body hamster kidney (BHK)21 cells as well as the NGF-induced TrkA endocytosis in the PC12 cells (Wang et 
al., 2011; HP Zhu et al., 2009). Rab31 is also a Rab5 subfamily GTPase that can be activated by the Rab5 GEF, RAP6, and perform its function in trans-Golgi Network-to-endosome trafficking (Lodhi et al., 2007). The overexpression of Rab31 impairs the GLUT4 translocation from the intracellular compartments to the cell surface whereas the knockdown of Rab31 potentiates both GLUT4 translocation and glucose uptake upon insulin stimulation (Lodhi et al., 2007).

Because of the essential role of Rab proteins in the regulation of endocytosis as well as in trafficking of glucose, I hypothesized that Rab5 and other Rab proteins participate in the 3T3-L1 pre-adipocytes adipogenesis process positively.

\section{II.2 Specific aims and research design}

\section{II.2.1 Specific aim 1: To examine the key determinants of Rab5 that are required in adipogenesis.}

Rab5 is a small GTPase required for several cellular processes, including proliferation, migration, and invasion. It functions as a molecular switch as it cycles between its GTP-bound form (the active form) and GDP-bound form (the inactive form). The switch of Rab5 is controlled by guanine nucleotide exchange factors (GEFs), which activate Rab5 by increasing the nucleotide status of Rab5 in the GTP-bound form, and also by GTPase activating proteins (GAPs), which inactivate Rab5 by accelerating the hydrolysis of GTP to GDP. Preliminary observations indicated that the expression of Rab5-Wild-type (WT) affected adipogenesis. Therefore, I determined 
1.a the effect of the Rab5 isoforms (Rab5A, Rab5B, and Rab5C) on adipogenesis.

1.b the nucleotide status of Rab5 during adipogenesis

1.c the effect of the deletion of the N-terminal or C-terminal of Rab5 on adipogenesis.

1.d the effect of point mutants in the effector domain of Rab5 on adipogenesis.

1.e the particular role of Rab5 in the differentiation process in comparison with other Rab5 family proteins.

\section{II.2.2 Research design 1}

Rab5 isoforms, and several point and deletion mutants of Rab5, as well as several selected Rab proteins, were inserted into the pMX-puro vector at the EcoRI and Notl restriction sites. Then the plasmid DNA were purified via the plasmid purification assay. The purified DNA was transfected into the Plat-A cells using Lipofectamine $^{\circledR} 2000$ reagent as specified by Invitrogen. After 48 hours, virus suspension from the Plat-A cells was applied to the 3T3-L1 mouse pre-adipocyte cell line for the expression of specific proteins. The transfected cells were then selected with puromycin. siRNA for the Rab5 isoforms were designed and synthesized by Ambion. The purchased specific siRNA was induced into the 3T3L1 cells by Lipofectamine ${ }^{\circledR} 2000$ reagent as specified by Invitrogen. The siRNAtransfected or the selected pMX-puro vector-transfected 3T3-L1 cells were utilized for several biological assays, including cell cycle testing, lipid accumulation testing (ORO assay, only for differentiated cells), microscopy, and western blotting. 
Cell lysates of the 3T3-L1 cells that have been transfected with GFP, Rab5:WT, Rab5:Q79L, and Rab5:S34N were incubated with GST-labeled EEA1. The bonded proteins were eluted and be used for immunoprecipitation analysis.

\section{II.3 Material and Methods}

\section{II.3.1 Materials}

The 3T3-L1 pre-adipocyte cell line was obtained from the Zen-Bio, Inc. (NC, USA). The Platinum A (Plat-A) retroviral packaging cell line and the pMX-puro retroviral vector were purchased from Cell Biolabs, Inc. (San Diego, CA, USA). Primary antibodies, including the insulin receptor (IR), GLUT4, Akt1, p-Akt (Ser473), PPARy, C/EBPa, Erk1/2, p-Erk1/2, FABP4, FAS, ACC, GAPDH, and Rab5, and secondary antibodies, including the anti-Rabbit lgG and anti-Mouse IgG, were purchased from the Cell Signaling Technology (Boston, MA, USA). Fetal bovine serum (FBS) was purchased from the RMBIO, Inc. (Missoula, MT, USA). Other reagents and supplies, if not specifically described, were purchased from Thermo Fisher Scientific (Weston, FL, USA).

\section{II.3.2 cDNA Construction.}

Complementary DNAs (cDNA) of green fluorescent protein (GFP), Rab5 isoforms, Rab4:wild-type (Rab4:WT), Rab7:WT, Rab11:WT, Rab22:WT, Rab31:WT, GFP-Rab5:WT, GFP-Rab5:S34N, and GFP-Rab5:Q79L were cloned into the pMX-puro vector at the EcoRI and Notl restriction sites (Onishi et al., 1998). GFP-Rab5:S34N, GFP-Rab5:Q79L, Rab5:S34N, Rab5:Q79L, Rab4:S22N, 
Rab4:Q67L, Rab7:S22N, Rab7:Q67L, Rab11:S22N, Rab11:Q70L, Rab22:S19N, Rab11:Q64L, Rab31:S19N, and Rab31:Q64L on the pMX-puro vector were made via the $Q 5^{\circledR}$ Site-Directed Mutagenesis Kit purchased from New England Biolabs, Inc. (NEB, Ipswich, MA, USA). Rab5:Q79L- $\Delta$ C4, Rab5:Q79L- $\Delta$ N19, Rab5:S34N$\Delta$ C4, Rab5:S34N- $\Delta$ N19, and GFP-Rab5:Q79L double mutants (GFP-Rab5:Q79LW57A, Rab5:Q79L-W74A, Rab5:Q79L-Y82A, Rab5:Q79L-Y89A, Rab5:Q79L$\mathrm{K} 116 \mathrm{E}$, and Rab5:Q79L-R120E) on the pMX-puro vector were purchased from GenScript, Inc. (Piscataway, NJ, USA).

\section{II.3.3 Site-directed mutagenesis.}

5' and 3' primers for specific mutant were designed via the online NEB primer design software, NEBaseChanger ${ }^{\mathrm{TM}}$, and obtained from Sigma-Aldrich, Inc. (Raleiga, NC, USA). The site-directed mutagenesis process was done following the protocol of the $Q 5^{\circledR}$ Site-Directed Mutagenesis Kit. Briefly, $0.5 \mu \mathrm{M}$ of 5' and 3' primers were mixed with $25 \mathrm{ng}$ of template vector DNA in the Q5 Hot Start HighFidelity 2X Master Mix reagent. 25 cycles of PCR were performed followed by the kinase, ligase, and Dpnl treatment for 5 minutes. The treated PCR mixture was then used for bacteria transformation, which will be described later.

\section{II.3.4 Bacteria transformation}

The cDNA-containing vectors (either purchased or cloned) and the treated PCR mixture generated via the site-directed mutagenesis were transformed into the 5-alpha Competent E. coli purchased from NEB via the transformation protocol 
described on the company website. Briefly, the competent cells were thawed on ice for 10 minutes. Then $100 \mathrm{ng}$ of cDNA-containing vectors or $5 \mu \mathrm{l}$ of the treated PCR mixture was mixed with $50 \mu$ of the competent cells in an Eppendorf tube and incubated on ice for 30 minutes followed by a 30 seconds heat shock at $42^{\circ} \mathrm{C}$. Then the Eppendorf tube was placed on ice for 5 minutes before mixing with 950 $\mu \mathrm{l}$ of SOC media provided by the kit. After a one-hour incubation at $37^{\circ} \mathrm{C}$ with shaking $(250 \mathrm{rpm})$, the transformed competent cells were spread on Lysogeny broth (LB) agar selection plates and incubated overnight at $37^{\circ} \mathrm{C}$.

\section{II.3.5 Vector DNA purification assay.}

Colonies grown on the LB agar selection plates or the cDNA constructs were grown in the LB media overnight at $37^{\circ} \mathrm{C}$. Then vectors containing specific cDNA constructs were collected according to the QIAprep Spin Miniprep Kit or Qiagen Plasmid Plus kits obtained from Qiagen Sciences, Inc. (Germantown, MD, USA). The optical density (OD) of vector DNA was tested and analyzed to ensure a high concentration and purity of DNA that can be used for mammalian cell transfection and yeast transformation.

\section{II.3.6 Generation of stable cell lines}

The cDNA containing vector was transfected into the Plat-A (80\% 90\% confluence) monolayer using Lipofectamine ${ }^{\circledR} 2000$ Transfection Reagent. The Plat-A cells were grown in the Plat-A growth media (1\% penicillin/streptomycin (P/S), $1 \mu \mathrm{g} / \mathrm{mL}$ puromycin, $10 \mu \mathrm{g} / \mathrm{mL}$ blasticidin, and 10\% FBS in Dulbecco's 
modified Eagle's medium (DMEM)) and incubated under a humid atmosphere containing $5 \% \mathrm{CO}_{2}$ under $37^{\circ} \mathrm{C}$ before and after transfection. 48 hours after transfection, the supernatant of media from the transfected Plat-A cells was filtered with $0.2 \mathrm{~nm}$ filter and applied to $90 \%$ confluent 3T3-L1 cells grown in the 3T3-L1 growth media (1\% P/S, 1\% L-glutamine, and 10\% FBS in DMEM). After another 24-hour incubation, transfected 3T3-L1 cells were selected with the 3T3-L1 selection media $(2 \mu \mathrm{g} / \mathrm{mL}$ puromycin in 3T3-L1 growth media).

\section{II.3.7 Cell culture and 3T3-L1 cell differentiation.}

Non-transfected 3T3-L1 cells were grown to $100 \%$ confluence in the 3T3L1 growth media and incubated in a humid atmosphere containing $5 \% \mathrm{CO}_{2}$ under $37^{\circ} \mathrm{C}$. The differentiation of the 3T3-L1 pre-adipocytes took a total of 10 days. The differentiation process was triggered by treatment of the 3T3-L1 differentiation media $(10 \mu \mathrm{g} / \mathrm{ml}$ insulin, $1 \mu \mathrm{g} / \mathrm{ml}$ DEX and $1 \mu \mathrm{g} / \mathrm{ml}$ IBMX in the 3T3-L1 growth media for day 1 to day 4 and $10 \mu \mathrm{g} / \mathrm{ml}$ insulin in the 3T3-L1 growth media for day 5 to day 10). Media was changed every 48 hours. The pMX-puro cDNA-containing vectortransfected 3T3-L1 cells were grown in the same conditions as the non-transfected 3T3-L1 cells except with an addition of $2 \mu \mathrm{g} / \mathrm{mL}$ puromycin in all types of media.

\section{II.3.8 Oil Red O (ORO) staining and quantification.}

On the tenth day of differentiation, the 3T3-L1 cells were washed and fixed with $10 \%$ formalin in phosphate buffer saline (PBS) for 5 minutes and 1 hour at room temperature, respectively. The ORO stock solution $(0.5 \mathrm{~g}$ of ORO in $100 \mathrm{ml}$ 
of isopropanol) was diluted freshly with deionized (DI) water to make the ORO working solution ( $60 \%$ of stock solution with $40 \%$ of DI water). The working solution was filtered with a $0.2 \mathrm{~nm}$ filter before applying to the fixed 3T3-L1 cells. Then the 3T3-L1 cells were stained with the filtered ORO working solution for 15 minutes at room temperature. Excessive ORO working solution was removed and the stained 3T3-L1 cells were washed with DI water. At last, $100 \%$ of isopropanol was used to elute the ORO from fixed cells by incubating the cells in a $37^{\circ} \mathrm{C}$ water bath for 10 minutes. The quantification of lipids was done by measuring OD of eluted ORO solution at $540 \mathrm{~nm}$ wavelength.

\section{II.3.9 Bright-field microscopy, confocal microscopy, and live-cell microscopy}

For bright-field and confocal microscopy, the normal 3T3-L1 cells and the transfected 3T3-L1 cells were seeded on glass coverslips at $1.0 \times 10^{5}$ per $3.8 \mathrm{~cm}^{2}$ well. The cells were incubated with different types of media and treatments as required. After the ORO staining (as described above), the cells were observed and taken image of under an inverted microscope at a 20X magnification objective lens via the AmScopeX software for bright-field images. Or the cells were mounted with DAPI and observed under the Olympus BX61 confocal microscope.

For live-cell microscopy, the normal/transfected 3T3-L1 cells were seeded in the $\mu$-Slide 4 Well chamber purchased from ibidi, Inc. (Fitchburg, WI, USA) with required media and treatments. Then live-cell images were taken under the Delta Vision Elite microscope. 


\section{II.3.10 Lysate preparation, protein quantification, and Western blotting}

\section{II.3.10.1 Lysate preparation}

To prepare whole cell lysates, 3T3-L1 cells were collected in ice-cold fresh lysis buffer $(50 \mathrm{mM}$ Tris- $\mathrm{HCl}, \mathrm{pH}$ 7.5, $150 \mathrm{mM} \mathrm{NaCl}, 1 \%$ NP-40, $1 \mathrm{mM}$ ethylenediaminetetraacetic acid (EDTA), 1\% sodium deoxycholate $(\mathrm{w} / \mathrm{v}), 0.1 \%$ SDS, $1 \mathrm{mM} \mathrm{Na}_{3} \mathrm{VO}_{4}, 10 \mathrm{mM} \mathrm{NaF}, 2 \mathrm{mM}$ phenylmethane sulfonyl fluoride (PMSF), and protease/phosphatase inhibitors purchased from Sigma-Aldrich, Inc.). 3T3-L1 cell lysates were then mixed with the $4 \mathrm{X}$ loading dye and heat-shocked at $100^{\circ} \mathrm{C}$ for 10 minutes. Supernatant were collected after centrifugation (2 minutes in $13,000 \mathrm{rpm}$ ) for western blotting. To prepare the whole yeast lysates, the yeast cells were first collected by centrifugation ( 5 minutes in $5000 \mathrm{rpm}$ ). After discarding the supernatant, 3 times of freeze-thaw cycles $\left(3\right.$ minutes in $-20^{\circ} \mathrm{C}$ ethanol then 3 minutes in $37^{\circ} \mathrm{C}$ water bath) were applied. The cells were then mixed with the fresh lysis buffer with addition of $5 \mathrm{mM}$ of DTT for 30 minutes.

\section{II.3.10.2 Protein quantification - the Pierce BCA Protein Assay}

Protein contents of the cell lysates were tested using the Pierce BCA Protein Assay Kit. Briefly, the working solution was made freshly by mixing the reagent $A$ and the reagent $B$ in a ratio of 1:20. Gradient volumes of the standard protein and same volume of sample proteins (preparation has been described above) were mixed thoroughly and incubated at $30^{\circ} \mathrm{C}$ for 30 minutes. The ODs of standards and samples were measured under an absorbance of $562 \mathrm{~nm}$ 
wavelength. Then the concentrations of sample proteins were calculated based on the standard curve.

\section{II.3.10.3 Western blotting}

The tested cell lysates were mixed with the $4 X$ loading dye and heatshocked in $95^{\circ} \mathrm{C}$ for 10 minutes. Supernatant was collected after centrifugation (2 minutes in $13,000 \mathrm{rpm}$ ). Same amount of cell lysate proteins (cased on the BCA assay) were resolved by $10 \%$ SDS-PAGE and transferred to nitrocellulose membranes. The membranes were blocked overnight with specific primary antibodies at $4^{\circ} \mathrm{C}$ in BSA-TBS-t $(20 \mathrm{mM}$ Tris- $\mathrm{HCl}, \mathrm{pH} 7.4,150 \mathrm{mM} \mathrm{NaCl}, 0.1 \%$ Tween 20 , and $5 \%$ bovine serum albumin (BSA)). After washing of the primary antibodies, specific secondary antibodies were applied and washed. Visualization of results was achieved by exposing. To determine relative protein amounts, three representative exposures for each sample were quantified using the Fiji software (National Institutes of Health).

\section{II.3.11 siRNA sequences and transfection.}

RNA interference (RNAi) directed against:

mouse Rab5A [5'-AAGCACAGTCCTATGCAGATG-3'], mouse Rab5B [5'-AATCCGTGTGTTTAGATGACA-3'], or mouse Rab5C [5'-AAGCAGCCATTGTGGTCTATG-3'] were designed and synthesized by Ambion (Austin, TX). A scrambled siRNA sequence was designed as a control [5'-CACCUAAUCCGUGGUUCAA-3']. Prior to siRNA sequence 
transfection, cells were plated in growth medium without antibiotics at $70-80 \%$ confluence. siRNA sequence (20 $\mathrm{nM}$ final concentration) transfection was performed using Lipofectamine ${ }^{\mathrm{TM}} 2000$ as specified by Invitrogen (Invitrogen, Carlsbad, CA). After transfection, cells were used for the indicated assay (e.g., for immunoblotting, differentiation or pull-down assays).

\section{II.3.12 Activation of Rab5 assay.}

Cells were lysed using a buffer containing 20 mM HEPES (pH 7.5), $100 \mathrm{mM}$ $\mathrm{NaCl}, 1 \mathrm{mM}$ DTT, $5 \mathrm{mM} \mathrm{MgCl}$, $5 \%$ glycerol and 1\% Triton-X-100, supplemented

with $1 \mathrm{mM}$ PMSF. Lysates were incubated with $100 \mathrm{~mL}$ glutathione beads containing $10 \mu \mathrm{g}$ of GST-EEA1, followed by rocking for 1 hour at $4^{\circ} \mathrm{C}$. After incubation, beads were washed three times with PBS. The pull-downs were subjected to SDS-PAGE and analyzed by immunoblotting using Rab5 antibodies. Relative levels of Rab5-GTP were determined using the ratio of Rab5- to totalRab5.

\section{II.3.13 Statistical analysis}

All experiments presented were repeated a minimum of three times. Normal distributed data were represented in mean \pm standard deviation (S.E.M.). The difference between groups were determined by the Student t-test. Tests were considered statistically significant if $p$-value were less than 0.05 . 


\section{II.4 Results}

\section{II.4.1 Nucleotide status of Rab5 is critical for the differentiation of 3T3-L1 pre-adipocytes}

Rab5 is known to regulate membrane fusion during vesicular trafficking where the Rab5:Q79L mutant, which has preferential affinity for GTP showed a dominant-positive effect and promotes early endosome fusion (Barbieri et al., 1996). In contrast, the Rab5:S34N mutant, which has preferential affinity for GDP and shows a dominant-negative effect, induced the accumulation of very small endocytic profile and inhibited transferrin endocytosis (Stenmark et al., 1994).

\section{II.4.1.1 The induction of pMX-puro retroviral vector expression-system did not alter the differentiation process}

To access whether Rab5 plays a regulatory role in the 3T3-L1 preadipocytes differentiation, I used the pMX-puro retroviral vector expression-system to induce the expression of a specific protein. The retroviral system is designed to express a specific exogenous protein in mammalian cells permanently. To establish that the transfection system will not affect the normal differentiation process, I induced the green fluorescent protein (GFP) into the 3T3-L1 cells as a control. In Figure 9.A, the overexpression of GFP alone did not affect the accumulation of lipids as compared with the un-transfected 3T3-L1 cells. As expected, the expression level of GAPDH, which served as the whole cell lysate loading control, was similar in both GFP-transfected and un-transfected cells before (day 1) and after (day 9) differentiation, respectively (Figure 9.B). Both cells 
expressed similar amount of PPARy at day 9, suggesting that the usage of the pMX-puro retroviral vector expression-system did not significantly alter the differentiation process of the 3T3-L1 pre-adipocytes. Bright-field images of ORO stained cells were taken at day 1 and day 9 after differentiation (Figure 9.C).

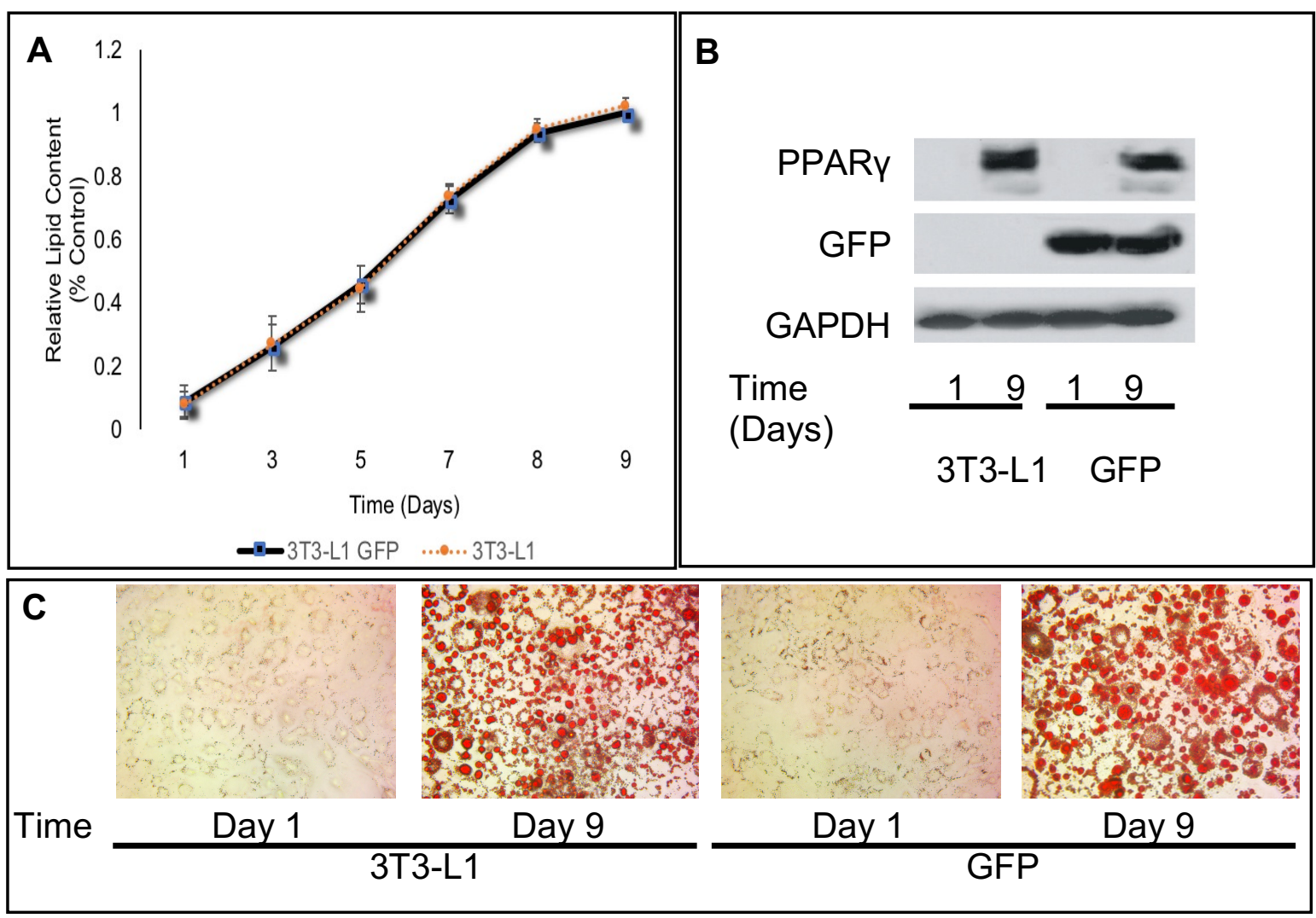

Figure 9. Differentiation of un-transfected and GFP-overexpressing 3T3-L1 pre-adipocytes.

The un-transfected (3T3-L1) or GFP-overexpressing (GFP) 3T3-L1 pre-adipocytes were differentiated into adipocytes in the absence or in the presence of induction media, and the accumulation of lipid droplets was measured by the incorporation of Oil Red $\mathrm{O}$ as described in Material and Methods. A. Relative lipid content of 3T3-L1 and GFP 3T3-L1 cells. Results were represented as relative lipid contents. Data represent the mean \pm S.E.M. of three independent experiments. B. Representative Western blot of the content of GFP, PPARy, and GAPDH proteins. C. Bright-field images of ORO stained day 1 and day 9 cells under 20X objective lens. ORO stained lipid droplets were shown as red color under the microscope. 


\section{II.4.1.2 The overexpression or deletion of individual Rab5 isoforms inhibited the differentiation of 3T3-L1 pre-adipocytes}

For the purpose of understanding the role of different Rab5 isoforms during adipogenesis, individual overexpression of the Rab5 isoforms (Rab5A, Rab5B, and Rab5C) was prepared. As shown in Figure 10.A, all the Rab5 isoforms, Rab5A, Rab5B, and Rab5C, showed a statistically inhibitory effect on the lipids accumulation. Specifically, the overexpression of Rab5A inhibited the accumulation of lipids by $32 \pm 6 \%$, while Rab5B and Rab5C inhibited the accumulation by $25 \pm 6 \%$ and $21 \pm 5 \%$, respectively. Then the depletion effect of each Rab5 isoforms was done via the RNA interference to individually or simultaneously knockdown the Rab5 isoforms. The accumulation of lipids in differentiated 3T3-L1 cells was examined under the knockdown of Rab5 isoforms by inducing specific siRNA. According to Figure 10.B, depletion of Rab5 was accompanied by a reduction of the accumulation of lipids. Importantly, individual removal of Rab5A isoform produced a small but statistically significant $(24 \pm 6 \%)$ inhibition on the accumulation of lipids as compared with scrambled siRNAinduced and siRNA-uninduced cells. Rab5B and Rab5C siRNA were also able to block the accumulation of lipids, though not as noticeable as Rab5A, by $14 \pm 2 \%$ and $16 \pm 4 \%$, respectively, as compared with scrambled siRNA and non-siRNA induced cells. Remarkably, combined depletion of all the Rab5 isoforms strongly inhibited $(84 \pm 5 \%)$ the accumulation of ORO (Figure 10.B). 


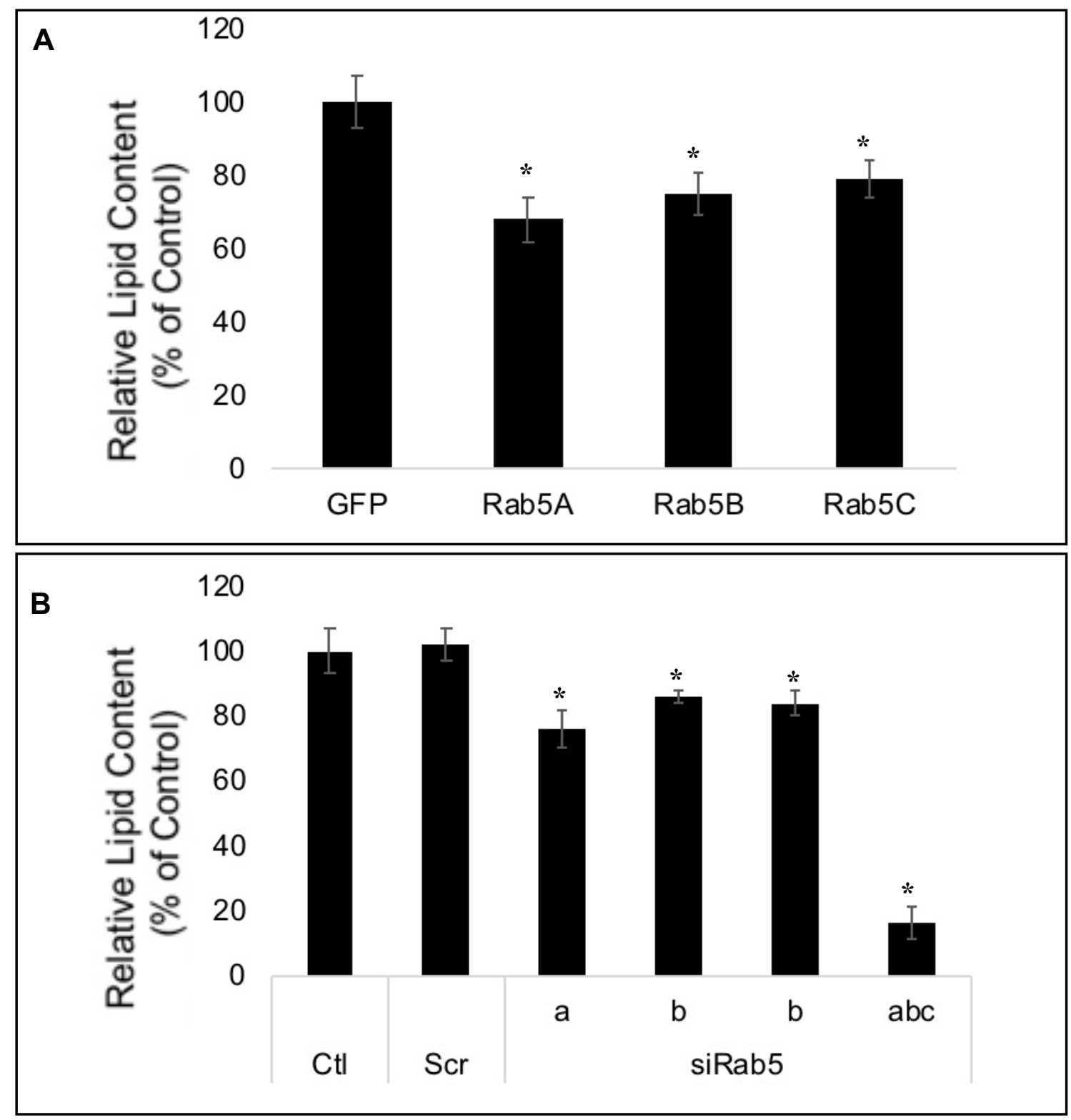

Figure 10. Selective effect of Rab5 isoforms on the differentiation of 3T3-L1 pre-adipocytes.

Results were represented as relative lipid contents. Data represent the mean \pm S.E.M. of three independent experiments. ( ${ }^{*} P<0.05$ by Student's t-test). A. Relative lipid content of cells expressing GFP or Rab isoforms. GFP or Rab5 isoformstransfected 3T3-L1 cells were differentiated into adipocytes in the presence of induction media. B. Relative lipid content of differentiated 3T3-L1 cells with depletion of the Rab5 isoforms. Non-transfected cells (CtI), or cells transfected with scramble RNAi (Scr), or individually RNAi against the Rab5 isoforms (siRab5a/b/c), or RNAi's against all Rab5 isoforms (siRab5abc) were differentiated as described in Material and Methods. 
Since the Rab5A exhibited the most remarkable results in lipid formation during adipogenesis of the 3T3-L1 pre-adipocytes, the rest of the experiments were designed based on the Rab5A isoform. And in the rest of this section, Rab5 represents the Rab5A isoform if not specifically stated.

\section{II.4.1.3 The GTP-bound Rab5 decreased during adipogenesis}

As described above, Rab5 functions as a molecular switch that cycles between the active GTP-bound form and the inactive GDP-bound form. The overexpression and depletion of the three Rab5 isoforms individually exhibited inhibitory role in the adipogenesis process of 3T3-L1 pre-adipocytes (Figure 10). Thus, it is hypothesized that the nucleotide states of Rab5 may change during the differentiation process and the states of Rab5 may play a regulatory role in governing the adipogenesis process of 3T3-L1 cells.

In order to detect the endogenous nucleotide states of Rab5 during the differentiation of 3T3-L1 pre-adipocytes, the 3T3-L1 cells overexpressing GFP were differentiated into adipocytes in the absence (as the negative control) or in the presence (as the positive control) of induction media. Endogenous GTP-bound activated Rab5 was analyzed by Rab5 GST pull-down assay followed by immunoblotting at specific days during the differentiation. In Figure 11, along with the progression of adipogenic differentiation, the expression level of the adipocytespecific transcription factor, PPARy, gradually elevated (Figure 11.A\&B). In contrast, the relative Rab5-GTP level gradually decreased over time during the differentiation process (Figure 11.C\&D). 


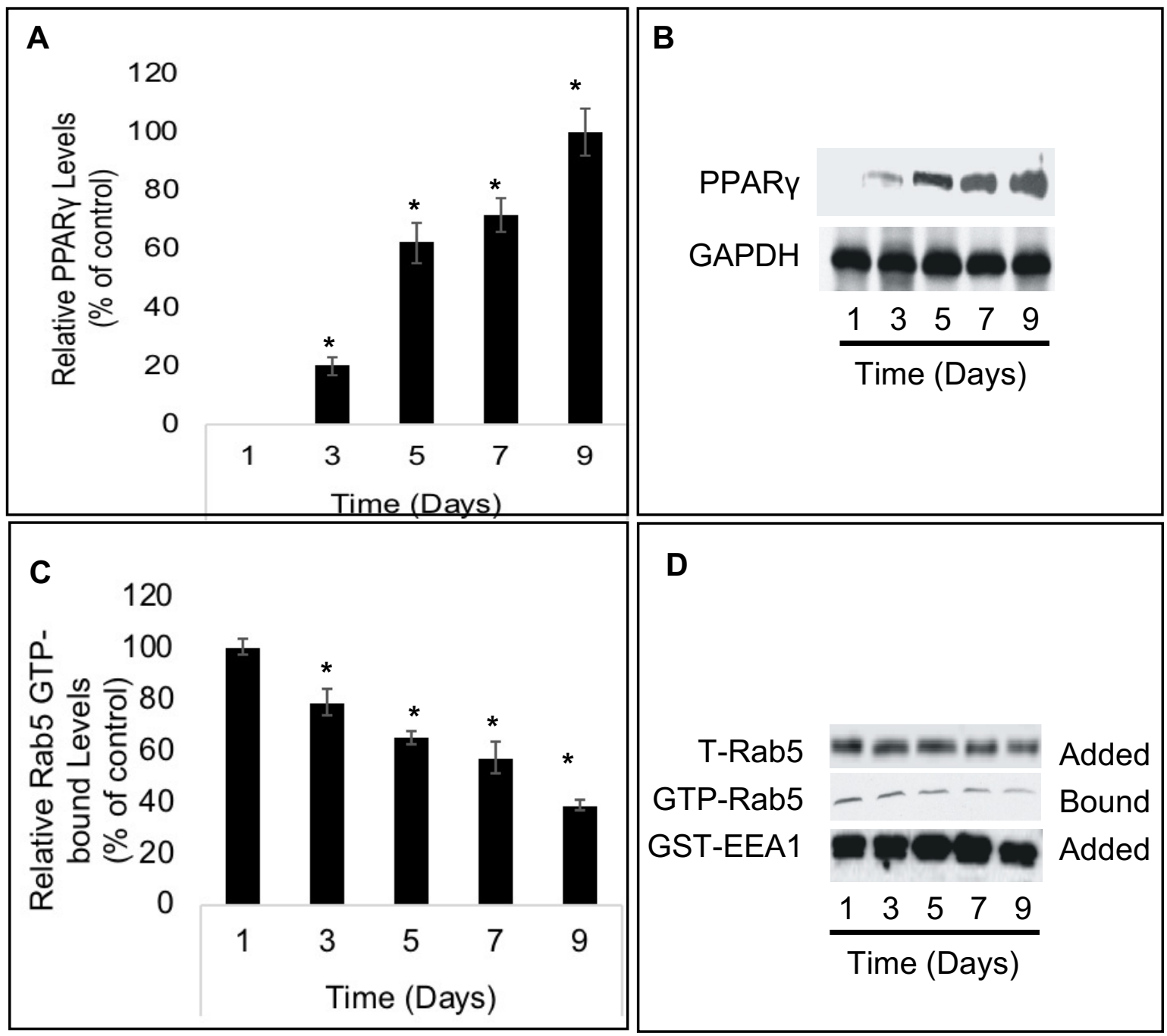

Figure 11. GTP levels of endogenous Rab5 in comparison with expression of PPARY during the differentiation of 3T3-L1 pre-adipocytes.

3T3-L1 pre-adipocytes overexpressing GFP were differentiated into adipocytes in presence of induction media, and the endogenous GTP-bound activated Rab5 was analyzed by GST pull-down assay followed by immunoblotting at specific day of the differentiation as described in Material and Methods. A. Relative PPARY expression levels in comparison with GAPDH during differentiation. Data represent the mean \pm S.E.M. of three independent experiments. ( ${ }^{*} P<0.05$ by Student's t-test). B. Representative Western blot of the content of PPARY and GAPDH. C. Relative Rab5 GTP-bound levels as compared with total Rab5 loaded. Data represent the mean \pm S.E.M. of three independent experiments. ( ${ }^{*} P<0.05$ by Student's t-test). $D$. Representative immunoblots of samples probed with anti-Rab5 antibodies for total Rab5 (T-Rab5) and active Rab5 (GTP-Rab5). 


\section{II.4.1.4 Increase the Rab5-GTP level hampered the differentiation of 3T3-L1 pre-adipocytes}

In order to address the role of Rab5 in the differentiation of 3T3-L1 preadipocytes, cell lines overexpressing GFP, Rab5:wild-type (WT), the GTP-bound defective Rab5 mutant (Rab5:S34N), or the GTPase-defective, constitutively activated Rab5 mutant (Rab5:Q79L) were prepared, and the accumulation of lipids was measured via the oil red O (ORO) assay. To observe the localization of Rab5 and the two Rab5 mutants, the GFP conjugated Rab5:WT, Rab5:S34N, and Rab5:Q79L were transfected into the 3T3-L1 cells. Then the day 1 and day 9 cells were fixed for confocal microscopy and observed under the Olympus BX61 confocal microscope (Figure 13). As shown in Figure 12, the overexpression of Rab5:Q79L mutant decreased the accumulation of lipids in 3T3-L1 pre-adipocytes at day 9 of differentiation. Moreover, Rab5:WT decreased the accumulation of lipids in less extent as compared with the Rab5:Q79L mutant but is statistically significant in comparison with the GFP cells (Figure 12.A). Surprisingly, the expression of Rab5:S34N mutant stimulated this differentiation process as the lipid content increased by about $28 \%$ in comparison with the GFP cells (Figure 12). The observation suggests that Rab5 inactivation improves the differentiation of 3T3-L1 pre-adipocytes, whereas constitutively activating Rab5 resulted in decreased lipid accumulation. 


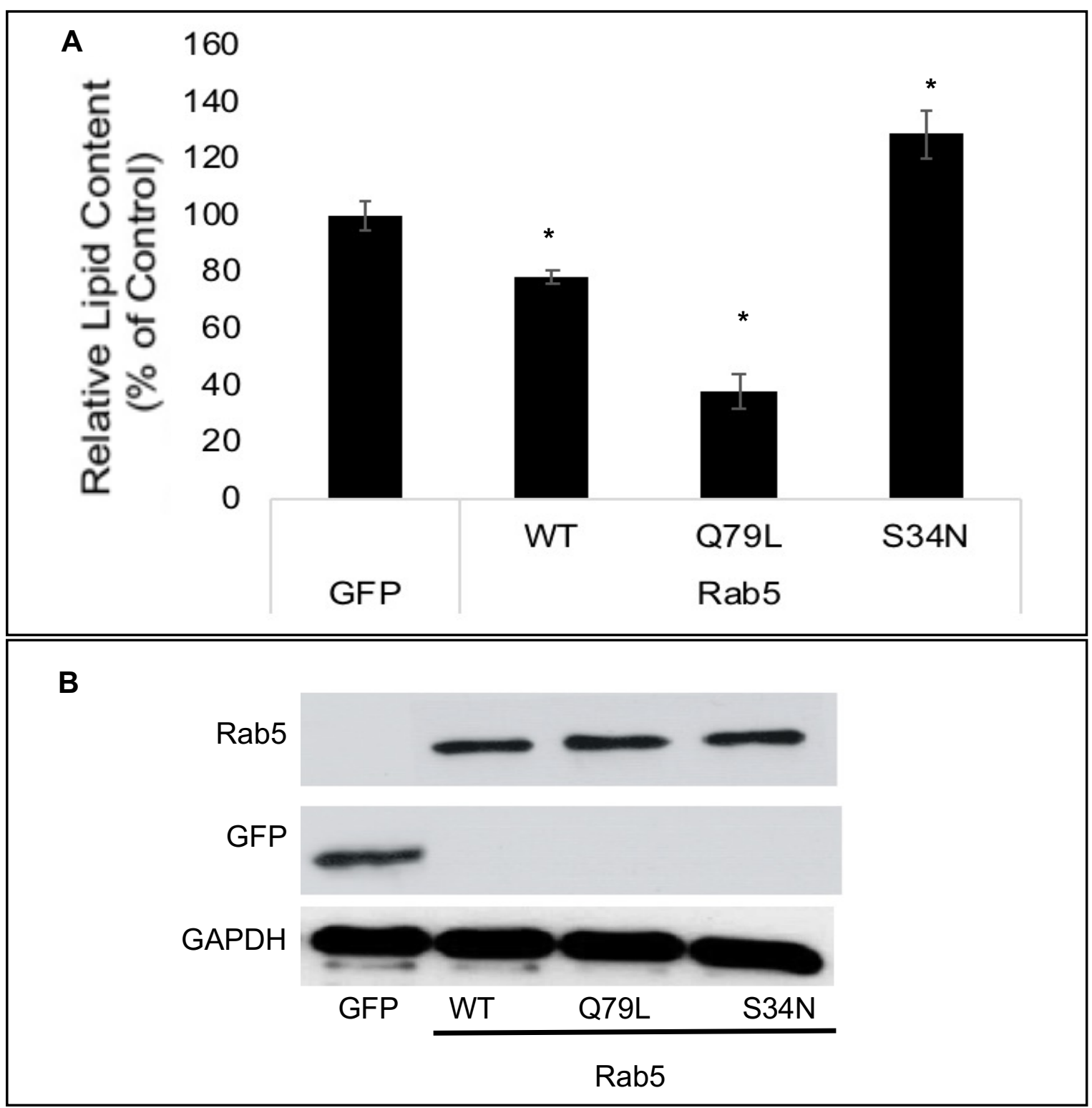

Figure 12. Selective effect of Rab5 constructs on the differentiation of 3T3L1 pre-adipocytes.

3T3-L1 pre-adipocytes expressing GFP or Rab5 constructs (Rab5:WT, Rab5S34N, and Rab5:Q79L) were differentiated as described in Material and Methods. A. Relative lipid content of 3T3-L1 cells overexpressing GFP, Rab5:WT, Rab5:Q79L, and Rab5:S34N. Results were represented as relative lipid contents. Data represent the mean \pm S.E.M. of three independent experiments. $\left({ }^{*} P<0.05\right.$ by Student's t-test). B. Representative Western blot of the content of GFP, Rab5, and GAPDH proteins. 
Adipocyte differentiation can be also monitored by formation of intracellular lipid droplets (Qi et al., 2017). Thus, with the overexpression of GFP-conjugated Rab5 and Rab5 mutants, combining with the ORO staining assay, morphological experiments were carried out to visualize the lipid droplets and the localization of Rab5 or Rab5 mutants. Under the microscope, GFP and GFP-conjugated constructs were visualized as green, ORO stained lipid droplets were observed as red, whereas nucleus were stained with DAPI, which gave a color of blue under the microscope. As described above, 3T3-L1 pre-adipocytes expressing GFP and Rab5 constructs were cultivated and induced to differentiate into adipocytes with induction media. At day 9, Oil Red $\mathrm{O}$ staining showed an abundant red round structures in GFP- and Rab5:S34N-overexpressed 3T3-L1 cells, which suggested a significant lipid accumulation in the GFP-control and the Rab5:S34N mutant cells. However, lipid droplets were not observed in untreated non-differentiated day 1 cells (images in the left column of Figure 13). More importantly, formation of lipid droplets was inhibited in the Rab5:Q79L mutant cells (Figure 13). In cells overexpressing the Rab5:WT, lipid droplets were observed but in less amount in comparison with the GFP-control cells (Figure 13). These observations were further supported with the quantitative measurement of lipid content (Figure 12). In addition, the overexpression of Rab5:Q79L mutant significantly inhibited adipogenic morphology (e.g., the transition from a fibroblast-like shape to an increasingly rounded-up appearance with an accumulation of cytoplasmic lipid droplets), which can be confirmed by comparing the GFP-expressing cells with the Rab5:Q79L-expressing cells at day 9 of differentiation. 


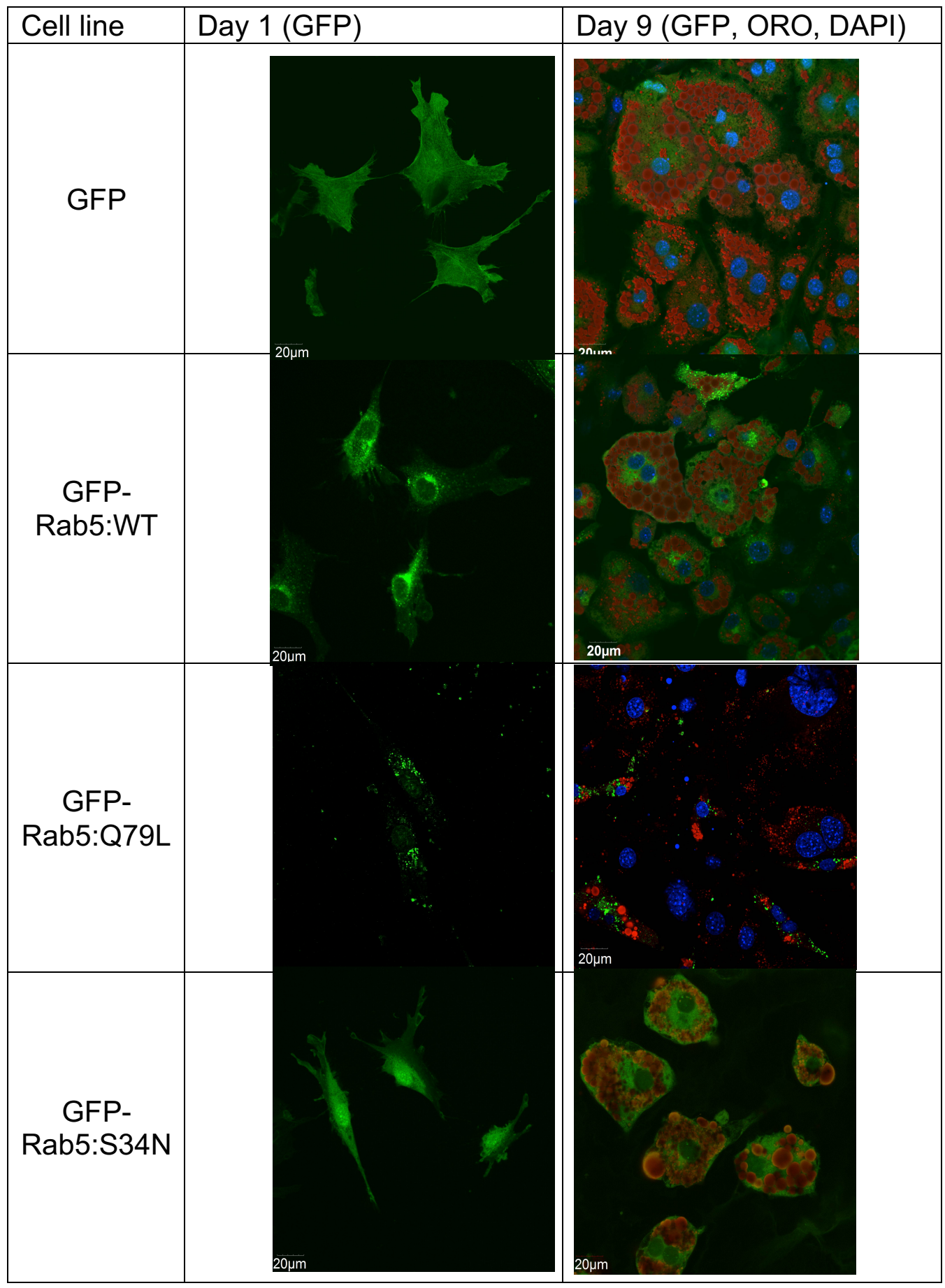

Figure 13. Confocal images of 3T3-L1 cells overexpressing GFP and GFPconjugated Rab5 constructs.

GFP, lipid droplets, and nucleus were represented in green, red, and blue, respectively. Morphological changes of 3T3-L1 pre-adipocytes were monitored by a Olympus BX61 and photographed before (day 1) after 9 days from the onset of differentiation. 

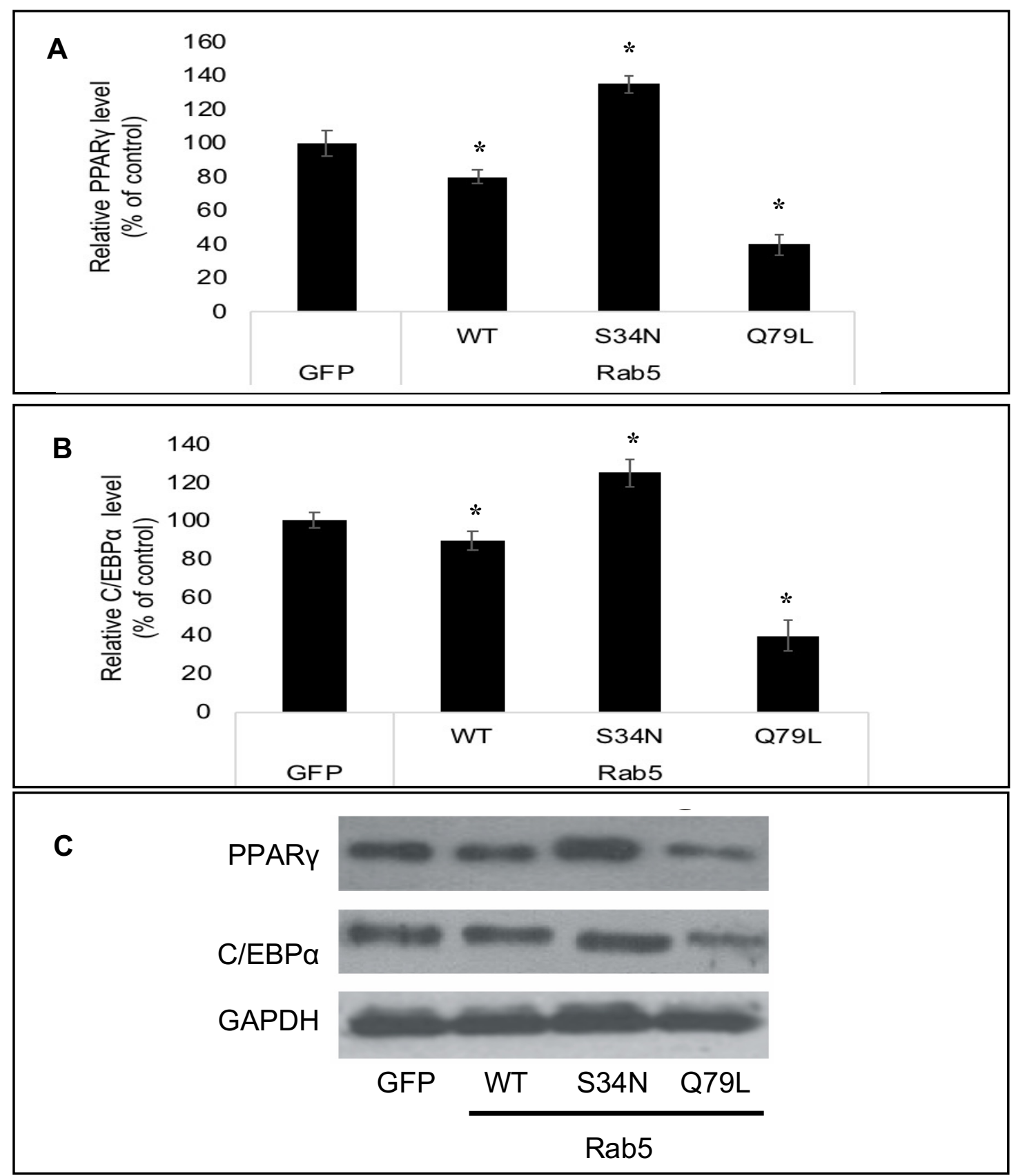

Figure 14. Effect of Rab5 constructs on the expression of PPARY and CEB/Pa. 3T3-L1 pre-adipocytes overexpressing GFP or Rab5 constructs were differentiated as described in Material and Methods, and the endogenous levels of PPARY, GEB/Pa and GAPDH proteins were analyzed with specific antibodies by immunoblotting. Data represent the mean \pm S.E.M. of three independent experiments. ( ${ }^{*} \mathrm{P}<0.05$ by Student's t-test). 
Next, the 3T3-L1 pre-adipocytes overexpressing GFP, Rab5:WT and the Rab5 mutants were differentiated and then harvested for immunoblotting analysis with specific antibodies. With the overexpression of Rab5:S34N mutant, but not the Rab5:Q79L mutant, the protein expression of the adipogenesis-associated transcription factors, PPARY and C/EBPa, were up-regulated as compared with the GFP-overexpressing cells (Figure 14). The Rab5:WT affected the expression of the two transcription factors in less extent in comparison with the Rab5:Q79L mutant. Thus, these observations suggest that the nucleotide status of Rab5 is critical for the differentiation process of 3T3-L1 pre-adipocytes. The effect of Rab5 nucleotide status on adipogenesis relies, at least partially, on its regulatory role towards the two adipogenic transcription factors, PPARY and C/EBPa.

\section{II.4.2 The determinants of Rab5 in promoting adipogenesis.}

In the previous section, Rab5:Q79L, the dominant-positive mutant of Rab5, has demonstrated an inhibitory role in adipogenesis process. Since specific residues, especially the Y57A, W74A, Y82A, and Y89A residues on the Rab5 GTPase domain affect the binding affinity of Rab5 with Rab5 effectors (e.g. Rabaptin-5, Ranenosyn-5, and EEA1), several additional mutants (Y57A, W74A, Y82A, Y89A, K116E, and R120E) were made based on the Rab5:Q79L mutant. Then the Rab5:Q79L double mutants were transfected into the 3T3-L1 cells through the pMX-puro vector system, respectively. Surprisingly, the Rab5:Q79LK116E double mutant, not the other mutants that showed positive role in effector binding, advanced the lipid formation of differentiated 3T3-L1 cells, whereas the 
other double mutants exhibited similar inhibitory role in adipogenesis as the Rab5:Q79L single mutant (Figure 15).
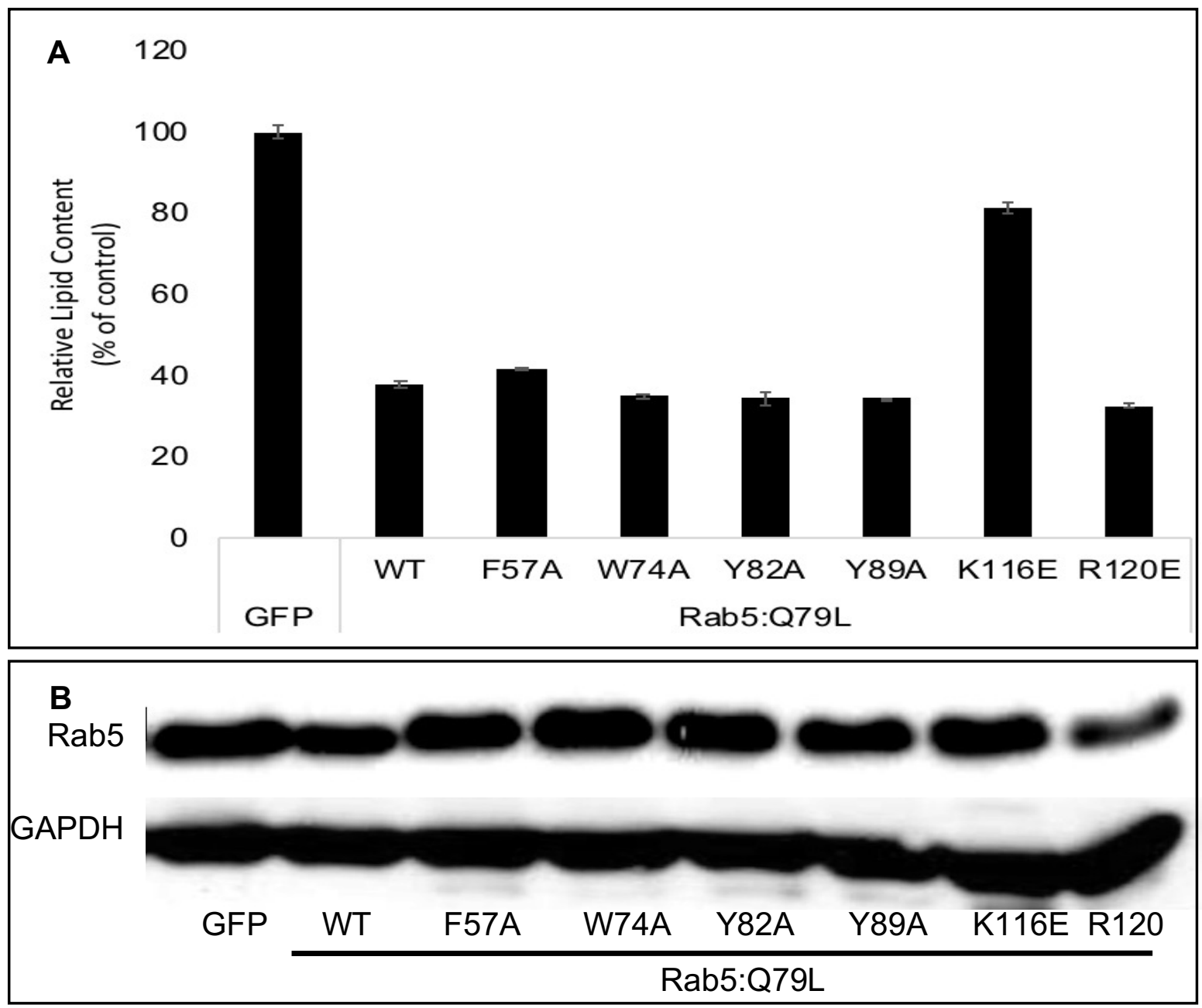

Figure 15. Selective effects of Rab5:Q79L double mutants on the differentiation of 3T3-L1 pre-adipocytes.

3T3-L1 pre-adipocytes overexpressing GFP, Rab5:Q79L, or Rab5:Q79L double mutants were differentiated into adipocytes in the presence of induction media, and the accumulation of lipid droplets was measured by the incorporation of ORO as described in Material and Methods. A. Relative lipid content of differentiated 3T3-L1 cells overespression GFP, Rab5:Q79L mutant, and Rab5:Q79L double mutants. Data represent the mean \pm S.E.M. of three independent experiments. ${ }^{*} P<0.05$ by Student's t-test. B. Representative Western blot of the content of GFP, Rab5 constructs, and GAPDH proteins. 


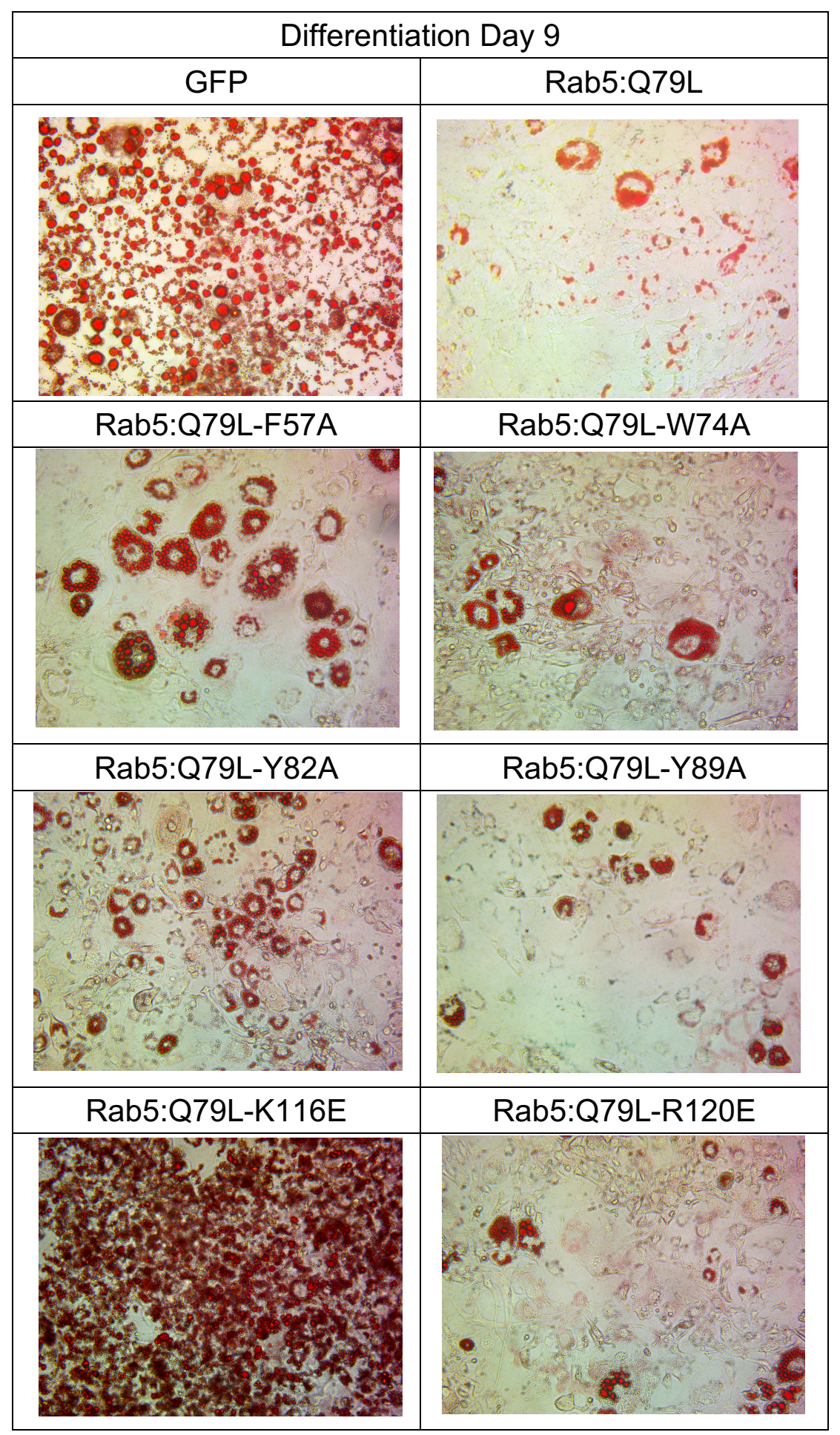

Figure 16. Bright-field images of 3T3-L1 cells overexpressing GFP, Rab5:Q79L, or Rab5:Q79L double mutants. 
Bright-field images of the 3T3-L1 cells overexpressing GFP, Rab5:Q79L, or Rab5:Q79L double mutants revealed parallel results in comparison with the quantitative ORO results (Figure $15 \& 16$ ).

To further examine the specific molecular requirement for the effect of Rab5 on the differentiation of 3T3-L1 pre-adipocytes, I investigated the effect of deletion of the N-/C-terminal of Rab5 or the Rab5 mutants. These N-/C-terminal residues are essential for Rab5 function. The $\mathrm{N}$-terminal is critical for efficient geranylgeranylation of the C-terminal of Rab5 (Sanford et al., 1995). The Cterminal contains a CCXX motif that is responsible for the post-transcriptional modification, geranylgeranylation, of Rab5 (Farnsworth et al., 1994). The biological activity of Rab5: $\Delta \mathrm{N} 19$ and Rab5: $\Delta \mathrm{C} 4$ deletion mutants were examined (Figure 17.A). In comparison with Rab5:S34N, the mutant Rab5:S34N- $\Delta$ N19 resulted in a partial, though not significant, loss of differentiation of the 3T3-L1 pre-adipocytes. For the C-terminal deletion, the elimination of the entire CCXX motif (Rab5:S34N$\Delta \mathrm{C} 4)$ completely abolished the effect of Rab5:S34N on the differentiation of 3T3L1 pre-adipocytes. In Figure 17, the introduction of the C-terminal deletion in Rab5:Q79L mutant (Rab5:Q79L- $\triangle$ C4), but not the introduction of the N-terminal deletion (Rab5:Q79L- $\Delta$ N19), reversed the inhibitory effect of Rab5:Q79L mutant on differentiation of 3T3-L1 pre-adipocytes. These data suggest that posttranslational isoprenylation modifications of Rab5 are essential for its biological function during differentiation of 3T3-L1 pre-adipocytes. 


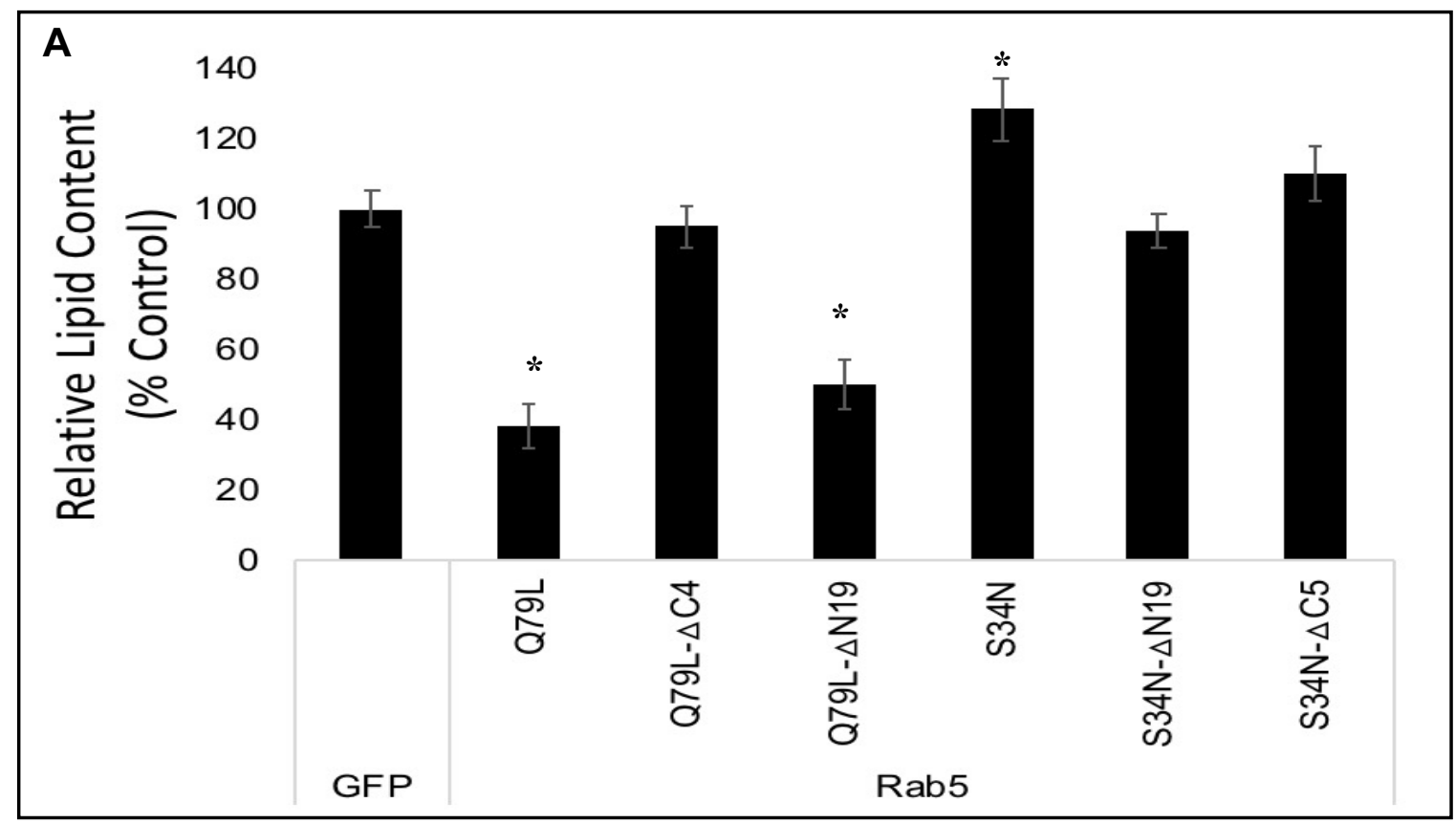

B
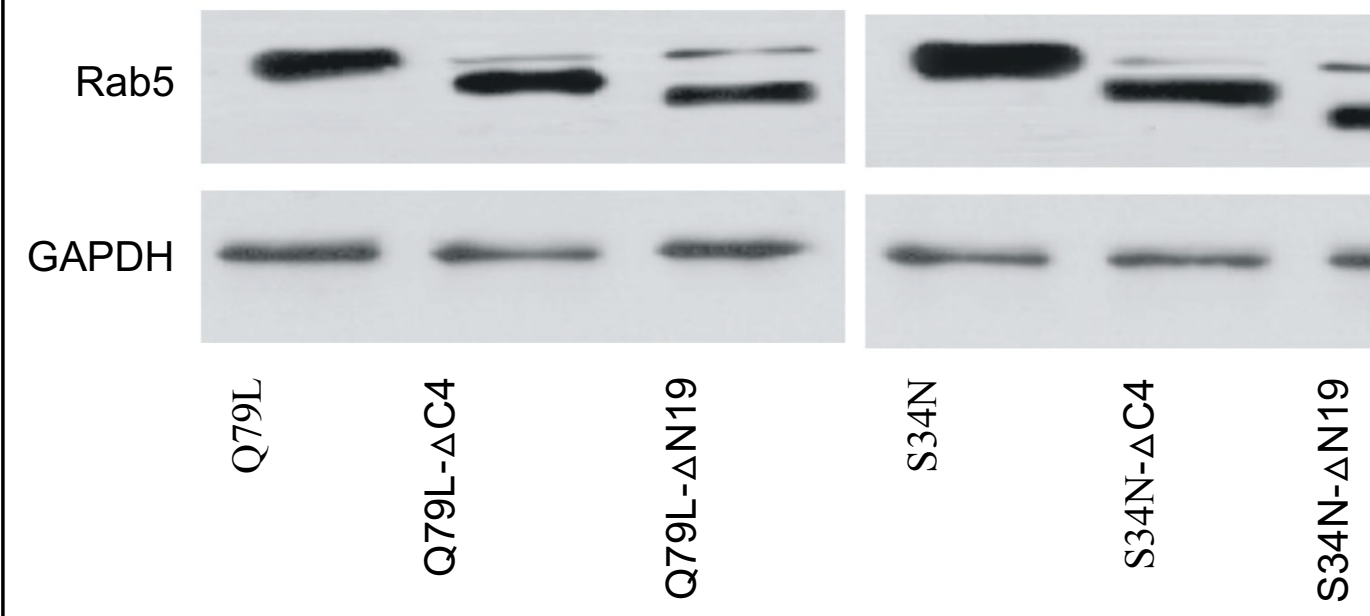

Figure 17. Selective effect of Rab5 constructs on the differentiation of 3T3L1 pre-adipocytes.

3T3-L1 pre-adipocytes overexpressing GFP or Rab5 constructs (Rab5:S34N, Rab5:S34N- $\Delta$ C4/ $\Delta$ N19, Rab5:Q79L and Rab5:Q79L- $\Delta$ C4/ $\Delta$ N19) were differentiated as described in Material and Methods. A. Relative lipid content of differentiated 3T3-L1 cells overespression GFP or Rab5 constructs. Results were represented as relative lipid contents. Data represent the mean \pm S.E.M. of three independent experiments. ( ${ }^{*} \mathrm{P}<0.05$ by Student's t-test). B. Representative Western blot of the content of GFP, Rab5 proteins. 


\section{II.4.3 Rab5 plays an irreplaceable role in the regulation of adipogenesis}

Based on the results collected so far, Rab5 played a regulatory role in adipogenesis. Since the primary role of Rab5 is to promote early endosome fusion in the membrane trafficking process and receptor-mediated endocytosis, I questioned if the other Rab family proteins had their particular roles in the process of adipogenesis. Thus, several small GTPases, including Rab4, Rab7, Rab11, Rab22, and Rab31, as well as the dominant-negative forms (e.g., Rab4:Q67L, Rab7:Q67L, Rab11:Q70L, Rab22:Q64L, Rab31:Q64L) and the dominant-positive forms (e.g., Rab4:S22N, Rab7:S22N, Rab11:S25N, Rab22:S19N, Rab31:S19N) were transfected into the 3T3-L1 pre-adipocytes, respectively. As introduced above, each of these Rab GTPase proteins exhibits particular function in the endocytic pathway, and the active/inactive form of these Rab proteins affect the endocytic pathway in different manners.

In Figure 18, unlike the Rab5:Q79L, none of the Rab GTP-hydrolysis defective mutants (the Rab:QL mutants) tested here inhibited the differentiation of 3T3-L1 pre-adipocytes. Furthermore, none of the Rab GTP-binding defective mutant (the Rab:SN mutants) increased the accumulation of lipids. In addition, the overexpression of Rab:WT proteins did not affect the differentiation process. However, it is also important to note that the overexpression of Rab4:Q67L mutant showed a modest but statistically significant increased accumulation of lipids, while the overexpression of Rab4:S22N decreased it. These data suggest that increasing the levels of Rab5 in the GTP-bound form by overexpressing the Rab5:Q79L mutant and to some extent, overexpressing of Rab5:WT, has a 
detrimental and non-substitutable role on the differentiation of 3T3-L1 preadipocytes. Furthermore, the data suggest that the Rab5 GDP-bound form plays a particular and significant role in the differentiation process.
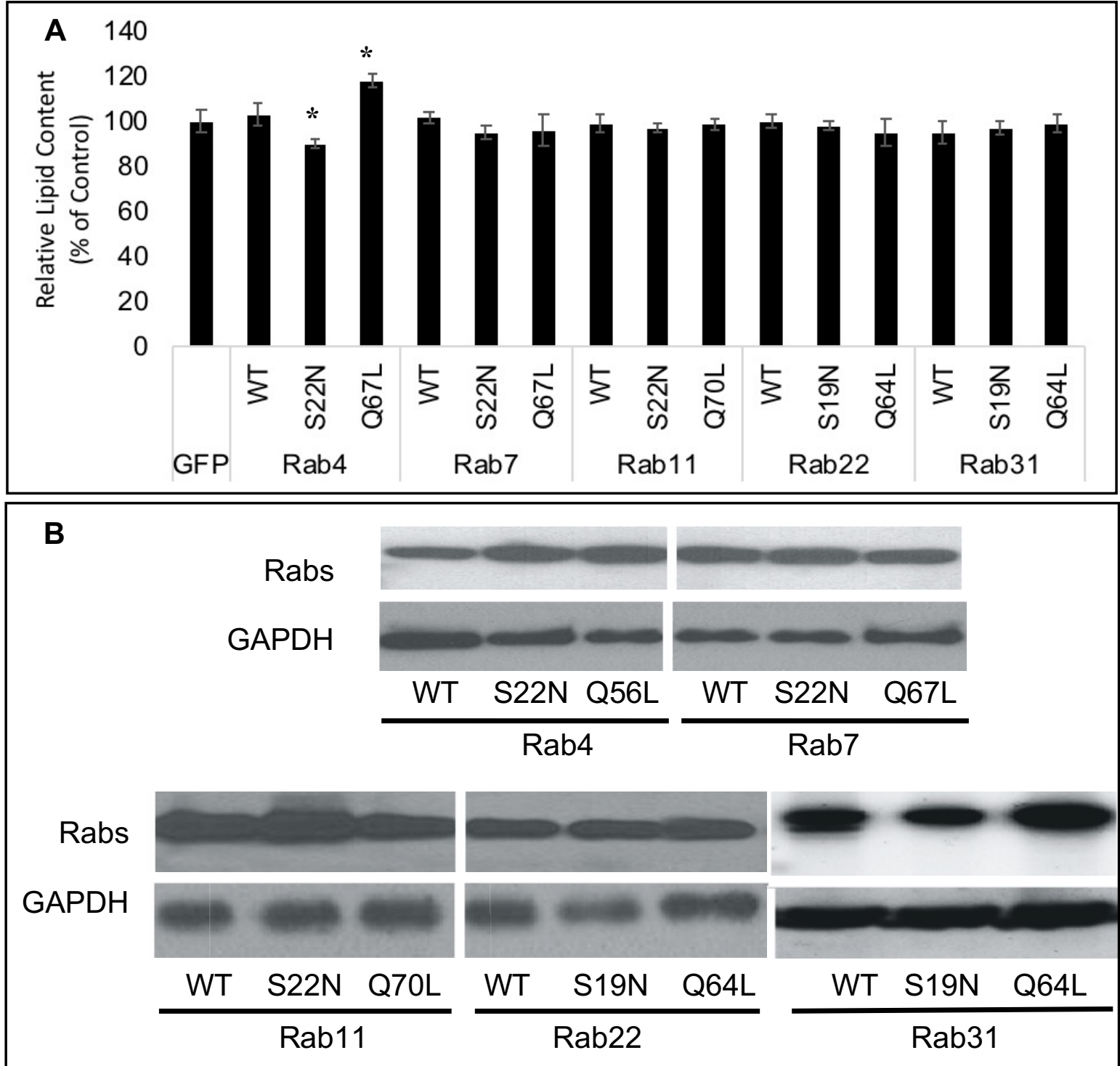

Figure 18. A. Selective effect of Rab proteins on the differentiation of 3T3-L1 pre-adipocytes.

3T3-L1 pre-adipocytes overexpression different Rab:WT, Rab:SN, and Rab:QL were differentiated into adipocytes in the presence of induction media, and the accumulation of lipid droplets was measured by the incorporation of ORO as described in Material and Methods. Data represent the mean \pm S.E.M. of three independent experiments. ( ${ }^{*} \mathrm{P}<0.05$ by Student's $\mathrm{t}$-test). B. Representative Western blot of the content of GFP, Rab p, and GAPDH proteins. 


\section{II.4.4 Rab5 performs its function via the insulin signaling pathway during the adipogenesis process}

Based on the observations above, Rab5, not the other Rab proteins (e.g., Rab7, Rab11, Rab22, and Rab 31), uniquely affects the expression of adipogenesis-associated transcription factors. Then, I wondered what effect of Rab5 constructs overexpression on the expression of other factors (e.g., insulin receptor, GLUT4 and Akt) during adipogenesis would be. This is because the IR, GLUT4, and Akt (the key protein in the PI3K/Akt signaling pathway triggered upon insulin stimulation) have been showed to play a key role during the differentiation of 3T3-L1 pre-adipocytes. Not surprisingly, the expression of the IR, GLUT4, and Akt exhibited an increase in cells overexpressing the Rab5:S34N mutant (Figure 19, Figure 20, and Figure 21). These data further supported the increase of lipids formation observed in this Rab5 mutant cell line (Figure 12). It is important to note that not only the expression level of IR and GLUT4 were increased in Rab5:S34N cell lines, but also the relative phosphorylated IR level was enhanced at day 9 of differentiation (Figure 19, Figure 21). An increase in the phosphorylation of Akt, but not the phosphorylation of Erk1/2 was also observed upon insulin stimulation (Figure 20). Taken together, the data suggest that the overexpression of the Rab5:S34N mutant, which constitutively inhibited the biological function of Rab5 selectively contribute to the up-regulation of expression as well as phosphorylation of the IR by diminishing the internalization of the receptor. This impaired internalization in turn augment the level of phosphorylated Akt and enhance the translocation of GLUT4 to the plasma membrane. Therefore, it is possible to 
speculate that Rab5 GTP/GDP ratio has an essential role on differentiation of 3T3L1 pre-adipocytes.

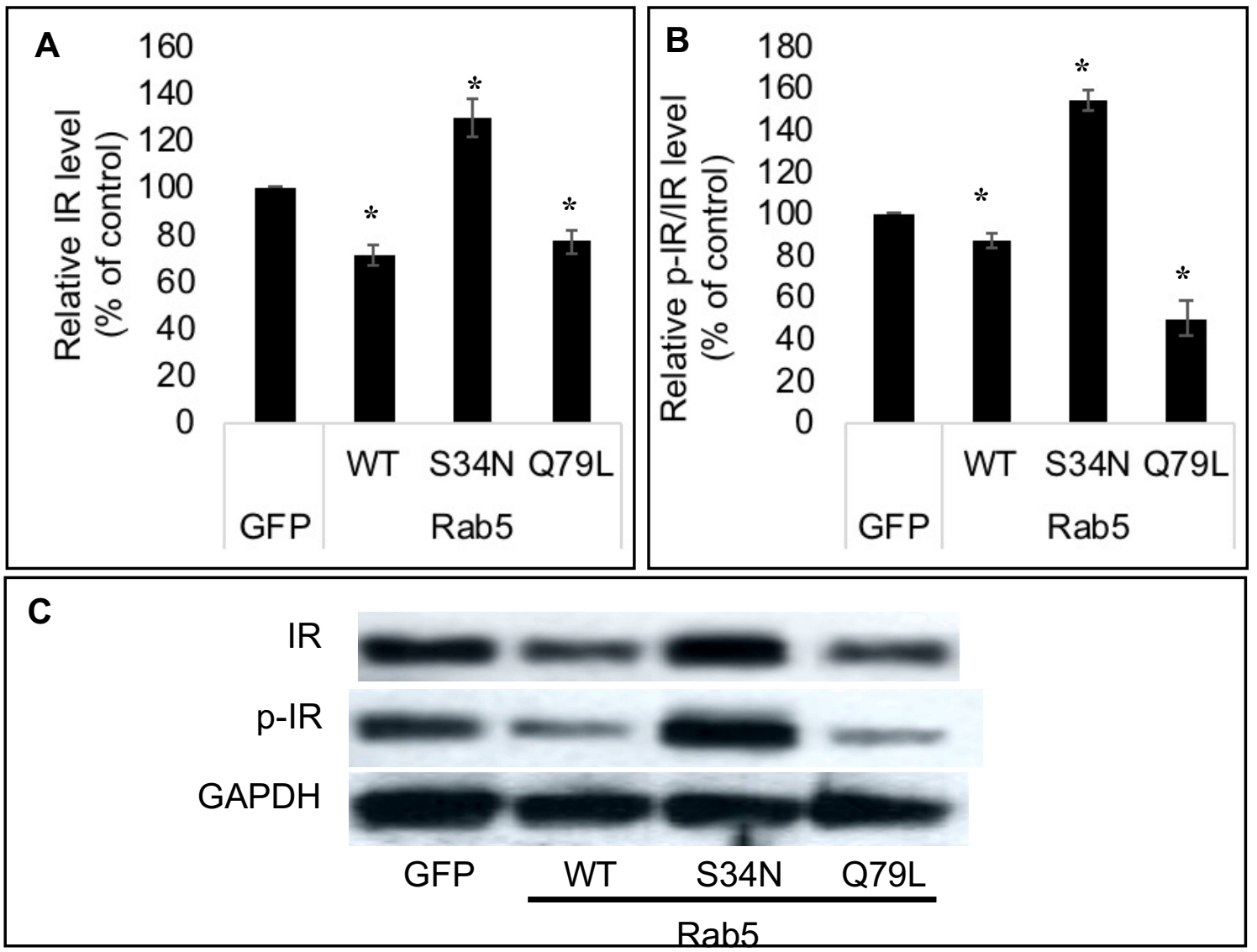

Figure 19. Effect of Rab5 and the Rab5 mutations on the expression and phosphorylation of the IR.

3T3-L1 pre-adipocytes overexpressing GFP or Rab5 constructs were differentiated as described in Material and Methods. The endogenous levels of IR, phosphorylated-IR (p-IR), and GAPDH proteins were analyzed with specific antibodies by immunoblotting as indicated in the figure upon insulin stimulation. Data represent the mean \pm S.E.M. of three independent experiments. Inset: Representative Western blot of the content of IR, phospho-IR, and GAPDH proteins. ${ }^{*} P<0.05$ by Student's t-test. A. Relative IR expression level (as compared with GAPDH) of GFP- or Rab5 constructs-overexpressed 3T3-L1 cells. B. Relative p-IR expression level (in comparison with IR) of GFP- or Rab5 constructsoverexpressed 3T3-L1 cells. C. Representative Western blot of the content of IR, phospho-IR, and GAPDH proteins. 

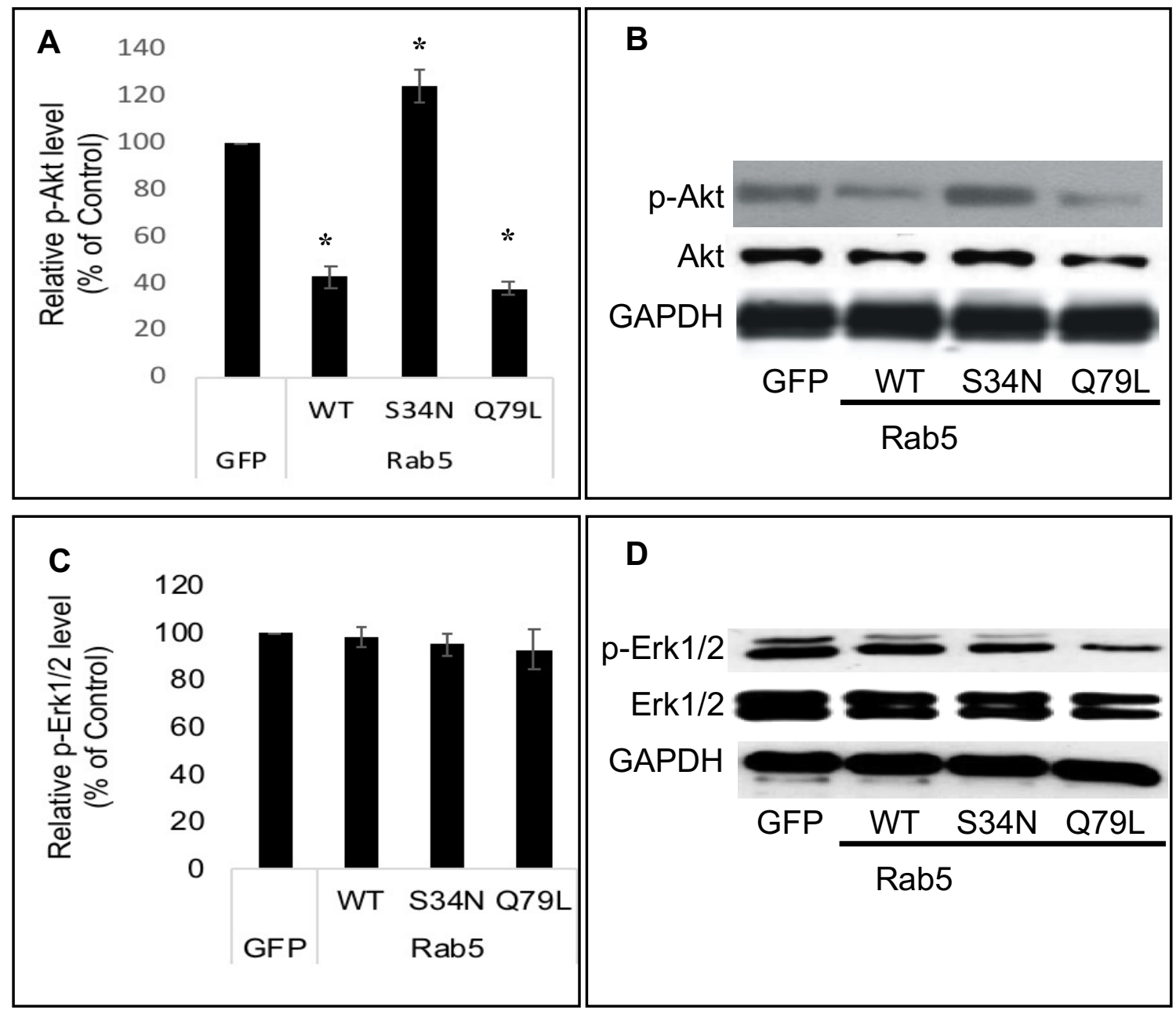

Figure 20. Effect of Rab5 constructs on the activation of Akt and Erk1/2.

3T3-L1 pre-adipocytes overexpressing GFP or Rab5 constructs were differentiated as described in Material and Methods. The activation of Akt and Erk1/2 were analyzed with specific antibodies by immunoblotting as indicated in the figure upon insulin stimulation. GAPDH served as loading control. Data represent the mean \pm S.E.M. of three independent experiments. ${ }^{*} P<0.05$ by Student's t-test. A. Relative p-Akt level of 3T3-L1 cells expressing GFP or Rab5 constructs. B. Representative Western blot of the content of total Akt, phosphor Akt (p-Akt), and GAPDH. C. Relative p-Erk1/2 level of 3T3-L1 cells expressing GFP or Rab5 constructs. D. Representative Western blot of the content of total Erk1/2, phosphor Erk1/2 (p-Erk1/2), and GAPDH. 


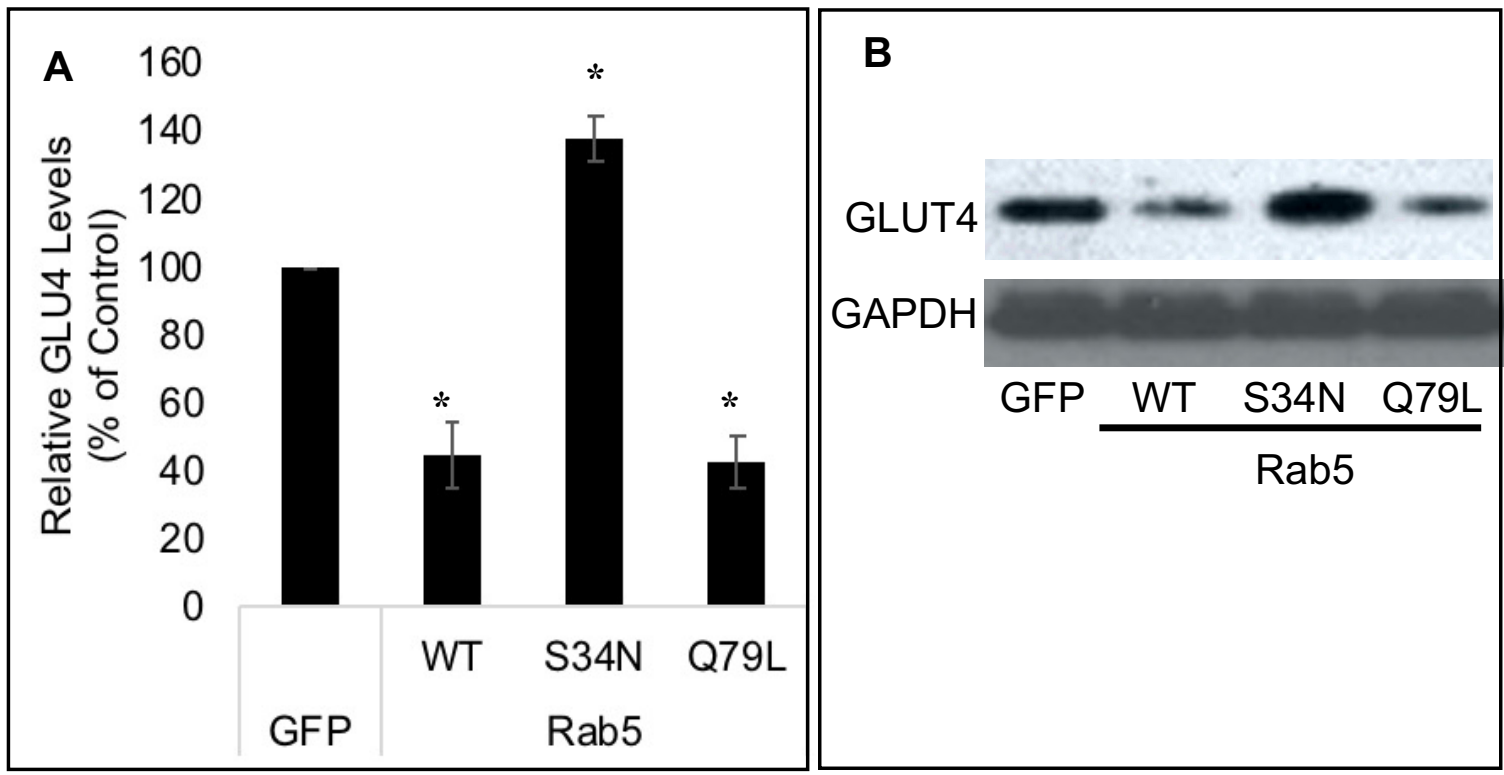

Figure 21. Effect of Rab5 and the Rab5 mutants on the expression of GLUT4. 3T3-L1 pre-adipocytes overexpressing GFP or Rab5 constructs were differentiated as described in Material and Methods and the endogenous levels of GLUT4 and GAPDH were analyzed with specific antibodies by immunoblotting as indicated in the figure. A. Relative GLUT4 level in comparison with GFP cells. Data represent the mean \pm S.E.M. of three independent experiments. ${ }^{*} \mathrm{P}<0.05$ by Student's t-test. B. Representative Western blot of the content of GLUT4 and GAPDH.

\section{II.5 Discussion}

In this Chapter, Rab5 has been established to play a detrimental role in the process of adipogenesis with a decreased GTP-bound Rab5 level and without affecting the total expression of Rab5 in the 3T3-L1 pre-adipocytes. Consistent with these observations, I show that increasing the Rab5-GTP level is also detrimental and irreplaceable for the differentiation of 3T3-L1 pre-adipocytes.

First, the expression of different Rab5 isoforms revealed a slight but statistically significant decrease in the accumulation of lipids in the cytosol, which was detected via the ORO staining assay (Figure 10). Interestingly, the deletion of 
individual Rab5 isoforms, as well as all three isoforms via RNA interference also resulted in a decrease of lipids accumulation. The Rab5 isoforms exhibit different roles in different cell types. For instance, the overexpression of Rab5B or Rab5A hampered the degradation of EGFR as well as the progression of EGFR from early to late endosomes upon EGF stimulation in Hela cells (Chen et al., 2009). Rab5A is also found to regulate autophagosome formation in the U2OS cells (human bone osteosarcoma epithelial cells). And Rab5C has been shown to enhance $\beta$-integrin recycling in EGF-induced cancer cell invasion (Onodera et al., 2012). Since the insulin receptor and the EGFR are both a member of the receptor tyrosine kinases, these data suggest that Rab5 may affect the process of differentiation by impairing the endocytosis process of the IR.

Second, the activated GTP-bound Rab5 has been demonstrated to undergo a graduated decrease over the differentiation of 3T3-L1 cells (Figure 11). The reduction of Rab5 GTP-bound form exhibited a negative relationship with the accumulation of adipogenesis-associated transcription factor, PPARy, which served as the marker of adipogenesis process (Figure 11). In addition, the decrease of Rab5 GTP-bound level during adipogenesis happened without any changes in the total endogenous expression level of Rab5 (Figure 11.D). These data suggest that the ratio of Rab5-GTP over total Rab5 may be important for the differentiation of 3T3-L1 pre-adipocytes.

Third, two Rab5 mutants, the dominant-negative Rab5:S34N and the dominant-positive Rab5:Q79L, exhibited opposite roles in the differentiation of 3T3-L1 cells, where the Rab5:Q79L inhibited this process whereas the Rab5:S34N 
promoted the process. In addition, the expression of the Rab5:Q79L mutant, but not the Rab5:S34N mutant, blocked this process by inhibiting the expression of PPARY and C/EBPa in the 3T3-L1 pre-adipocytes. In previous studies, the expression of Rab5:Q79L mutant results in enlarged endosomes in multiple cell types, whereas the expression of Rab5:S34N inhibited the internalization of the EGFR in Hela cells as well as phagosome formation and T. cruzi internalization in the Raw 264.7 mouse macrophage cells (Dinneen \& Ceresa, 2004; Galperin \& Sorkin, 2003; Li et al., 1994; Maganto-Garcia et al., 2008; Stenmark et al., 1994). In the confocal images, enlarged endosomes can be observed in the Rab5-Q79Loverexpressed cells, which suggests that GTP-Rab5 may diminish the accumulation of lipids by impairing the endocytosis process. Furthermore, Rab5:Q79L- $\triangle$ C4, a mutant lacking CCXX (X refers to any amino acid) motif that is required for isoprenylation, completely reversed the inhibitory effect of Rab5. Previously, researchers show that the $\mathrm{N}$-terminal is critical for efficient geranylgeranylation of the C-terminal of Rab5, whereas the C-terminal contains a CCXX motif that is responsible for the post-transcriptional modification of Rab5 (Farnsworth et al., 1994) (Sanford et al., 1995). My data suggest that the Cterminal is essential for the function of Rab5 in regulating the differentiation process. Though the $\mathrm{N}$-terminal supports the function of the C-terminal, deletion of the $\mathrm{N}$-terminal alone does not have a significant effect on the differentiation of 3T3-L1 pre-adipocytes.

Fourth, the overexpression of Rab5:Q79L-K116E, but not the other Rab5:Q79L double mutants (Rab5:Q79L-Y57A, Rab5:Q79L-W74A, Rab5:Q79L- 
Y82A, Rab5:Q79L-Y89A, or Rab5:Q79L-R120E), significantly promoted the accumulation of lipids in the differentiated 3T3-L1 cells (Figure 15). Previously, the Y57A, W74A, Y82A, and Y89A were predicted to be decisive binding epitopes for EEA1 and Rabenosyn-5, and the Rab5:Q79L-Y57A, Rab5:Q79L-W74A, Rab5:Q79L-Y82A, and Rab5:Q79L-Y89A mutants all showed reduced binding affinity to Rab5 effector Rabaptin-5 (G Zhu et al., 2004; Mishra et al., 2010). The K116 serves as a mono-ubiquitination site of Rab5 (Wagner et al., 2011). But the Rab5:K116R mutant did not affect the recruitment of Rab5 effectors or alter the GTP loading/GDP release activities of Rab5 (Shin et al., 2017). My data suggested a novel role of the $\mathrm{K} 116$ residue in regulating the function of Rab5 in adipogenesis process.

Fifth, several small GTPases (e.g., Rab4, Rab7, Rab11, Rab22, and Rab31) were unable to affect this differentiation process as compared with Rab5. Though each of the tested Rab proteins exhibits particular functions in different steps of endocytosis (Frittoli et al., 2014; Lodhi et al., 2007; Takahashi et al., 2012; Vanlandingham \& Ceresa, 2009; HP Zhu et al., 2009). None of the chosen Rab5 proteins displayed a similar role as Rab5 in the differentiation process.

Sixth, both the expression levels of insulin receptor and GLUT4 were upregulated under the overexpression of Rab5:S34N and down-regulated under the overexpression of Rab5:Q79L. Besides, the levels of phosphorylated Akt and phosphorylated insulin receptor were increased in the Rab:S34N cells.

These observations can be explained, at least in part, by the fact that Rab5:Q79L, but not Rab5:S34N mutant, increased internalization of the insulin 
receptor, thus, decreasing both cell surface localization as well as tyrosine autophosphorylation of the insulin receptor at day 9 day of the differentiation process. Consistent with this idea, internalized and less active insulin receptor will not be able to fully activate Akt, a key molecule required for the activation of GLUT4. These molecules have been implicated in the differentiation of 3T3-L1 preadipocytes.

\section{II.6 References}

Audhya, A., Desai, A., \& Oegema, K. (2007). A role for Rab5 in structuring the endoplasmic reticulum. J Cell Biol, 178(1), 43-56. doi:10.1083/jcb.200701139

Balaji, K., Mooser, C., Janson, C. M., Bliss, J. M., Hojjat, H., \& Colicelli, J. (2012). RIN1 orchestrates the activation of RAB5 GTPases and ABL tyrosine kinases to determine the fate of EGFR. J Cell Sci, 125(Pt 23), 5887-5896. doi:10.1242/jcs. 113688

Barbieri, M. A., Fernandez-Pol, S., Hunker, C., Horazdovsky, B. H., \& Stahl, P. D. (2004). Role of rab5 in EGF receptor-mediated signal transduction. Eur J Cell Biol, 83(6), 305-314. doi:10.1078/0171-9335-00381

Barbieri, M. A., Li, G., Mayorga, L. S., \& Stahl, P. D. (1996). Characterization of Rab5:Q79L-stimulated endosome fusion. Arch Biochem Biophys, 326(1), 64-72. doi:10.1006/abbi.1996.0047

Barbieri, M. A., Roberts, R. L., Gumusboga, A., Highfield, H., Alvarez-Dominguez, C., Wells, A., \& Stahl, P. D. (2000). Epidermal growth factor and membrane trafficking: EGF receptor activation of endocytosis requires Rab5a. Journal of Cell Biology, 151(3), 539-550. doi:DOI 10.1083/jcb.151.3.539

Bryant, N. J., Govers, R., \& James, D. E. (2002). Regulated transport of the glucose transporter GLUT4. Nat Rev Mol Cell Biol, 3(4), 267-277. doi:10.1038/nrm782

Capalbo, L., D'Avino, P. P., Archambault, V., \& Glover, D. M. (2011). Rab5 GTPase controls chromosome alignment through Lamin disassembly and relocation of the NuMA-like protein Mud to the poles during mitosis. Proceedings of the National Academy of Sciences of the United States of America, 108(42), 17343-17348. doi:10.1073/pnas.1103720108 
Chen, P. I., Kong, C., Su, X., \& Stahl, P. D. (2009). Rab5 isoforms differentially regulate the trafficking and degradation of epidermal growth factor receptors. J Biol Chem, 284(44), 30328-30338. doi:10.1074/jbc.M109.034546

Chen, P. I., Schauer, K., Kong, C., Harding, A. R., Goud, B., \& Stahl, P. D. (2014). Rab5 isoforms orchestrate a "division of labor" in the endocytic network; Rab5C modulates Rac-mediated cell motility. PLoS One, 9(2), e90384. doi:10.1371/journal.pone.0090384

Czech, M. P., \& Buxton, J. M. (1993). Insulin action on the internalization of the GLUT4 glucose transporter in isolated rat adipocytes.pdf. J. Biol. Chem., 268, 9187-9190.

Das, S., Hehnly, H., \& Doxsey, S. (2014). A new role for Rab GTPases during early mitotic stages. Small GTPases, 5. doi:10.4161/sgtp.29565

Dinneen, J. L., \& Ceresa, B. P. (2004). Expression of dominant negative rab5 in HeLa cells regulates endocytic trafficking distal from the plasma membrane. Exp Cell Res, 294(2), 509-522. doi:10.1016/j.yexcr.2003.12.006

Farnsworth, C. C., Seabra, M. C., Ericsson, L. H., Gelb, M. H., \& Glomset, J. A. (1994). Rab geranylgeranyl transferase catalyzes the geranylgeranylation of adjacent cysteines in the small GTPases Rab1A, Rab3A, and Rab5A. Proc Natl Acad Sci U S A, 91(25), 11963-11967.

Frittoli, E., Palamidessi, A., Marighetti, P., Confalonieri, S., Bianchi, F., Malinverno, C., Mazzarol, G., Viale, G., Martin-Padura, I., Garre, M., Parazzoli, D., Mattei, V., Cortellino, S., Bertalot, G., Di Fiore, P. P., \& Scita, G. (2014). A RAB5/RAB4 recycling circuitry induces a proteolytic invasive program and promotes tumor dissemination. J Cell Biol, 206(2), 307-328. doi:10.1083/jcb.201403127

Galperin, E., \& Sorkin, A. (2003). Visualization of Rab5 activity in living cells by FRET microscopy and influence of plasma-membrane-targeted Rab5 on clathrindependent endocytosis. J Cell Sci, 116(Pt 23), 4799-4810. doi:10.1242/jcs.00801

Gurkan, C., Lapp, H., Alory, C., Su, A. I., Hogenesch, J. B., \& Balch, W. E. (2005). Large-scale profiling of Rab GTPase trafficking networks: the membrome. Mol Biol Cell, 16(8), 3847-3864. doi:10.1091/mbc.E05-01-0062

Hoffenberg, S., Liu, X., Nikolova, L., Hall, H. S., Dai, W., Baughn, R. E., Dickey, B. F., Barbieri, M. A., Aballay, A., Stahl, P. D., \& Knoll, B. J. (2000). A novel membrane-anchored Rab5 interacting protein required for homotypic endosome fusion. J Biol Chem, 275(32), 24661-24669. doi:10.1074/jbc.M909600199 
Huang, J., Imamura, T., \& Olefsky, J. M. (2001). Insulin can regulate GLUT4 internalization by signaling to Rab5 and the motor protein dynein. PNAS, 98. doi:10.1073/pnas.241368698

Hunker, C. M., Kruk, I., Hall, J., Giambini, H., Veisaga, M. L., \& Barbieri, M. A. (2006). Role of Rab5 in insulin receptor-mediated endocytosis and signaling. Arch Biochem Biophys, 449(1-2), 130-142. doi:10.1016/j.abb.2006.01.020

James, D. E., Brown, R., Navarro, J., \& Pilch, P. F. (1988). Insulin-regulatable tissues express a unique insulin-sensitive glucose transport protein. Nature, 333(6169), 183-185. doi:10.1038/333183a0

Jozic, I., Blanco, G., \& Barbieri, M. A. (2011). Inhibition of Rab5 Activation During Insulin Receptor-Mediated Endocytosis. Curr Cell Biochem, 1(1), 20-32.

Jozic, I., Saliba, S. C., \& Barbieri, M. A. (2012). Effect of EGF-receptor tyrosine kinase inhibitor on Rab5 function during endocytosis. Arch Biochem Biophys, 525(1), 16-24. doi:10.1016/j.abb.2012.05.023

Kauppi, M., Simonsen, A., Bremnes, B., Vieira, A., Callaghan, J., Stenmark, H., \& Olkkonen, V. M. (2002). The small GTPase Rab22 interacts with EEA1 and controls endosomal membrane trafficking. J Cell Sci, 115(Pt 5), 899-911.

Lebrand, C., Corti, M., Goodson, H., Cosson, P., Cavalli, V., Mayran, N., Faure, J., \& Gruenberg, J. (2002). Late endosome motility depends on lipids via the small GTPase Rab7. EMBO J, 21(6), 1289-1300. doi:10.1093/emboj/21.6.1289

Li, G. P., Barbieri, M. A., Colombo, M. I., \& Stahl, P. D. (1994). Structural Features of the Gtp-Binding Defective Rab5 Mutants Required for Their Inhibitory Activity on Endocytosis. Journal of Biological Chemistry, 269(20), 14631-14635.

Lodhi, I. J., Chiang, S. H., Chang, L., Vollenweider, D., Watson, R. T., Inoue, M., Pessin, J. E., \& Saltiel, A. R. (2007). Gapex-5, a Rab31 guanine nucleotide exchange factor that regulates Glut4 trafficking in adipocytes. Cell Metabolism, 5(1), 59-72. doi:10.1016/j.cmet.2006.12.006

Maganto-Garcia, E., Punzon, C., Terhorst, C., \& Fresno, M. (2008). Rab5 activation by Toll-like receptor 2 is required for Trypanosoma cruzi internalization and replication in macrophages. Traffic, 9(8), 1299-1315. doi:10.1111/j.16000854.2008.00760.x

Mendoza, P., Ortiz, R., Diaz, J., Quest, A. F., Leyton, L., Stupack, D., \& Torres, V. A. (2013). Rab5 activation promotes focal adhesion disassembly, migration and invasiveness in tumor cells. J Cell Sci, $126(\mathrm{Pt} 17), \quad 3835-3847$. doi:10.1242/jcs.119727 
Millar, C. A., Shewan, A., Hickson, G. R., James, D. E., \& Gould, G. W. (1999). Differential regulation of secretory compartments containing the insulin-responsive glucose transporter 4 in 3T3-L1 adipocytes. Mol Biol Cell, 10(11), 3675-3688.

Mishra, A., Eathiraj, S., Corvera, S., \& Lambright, D. G. (2010). Structural basis for Rab GTPase recognition and endosome tethering by the $\mathrm{C} 2 \mathrm{H} 2$ zinc finger of Early Endosomal Autoantigen 1 (EEA1). Proc Natl Acad Sci U S A, 107(24), 1086610871. doi:10.1073/pnas.1000843107

Mustafi, S., Rivero, N., Olson, J. C., Stahl, P. D., \& Barbieri, M. A. (2013). Regulation of Rab5 function during phagocytosis of live Pseudomonas aeruginosa in macrophages. Infect Immun, 81(7), 2426-2436. doi:10.1128/IAI.00387-13

Onishi, M., Nosaka, T., Misawa, K., Mui, A. L. F., Gorman, D., McMahon, M., Miyajima, A., \& Kitamura, T. (1998). Identification and characterization of a constitutively active STAT5 mutant that promotes cell proliferation. Molecular and Cellular Biology, 18(7), 3871-3879. doi:Doi 10.1128/Mcb.18.7.3871

Onodera, Y., Nam, J. M., Hashimoto, A., Norman, J. C., Shirato, H., Hashimoto, S., \& Sabe, H. (2012). Rab5c promotes AMAP1-PRKD2 complex formation to enhance beta1 integrin recycling in EGF-induced cancer invasion. J Cell Biol, 197(7), 983-996. doi:10.1083/jcb.201201065

Potokar, M., Lacovich, V., Chowdhury, H. H., Kreft, M., \& Zorec, R. (2012). Rab4 and Rab5 GTPase are required for directional mobility of endocytic vesicles in astrocytes. Glia, 60(4), 594-604. doi:10.1002/glia.22293

Qi, Y., Sun, L., \& Yang, H. (2017). Lipid droplet growth and adipocyte development: mechanistically distinct processes connected by phospholipids. Biochim Biophys Acta, 1862(10 Pt B), 1273-1283. doi:10.1016/j.bbalip.2017.06.016

Rosen, E. D., Hsu, C. H., Wang, X., Sakai, S., Freeman, M. W., Gonzalez, F. J., \& Spiegelman, B. M. (2002). C/EBPalpha induces adipogenesis through PPARgamma: a unified pathway. Genes Dev, 16(1), 22-26. doi:10.1101/gad.948702

Sadacca, L. A., Bruno, J., Wen, J., Xiong, W., \& McGraw, T. E. (2013). Specialized sorting of GLUT4 and its recruitment to the cell surface are independently regulated by distinct Rabs. Mol Biol Cell, 24(16), 2544-2557. doi:10.1091/mbc.E13-02-0103

Sandri, C., Caccavari, F., Valdembri, D., Camillo, C., Veltel, S., Santambrogio, M., Lanzetti, L., Bussolino, F., Ivaska, J., \& Serini, G. (2012). The R-Ras/RIN2/Rab5 complex controls endothelial cell adhesion and morphogenesis via active integrin endocytosis and Rac signaling. Cell Res, 22(10), 1479-1501. doi:10.1038/cr.2012.110 
Sanford, J. C., Pan, Y., \& Wessling-Resnick, M. (1995). Properties of Rab5 Nterminal domain dictate prenylation of C-terminal cysteines. Mol Biol Cell, 6(1), 7185.

Shin, D., Na, W., Lee, J. H., Kim, G., Baek, J., Park, S. H., Choi, C. Y., \& Lee, S. (2017). Site-specific monoubiquitination downregulates Rab5 by disrupting effector binding and guanine nucleotide conversion. Elife, 6. doi:10.7554/eLife.29154

Shisheva, A., \& Czech, M. P. (1997). Association of cytosolic Rab4 with GDI isoforms in insulin-sensitive 3T3-L1 adipocytes. Biochemistry, 36(22), 6564-6570. doi:10.1021/bi970202g

Stenmark, H., Parton, R. G., Steele-Mortimer, O., Lutcke, A., Gruenberg, J., \& Zerial, M. (1994). Inhibition of rab5 GTPase activity stimulates membrane fusion in endocytosis. EMBO J, 13(6), 1287-1296.

Su, X., Lodhi, I. J., Saltiel, A. R., \& Stahl, P. D. (2006). Insulin-stimulated Interaction between insulin receptor substrate 1 and p85alpha and activation of protein kinase B/Akt require Rab5. J Biol Chem, 281(38), 27982-27990. doi:10.1074/jbc.M602873200

Suzuki, M., Shinohara, Y., Ohsaki, Y., \& Fujimoto, T. (2011). Lipid droplets: size matters. J Electron Microsc (Tokyo), 60 Suppl 1, S101-116. doi:10.1093/jmicro/dfr016

Takahashi, S., Kubo, K., Waguri, S., Yabashi, A., Shin, H. W., Katoh, Y., \& Nakayama, K. (2012). Rab11 regulates exocytosis of recycling vesicles at the plasma membrane. J Cell Sci, 125(Pt 17), 4049-4057. doi:10.1242/jcs.102913

Tamori, Y., Masugi, J., Nishino, N., \& Kasuga, M. (2002). Role of Peroxisome Proliferator-Activated Receptor- $y$ in Maintenance of the Characteristics of Mature 3T3-L1 Adipocytes.pdf. Diabetes, 51, 2045-2055.

Tang, Q. Q., \& Lane, M. D. (2012). Adipogenesis: from stem cell to adipocyte. Annu Rev Biochem, 81, 715-736. doi:10.1146/annurev-biochem-052110-115718

Terzyan, S., Zhu, G., Li, G., \& Zhang, X. C. (2003). Refinement of the structure of human Rab5a GTPase domain at $1.05 \AA$ resolution. Acta Crystallographica Section $D$ Biological Crystallography, 60(1), 54-60. doi:10.1107/s0907444903021632

Tessneer, K. L., Jackson, R. M., Griesel, B. A., \& Olson, A. L. (2014). Rab5 activity regulates GLUT4 sorting into insulin-responsive and non-insulin-responsive endosomal compartments: a potential mechanism for development of insulin resistance. Endocrinology, 155(9), 3315-3328. doi:10.1210/en.2013-2148 
Vanlandingham, P. A., \& Ceresa, B. P. (2009). Rab7 regulates late endocytic trafficking downstream of multivesicular body biogenesis and cargo sequestration. J Biol Chem, 284(18), 12110-12124. doi:10.1074/jbc.M809277200

Wagner, S. A., Beli, P., Weinert, B. T., Nielsen, M. L., Cox, J., Mann, M., \& Choudhary, C. (2011). A proteome-wide, quantitative survey of in vivo ubiquitylation sites reveals widespread regulatory roles. Mol Cell Proteomics, 10(10), M111 013284. doi:10.1074/mcp.M111.013284

Wang, L., Liang, Z., \& Li, G. (2011). Rab22 controls NGF signaling and neurite outgrowth in PC12 cells. Mol Biol Cell, 22(20), 3853-3860. doi:10.1091/mbc.E1103-0277

Zhu, G., Zhai, P., Liu, J., Terzyan, S., Li, G., \& Zhang, X. C. (2004). Structural basis of Rab5-Rabaptin5 interaction in endocytosis. Nat Struct Mol Biol, 11(10), 975-983. doi: $10.1038 / n s m b 832$

Zhu, H. P., Liang, Z. M., \& Li, G. P. (2009). Rabex-5 Is a Rab22 Effector and Mediates a Rab22-Rab5 Signaling Cascade in Endocytosis. Molecular Biology of the Cell, 20(22), 4720-4729. doi:10.1091/mbc.E09-06-0453 


\section{CHAPTER III}

\section{Role of Rab5 regulators and effectors in the process of adipogenesis}

\section{III.1 Introduction}

Adipogenesis is a complicated process triggered by hormones and governed by corresponding signaling pathways (Chi et al., 2017; Hinoi et al., 2014; Nam et al., 2015; Wu et al., 2015). The insulin signaling pathway plays an essential role in multiple cellular processes, including cell proliferation, cell migration, and cell differentiation, in a wide range of cell types (Huttala et al., 2016; Shukla et al., 2009; Yen et al., 2015). Specifically, insulin is proved to be the most potent hormone to trigger the differentiation of the pre-adipocytes (Klemm et al., 2001). The dominant effects of insulin on the pre-adipocytes coincide with the high expression of IR on the plasma membrane of the pre-adipocytes, with a number of about $200 \sim 300 \times 10^{3}$ per pre-adipocyte compared to $\sim 40$ per erythrocyte (Watanabe et al., 1998). The binding of insulin to the IR triggers autophosphorylation of several tyrosine sites on the intracellular portion of the IR $\beta$-subunit (Saltiel \& Kahn, 2001). The insulin signaling pathway activated upon insulin stimulation governs the body metabolism by affecting the rates of glucose transport, glycogen synthesis, fatty acid synthesis, and enzyme/protein synthesis, and the expression of adipocyte differentiation-associated proteins (Dimitriadis et al., 2011). Under the stimulation of insulin, the IR undergoes a rapid internalization process $\left(\mathrm{t}_{1 / 2}<3 \mathrm{~min}\right)$ through the receptor-mediated endocytosis (RME), in which the insulin-IR complex is engulfed into the cell with a region of the plasma 
membrane as a clathrin-coated pit (CCP) in an insulin concentration-dependent manner (Jochen et al., 1989; Marshall, 1985). Internalized CCP is then delivered through the intracellular membrane trafficking system, in which the CCP is transport to the early endosome, the late endosome, and eventually the lysosome to be degraded or the plasma membrane to be reused (Scheidel et al., 2015).

The small GTPase Rab5 is dynamically involved in several cellular trafficking and signaling events, including receptor internalization, fusion of endocytic vesicles with early endosomes, and signaling to the nucleus (Barbieri et al., 2000; Bucci et al., 1992; GP Li et al., 1994). As is described in Chapter II, Rab5 regulate the adipogenic differentiation of the pre-adipocytes through the insulin signaling pathway. Specifically, the overexpression of the GTP-binding defective mutant of Rab5 (Rab5:S34N) increases differentiation of the 3T3-L1 preadipocytes, whereas the overexpression of the GTPase-defective mutant of Rab5 (Rab5:Q79L) improves differentiation of 3T3-L1 pre-adipocyte. Besides, previous study shows that the formation of Rab5-positive endosomes and the activation of Rab5 upon insulin in intact cells were both blocked by the treatment of a receptor tyrosine kinase inhibitor (Jozic et al., 2011). In addition, the impaired Rab5 activation can be rescued by the overexpression of Rab5:Q79L, which parallels with the fact that the formation of Rab5:Q79L mutant-positive endosomes is not affected by the receptor tyrosine kinase inhibitor (Jozic et al., 2011).

Rab5 cycles between the active GTP-bound form and the inactive GDPbound form to serve as the molecular switch in the early endosome fusion process ( $G \mathrm{Li}, 2015)$. The activation of Rab5 is regulated by a number of guanine nucleotide 
exchange factors (GEFs). All these proteins contain a highly conserved VPS9 domain that catalyzes nucleotide exchange on GTP-bound form Rab5. The Rab5 GEFs include Rabex-5, Alsin, the RIN family proteins, RAP6 (which is also known as RME-6 and GAPex-5), and Rinl (Han \& Colicelli, 1995; Horiuchi et al., 1997; Hunker, Galvis, et al., 2006; Kajiho et al., 2003; Otomo et al., 2003; Saito et al., 2002; Woller et al., 2011). Furthermore, it seems that these Rab5 GEFs also interact with several receptors via diverse mechanisms (Barbieri et al., 2003; Deininger et al., 2008; Penengo et al., 2006; Su et al., 2007; Tall et al., 2001). The GTPase activating proteins (GAPs) convert Rab5 to its GDP-bound form. Two well-characterized Rab5 GAPs are RabGAP-5 and RN-tre. The deletion of RabGAP-5 or RN-tre increase the level of active Rab5 in vitro (Haas et al., 2005; Palamidessi et al., 2013).

One of the best-characterized Rab5 GEFs is RIN1 (Ras interference 1), a multifunctional protein composed of several functional domains, including an SRC homology 2 (SH2) domain, a proline-rich (PR) domain, a vacuolar protein sorting 9 (VPS9) domain, and a Ras association (RA) domain (Balaji et al., 2014). Previous work suggested that RIN1 is an exchange factor for the small GTPase Rab5, whose overexpression stimulates IR-mediated endocytosis. And it has shown that deletion of the RIN1 N-terminal, which contains the $\mathrm{SH} 2$ domain and PR domain of RIN1, blocked the insulin stimulated receptor-mediated endocytosis (Hunker, Giambini, et al., 2006). Specific residues, such as RIN1:D537A and RIN1:Y561F on the RIN1-VPS9 domain are critical for Rab5 activation, whereas RIN1-R94A on the RIN1-SH2 domain is crucial for the interaction between EGFR 
and RIN1 upon EGF stimulation (Barbieri et al., 2003; Galvis, Balmaceda, et al., 2009; Galvis, Giambini, et al., 2009). Thus, relationship of key residues required for optimal RIN1 functionality is critical in order to understand the connection between receptor signaling and trafficking.

The Rabex- 5 protein structure is identified to be made up of an N-terminal domain, a membrane binding domain, a helical bundle (HB) domain, a VPS9 domain, a coiled-coil (CC) domain, and a PR domain (Shin et al., 2012). Besides the well-studied VPS9 domain to interact and activate Rab5, the HB domain has been found to play a role in the association with early endosomes and activating Rab5 in vivo (Zhu et al., 2007). The GEF activity of Rabex-5 is initially autoinhibited by its CC domain, which binds weakly to the substrate-binding site of the VPS9 domain (Zhang et al., 2014). When the Rabex-5 activates Rab5 and recruits Rabaptin-5 (a Rab5 effector), Rabaptin-5 will in turn bind to the GTP-bound Rab5 and recruits Rabex-5 in a positive loop. The binding with Rabaptin- 5 displaces the CC domain of Rabex-5 thus exposes a larger substrate-binding site for Rab5, causing the release of the GEF activity (Zhang et al., 2014). The autoinhibition of Rabex- 5 explains why in comparison to other well-characterized small GTPases and their corresponded GEFs, Rabex-5 exhibits a relatively lower affinity to Rab5 (Esters et al., 2001). The autoinhibition also gives a clue to why the GTP exchange activity of Rabex-5 is much higher when in the Rabex-5-Rabaptin5 complex (Delprato et al., 2004). Besides, the VPS9 domain of Rabex-5 alone also shows a higher GTP exchange activity than the full-length Rabex-5 (Delprato et al., 2004). Thus, Rabex-5 is involved in early endosome fusion as a Rab5 activator with 
regulated activity. Thus, the GTP exchange activity of Rabex-5 is much higher when in the Rabex-5-Rabaptin5 complex (Delprato et al., 2004). A study has shown that the Ras ubiquitination been mediated by Rabex- 5 promoted Ras endosomal localization and led to the suppression of Erk activation (Xu et al., 2010). Interestingly, the VPS9 domain of Rabex-5 alone shows a higher GTP exchange activity than the full-length Rabex-5 (Delprato et al., 2004).

In the processes of vesicle formation and delivery, Rab5 is also regulated by multiple Rab5 effectors. As one of the best studied Rab proteins to date, Rab5 has been found to interacts with as many as 30 different effector proteins (Pfeffer, 2005). For instance, a novel Rab5 effector, VPS34, is classified as the Class III enzyme of the phosphoinositide 3 kinase (PI3K) family and only uses phosphatidylinositol as substrate to generate phosphoinositide (PI) at the 3position of the inositol ring, which is named the phosphatidylinositol 3-phosphate (PI3P) (Backer, 2008). Since PI3P is required for the recruitment of EEA1 and Rabenosyn-5 to the active form of Rab5, VPS34 plays a positive role in early endosome fusion and the endocytosis process (Siddhanta et al., 1998) (Christoforidis, Miaczynska, et al., 1999). EEA1, an important Rab5 effector that binds to Rab5-GTP form, is the only effector that is necessarily required by minimal fusion and mediates endosome docking (Christoforidis, McBride, et al., 1999). Though Rabenosyn-5 is also recruited to the early endosome in a PI3P-dependent manner, it does not bind to GTP-bound Rab5 directly but is required for fusion of the plasma membrane-derived CCVs with early endosomes, as well as for homotypical early endosome fusion (Nielsen et al., 2000). Another Rab5 effector, 
Rabaptin-5, was initially identified as an GTP-bound Rab5 effector through a yeast 2-hybrid screen (Stenmark et al., 1995). Rabaptin-5 is mostly found as a complex with Rabex-5 in the cell (Horiuchi et al., 1997). Rabex-5 and Rabaptin-5 recruit each other in a positive loop upon Rab5 activation and thus keep the membrane Rab5-postive until the loop is interrupted by other recruited compartments (Kalin et al., 2015). Deletion of the Rab5-binding domain of Rabaptin-5 results in giant endosomes as well as impaired endocytosis process (Kalin et al., 2015).

In this project, I examined the effect of Rab5 GEFs (e.g., Rabex-5 and RIN1), Rab5 GAPs (e.g., RN-tre), and Rab5 effector (e.g., VPS34) on adipogenesis. In addition, I also elucidated the determinant residues and domains of RIN1 during adipogenesis process. Based on the determined specific residues and domains of RIN1 that are required for signal transduction during adipogenesis, and the in silico docking analysis between the IR and RIN1, a model of RIN1 function on the insulin signaling pathway during adipogenesis is proposed.

\section{III.2 Specific aims and research design}

III.2.1 Specific aim 2: To determine the effect of Rab5 regulators on adipogenesis.

Rab5 effectors denote a set of proteins that interact with the GTP-bonded Rab5. Each effector mediates a feature of Rab5 function and thus affects different aspects of downstream signaling. For example, Rabaptin-5 is involved in membrane fusion, it interacts with GTP-bonded Rab5 and stabilizes Rab5 in its active form. VPS34 generates PI3P, which is required for the recruitment of EEA1 
and Rabenosyn- 5 to the active form of Rab5. These recruitments allow both EEA1 and Rabenosyn-5 then take part in the molecular machinery of regulating endosome fusion. The function of Rab5 dramatically depends on the recruitment of different effectors to clear several downstream trafficking and signaling events.

One of the best-characterized Rab5 GEF is RIN1, which is required for the activation of Rab5 upon ligand stimulation in several cellular processes. The expression of RIN1:Wild-type, but not its depletion, affects the nucleotide status of Rab5. Preliminary results indicated that RIN1 interacted with the activated insulin receptor. Thus, I elucidated

2.a. whether the expression (or depletion) of Rab5 GAPs (RN-tre, RabGAP-5), Rab5 GEFs (RIN1, Rabex-5, and RAP6), or Rab5 effector (VPS34) affected adipogenesis.

2.b. the domains of Rab5 regulators required for adipogenesis.

2.c. the specific effect of the expression of RIN1 and its mutants on adipogenesis.

2.d. the key residues on RIN1 and the insulin receptor in the IR - RIN1 interaction. 2.e. a 3-dimensional model of the interaction between the VPS9-HB domain of RIN1 and the IR cytoplasmic tail.

\section{III.2.2 Research design 2}

Cell lysates of the 3T3-L1 cells that have been transfected with GFP, RIN1, Rabex-5, RAP6, RabGAP-5, and RN-tre were incubated with GST-labeled EEA1. The bonded proteins were eluted and be used for immunoprecipitation analysis. 
Then the cDNA of RIN1:WT and RIN1 mutants were cloned into the pMXpuro vector at EcoRI and Notl restriction sites and plasmid DNA were purified via the plasmid purification assay. The purified DNA was then transfected into the PlatA cells using Lipofectamine $® 2000$. After 48 hours, virus suspension from the PlatA cells were applied to the 3T3-L1 mouse pre-adipocyte cell line for the expression of RIN1 or RIN1 mutants. The transfected cells were then selected with puromycin, and used for several biological assays, including cell cycle testing, lipid accumulation testing (ORO assay, only for differentiated cells) or western blotting.

The RIN1:WT, RIN1:VPS9, RIN1 mutants and RIN1:VPS9 mutants were cloned into the pB42AD vector at the EcoRI and Xhol restriction sites. The insulin receptor tail (IR- $\beta)$ and the catalytic defective mutant of the insulin receptor were cloned into the pLex-A vector at the $\mathrm{EcoRI}$ and BamHI restriction sites. All plasmids were purified and transfected into the yeast EGY48 stain. One pLex-A plasmid was combined with one pB42AD plasmid and co-transfected into the yeast cells. The co-transfected yeast was used for yeast $\beta$-Galactosidase Assay to test the intensity of protein-protein interaction. At last, the data were input into the software, i.e., the SWISS MODEL serve and the PyMOL, to build the 3-dimensional structural model of the interaction between the RIN1:VPS9 and the IR-tail. 


\section{III.3 Materials and Methods}

Methods that have been described in the previous chapter are not shown in this section.

\section{III.3.1 Materials}

The 3T3-L1 pre-adipocyte cell line was obtained from the Zen-Bio, Inc. (NC, USA). The Platinum A (Plat-A) retroviral packaging cell line and the pMX-puro retroviral vector were purchased from Cell Biolabs, Inc. (San Diego, CA, USA). The yeast Saccharomyces cerevisiae strain EGY48 was obtained from American Type Culture Collection (ATCC, Manassas, CA, USA). The pLex-A and pB42AD control vectors were purchased from Addgene (Cambridge, MA, USA). Yeast minimal SD Agar base, yeast minimal SD base, yeast dropout supplements were purchased from Takara Bio, Inc. (Mounting View, CA, USA). Primary antibodies, including the Akt1, p-Akt (Ser473), PPARy, C/EBPa, Erk1/2, p-Erk1/2, FABP4, FAS, ACC, GAPDH, and Rab5, and secondary antibodies, including the antiRabbit IgG AND anti-Mouse IgG, were purchased from the Cell Signaling Technology (Boston, MA, USA). Fetal bovine serum (FBS) was purchased from the RMBIO, Inc. (Missoula, MT, USA). Other reagents and supplies, if not specifically described, were purchased from Thermo Fisher Scientific (Weston, FL, USA). 


\section{III.3.2 cDNA Construction.}

Complementary DNAs (cDNA) of green fluorescent protein (GFP), GFPRab5:wild-type (GFP-Rab5:WT), and RIN1:WT were cloned into the pMX-puro vector at the EcoRI and Notl restriction sites (Onishi et al., 1998). cDNA of IR $\beta$ subunit intracellular tail (IR- $\beta$ ) was cloned into the pLex-A vector at the EcoRI and BamHI restriction sites. cDNA of RIN1:WT and the C-terminal of RIN1 containing both the VPS9 and RA domains (R3:WT) were cloned into the pB42AD vector at the EcoRI and Xhol sites. RIN1-SH2 mutants (RIN1:W69F, RIN1:A76F, RIN1:R94A, RIN1:H120F, RIN1:121F, RIN1:Y148F) conjugated the pB42AD vector were purchased from GenScript, Inc. (Piscataway, NJ, USA). IR-kinase dead (IR:KD, IR:K1030A) and IR- $\beta$ mutants (IR:Y972F, IR:Y1158F, IR:Y1328F, and IR:Y1334F) on the pLex-A vector, RIN1-SH2 mutants and RIN1-VPS9 mutants (RIN1:Y537F, RIN1:Y561F, RIN1:T580A) on the pMX-puro vector, and R3 mutants (R3:Y506F, R3:Y523F, R3:Y537F, R3:P541A, R3:Y561F, R3:Y572F, R3:Y577F, R3:Y578F, R3:T580A, R3Y:Y629F) on the pB42AD vector were made via the $Q 5^{\circledR}$ Site-Directed Mutagenesis Kit purchased from New England Biolabs, Inc. (NEB, Ipswich, MA, USA).

\section{III.3.3 siRNA sequences and transfection.}

RNA interference (RNAi) directed against:

mouse RIN1 [5'-UUAUACAUUUGCUUCACACCUAAGC-3'],

mouse Rabex-5 [5'-UUUAUAGAGACGCGUCAUGAUGUGC-3'], mouse RAP6 [5'-AAGAATCGATTACCTATAGCA-3'], 
mouse Rn-tre [5'-TAGACAGTATAATCACGCA-3'],

or mouse RabGAP-5 [5'-GGACGACTCTGTGACAGAAGGAGTA-3'] and [5' GAACATCAAGCAAACAGAGCTGGTA-3'] were designed and synthesized by Ambion (Austin, TX). A scrambled siRNA sequence was designed as a control [5'CACCUAAUCCGUgGUUCAA-3']. Prior to siRNA sequence transfection, cells were plated in growth medium without antibiotics at $70-80 \%$ confluence. siRNA sequence (20 nM final concentration) transfection was performed using Lipofectamine-2000 as specified by Invitrogen (Invitrogen, Carlsbad, CA). After transfection, cells were used for the indicated assay (e.g., for immunoblotting, diffenrentiation or pull-down assays).

\section{III.3.4 Cell counting assay.}

The 3T3-L1 pre-adipocytes under different treatment (e.g., with or without treatment of the differentiation media) and at different time points during differentiation (e.g., $0 \mathrm{~h}$ time point before the treatment of differentiation media, 15 minutes/24 hours/48 hours time points after the treatment of differentiation media) were detached by trypsin and diluted with DMEM. $100 \mu \mathrm{l}$ of the cell suspension will be mixed with $100 \mu \mathrm{l}$ of the Trypan Blue solution. $10 \mu \mathrm{l}$ of the mixture was applied to a hemocytometer or a TC20 ${ }^{\mathrm{TM}}$ Automated Cell Counter (Bio-Rad, Inc.) to be counted. 


\section{III.3.5 Yeast 2 hybrid system.}

\section{III.3.5.1 Yeast transformation}

Protein-protein interactions were tested and analyzed by the yeast 2-hybrid system $(\mathrm{Y} 2 \mathrm{H})$. The generation of cDNA-containing vectors were described above. These pvectors were transformed into the yeast stain EGY48 containing a pSH1834 reporter vector. A cDNA-containing pB42AD vector and a cDNA-containing pLexA vector were co-transformed into yeast cells by the Yeast Transformation Kit. Transformed yeast cells were selected by SD agar plates that lack leucine (for selection of pSH18-34), histidine (for selection of pLexA), tryptophan (for selection of pB42AD) and uracil (for selection of yeast stain EGY48).

\section{III.3.3.2 Yeast $\beta$-galactosidase Assay}

The protein-protein interaction was quantified by the Yeast $\beta$-galactosidase ( $\beta$-gal) Assay. Yeast cells were collected in the log phase followed by three freezethaw cycles and lyased in $70 \mu \mathrm{l}$ of Y-PER buffer $(50 \mathrm{mM}$ Tris- $\mathrm{HCl}, \mathrm{pH} 8 ; 50 \mathrm{mM}$ $\left.\mathrm{NaCl} ; 5 \mathrm{mM} \mathrm{MgCl} 2 \cdot 6 \mathrm{H}_{2} \mathrm{O} ; 5 \mathrm{mM} \mathrm{DTT}\right)$. The $\beta$-gal reaction was triggered by adding $70 \mu \mathrm{l}$ of $2^{*} \beta$-gal buffer. Then samples were incubated in $37^{\circ} \mathrm{C}$ until an obvious yellow color showed up. At last, $56 \mu$ of stop solution was added and samples were tested under $420 \mathrm{~nm}$ wavelength. The $\beta$-gal activity can be calculated by the formula below:

$\beta-G a l$ activity $=\frac{1000 * O D_{420}}{t * V * O D_{660}}(\mathrm{t}=$ total incubation time, $\mathrm{V}=0.196 \mathrm{ml})$ 


\section{III.3.6 In silico Studies}

The homology model of the VPS9 domain with N-terminal helical bundle of RIN1 was built by the SWISS-MODEL (Arnold et al., 2006) using the crystal structure of the VPS9 domain of Rabex-5 (Pdb Id:1TXU) as a template (Delprato et al., 2004). The model was built from residue M350 to L612 of RIN1. The sequence identity between the VPS9 domain of RIN1 and Rabex-5 is $30.0 \%$. The coordinate of Rab5 (1R2Q) was taken from the protein data bank (Terzyan et al., 2003; Zhang et al., 2014). The RIN1:VPS9-Rab5 complex was built using the crystal structure of the complex of Rab5 and Rabex-5 (Pdb Id: 4Q9U) (Zhang et al., 2014). The RIN1:VPS9-Rab5 complex was minimized by using NAMED and VMD (Humphrey et al., 1996; Phillips et al., 2005). The whole RIN1 model was built by using RaptorX structure prediction server (Kallberg et al., 2012). The server used the SH2 domain of human carboxyl-terminal Src kinase (Pdb Id: 3EAC) (Liu \& Cowburn, 2016), Rabex-5 (Pdb Id: 2OT3) (Delprato \& Lambright, 2007) and the RA domain (Pdb Id: 4K81) (Qamra \& Hubbard, 2013) as templates. The molecular model was drawn with PYMOL (Delano, 2001).

\section{III.3.7 Statistical analysis}

All experiments presented were repeated a minimum of three times. Normal distributed data were represented in mean \pm standard deviation (Wilfling et al.). The difference between groups were determined by the Student t-test. Tests were considered statistically significant if $p$-value were less than 0.05 . 


\section{III.4 Results}

In chapter II, Rab5 has been established to play a detrimental role in the process of adipogenesis with a decreased GTP-bound Rab5 level. However, the total expression of Rab5 in the 3T3-L1 pre-adipocytes was not affected. The overexpression of the Rab5:Q79L mutant, which increased GTP-bound Rab5 level due to its low GTP hydrolysis rate, impaired the accumulation of cytosolic lipid droplets in the 3T3-L1 differentiated cells. Whereas the overexpression of Rab5:S34N, the GTP-binding defective mutant that maintained Rab5 in its inactive form, promoted the formation of lipid droplets in the differentiated 3T3-L1 cells. Besides, a gradient decrease of GTP-bound Rab5 was observed during the 3T3L1 cell differentiation process in a time-dependent manner. Thus, I questioned if the Rab5 GEFs, Rab5 GAPs, and Rab5 effectors participate in the regulation of Rab5 during the adipogenesis process.

\section{III.4.1 Rab5 GEFs were down-regulated during the differentiation of 3T3-}

\section{L1 pre-adipocytes}

In order to address whether the Rab5 GEFs participate in the differentiation of adipocytes, cell lysates collected from 3T3-L1 pre-adipocytes at before (day 1) and after (day 9) differentiation were prepared and utilized for immunoblotting, The expression of several Rab5 GEFs, such as RAP6 and Rabex-5, and Rab5 GAPs, such as RabGAP-5 and RN-tre, were analyzed. As described early, GAPDH served as the whole cell lysate loading control. PPAR $\gamma, \mathrm{C} / \mathrm{EBPa}$, acetyl-CoA 
carboxylase (ACC), fatty acid synthase (Kralisch \& Fasshauer), GLUT4, and IR were adipogenic markers indicating the extent of differentiation.

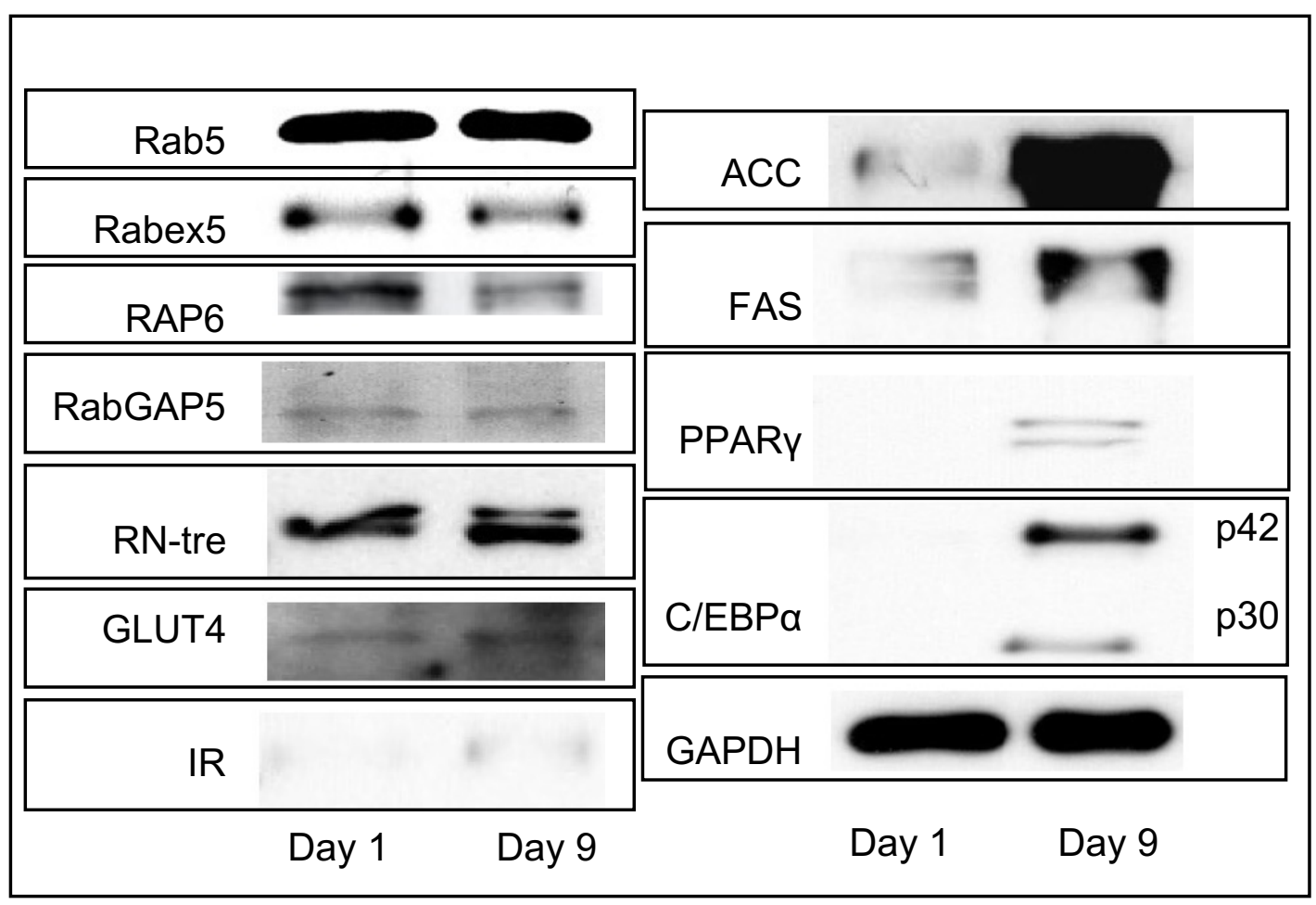

Figure 22. Representative Western blot of the content of Rab5 GEPs, Rab5 GAPs, typical adipogenic markers, and GAPDH.

3T3-L1 pre-adipocytes expressing GFP were lysed before (day1) and after (day9) of differentiation as described in Material and Methods.

In Figure 22, all adipogenic markers, including PPARy, C/EBPa, ACC, FAS, GLUT4, and IR exhibited an increased expression level at day 9 after differentiation in comparison with day 1 . The two Rab5 GEFs tested, Rabex-5 and RAP6, showed a decreased expression in mature adipocytes (day 9). However, the two Rab5 GAPs, RabGAP-5 and RN-tre, did not exhibit obvious changes between day 1 and day 9 during differentiation. The results suggest an essential 
role of Rab5 GEFs in the regulation of Rab5 nucleotide states during the differentiation process.

\section{III.4.2 The Rab5 GEFs downregulated the accumulation of lipids in the differentiated 3T3-L1 cells.}

In order to address the specific role of different Rab5 GEFs (e.g., RIN1, Rabex-5, and RAP6) and Rab5 GAPs (RN-tre and RabGAP-5) in the differentiation of 3T3-L1 cells, the individual overexpression of specific Rab5 GEFs/GAPs in 3T3L1 cells was accomplished via the pMX-puro retroviral vector system that has been described in the Materials and Methods. And to further explain the role of a specific Rab5 GEF/GAP in regulating the Rab5 nucleotide states, I lysed the 3T3-L1 cells overexpressing RIN1, Rabex-5, RAP6, RN-tre, or RabGAP-5 before (day1) and after (day 9) differentiation. The cell lysates were incubated with GST-EEA1 (glutathione-S-transferase-EEA1) followed by GTP-Rab5 pull-down assay, and the pull-downs were subjected to immunoblotting analysis to determine the ratio of GTP-Rab5 (G-Rab5) to total Rab5 (T-Rab5). Besides, siRNA targeting specific Rab5 GFF and Rab5 GAP, as well as scrambled siRNA as control, were designed and induced into the 3T3-L1 cells to selectively silence a particular Rab5 GEF/GAP. At last, 3T3-L1 cells overexpressing GFP or a specific Rab5 GEF/Rab5 GAP, and 3T3-L1 cells induced with scrambled siRNA or Rab5 GEF/GAP siRNA, were stained with ORO followed by quantification of lipid content.

In Figure 23, I show that the overexpression of RabGAP-5 affected the differentiation of 3T3-L1 pre-adipocytes as evidenced by the increase in the 
accumulation of cytosolic lipids. This increase in the accumulation of lipid droplets was consistent with the decreased Rab5-GTP level in cells overexpressing RabGAP-5 as compared with the GFP cells (Figure 23). Specifically, I also observed statistically significant inhibition of the Rab5-GTP level in cell lines expressing RabGAP-5 at both day 1 and 9 as compared with GFP-control cells. Similarly, the overexpression of RN-tre increased adipogenesis (Figure 23). More importantly, RabGAP-5 (137 $\pm 4 \%)$ is more active than RN-tre $(121 \pm 4 \%)$ during the differentiation process (compare Figure 23.A with Figure 24.A) as well as in the levels of GTP-bound Rab5 (compare Figure 23.C with Figure 24.C). Moreover, the Rab5-GTP level was dramatically reduced in cells expressing Rab5 GAPs, and no further reduction of the Rab5-GTP level was observed at day 9 of differentiation (Figure 23.C and Figure 24.C). To further uncover the role of Rab5 GAPs in the differentiation of 3T3-L1 pre-adipocytes, I utilized specific siRNA to induce the deletion of specific Rab5 GAP in the 3T3-L1 pre-adipocytes. Individual removal of Rab5 GAPs produced a significant inhibition on the accumulation of lipids (Figure 23.B and Figure 24.B). These observations suggest that the decrease of the GTPbound Rab5 induced by the two Rab5 GAPs has a positive effect on the differentiation of 3T3-L1 pre-adipocytes. 

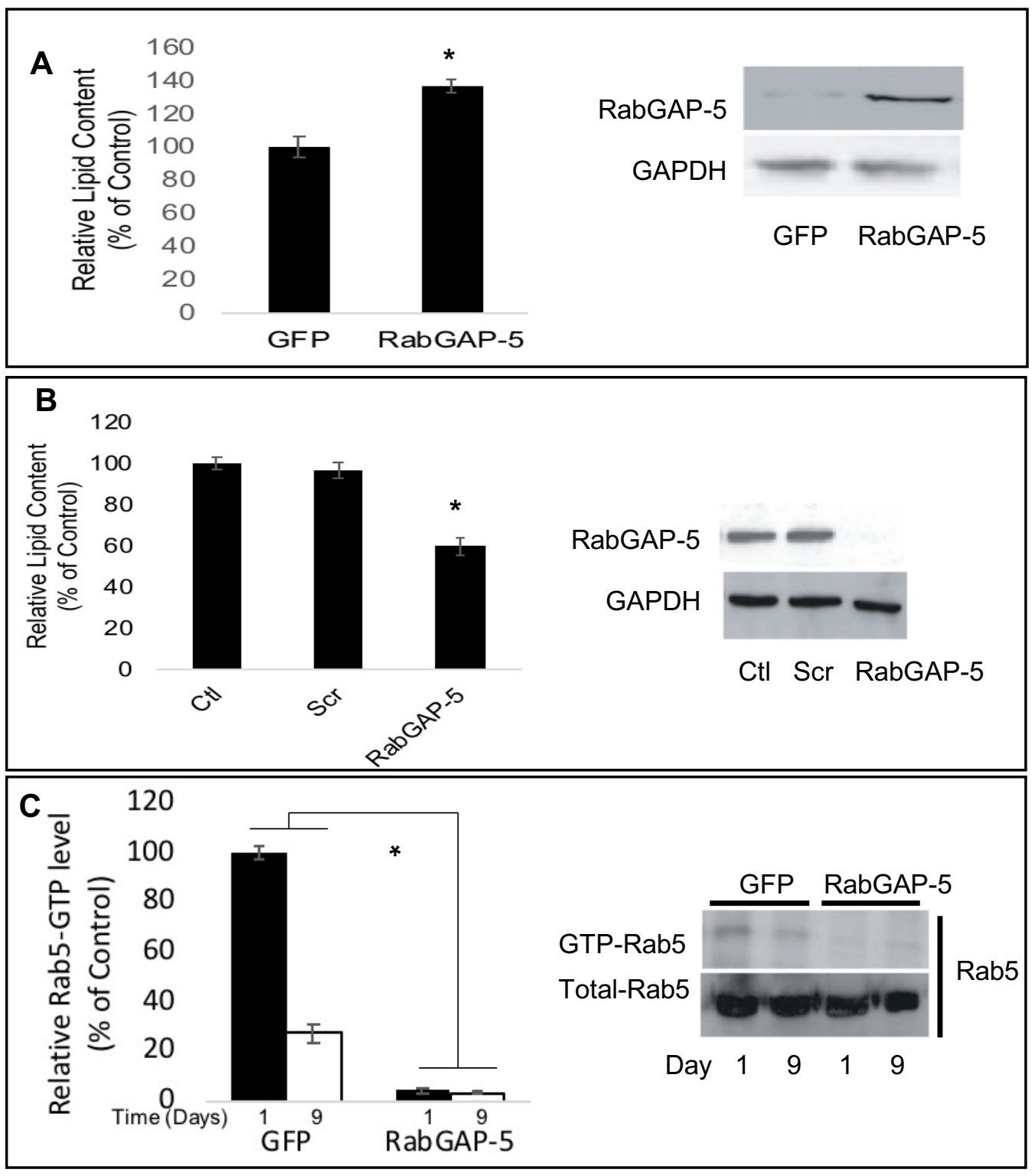

Figure 23. Selective effect of RabGAP-5 on the differentiation of 3T3-L1 preadipocytes.

Data represent the mean \pm S.E.M. of three independent experiments. A. 3T3-L1 cells expressing GFP and RabGAP-5 were differentiated. The accumulation of lipid droplets quantified via ORO assay and were represented as relative lipid contents. Inset: Representative Western blot of content of RabGAP-5 and GAPDH proteins. B. Non-transfected cells (Ctl), and cells transfected with scramble RNAi (Scr) or RNAi against RabGAP-5 were differentiated as described. Results were represented as relative lipid contents. Inset: Representative Western blot of content of RabGAP-5, RIN1 and GAPDH proteins. C. Cell lysates of 3T3-L1 preadipocytes expressing GFP and RabGAP-5 were prepared at specific day (Day 1 and Day 9) of the differentiation, and the endogenous GTP-bound Rab5 was analyzed by immunoblotting as indicated in the figure. 

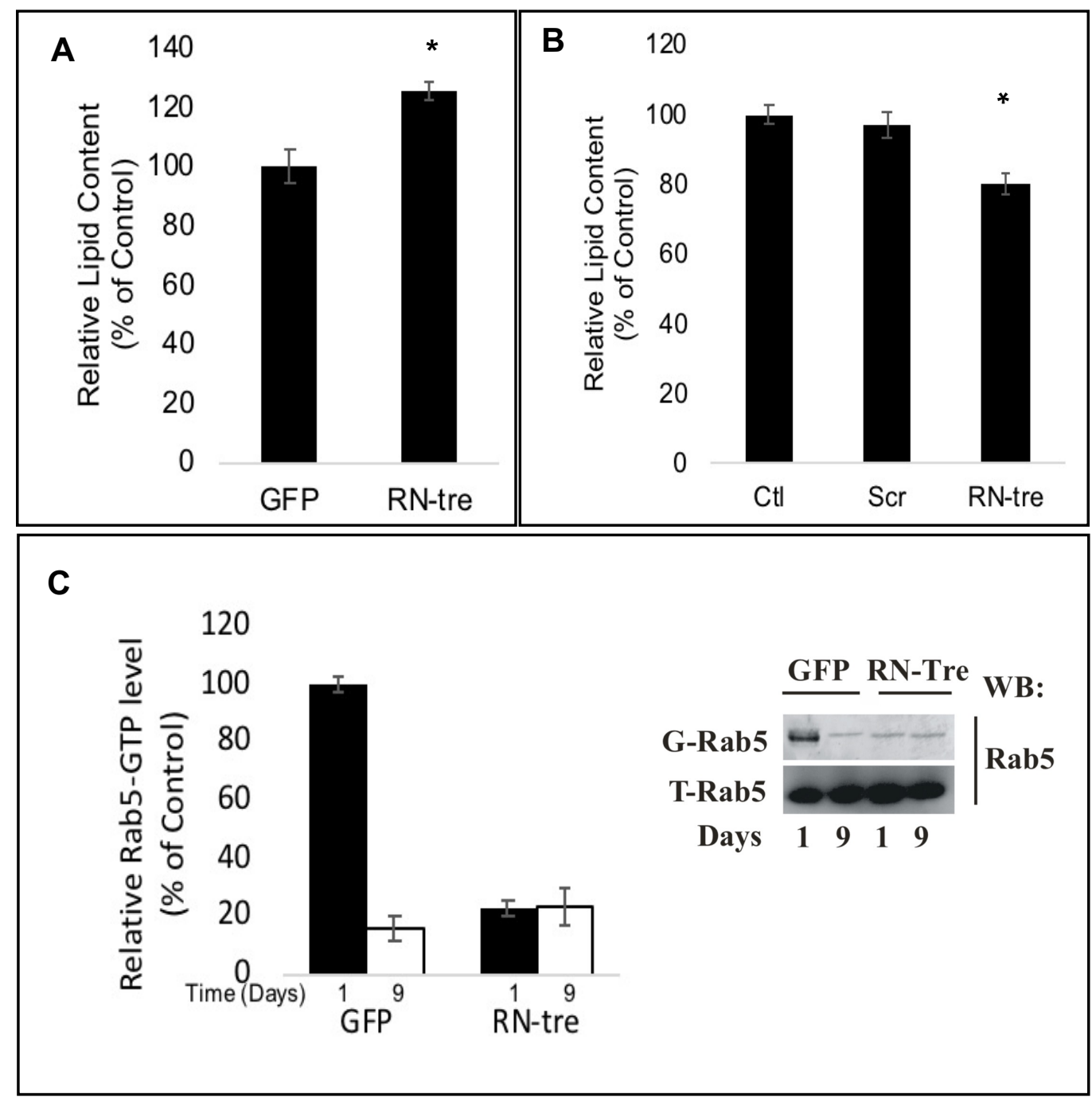

Figure 24. Selective effect of RN-tre on the differentiation of 3T3-L1 preadipocytes.

Data represent the mean \pm S.E.M. of three independent experiments. A. 3T3-L1 pre-adipocytes expressing GFP and RN-tre were differentiated. The accumulation of lipid droplets quantified via ORO assay and were represented as relative lipid contents. Inset: Representative Western blot of content of RN-tre and GAPDH proteins. B. Non-transfected cells (Ctl), and cells transfected with scramble RNAi (Scr) or RNAi against RN-tre were differentiated as described. Results were represented as relative lipid contents. C. Cell lysates of 3T3-L1 pre-adipocytes expressing GFP and RN-tre were prepared at specific day (Day 1 and Day 9) of the differentiation, and the endogenous GTP-bound Rab5 was analyzed by immunoblotting as indicated in the figure. 
To gain more information about the regulation of Rab5 cycle during adipogenesis, I analyzed the effect of the expression of Rab5 GEFs (RIN1, Rabex6, and RAP6) on the differentiation of 3T3-L1 pre-adipocytes (Figure 25 27). In Figure 25, the overexpression of RIN1 blocked the accumulation of lipids. Consistent with this observation, the overexpression of RIN1 increased the Rab5GTP level as compared with GFP-control pre-adipocytes at day 1 and 9 of differentiation (Figure 25.C). Interestingly, a decrease of the level of Rab5-GTP was observed in RIN1-overexpressed cells at day 9 as compared with day 1 of differentiation, but this reduction in the Rab5-GTP level was less significant as compared with the GFP-control cells (e.g., Rab5-GTP level in GFP-control exhibited a reduction of $75 \%$ whereas reduced by only $50 \%$ in the RIN1overexpressed cells) (Figure 25.C).

The effect of the overexpression of Rabex- 5 and RAP6 on the differentiation of 3T3-L1 pre-adipocytes were also examined (results are shown in Figure 26 and Figure 27). In Figure 26.A and Figure 27.A, similar to the effect of RIN1overexpression, the individual overexpression of Rabex-5 and RAP6 blocked the accumulation of ORO by $63 \pm 7 \%$ and $56 \pm 4 \%$, respectively. Consistent with these results, I observed that the individual overexpression of wither Rabex-5 or RAP6 statistically significant increased the Rab5-GTP level as compared with GFPcontrol pre-adipocytes at day 1 and 9 (Figure 26.C and Figure 27.C). Furthermore, a statistically significant decrease in the level of Rab5-GTP was also observed in the GFP-overexpressing cells when day 9 was compared with day 1 (a $\sim 75 \%$ reduction can be observed). A decrease of the level of Rab5-GTP can also be 
detected in Rabex-5- and RAP6-overexpressing cell lines at day 9 as compared with day 1 of the differentiation process. But this reduction between day 9 and day 1 in the Rab5-GTP level was less significant as compared with GFP-control cells (e.g., Rabex-5-cells showed a $\sim 70 \%$ decrease whereas the RAP6-cells showed a $\sim 50 \%$ decrease) (Figure 26.C and Figure 27.C).

Then the depletion effect of these Rab5 GEFs was examined by inducing specific siRNA on the 3T3-L1 pre-adipocytes during the differentiation process. The down-regulation of each one of the Rab5 GEFs was accompanied by an increase of the accumulation of ORO as compared with control siRNA-induced cells. Specifically, cells overexpressing RIN1 promoted the lipid formation by $26 \%$, Rabex- 5 increased lipids accumulation by 20 , while the overexpression of RAP6 increased lipids accumulation by 25 (Figure 26.A and Figure 27.A). 3T3-L1 preadipocytes differentiation process and also increased the levels of Rab5-GTP as compared with GFP-control cells (data not shown). Taken together, these data suggest that the overexpression or deletion of the specific Rab5 GFE (or the Rab5 GAPs) have essential effects on differentiation of 3T3-L1 pre-adipocytes. The affected differentiation process by these Rab5 GEFs/GAPs were because, at least partially, of their role in regulating the Rab5 nucleotide states. 


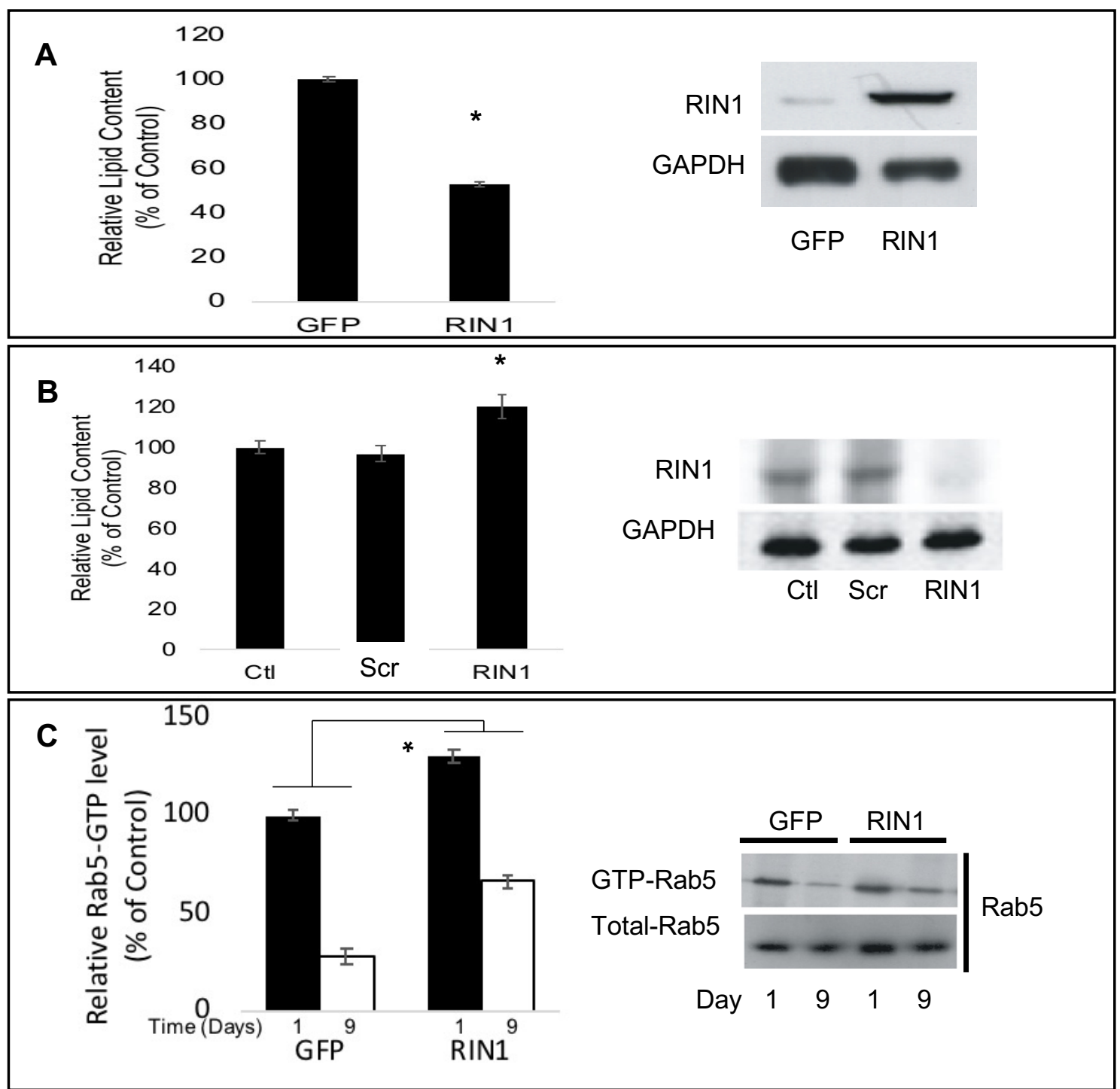

Figure 25. Selective effect of RIN1 on the differentiation of 3T3-L1 preadipocytes.

Data represent the mean \pm S.E.M. of three independent experiments. A. 3T3-L1 pre-adipocytes expressing GFP and RIN1 were differentiated. The accumulation of lipid droplets quantified via ORO assay and were represented as relative lipid contents. Inset: Representative Western blot of content of RIN1 and GAPDH proteins. B. Non-transfected cells (Ctl), and cells transfected with scramble RNAi (Scr) or RNAi against RabGAP-5 were differentiated as described. Results were represented as relative lipid contents. Inset: Representative Western blot of content of RIN1, RIN1 and GAPDH proteins. C. Cell lysates of 3T3-L1 preadipocytes expressing GFP and RIN1 were prepared at specific day (Day 1 and Day 9) of the differentiation, and the endogenous GTP-bound Rab5 was analyzed by immunoblotting as indicated in the figure. Inset: Representative immunoblots of samples probed with anti-Rab5 antibodies for total Rab5 (T-Rab5) and active Rab5 (G-Rab5) respectively. 


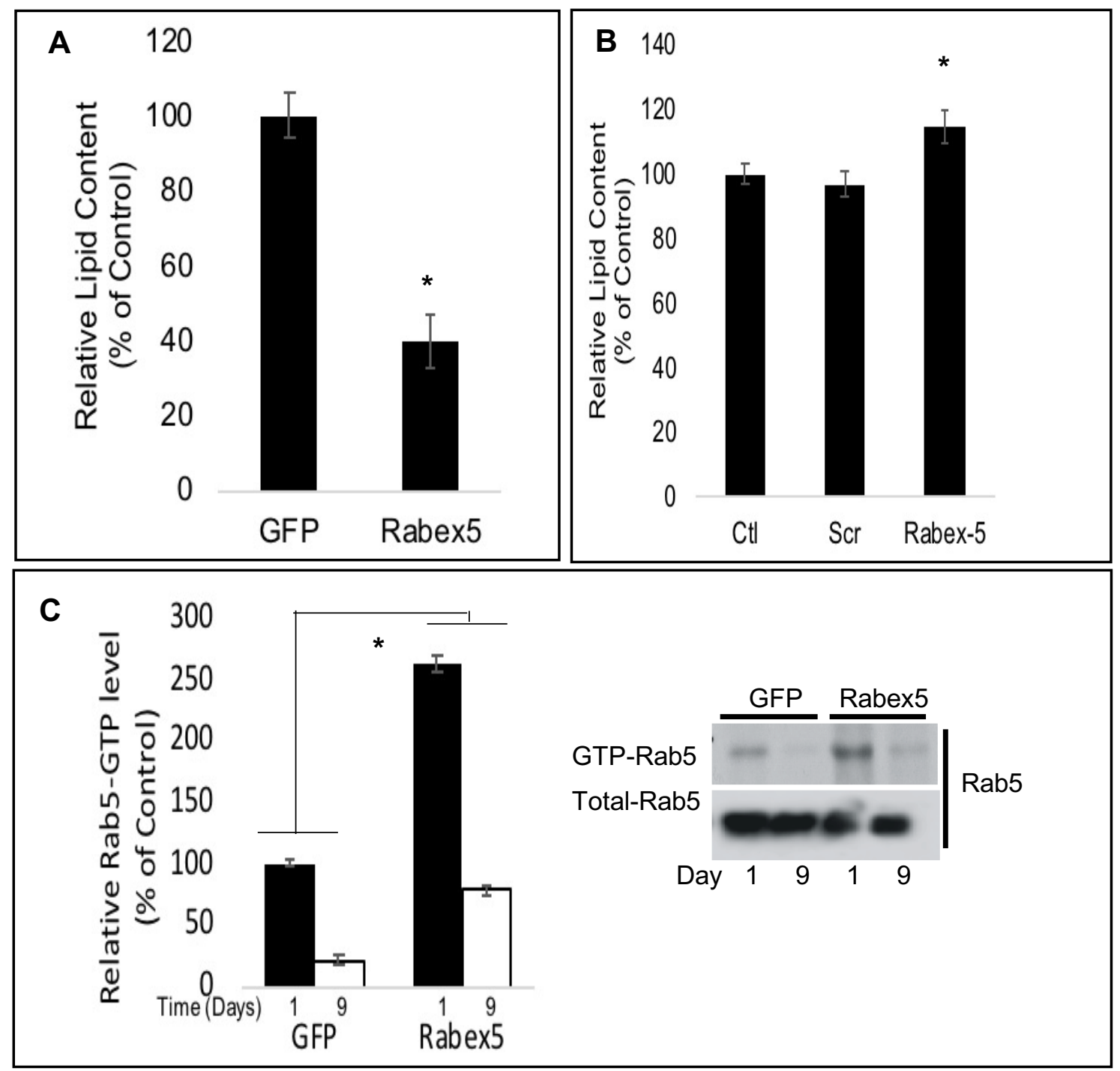

Figure 26. Selective effect of Rabex-5 on the differentiation of 3T3-L1 preadipocytes.

Data represent the mean \pm S.E.M. of three independent experiments. A. 3T3-L1 pre-adipocytes expressing GFP and Rabex-5 were differentiated. The accumulation of lipid droplets quantified via ORO assay and were represented as relative lipid contents. Inset: Representative Western blot of content of Rabex-5 and GAPDH proteins. B. Non-transfected cells (Ctl), and cells transfected with scramble RNAi (Scr) or RNAi against Rabex-5 were differentiated as described. Results were represented as relative lipid contents. C. Cell lysates of 3T3-L1 preadipocytes expressing GFP and Rabex- 5 were prepared at specific day (Day 1 and Day 9) of the differentiation, and the endogenous GTP-bound Rab5 was analyzed by immunoblotting as indicated in the figure. 


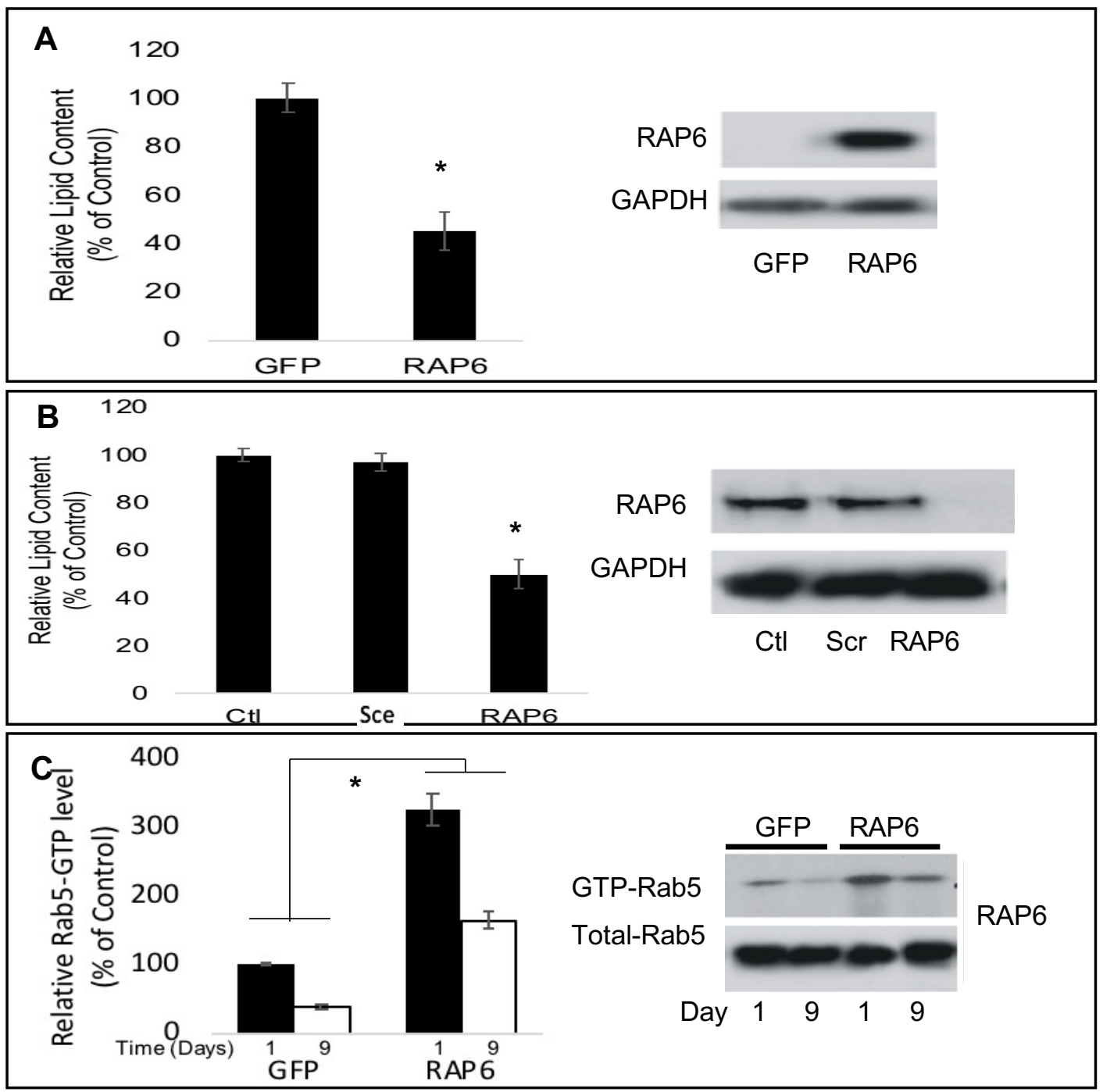

Figure 27. Selective effect of RAP6 on the differentiation of 3T3-L1 preadipocytes.

Data represent the mean \pm S.E.M. of three independent experiments. A. 3T3-L1 pre-adipocytes expressing GFP and RAP6 were differentiated. The accumulation of lipid droplets quantified via ORO assay and were represented as relative lipid contents. Inset: Representative Western blot of content of RAP6 and GAPDH proteins. B. Non-transfected cells (Ctl), and cells transfected with scramble RNAi (Scr) or RNAi against RAP6 were differentiated as described. Results were represented as relative lipid contents. Inset: Representative Western blot of content of RabGAP-5, RIN1 and GAPDH proteins. C. Cell lysates of 3T3-L1 preadipocytes expressing GFP and RAP6 were prepared at specific day (Day 1 and Day 9) of the differentiation, and the endogenous GTP-bound Rab5 was analyzed by immunoblotting as indicated in the figure. Inset: Representative immunoblots of samples probed with anti-Rab5 antibodies for total Rab5 (T-Rab5) and active Rab5 (G-Rab5) respectively. 


\section{III.4.3 Selective effect of RIN1 and its mutants on insulin signaling during pre-adipocyte differentiation}

\section{III.4.3.1 RIN1 overexpression inhibited adipogenesis in vitro}

Previous results showed that the adipogenic differentiation of Rab5overexpressed 3T3-L1 cells was promoted. Also, GTP-bound Rab5 were progressively down-regulated over the process of differentiation. In addition, in the previous section, I showed a regulatory role of Rab GEFs in the adipogenesis process. Here, to further examine the effect of RIN1 on the differentiation of 3T3L1 pre-adipocytes, I overexpressed RIN1:wild-type (RIN1:WT) in the 3T3-L1 cells and tested the effect of RIN1 overexpression on the adipogenic markers (results shown in Figure 28 and Figure 29).
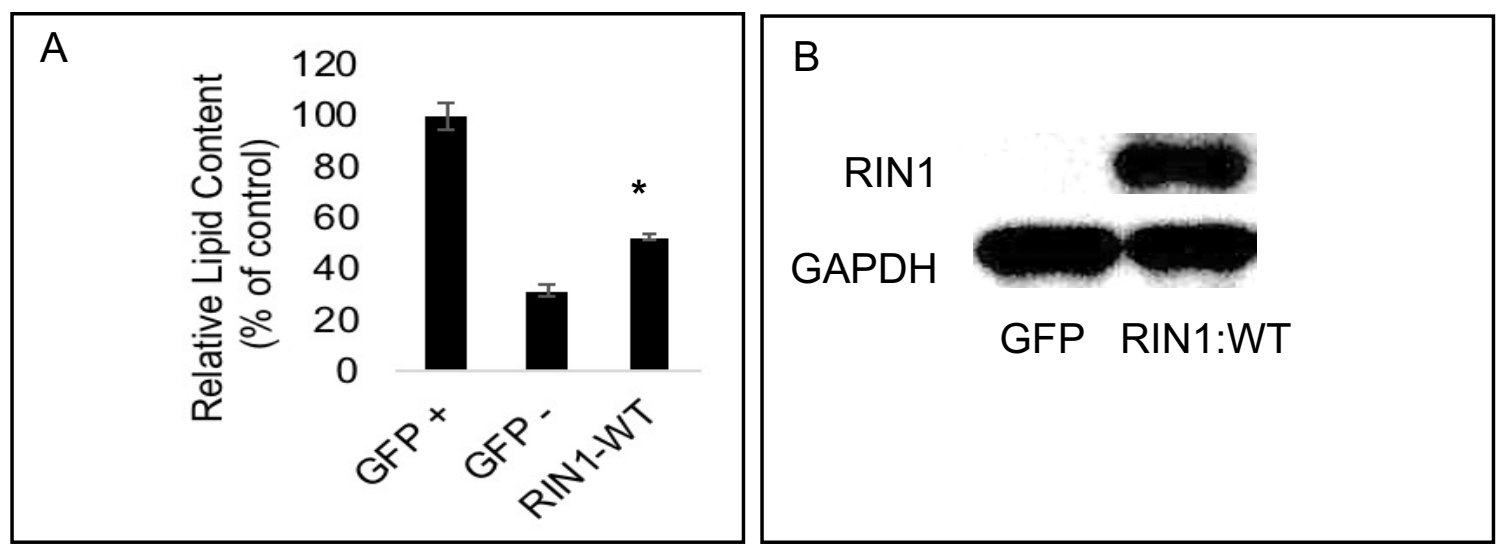

Figure 28. RIN1 effect on the differentiation of 3T3-L1 pre-adipocytes.

A. Relative lipid content of GFP ( $\mathrm{C}+/ \mathrm{C}$-, represent positive control and negative control, respectively) or RIN1:WT transfected 3T3-L1 cells. Cells that were not treated with hormone cocktail served as negative control. Data represent the mean \pm S.E.M. of three independent experiments. ${ }^{*} \mathrm{P}<0.001$ by Student's t-test compared to differentiated GFP-overexpressed cells. S.E.M. = Standard error of the mean.

B. Representative Western blot results of RIN1:WT and GFP overexpressed cells. 
I used the Plat-A cells to transfer the RIN1:WT or the GFP-containing retrovirus into 3T3-L1 pre-adipocytes. The transfected cells were treated with or without hormone cocktail as was described in Materials and Methods. Then the ORO staining and spectroscopy was used to quantify lipid accumulation in the cytosol (Figure 28). Then the expression of adipogenic transcription factors, PPARY and C/EBPa, and adipogenic markers, ACC, FABP4 and FAS in differentiated cells were tested to confirm the ORO results (Figure 29).

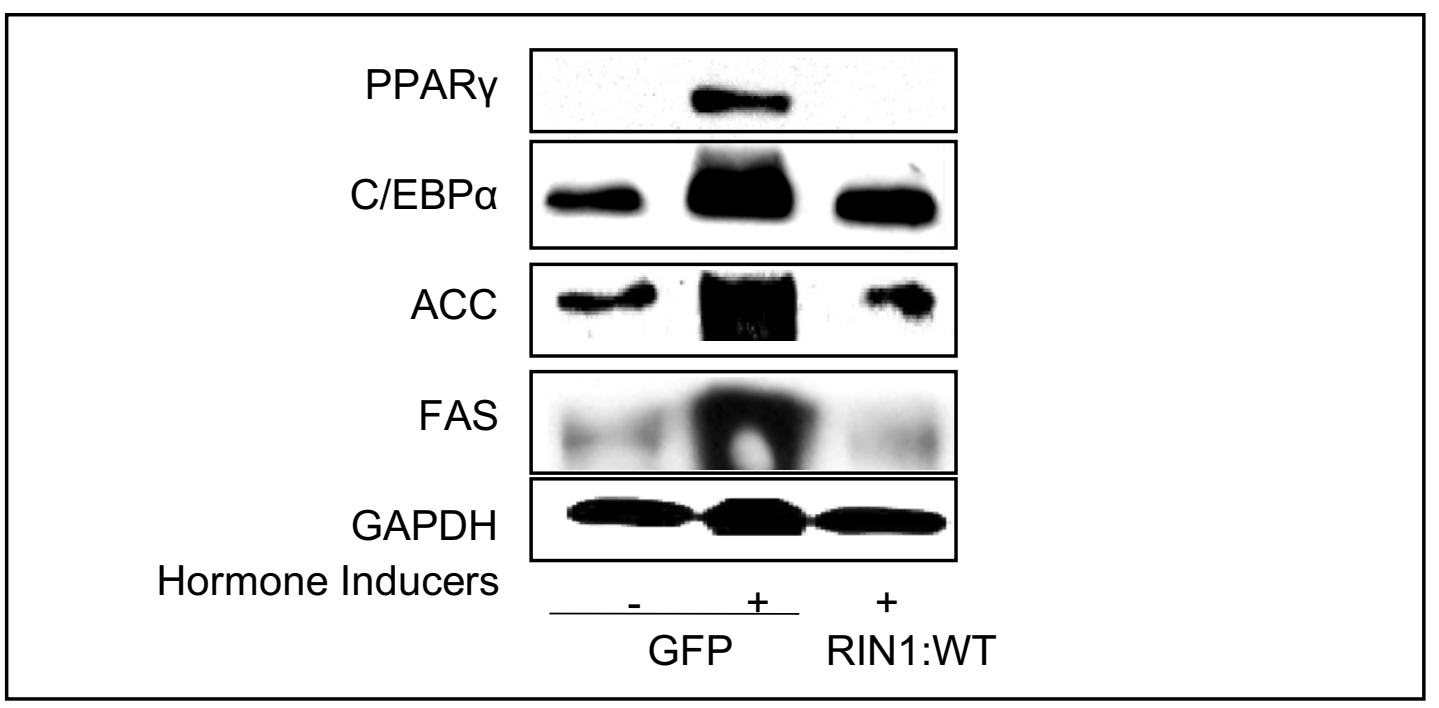

Figure 29. Effect of RIN1:WT on transcription factors.

3T3-L3 cells overexpressing GFP or RIN1:WT were differentiated with (positive control) or without hormone inducers.

In Figure 29, the expression level of PPARy, C/EBPa, ACC, and FAS in GFP- (cells were treated with or without hormone inducers, which represent the positive control and the negative control, respectively) and RIN1:WT- (cells were hormone treated) overexpressed 3T3-L1 cells were tested via Western blotting. The differentiated GFP-overexpressed cells showed a significantly higher 
expression of the two adipogenic transcription factors, PPARY and C/EBPa, and the two adipogenic markers, ACC and FAS. However, the differentiated RIN1:WToverexpressed cells showed a decreased expression of all tested proteins (Figure 29).

These results, showing that RIN1:WT played an inhibitory role in preadipocyte differentiation, lead me to further examine the mechanism by which RIN1 affects the adipogenesis process.

\section{III.4.3.2 Two RIN1 selective mutants rescued the inhibitory effects of RIN1 on adipogenesis}

RIN1 performs multiple functions in cell metabolism due to its availability of interacting with numerous proteins through different domains. Through its Src homology $2(\mathrm{SH} 2)$ domain, RIN1 interacts with several receptor tyrosine kinases, such as epidermal growth factor receptor (EGFR) and insulin receptor (IR) (Barbieri et al., 2003; Hunker et al., 2006b). Through its VPS9 domain, RIN1 can activate Rab5, a small GTPase that is essential in early endosome fusion process (Tall et al., 2001). Thus, I used two selective mutants, the RIN1:R94A and the RIN1:Y561, to examine the inhibitory role of RIN1 in adipogenesis process. The R94A mutation locates in the SH2 domain of RIN1 and leads a diminished interaction between RIN1 and the IR (Barbieri et al., 2003). The Y561F mutant, however, interferes with the activation of Rab5, resides in the VPS9 domain (Mustafi and Barbieri, 2016). 
Again, the ORO staining and spectroscopy assay and the western blot assay were used to quantify the lipid content and to qualify the maturity of differentiated adipocytes, respectively. Interestingly, the overexpression of either mutant could rescue the prohibited effects on adipogenesis caused by RIN1:WT overexpression. In Figure 30, the ORO results presented that the RIN-R94A and RIN1:Y561F mutant increased lipid content from $53 \%$ to $77 \%$ and $64 \%$, respectively in comparison to the RIN1:WT. The western blot analysis convinced the ORO results where the cells overexpressing either RIN1:R94A or RIN1:Y561F showed a higher expression of the adipogenic transcription factors, PPARY and C/EBPa, and two adipogenic markers, ACC and FAS (Figure 30).

Due to the fact that the function-declined RIN1 mutants, either in the SH2 domain or the VPS9 domain, could extricate adipogenesis of 3T3-L1 cells from obstructed effects of RIN1:WT, I suspected that both the $\mathrm{SH} 2$ domain and the VPS9 domain are necessary for RIN1 to complete its molecular function in adipogenesis process. As described above, the two mutants are from different domains of RIN1. Thus, the data here suggested that RIN1 affected the adipogenesis process through at least two cellular processes, the endosome pathway and the insulin signaling pathway. 

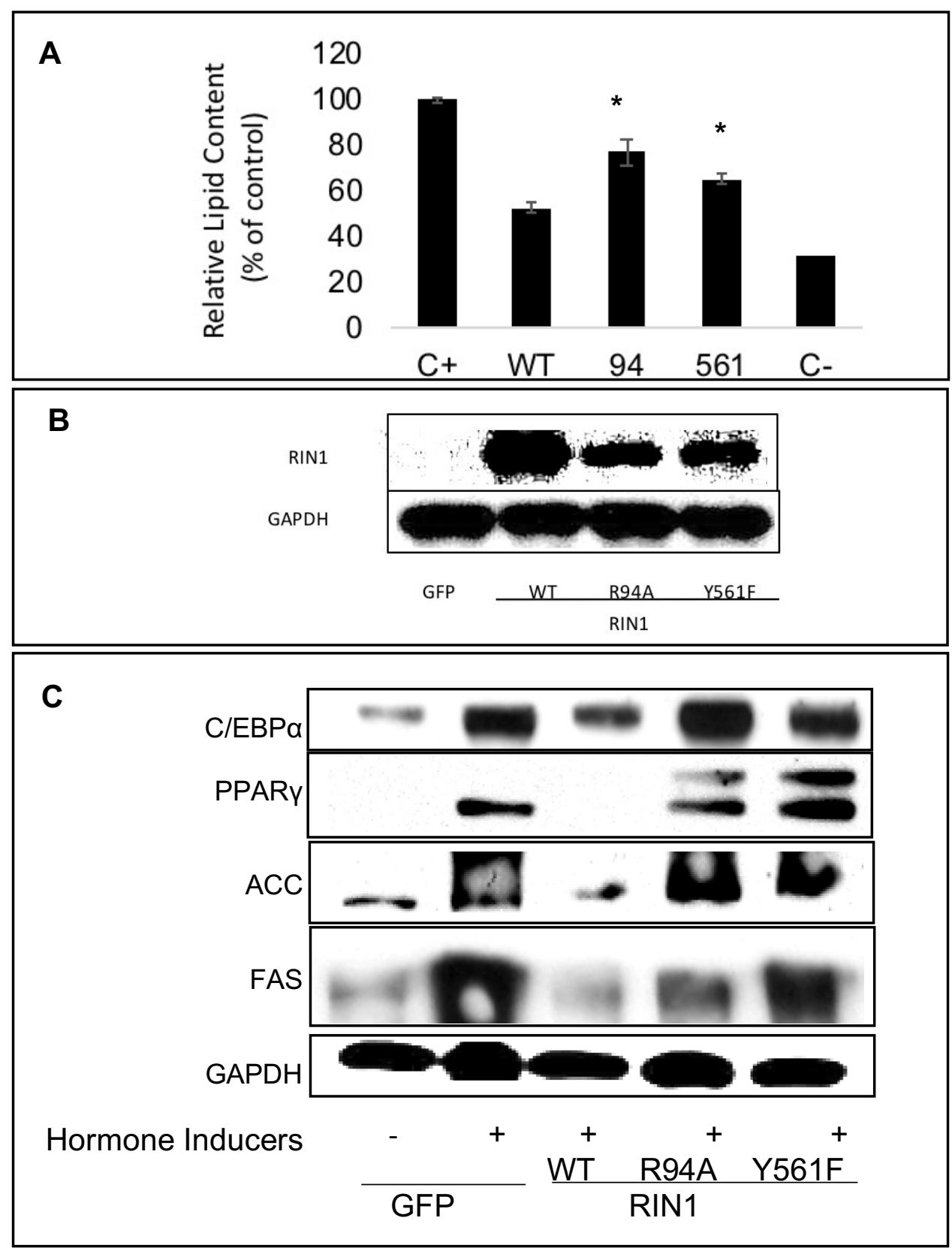

Figure 30. Effect of RIN1 selective mutants on adipogenesis.

A. Relative lipid content of GFP or RIN1:WT transfected 3T3-L1 cells. 3T3-L1 cells overexpressing GFP, RIN1:WT, and RIN1 mutants were treated with or without hormone cocktail as described in Materials and Methods. Cells that were not treated with hormone cocktail served as negative control (C-). (Data represent the mean \pm S.E.M. of three independent experiments. ${ }^{*} \mathrm{P}<0.01$ by Student's t-test compared to differentiated RIN1:WT-overexpressed cells). S.E.M. = Standard error of the mean. B. C. Western blot result of RIN1:WT, RIN1:R94A, RIN1:Y561F and GFP overexpressed cells. 


\section{III.4.3.3 RIN1 mutants recovered both Erk1/2 and Akt signaling in compare with RIN1-WT}

In the previous study, RIN1 showed co-localization with the IR on both cell membrane and endosomes upon insulin stimulation, and the expression of RIN1WT blocks the activation of both Erk1/2 and Akt signaling pathway in cancer cells in vitro (Hunker, Giambini, et al., 2006). Evidence also showed that both Akt and Erk1/2 signaling reached their maximal level at 15 minutes upon insulin stimulation in vitro (Zecchin et al., 2007). Because of the glaring effects of RIN1 and its mutants on the process of adipogenesis and the regulatory role of RIN1 in insulin signaling pathway, I examined the activation of Erk1/2 and Akt, two important proteins in the MAPK and PI3K signaling pathways, respectively, at 15 minutes after hormone treatment (Figure 31). The western blot analysis revealed that both the MAPK and the PI3K signaling pathways were activated upon a 15-minutes

hormone treatment in all cell lines (Figure 31). Both activated Akt and Erk1/2 appeared to be downregulated in the RIN1-WT overexpressed cells upon hormone treatment (Fig. 5A) However, the RIN1-R94A overexpressed cells attended to reach a significantly higher signal than the RIN1-WT overexpressed cells at 15 minutes after and even before hormone treatment (Figure 31). Simultaneously, the RIN1-Y561F overexpressed cells presented higher signal of activated Akt ( $p$-Akt) both before and 15 minutes after hormone treatment (Figure 31). The RIN-Y561F mutant increased the Erk1/2 signal before hormone treatment and slightly higher signal after hormone treatment (Figure 31). 


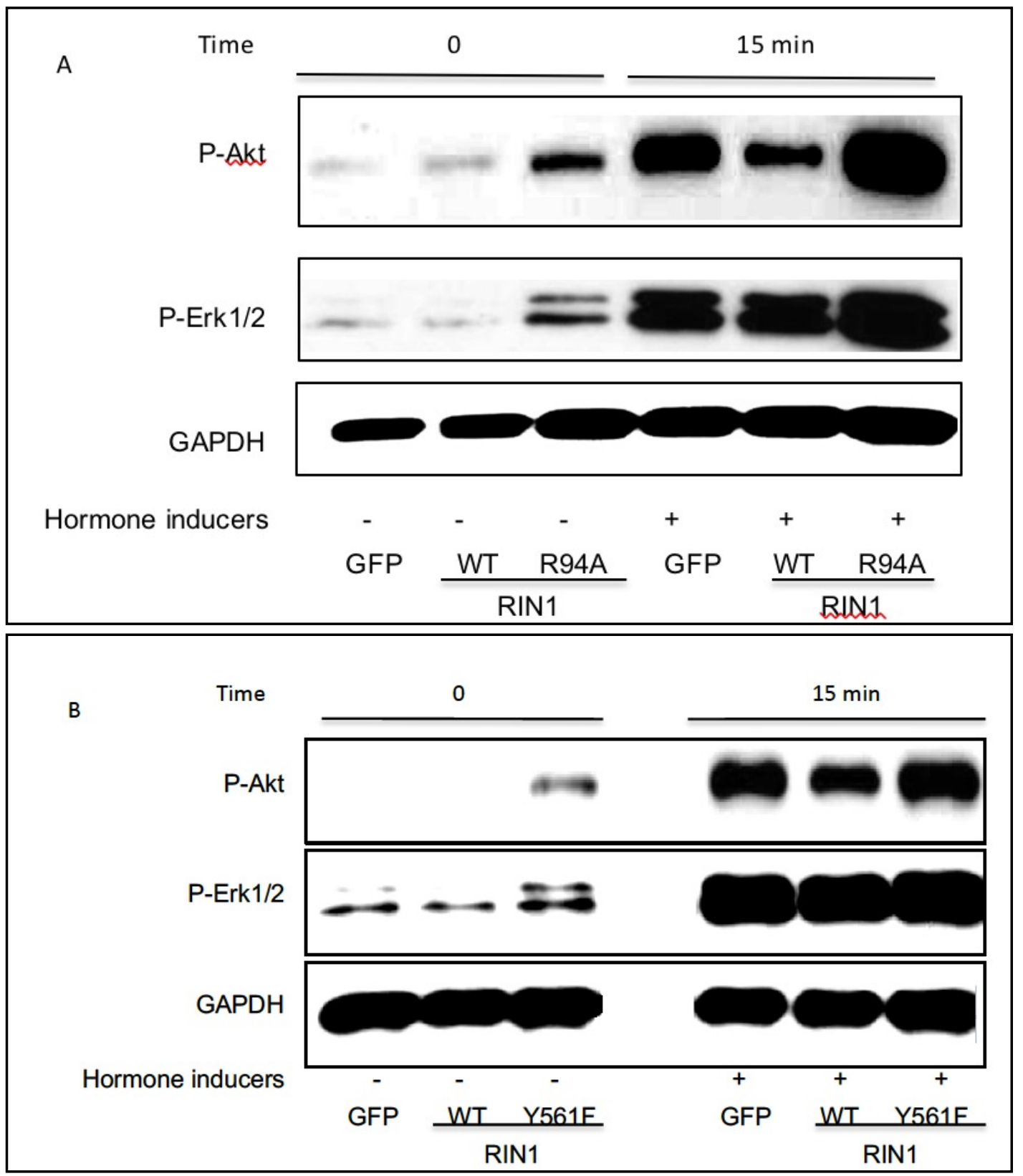

Figure 31. The activity of Akt and Erk1/2 before (0) and 15 minutes after hormone treatment.

3T3-L1 cells overexpressing GFP, RIN1:WT, and RIN1 mutants were treated with or without hormone cocktail as described in Materials and Methods. Cells that were not treated with hormone cocktail served as negative control (C-). (Data represent the mean \pm S.E.M. of three independent experiments. ${ }^{*} P<0.01$ by Student's t-test compared to differentiated RIN1:WT-overexpressed cells). S.E.M. = Standard error of the mean. Representative Western blot of the content of p-Akt and pErk1/2 in comparison with GAPDH were shown. 


\section{III.4.3.4 RIN1 mutants promote cell proliferation in clonal expansion phase during adipogenesis}

Proliferative 3T3-L1 pre-adipocytes were growth-arrested upon contact inhibition before hormone treatment. Prior to terminal differentiation, the hormone triggered growth-arrested cells re-entered cell cycle to perform 2 rounds of postconfluence mitosis, which is named as the clonal expansion phase. Establishing that the RIN1:WT and RIN1 mutants had noticeable effects on the MAPK and PI3K signaling pathways upon hormone treatment in the previous unit, I hypothesized that the ultimate consequences of the protein overexpression would cause notable effects on the clonal expansion phase. proliferation in the early stage of adipogenesis.

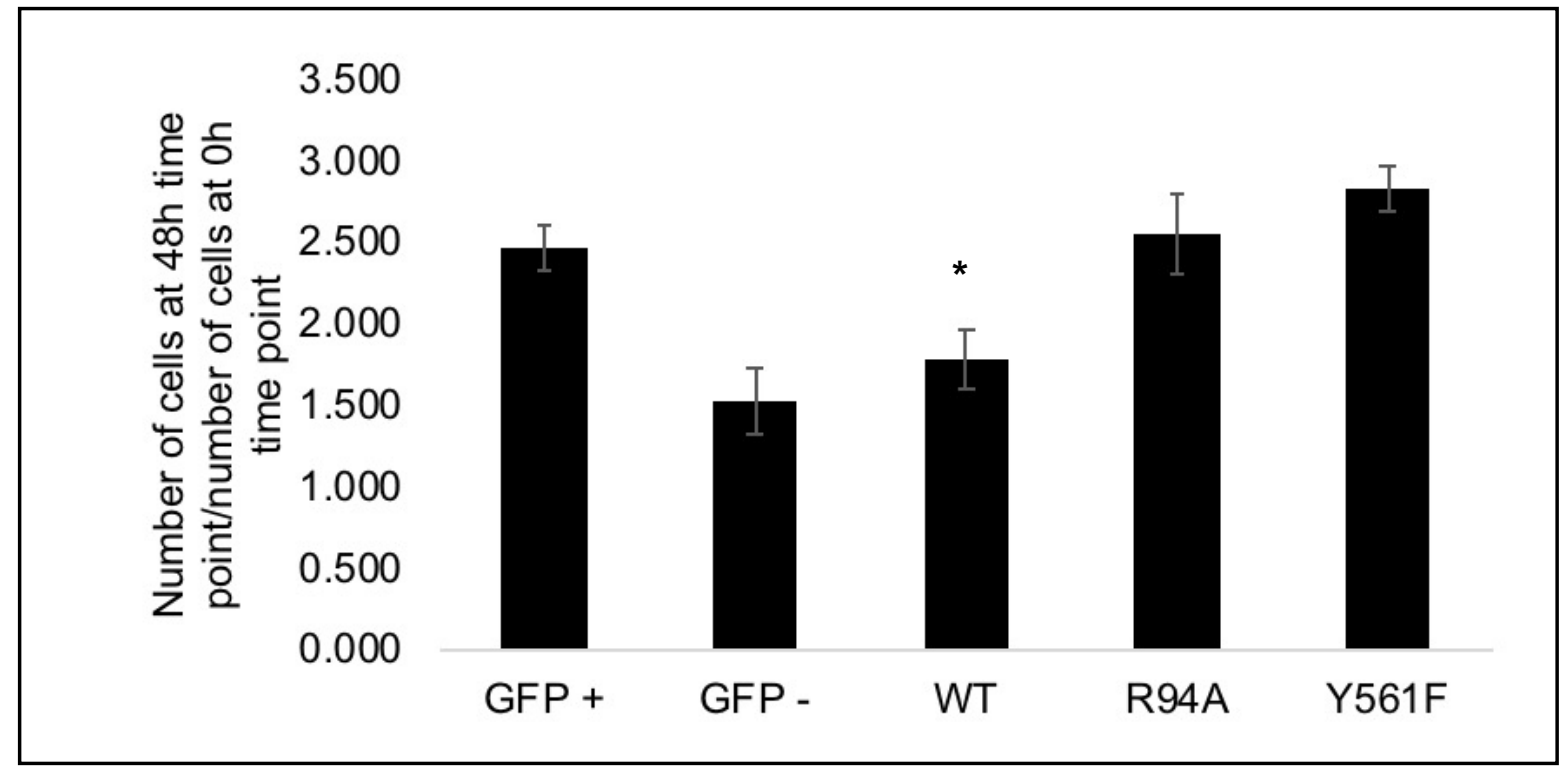

Figure 32. Cell proliferation of GFP-, RIN1-, RIN1:R94A-, or RIN1:Y561Foverexpressed cells in the first $48 \mathrm{~h}$ after hormone induction.

The results indicated a depressed cell growth rate of RIN1 expressed cells while a rescue of cell proliferation when expressing the two selective mutants. 


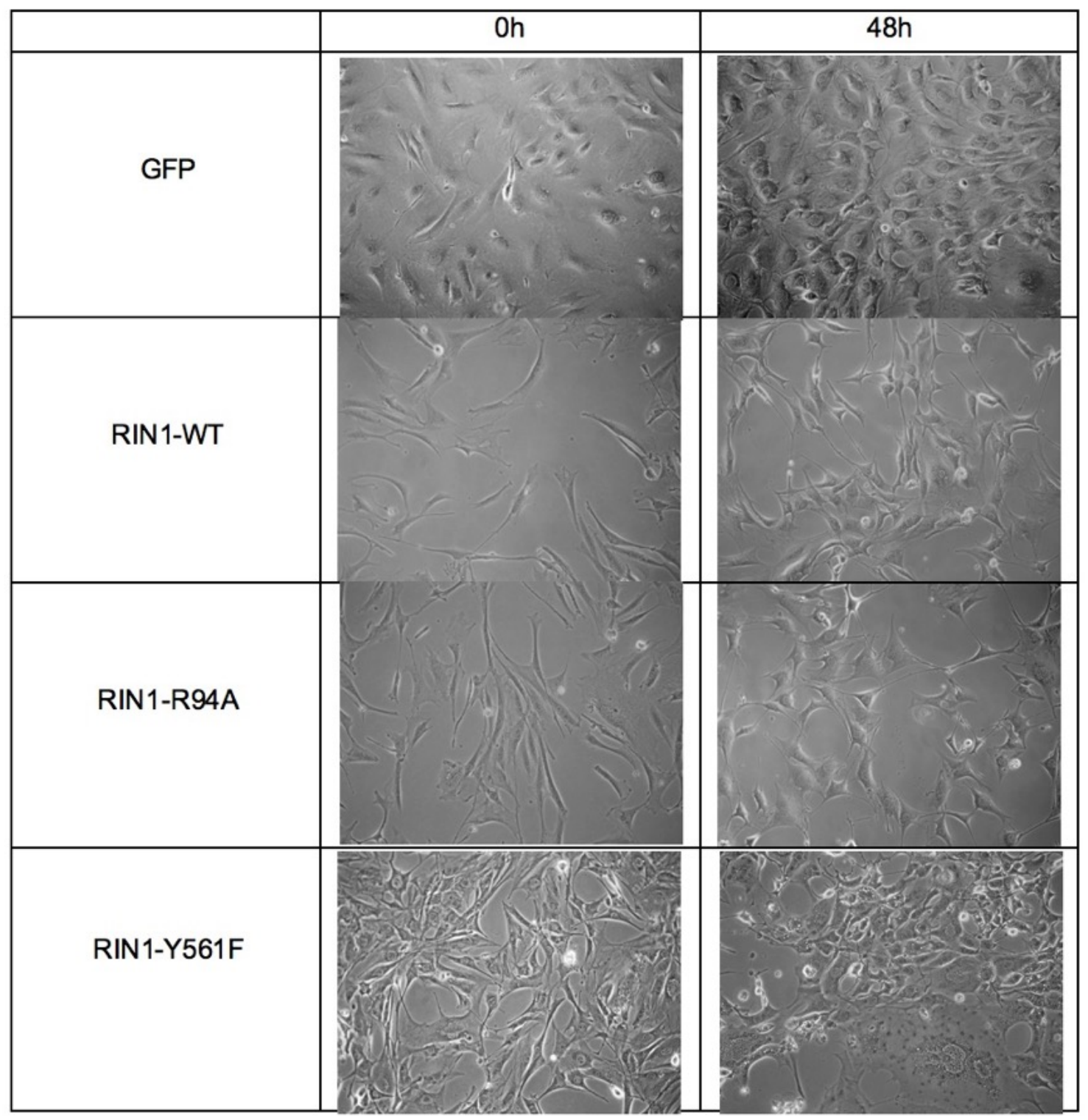

Figure 33. Bright-field images of GFP-, RIN1-, RIN1:R94A-, or RIN1:Y561Foverexpressed cells in the first $48 \mathrm{~h}$ after hormone induction.

Images were taken under bright-field microscope at $\mathrm{Oh}$ (before differentiation) and $48 \mathrm{~h}$ (after differentiation) with the same magnification of 20X objective lens. The results indicated a depressed cell growth rate of RIN1 expressed cells while a rescue of cell proliferation when expressing the two selective mutants.

To address the effect of RIN1 and its mutants on adipogenesis, I used cell counting assay, both manually and automatically, to intuitively investigate the growth of transfected cells in the first 48 hours upon hormone treatment. In Figure 
32 and 33, RIN1 inhibited cell proliferation whereas the two mutants of RIN1 rescued it during the clonal expansion phase of adipogenesis. The results suggest that RIN1 plays an inhibitory role in adipogenesis by, at least partially, impairing the cell mitotic clonal expansion phase of adipogenesis.

\section{III.4.4 The expression of Rab5 effector, VPS34, impaired the} differentiation of 3T3-L1 preadipocytes.

Rab5 is regulated by Rab5 GAPs and GEFs, and eventually perform its function by recruiting different Rab5 effectors. In order to investigate the effect of VPS34, a Class III PI3K to generate PI3P upon recruitment by Rab5, I transfected the 3T3-L1 pre-adipocytes with GFP-VPS34 via the pMX-puro retroviral vector system. The transfected cells were treated with or without hormone cocktail as was described in Materials and Methods. Then the ORO staining and spectroscopy was used to quantify lipid accumulation in the cytosol (Figure 34). Then I tested the effect of VPS34 on the insulin signaling pathway by analyzing the phosphorylation levels of Akt and Erk1/2 in the cell lysates. The VPS34- and GFPtransfected cell lysates were collected before differentiation (0h) and 15 minutes after hormone treatment (Figure 35). At last, live cell images were taken under the inverted microscope at the same field of view to analyze the proliferation rate of transfected cells (Figure $36 \& 37$ ). Bright-field images were taken at either before differentiation(0h), 15 minutes, 24 hours, and 48 hours (48 hour time point is considered as the end of the mitotic clonal expansion phase) after hormone treatment. 

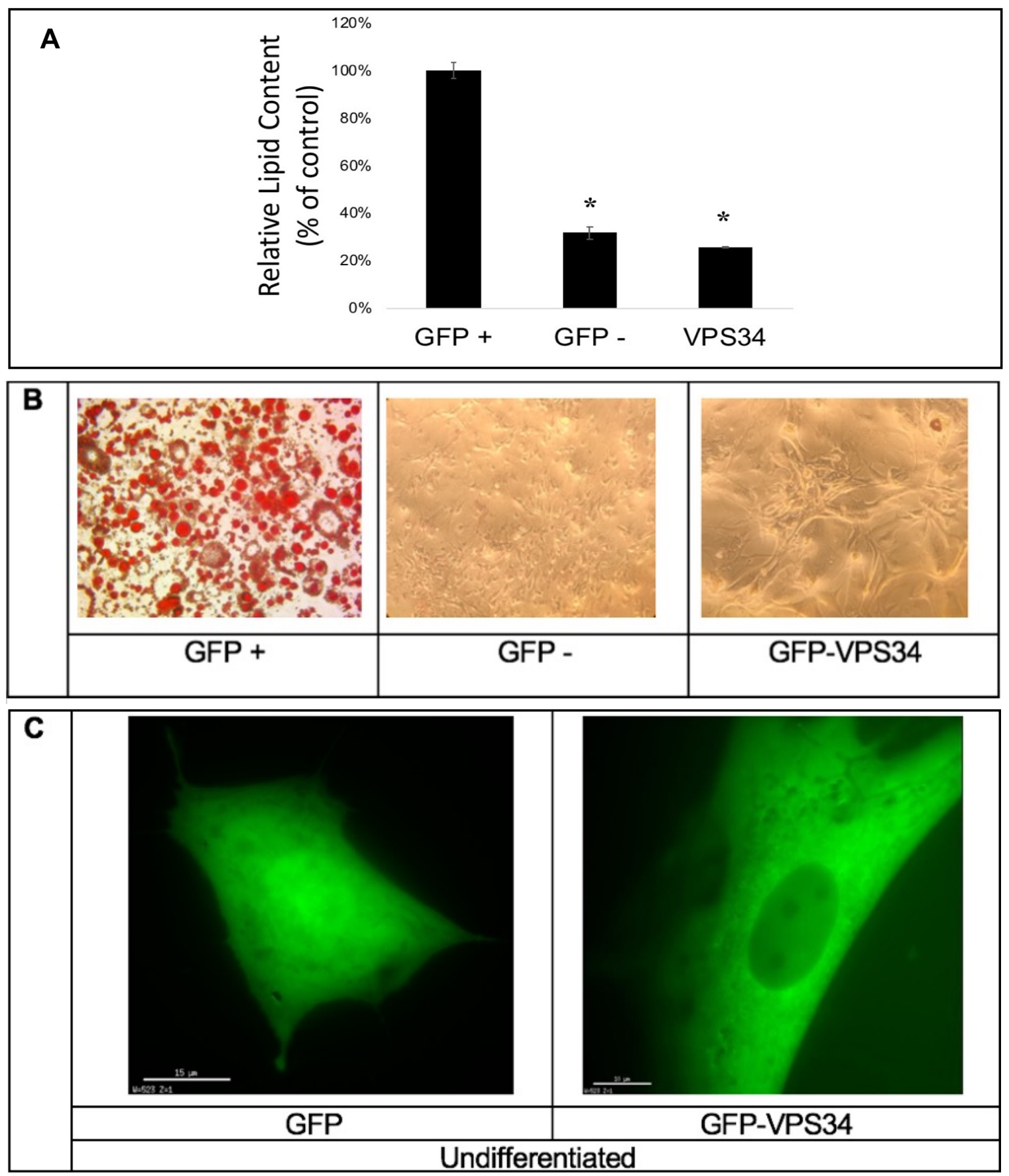

Figure 34. Differentiation of GFP and VPS34 overexpressed cells.

A. Relative lipid content of cells expressing GFP or GFP-VPS34. Data represent the mean \pm S.E.M. of three independent experiments. ${ }^{*} \mathrm{P}<0.05$ by Student's $\mathrm{t}-$ test.B. Bright-field images of 3T3-L1 cells overexpressing GFP or GFP-VPS34. C. Confocal images of 3T3-L1 cells overexpressing GFP or GFP-VPS4 before differentiation. 
In Figure 34.A and $\mathrm{B}$, the ORO quantification assay revealed a significant decreased lipid content of VPS34 overexpressed cells as compared with the GFP positive control (GFP+, cells were treated with hormone inducers during the 10day differentiation). Interestingly, the VPS34-transfected cells exhibited similar lipid content as the GFP negative control cells which were not treated with hormone inducers during the differentiation process. To my surprise, the size of the VPS34-transfected cells was much bigger than the GFP-transfected cells, which can be observed through both bright-field images and confocal images taken under the same magnification (Figure 34.B \& C).

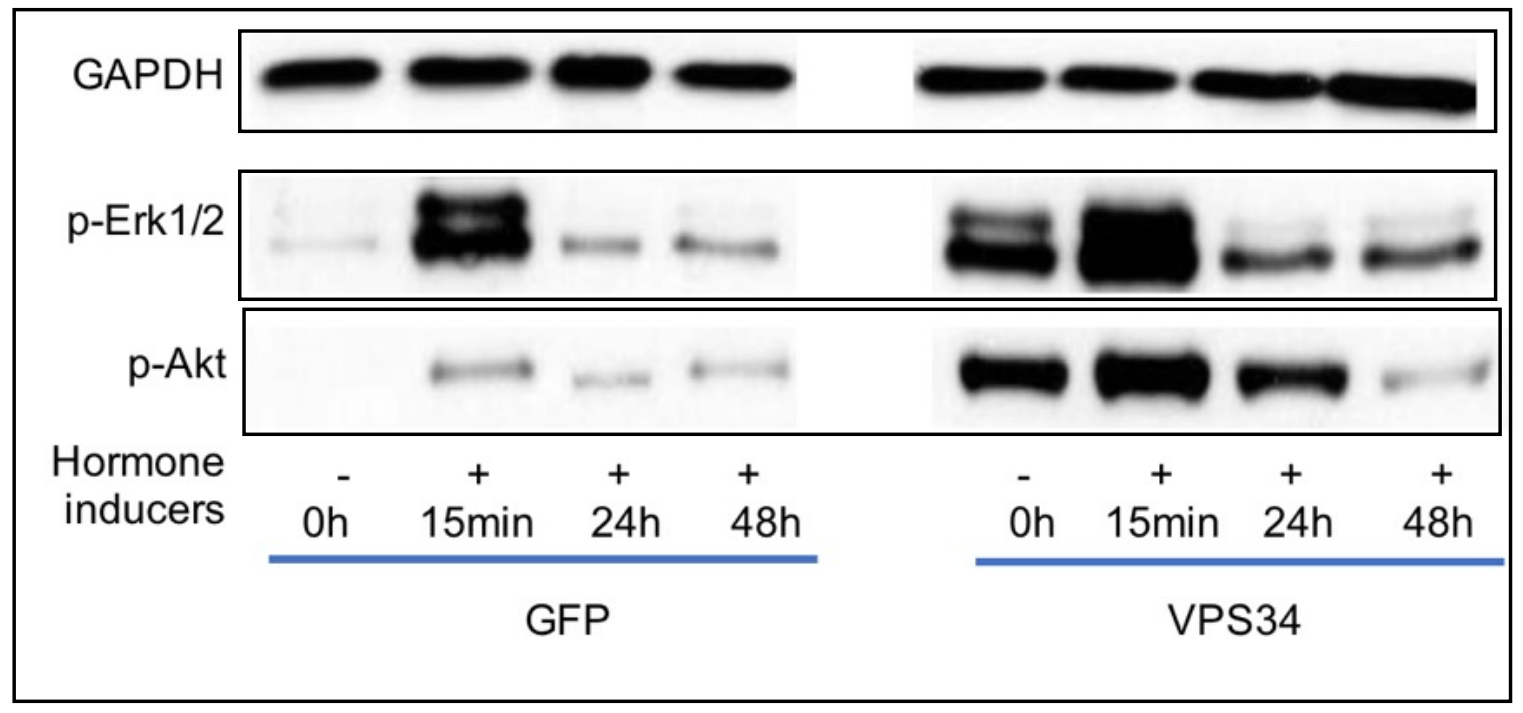

Figure 35. The activity of Akt and Erk1/2 at $0 \mathrm{~h}, 15 \mathrm{~min} 24 \mathrm{~h}$, and $48 \mathrm{~h}$ after hormone treatment.

3T3-L1 cells overexpressing GFP or GFP-VPS34 were treated with or without hormone cocktail as described in Materials and Methods. Cells that were not treated with hormone cocktail served as negative control. Representative Western blot of the content of p-Akt and p-Erk1/2 in comparison with GAPDH were shown. 
In Figure 35, phosphorylated Akt and Erk1/2 were tested at 0h, 15min, 25h, and $48 \mathrm{~h}$ time points. Surprisingly, the VPS34-transfected cells had an increased activity of both Akt and Erk1/2 as compared with the GFP cells at the same time points. What is more, the VPS34 transfected cells even exhibited a higher phosphorylation base line (compare the activity of both Akt and Erk1/2) and experienced a higher increase at $15 \mathrm{~min}$ after hormone induction.

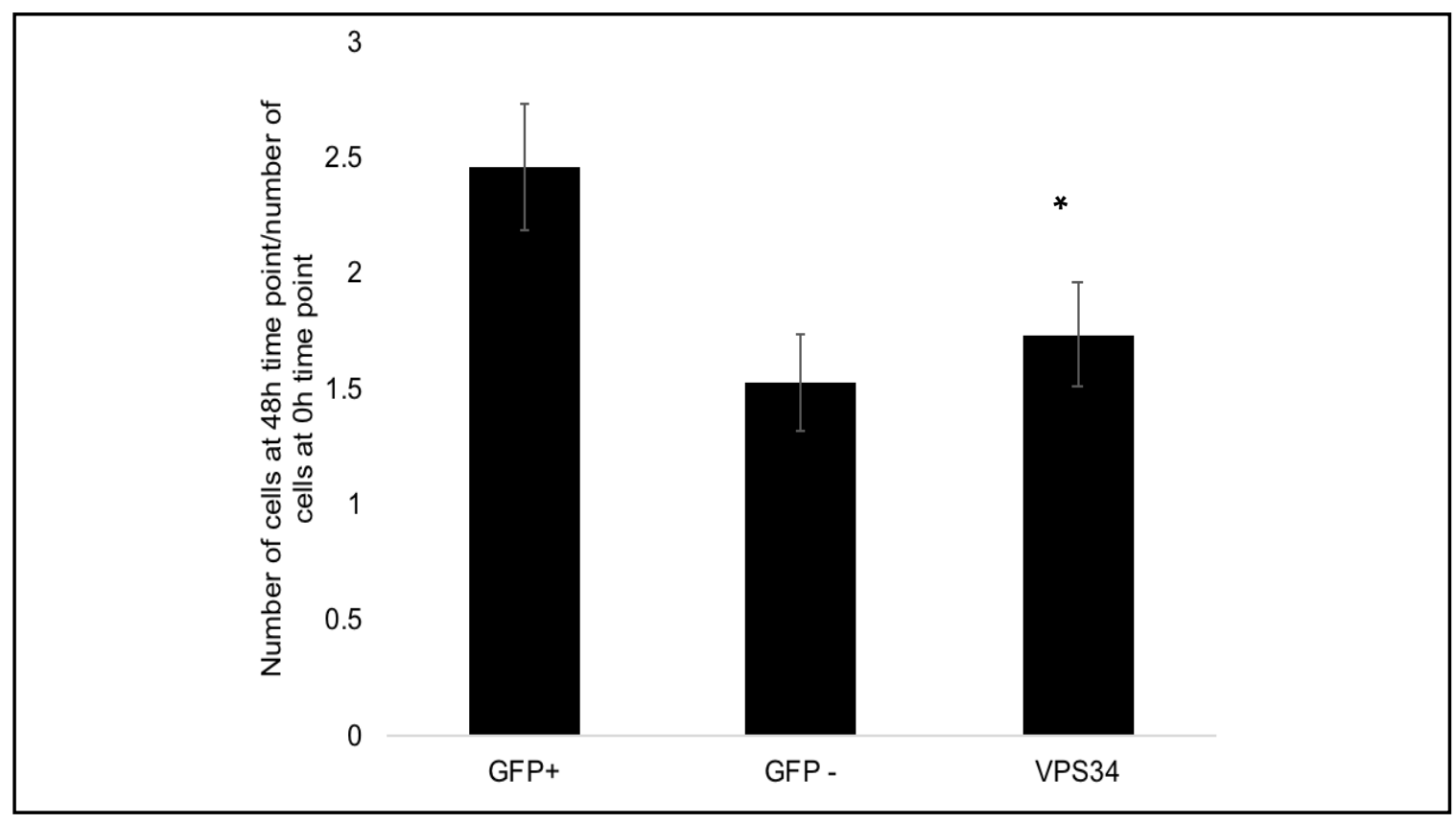

Figure 36. The activity of Akt and Erk1/2 at $0 \mathrm{~h}, 15 \mathrm{~min} 24 \mathrm{~h}$, and $48 \mathrm{~h}$ after hormone treatment.

3T3-L1 cells overexpressing GFP or GFP-VPS34 were treated with or without hormone cocktail as described in Materials and Methods. Cells that were not treated with hormone cocktail served as negative control. Representative Western blot of the content of p-Akt and p-Erk1/2 in comparison with GAPDH were shown. 


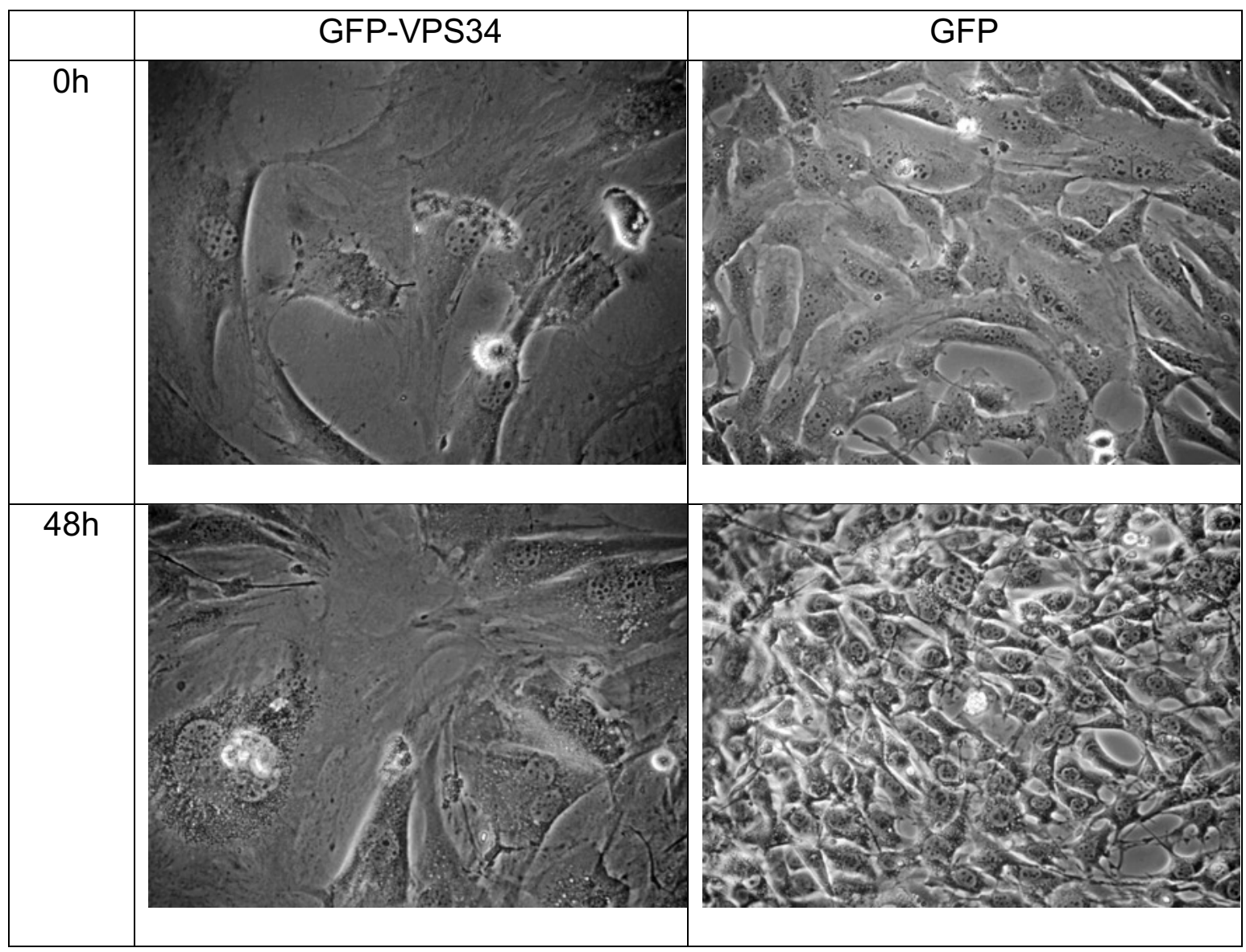

Figure 37. Bright-field images of GFP and GFP-VPS34 overexpressed cells in the first $48 \mathrm{~h}$ after hormone induction.

Images were taken under bright-field microscope at $0 \mathrm{~h}$ (before differentiation) and $48 \mathrm{~h}$ (after differentiation) with the same magnification of $20 \mathrm{X}$ objective lens. The results indicated a depressed cell growth rate of VPS34 expressed cells while a rescue of cell proliferation when expressing the two selective mutants.

As described above, the Akt signaling pathway governs cell metabolism and plays a positive role in 3T3-L1 pre-adipocyte differentiation whereas the Erk1/2 signaling pathway controls gene expression, protein translation, and plays a negative role in promoting the adipogenesis process. Thus, it will be interesting to investigate how the clonal expansion phase is affected during the differentiation 
process. In Figure 36 and 37, cell counting data revealed that the expression of VPS34 in the 3T3-L1 cells not only enlarge the size of the pre-adipocytes, but also decreased the cell proliferation rate in the first 48 hours of differentiation.

\section{III.4.5 Selective association of IR with Rab5 GEFs}

Based on my observations where the diminishing of the Rab5-GTP levels during the differentiation process is linked to insulin stimulation together with the differential effect of Rab5 GEFs, Rab5 GAPs, and Rab5 constructs on differentiation of 3T3-L1 pre-adipocytes, I concluded that decreasing the Rab5GTP levels could be related to the inability of Rab5 GEFs and Rab5 GAPs to regulate and/or access to Rab5 proteins during differentiation of 3T3-L1 preadipocytes.

To determine the possible cellular mechanism under the regulation of Rab5, I examined whether the IR was associated with specific Rab5 GEFs and/or Rab5 GAPs. 3T3-L1 pre-adipocytes individually expressing each Rab5 GEF and Rab5 GAP were differentiated, and then cells at day 9 of the differentiation process were

incubated in the absence or in the presence of insulin for 5 min at $37^{\circ} \mathrm{C}$. After the incubation, cells were lysed, and IR was immunoprecipitated followed with immunoblotting analysis with specific anti-Rab5 GEFs antibodies. In Figure 38, I show that RIN1 (Figure 38.A), Rabex5 (Figure 38.B) and RAP6 (Figure 38.C) are able to interact with the IR in the presence of insulin. Results were tested via immunoprecipitation with anti-IR antibodies. In contrast, it was not possible to immunoprecipitate these Rab5 GEFs with IR in the absence of insulin (Figure 38.A, 
$\mathrm{B}$, and $\mathrm{C})$. The $\mathrm{SH} 2$ domain of RIN1 has been established previously to interact with activated insulin receptor tyrosine kinase domain, which is also confirmed in Figure 38.D. The SH2 domain of RIN1 alone was able to interact with the activated insulin receptor, whereas this domain was not able to interact with the catalytic inactive mutant of the insulin receptor (IR:KD). Interestingly, besides the wellestablished SH2 domain, another domain of RIN1, the VPS9 domain showed strong interaction with the IR-tail in the yeast two-hybrid system (Figure 38.D). However, the domains that showed higher affinity to the activated IR did not show any binding affinity to the catalytic inactive IR-tail. Taken together, these observations suggest that, IR interacts with Rab5 GEFs only upon the stimulation of insulin. These observations were not surprising for RIN1 since it contains an $\mathrm{SH} 2$ domain. However, Rabex5 and RAP6 do not have an SH2 domain, even the association of the latter molecules can be attributed to the requirement of additional factors as it has been shown in the case of the interaction with EGFR. Thus, is reasonable to consider that the VPS9 domain, which is a common domain between these Rab5 GEFs, may be responsible for this interaction with the IR upon insulin stimulation. 

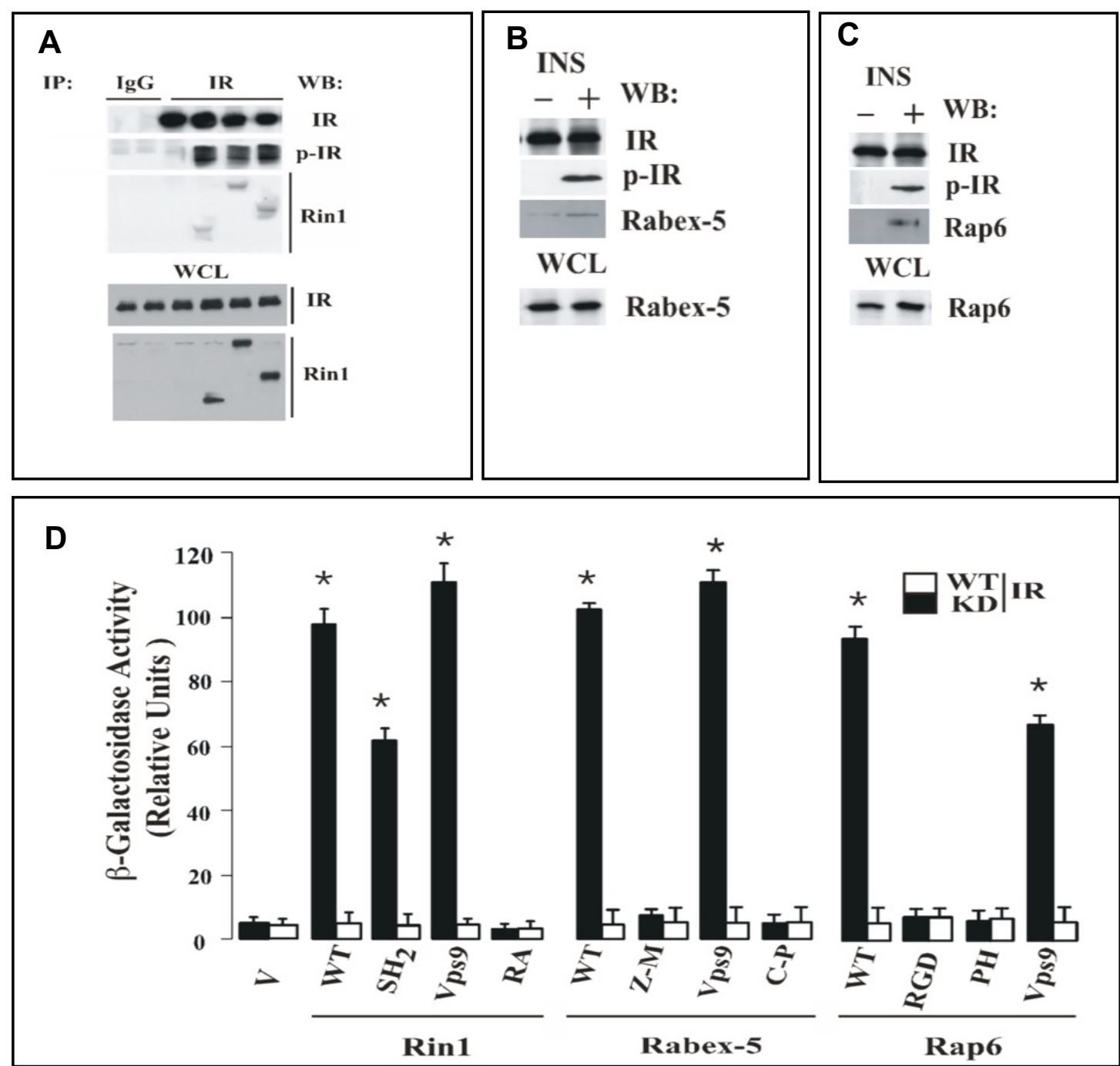

Figure 38. Interaction of the IR-cytoplasmic tail and VPS9 containing proteins. 3T3-L1 preadipocytes expressing GFP, RIN1 (A), Rabex-5 (B), and RAP6 (C) were differentiated into adipocytes in the absence (Control) or in the presence of insulin at $37^{\circ} \mathrm{C}$ for $5 \mathrm{~min}$. After the incubation, cells were lysed and analyzed by immunoprecipitation followed by immunoblotting as described in the figure. Results were represented as relative lipid contents. Data represent the mean \pm S.E.M. of three independent experiments. A./B./C. Representative Western blot of the content of Rabex-5, RAP6, RIN1 constructs, IR, and phospho-IR proteins. ${ }^{*} P<0.05$ by Student's t-test. $D$. Yeast cells were co-transformed with plasmids pB42AD fused with Rab5 GEF constructs and plasmids pLexA fused with IRtail:WT/KD. Co-transformed cells were selected as described in Material and Methods. Liquid cultures in selective media were also assayed for $\beta$-Galactosidase $(\beta-\mathrm{Gal})$ to verify and quantify two-hybrid interactions. The data are presented as means \pm SD of five independent experiments, $n=5{ }^{*} P<0.005$. Each independent experiment was performed in quintuplicate. 
To further investigate the specificity of the interaction between Rab5 GEFs and IR, I then asked whether a specific domain of Rab5 GEFs was involved in the interaction with the cytoplasmic tail of IR. To address this, I utilized a yeast twohybrid system to analyze the interaction of the cytoplasmic tail of IR:WT with the following Rab5 GEFs constructs: a) RIN1:SH2, RIN1:VPS9 and RIN1:RA; b) Rabex-5:Z-M (Z: zinc-finger, which displays Ub protein ligase (E3) activity and binds Ub; M: MIU, a motif interacts with ubiquitin), Rabex-5:VPS9, Rabex-5:C-P (Lee et al., 2006); c) RAP6:VPS9, RAP6:PH and RAP6:RGD (Figure 38). The cytoplasmic tail of IR kinase-dead (IR:K1077M), as well as blank vectors that were not conjugated with Rab5 GEF constructs, were used as negative controls. Consistent with previous observations, I found that RIN1:SH2 domain interacted with the cytoplasmic tail of IR (Figure 38.A). However, I also noticed that RIN1:VPS9 domain, but not RIN1:RA domain, interacted with the cytoplasmic tail of IR. Interestingly, the VPS9 domain of RAP6 and Rabex-5, but not other domains from these Rab5 GEFs, also interacted with the cytoplasmic tail of IR (Figure 38.D). These observations, indicates Rab5 GEFs interact with the cytoplasmic tail of IR via VPS9 domain. For additional examination of this novel interaction between the RIN1:VPS9 domain and with the cytoplasmic tail of IR, I built the in silico model of the complex of RIN1:VPS9-HB and the cytoplasmic tail of IR using the X-ray crystal structure of the IR and VPS9-HB of Rabex-5. In Figure 34, I show the model of the interaction of VPS9-HB domain and IR-cytoplasmic tail. The molecular analysis of the RIN1:VPS9-HB:IR cytoplasmic tail complex shows that there are 24 residues in RIN1 VPS9-HB and 28 residues in IR-cytoplasmic tail are placed in the interface 
between them (Table 4). This complex is being stabilized by hydrogen bonds, van der Walls, hydrophobic and ionic interactions at the interface, and it also predicts that a number of exposed residues in the RIN1; VPS9-HB (Asp537, Pro541, Tyr561, and Thr580) domain. Thr580 places in the $\alpha$ V6 helix on the VPS9 domain and is conserved in hRabex-5, hRIN1, hAlsin, hVarp, but not in hRAP6 proteins. It is placed in the interface, where the side chain of the Thr580 is almost buried into the interface. The side chain of Thr580 in VPS9 domain makes the hydrogen bond interaction with the backbone of Ser1096 of IR cytoplasmic tail. The distance between OG1 atom of Thr580 and OG atom of Ser1096 of IR cytoplasmic tail is nearly $4.5 \AA$, and it could also form the hydrogen bond between them (Figure 39).

Table 4. In silico analysis of the interaction between the VPS9-HB ${ }^{1}$ domain of RIN1 and the IR-tail ${ }^{2}$

1 The numbering of amino acids of corresponds to the protein of Han and Colicelli (Han \& Colicelli, 1995).

2 The numbering of amino acids of IR-B differs from that of the receptor of Ebina et al. by being 47 amino acids greater (Ebina et al., 1985).

Table 4.A Hydrophobic interactions between the VPS9-HB domain of RIN1 and the IR-tail

\begin{tabular}{ll}
\hline \hline VPS9-HB Domain & IR-tail \\
\hline Leu571 & Trp1036 \\
Pro599 & Leu1085 \\
Leu540 & Ile1089, Leu1092 \\
Pro541 & Ile1089 \\
Leu588 & Ile1089, Leu1092 \\
Ala584 & Leu1092 \\
Trp577 & Val1097, Phe1175 \\
\hline \hline
\end{tabular}


Table 4.B Cation-Pi interactions between the VPS9-HB domain of RIN1 and the IR-tail within $6 \AA$

\begin{tabular}{ll}
\hline \hline VPS9-HB Domain & IR-tail \\
\hline Lys520 & Tyr1205 \\
\hline \hline
\end{tabular}

Table 4.C Aromatic-aromatic Interactions between VPS9-HB and IR-tail within 4.5 and $7 \AA$

\begin{tabular}{ll}
\hline \hline VPS9-HB Domain & IR-tail \\
\hline Tyr577 & Phe1175 \\
\hline \hline
\end{tabular}

Table 4.D lonic interactions between VPS9-HB and IR-tail within $6 \AA$

\begin{tabular}{ll}
\hline \hline VPS9-HB Domain & IR-tail \\
\hline Glu564 & Lys1067 \\
Asp537 & Arg1086, Glu1090 \\
Lys520 & Asp1203, Glu1206 \\
Glu532 & Arg1211, Lys1212 \\
Glu530 & Lys1212 \\
Glu538 & Lys1212, Lys1215 \\
Lys426 & Glu1327 \\
Glu574 & Glu1328 \\
\hline \hline
\end{tabular}

Table 4.E Hydrogen bond interactions between VPS9-HB and IR-tail.

\begin{tabular}{clll}
\hline $\begin{array}{c}\text { VPS9-HB } \\
\text { Domain }\end{array}$ & IR-tail & $\begin{array}{l}\text { VPS9-HB } \\
\text { Domain }\end{array}$ & IR-tail \\
\hline Leu571 & Phe1101 & Asp537 & Arg1086, Arg1202 \\
Ala536 & Asn1093 & Glu530 & Lys1212, Lys 1215 \\
Thr572 & Lys1173 & Glu538 & Lys1212, Lys 1215 \\
Glu532 & Arg1211, Lys1212, Lyr1209 & Lys426 & Glu1327 \\
Gly533 & Lys1212 & Lys520 & Asp1203, Glu1206 \\
Thr580 & Ser1096 & Ser563 & Glu1035 \\
Arg403 & Lys1067, Thr1207 & Tyr577 & Asp1203 \\
Tyr523 & Asp1203 & & \\
\hline \hline
\end{tabular}




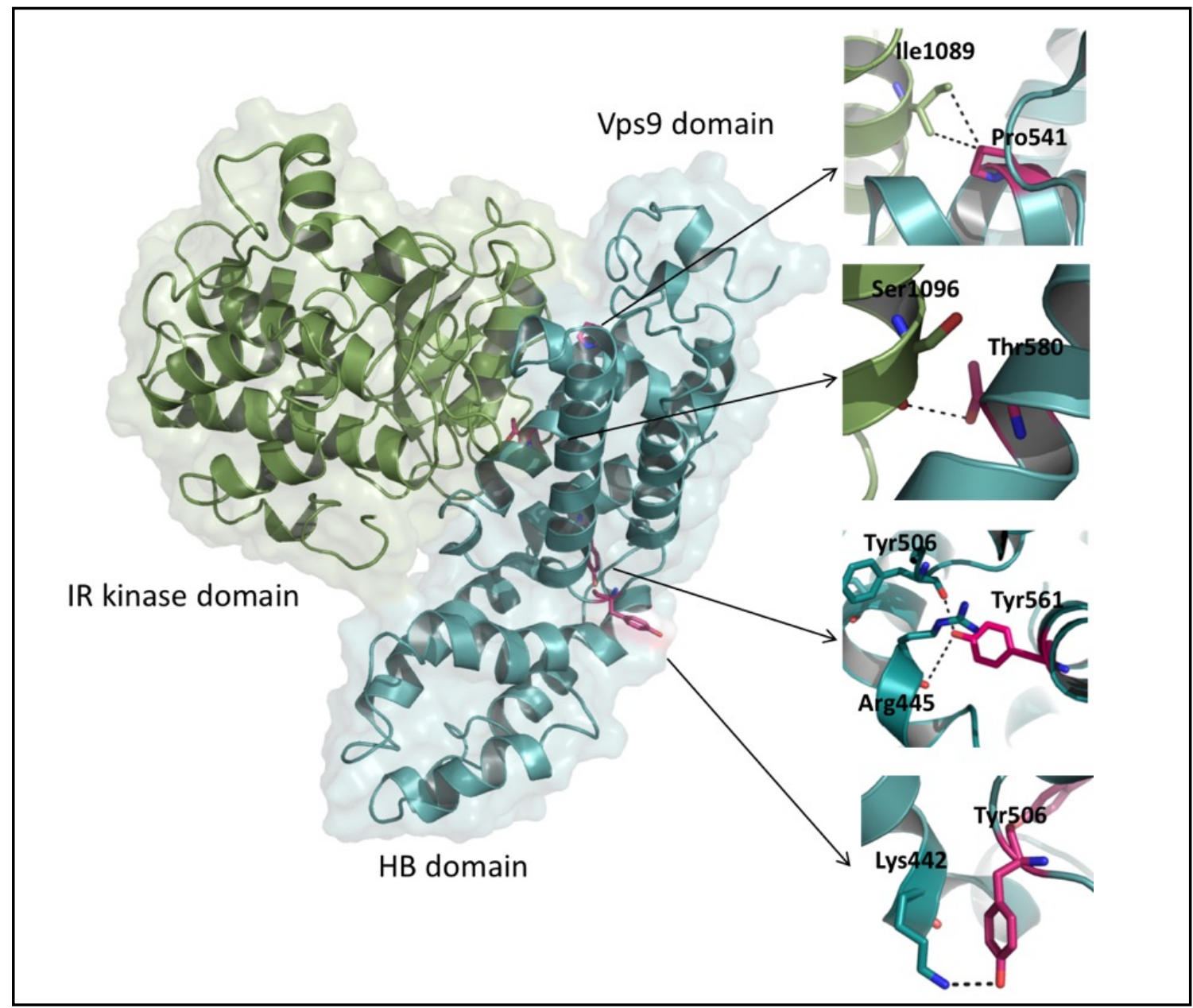

Figure 39. Analysis of the interaction between the IR-cytoplasmic tail and the RIN1:VPS9 mutants.

In silico docking analysis of the IR-cytoplasmic tail and the VPS9-HB domain of RIN1. RIN1:VPS9 domain's residues studied above are shown in magenta sticks and their interactions are shown in separate panels (Inserts). The polar distance less than $4.0 \AA$ are shown in dotted lines. Residues Pro541 and Thr580 of the VPS9 domain are buried in the interface of the complex. The Pro541 makes hydrophobic interaction with Ile1089 of IR-cytoplasmic tail. The side chain of Thr580 makes interaction with the main chain of Ser1096. These mutations of Pro541 and Thr580 to alanine destabilize this complex. The activated IRcytoplasmic tail structure is taken from the protein data bank (Pdb Id: 4XLV) for docking (Cabail et al., 2015). The homology model of VPS9-HB domain of RIN1 was built by SWISS-MODEL (Arnold et al., 2006) using the crystal structure of Rabex-5 (Pdb id:1TXU) as a template (Delprato et al., 2004). The docking of the IR-cytoplasmic tail and the VPA9-HB domain was done by the ZDOCK online server. The docked model was minimized by using NAMED (Phillips et al., 2005) and VMD (Humphrey et al., 1996). The molecular model was drawn with PYMOL (Delano, 2001). 
Tyr561 is also conserved in hRabex-5, hRIN1, hGAPVD1, hVarp but not in hAlsin proteins. It is placed in the $a \mathrm{~V} 5$ helix, and the side chain is fully buried into the interface between VPS9 and HB domain of RIN1. The hydroxyl group of Tyr561 makes hydrogen bonds with the backbone atom of Tyr506 and Arg455, placed in aH4 (Figure 34). Tyr506 is only present in hRIN1 and it can make a hydrogen bond with the backbone atom of tyr561. The mutation of Tyr561 and Tyr506 to phenylalanine may lose the hydrogen bond. Based on these observations, I utilized a two-hybrid system to analyze the interaction of the cytoplasmic tail of IR-WT with the following Rab5:VPS9-HB mutants: (Y506F, Y523F, Y537F, P5431A, Y561F, T572A, Y577F, Y578F, T580A) (Figure 39). I found that residues (Tyr506, P541, Y561, and T580) play an important role in the interaction of RIN1:VPS9-HB with the cytoplasmic tail of IR. As expected, the cytoplasmic tail of IR kinase-dead was used as negative control. These observations indicate selective residues of the VPS9-HB domain are required for the interaction of the cytoplasmic tail of IR, which may represent a distinctive and original protein-protein interaction. Taken together, these findings indicate that (a) Rab5 GEFs interact with the cytoplasmic tail of IR, but not with its catalytic inactive mutant, (b) the Rab5 GEFs VPS9 domain is sufficient for this interaction, and (c) Rab5 GAPs do not interact with the cytoplasmic tail of IR. Furthermore, these results also strengthen the possibility that interaction between VPS9 domain of Rab5 GEFs and the cytoplasmic tail of $I R$, defining a novel and selective interaction between VPS9 domain and the IR cytoplasmic tail. 


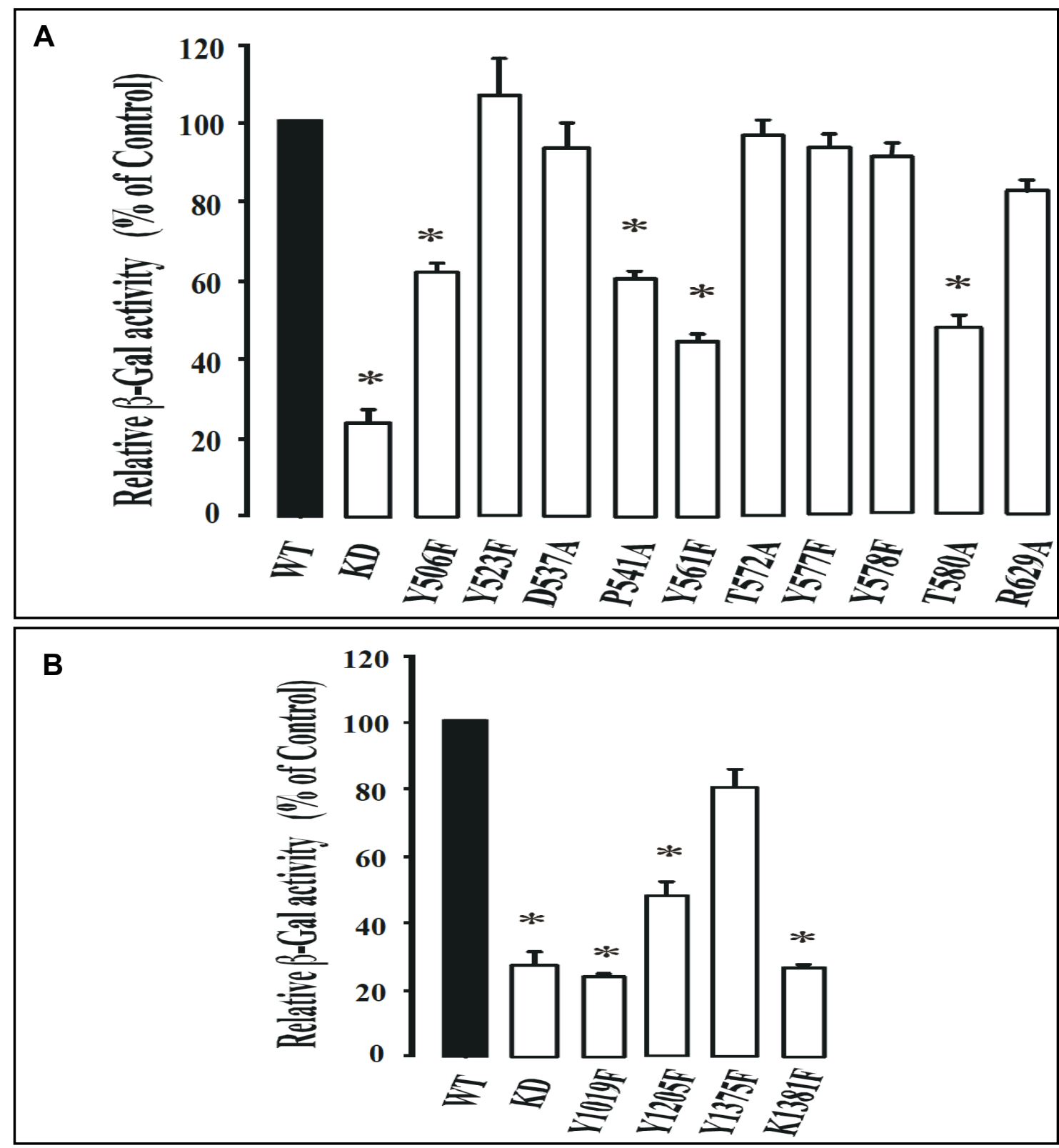

Figure 40. Analysis of interaction between the IR-cytoplasmic tail (IR- $\beta$ ) and RIN1:VPS9 mutants or IR- $\beta$ mutants and the RIN1:VPS9 domain.

Yeast cells were co-transformed with plasmids pLexA fused to the IR- $\beta$ :WT/KD or IR- $\beta$ mutants (Y972F, IR:Y1158F, IR:Y1328F, and IR:Y1334F) and $p B 42 A D$ fused to the RIN1:VPS9 or RIN1:VPS9 mutant (Y506F, Y523F, D537A, P541A, Y561F, Y572F, Y577F, Y578F, T580A). Co-transformed cells were spotted onto plates containing selected media and incubated at $30^{\circ} \mathrm{C}$ as described in Material and Methods. Liquid cultures in selective media were also assayed for $\beta$-Galactosidase ( $\beta$-Gal) to verify and quantify two-hybrid interactions. The data are presented as means $\pm S D$ of five independent experiments, $n=5{ }^{*} P<0.05$. Each independent experiment was performed in quintuplicate. 


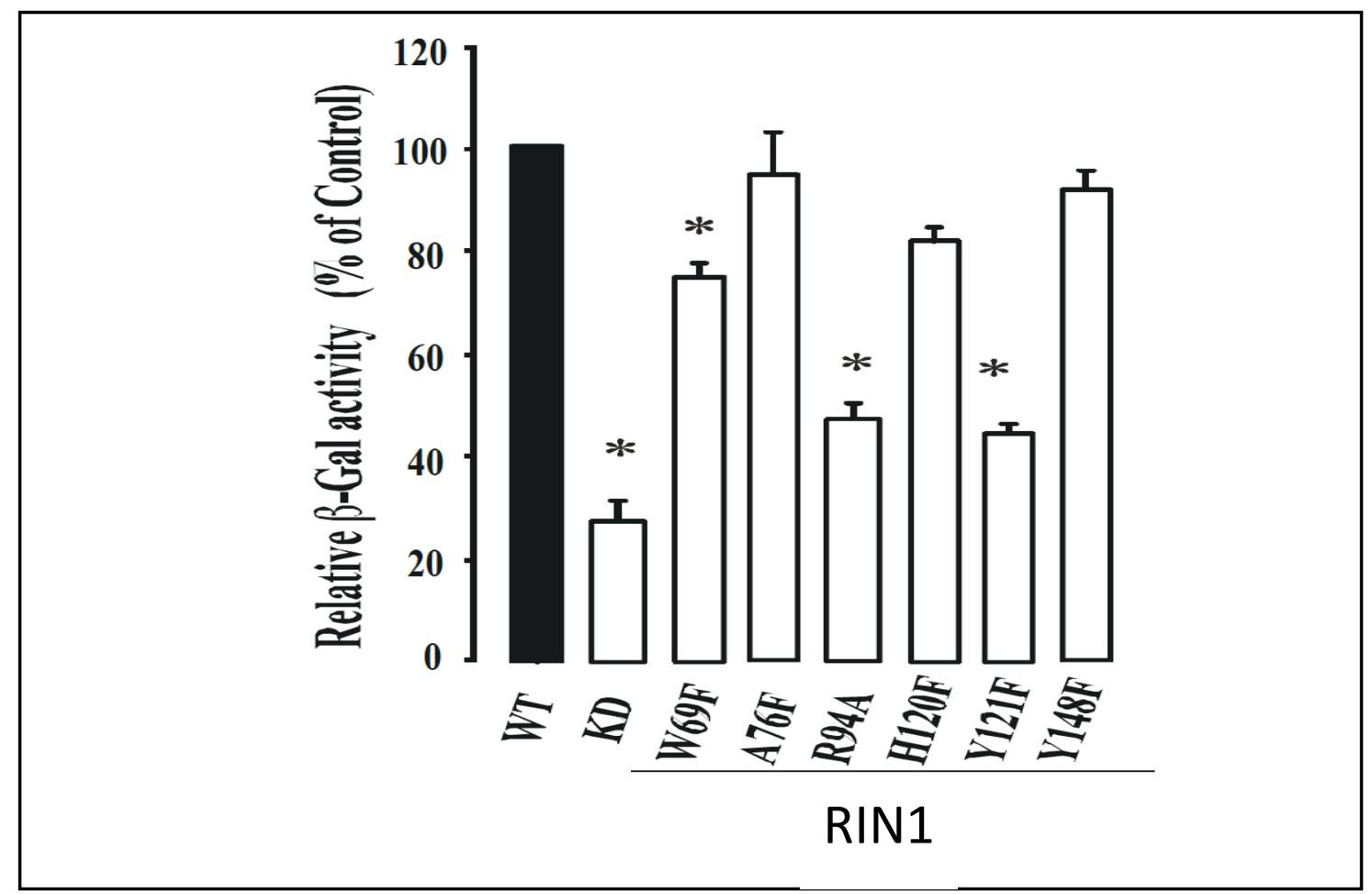

Figure 41. Analysis of interaction between the IR-cytoplasmic tail (IR- $\beta$ ) and RIN1:SH2 domain.

Yeast cells were co-transformed with plasmids pLexA fused to the IR- $\beta$ :WT/KD and pB42AD fused to the RIN1:SH2 or RIN1:SH2 mutants (RIN1:W69F, RIN1:A76F, RIN1:R94A, RIN1:H120F, RIN1:121F, RIN1:Y148F). Co-transformed cells were spotted onto plates containing selected media and incubated at $30^{\circ} \mathrm{C}$ as described in Material and Methods. Liquid cultures in selective media were also assayed for $\beta$-Galactosidase ( $\beta$-Gal) to verify and quantify two-hybrid interactions. The data are presented as means \pm SD of five independent experiments, $n=5$ ${ }^{*} \mathrm{P}<0.05$. Each independent experiment was performed in quintuplicate.

In order to further investigate the interaction between the IR and RIN1, I insert RIN1-SH2:WT, RIN1:VPS9:WT, several RIN1-SH2/NPS9 mutants into the pB42AD vector, and insert the IR- $\beta$ and IR- $\beta$ mutants into the pLex-A vector. Figure 40 showed the interaction between IR-cytoplasmic tail (IR- $\beta$ ) and RIN1:VPS9 mutants or IR- $\beta$ mutants and RIN1:VPS9 domain whereas Figure 41 showed the interaction between the IR- $\beta$ and RIN1:SH2. 


\section{III.5 Discussion}

In this section, I show the cellular mechanism of the Rab GEFs and the Rab GAPs in regulating Rab5 function during the differentiation of 3T3-L1 preadipocytes. My data indicate that Rab5 inactivation upon insulin stimulation is directly linked to the interaction between the activated insulin receptor and the VPS9 domain of the Rab5 GEFs. The interaction probably affects the availability of Rab5 GEFs to activate Rab5. In addition, the VPS9-IR-tail interaction also affected the recruitment of IRS-1 to the activated insulin receptor cytoplasmic tail.

The expression of Rab5 GEFs, which increased the Rab5-GTP levels, reduced the differentiation of 3T3-L1 pre-adipocytes, while the expression of Rab5 GAPs, which decreased Rab5-GTP levels, improved adipogenesis. I also show that the exposure of 3T3-L1 pre-adipocytes to insulin can stimulate the association of Rab5 GEF via its VPS9 domain to the activated insulin receptor. This observation strongly suggests a direct link between the Rab5 inactivation and the insulin receptor trafficking and signaling.

Analysis of the Rab5-GTP levels reveals a significant decrease in the GTP levels in an insulin-sensitive manner during 3T3-L1 pre-adipocytes differentiation without any significant decrease of the total level of Rab5 (Figures 11). One striking feature of the Rab5-GTP levels in cells expressing Rab5 GEFs is that not only an increase of the GTP levels can be observed, but also a statistically significant decrease in the Rab5-GTP levels is displayed by comparing the Rab5-GTP levels between day 1 and day 9 during differentiation. In contrast, in cells expressing the Rab5 GAPs, the Rab5-GTP levels were not further affected by the addition of 
insulin during the differentiation process. In this context, depletion of Rab5 GEFs or Rab5 GAPs by siRNA showed a remarkable characteristic; silencing of Rab5 GEFs decrease Rab5-GTP levels, while depletion of Rab5 GAPs increase it. These data suggest that regulation of these factors is critical to ensure and maintain the Rab5-GTP level during the differentiation process. Taken together, these results suggest a possible cellular mechanism of the regulation of Rab5 inactivation during adipogenesis, which is directly linked to the interaction of activated insulin receptor with the Rab5 GEFs.

It is reasonable to propose that association of activated insulin receptor with the Rab5 GEFs is specific and selective and will also affect the activation of Rab5. In support of this possibility, it has been shown that RIN1 interacts with activated insulin receptor via its SH2 domain (Hunker, Giambini, et al., 2006). Interestingly, Rabex-5 and RIN1 are recruited by activated EGF-receptor tail via two different mechanisms: RIN1 require tyrosine phosphorylation of the EGF-receptor, while Rabex -5 requires ubiquitination. In addition, it has been also shown that a deletion mutant of Rabex-5 containing the VPS9 domain is targeted to membrane without Rabaptin-5 and the ubiquitination domain (Aikawa, 2012). Together, these data suggest that Rab5 GEFs utilize several mechanisms to interact with the activated receptor. However, in this study, I found that these Rab5 GEFs utilize one common domain (the VPS9 domain) to interact with the activated insulin receptor, with the exception of RIN1 that also utilizes the RIN1:SH2 domain to interact with the activated insulin receptor (Figure 34). 
In addition, the VPS9 domain does not interact with insulin receptor catalytic inactive mutant or with other receptors (e.g., EGF-, transferrin- and LDL-receptor [data not shown]). However, the finding that the Rab5 GEFs VPS9 domain also interacts with the IGF-1R (data not shown) further support the idea that Rab5 GEFs VPS9 domain plays a critical function during the differentiation of pre-adipocytes since both the IR and IGF-1R have been implicated in the regulation of adipocyte differentiation and lipid accumulation in vitro (Boucher et al., 2010). It is also important to mention that beside the VPS9 domain, other domains of the Rab5 GEFs may also play critical roles in the differentiation of pre-adipocytes. For example, the Ras-binding domain found in both RIN1 and Rabex-5, as well as the Ras-GAP domain described in RAP6, may also be involved in the differentiation of pre-adipocytes since the expression of Ras GTP-hydrolysis defective mutant (Ras:V12G) increases the differentiation of pre-adipocytes (Murholm et al., 2010). These data suggest that Rab5 inactivation is a key and specific factor, yet not the only one, that is crucial to trigger the differentiation of 3T3-L1 pre-adipocytes.

In summary, my data show that the exposure of 3T3-L1 pre-adipocytes to insulin can stimulate the inactivation of Rab5, which strongly suggests a direct link between the inactivation of Rab5 and the activation of the insulin receptor. One explanation for this mechanism is lay on the association of Rab5 GEFs with the activated insulin receptor and IGF-1R. In either case, the VPS9 domain of Rab5 GEFs mediates this interaction with the activated receptor, indicating a novel cellular mechanism to regulate the activity of Rab5. This hypothesis is further supported by the observation that only tyrosine-phosphorylated insulin receptor 
interacted with more than one Rab5 GEFs. Therefore, Rab5 cannot be activated once the Rab4 GEFs were sequestered by the activated IR or IGF-1R. In agreement with these observations, the addition of insulin down-regulates Rab5 activity in the initial phase, but Rab5 activity could be recovered later, which coincides with activation and inactivation phases of the insulin receptor during the receptor-mediated endocytosis. This lack of Rab5 activation will block insulin receptor internalization allowing an increase of the tyrosine autophosphorylation of the insulin receptor and activation of Akt followed by translocation of GLUT4 to the plasma membrane. Another possibility is that decreasing the level of Rab5GTP is associated with diminishing the amount of Rab5 proteins during the differentiation process. Thus, inadequate level of Rab5 proteins would affect their activation by Rab5 GEFs. Moreover, it seems that it could be a case since the expression of Rab5 is differentially altered during the 3T3-L1 pre-adipocytes differentiation. However, it has been shown that the expression of Rab5 is not altered during the 3T3-L1 pre-adipocytes differentiation (Figure 22 and Figure 11). Additionally, secondary modification on Rab5 and/or Rab5 GEFs (e.g., phosphorylation, ubiquitination) would also be involved. Further investigation will be needed to define the potential requirements of specific modifications of Rab5. Additional explanations, such as how an increased GLUT4 internalization could be induced by an inhibitory effect of the Rab5 activity cannot be ruled out (Figure 13).

Here, I provided function and cellular evidence that Rab5 may be considered as a molecular switch on the cell fate determination of 3T3-L1 preadipocytes. Interestingly, Rab5 inactivation has been found to associate with 
neurite outgrowth and differentiation, where RabGAP-5 interacts with NGF-TrkA receptor and regulates the NGF-TrkA receptor signaling (Tam et al., 2015). Nevertheless, my studies indicate a finely orchestrated balance between GTP/GDP ratio of Rab5, Rab5 GEFs, and tyrosine autophosphorylation of the insulin receptor, and more importantly, demonstrate a fundamental role of Rab5 inactivation during the differentiation of 3T3-L1 pre-adipocytes.

\section{III.6 References}

Aikawa, Y. (2012). Rabex-5 protein regulates the endocytic trafficking pathway of ubiquitinated neural cell adhesion molecule L1. J Biol Chem, 287(39), 3231232323. doi:10.1074/jbc.M112.374322

Arnold, K., Bordoli, L., Kopp, J., \& Schwede, T. (2006). The SWISS-MODEL workspace: a web-based environment for protein structure homology modelling. Bioinformatics, 22(2), 195-201. doi:10.1093/bioinformatics/bti770

Backer, J. M. (2008). The regulation and function of Class III PI3Ks: novel roles for Vps34. Biochem J, 410(1), 1-17. doi:10.1042/BJ20071427

Balaji, K., French, C. T., Miller, J. F., \& Colicelli, J. (2014). The RAB5-GEF function of RIN1 regulates multiple steps during Listeria monocytogenes infection. Traffic, 15(11), 1206-1218. doi:10.1111/tra.12204

Barbieri, M. A., Kong, C., Chen, P. I., Horazdovsky, B. F., \& Stahl, P. D. (2003). The SRC homology 2 domain of Rin 1 mediates its binding to the epidermal growth factor receptor and regulates receptor endocytosis. J Biol Chem, 278(34), 3202732036. doi:10.1074/jbc.M304324200

Barbieri, M. A., Roberts, R. L., Gumusboga, A., Highfield, H., Alvarez-Dominguez, C., Wells, A., \& Stahl, P. D. (2000). Epidermal growth factor and membrane trafficking: EGF receptor activation of endocytosis requires Rab5a. Journal of Cell Biology, 151(3), 539-550. doi:DOI 10.1083/jcb.151.3.539

Boucher, J., Tseng, Y. H., \& Kahn, C. R. (2010). Insulin and insulin-like growth factor-1 receptors act as ligand-specific amplitude modulators of a common pathway regulating gene transcription. J Biol Chem, 285(22), 17235-17245. doi:10.1074/jbc.M110.118620 
Bucci, C., Parton, R. G., Mather, I. H., Stunnenberg, H., Simons, K., Hoflack, B., \& Zerial, M. (1992). The Small Gtpase Rab5 Functions as a Regulatory Factor in the Early Endocytic Pathway. Cell, 70(5), 715-728. doi:Doi 10.1016/00928674(92)90306-W

Cabail, M. Z., Li, S., Lemmon, E., Bowen, M. E., Hubbard, S. R., \& Miller, W. T. (2015). The insulin and IGF1 receptor kinase domains are functional dimers in the activated state. Nat Commun, 6, 6406. doi:10.1038/ncomms7406

Chi, Y., Li, J., Li, N., Chen, Z., Ma, L., Peng, W., Pan, X., Li, M., Yu, W., He, X., Geng, B., Cui, Q., Liu, Y., \& Yang, J. (2017). FAM3A enhances adipogenesis of 3T3-L1 preadipocytes via activation of ATP-P2 receptor-Akt signaling pathway. Oncotarget, 8(28), 45862-45873. doi:10.18632/oncotarget.17578

Christoforidis, S., McBride, H. M., Burgoyne, R. D., \& Zerial, M. (1999). The Rab5 effector EEA1 is a core component of endosome docking. Nature, 397(6720), 621625. doi:10.1038/17618

Christoforidis, S., Miaczynska, M., Ashman, K., Wilm, M., Zhao, L., Yip, S. C., Waterfield, M. D., Backer, J. M., \& Zerial, M. (1999). Phosphatidylinositol-3-OH kinases are Rab5 effectors. Nat Cell Biol, 1(4), 249-252. doi:10.1038/12075

Deininger, K., Eder, M., Kramer, E. R., Zieglgansberger, W., Dodt, H. U., Dornmair, K., Colicelli, J., \& Klein, R. (2008). The Rab5 guanylate exchange factor Rin1 regulates endocytosis of the EphA4 receptor in mature excitatory neurons. Proc Natl Acad Sci U S A, 105(34), 12539-12544. doi:10.1073/pnas.0801174105

Delano, W. L. (2001). The PyMol user's Manual. DeLano Scientific, San Carlos.

Delprato, A., \& Lambright, D. G. (2007). Structural basis for Rab GTPase activation by VPS9 domain exchange factors. Nat Struct Mol Biol, 14(5), 406-412. doi:10.1038/nsmb1232

Delprato, A., Merithew, E., \& Lambright, D. G. (2004). Structure, exchange determinants, and family-wide rab specificity of the tandem helical bundle and Vps9 domains of Rabex-5. Cell, 118(5), 607-617. doi:10.1016/j.cell.2004.08.009

Dimitriadis, G., Mitrou, P., Lambadiari, V., Maratou, E., \& Raptis, S. A. (2011). Insulin effects in muscle and adipose tissue. Diabetes Research and Clinical Practice, 93, S52-S59. doi:10.1016/s0168-8227(11)70014-6

Ebina, Y., Ellis, L., Jarnagin, K., Edery, M., Graf, L., Clauser, E., Ou, J. H., Masiarz, F., Kan, Y. W., Goldfine, I. D., \& et al. (1985). The human insulin receptor cDNA: the structural basis for hormone-activated transmembrane signalling. Cell, 40(4), 747-758. 
Esters, H., Alexandrov, K., lakovenko, A., Ivanova, T., Thoma, N., Rybin, V., Zerial, M., Scheidig, A. J., \& Goody, R. S. (2001). Vps9, Rabex-5 and DSS4: proteins with weak but distinct nucleotide-exchange activities for Rab proteins. J Mol Biol, 310(1), 141-156. doi:10.1006/jmbi.2001.4735

Galvis, A., Balmaceda, V., Giambini, H., Conde, A., Villasana, Z., Fornes, M. W., \& Barbieri, M. A. (2009). Inhibition of early endosome fusion by Rab5-binding defective Ras interference 1 mutants. Arch Biochem Biophys, 482(1-2), 83-95. doi:10.1016/j.abb.2008.11.009

Galvis, A., Giambini, H., Villasana, Z., \& Barbieri, M. A. (2009). Functional determinants of ras interference 1 mutants required for their inhbitory activity on endocytosis. Exp Cell Res, 315(5), 820-835. doi:10.1016/j.yexcr.2008.12.003

Giovannucci, E., Harlan, D. M., Archer, M. C., Bergenstal, R. M., Gapstur, S. M., Habel, L. A., Pollak, M., Regensteiner, J. G., \& Yee, D. (2010). Diabetes and cancer: a consensus report. CA Cancer J Clin, 60(4), 207-221. doi:10.3322/caac.20078

Haas, A. K., Fuchs, E., Kopajtich, R., \& Barr, F. A. (2005). A GTPase-activating protein controls Rab5 function in endocytic trafficking. Nat Cell Biol, 7(9), 887-893. doi:10.1038/ncb1290

Han, L., \& Colicelli, J. (1995). A human protein selected for interference with Ras function interacts directly with Ras and competes with Raf1. Mol Cell Biol, 15(3), 1318-1323.

Hinoi, E., lezaki, T., Fujita, H., Watanabe, T., Odaka, Y., Ozaki, K., \& Yoneda, Y. (2014). PI3K/Akt is involved in brown adipogenesis mediated by growth differentiation factor-5 in association with activation of the Smad pathway. Biochemical and Biophysical Research Communications, 450(1), 255-260. doi:10.1016/j.bbrc.2014.05.108

Horiuchi, H., Lippe, R., McBride, H. M., Rubino, M., Woodman, P., Stenmark, H., Rybin, V., Wilm, M., Ashman, K., Mann, M., \& Zerial, M. (1997). A novel Rab5 GDP/GTP exchange factor complexed to Rabaptin-5 links nucleotide exchange to effector recruitment and function. Cell, 90(6), 1149-1159.

Humphrey, W., Dalke, A., \& Schulten, K. (1996). VMD: visual molecular dynamics. J Mol Graph, 14(1), 33-38, 27-38.

Hunker, C. M., Galvis, A., Kruk, I., Giambini, H., Veisaga, M. L., \& Barbieri, M. A. (2006). Rab5-activating protein 6, a novel endosomal protein with a role in endocytosis. Biochem Biophys Res Commun, 340(3), 967-975. doi:10.1016/j.bbrc.2005.12.099 
Hunker, C. M., Giambini, H., Galvis, A., Hall, J., Kruk, I., Veisaga, M. L., \& Barbieri, M. A. (2006). Rin1 regulates insulin receptor signal transduction pathways. Exp Cell Res, 312(7), 1106-1118. doi:10.1016/j.yexcr.2005.12.021

Huttala, O., Mysore, R., Sarkanen, J. R., Heinonen, T., Olkkonen, V. M., \& Ylikomi, T. (2016). Differentiation of human adipose stromal cells in vitro into insulinsensitive adipocytes. Cell Tissue Res, 366(1), 63-74. doi:10.1007/s00441-0162409-7

Jochen, A., Hays, J., \& Lee, M. (1989). Kinetics of insulin internalization and processing in adipocytes: effects of insulin concentration. J Cell Physiol, 141(3), 527-534. doi:10.1002/jcp.1041410311

Jozic, I., Blanco, G., \& Barbieri, M. A. (2011). Inhibition of Rab5 Activation During Insulin Receptor-Mediated Endocytosis. Curr Cell Biochem, 1(1), 20-32.

Kajiho, H., Saito, K., Tsujita, K., Kontani, K., Araki, Y., Kurosu, H., \& Katada, T. (2003). RIN3: a novel Rab5 GEF interacting with amphiphysin II involved in the early endocytic pathway. J Cell Sci, 116(Pt 20), 4159-4168. doi:10.1242/jcs.00718

Kalin, S., Hirschmann, D. T., Buser, D. P., \& Spiess, M. (2015). Rabaptin5 is recruited to endosomes by Rab4 and Rabex5 to regulate endosome maturation. $J$ Cell Sci, 128(22), 4126-4137. doi:10.1242/jcs.174664

Kallberg, M., Wang, H. P., Wang, S., Peng, J., Wang, Z. Y., Lu, H., \& Xu, J. B. (2012). Template-based protein structure modeling using the RaptorX web server. Nature Protocols, 7(8), 1511-1522. doi:10.1038/nprot.2012.085

Klemm, D. J., Leitner, J. W., Watson, P., Nesterova, A., Reusch, J. E., Goalstone, M. L., \& Draznin, B. (2001). Insulin-induced adipocyte differentiation. Activation of CREB rescues adipogenesis from the arrest caused by inhibition of prenylation. $J$ Biol Chem, 276(30), 28430-28435. doi:10.1074/jbc.M103382200

Kralisch, S., \& Fasshauer, M. (2013). Adipocyte fatty acid binding protein: a novel adipokine involved in the pathogenesis of metabolic and vascular disease? Diabetologia, 56(1), 10-21. doi:10.1007/s00125-012-2737-4

Lee, S., Tsai, Y. C., Mattera, R., Smith, W. J., Kostelansky, M. S., Weissman, A. M., Bonifacino, J. S., \& Hurley, J. H. (2006). Structural basis for ubiquitin recognition and autoubiquitination by Rabex-5. Nat Struct Mol Biol, 13(3), 264-271. doi:10.1038/nsmb1064

Li, G. (2015). Rab GTPases.

Li, G. P., Barbieri, M. A., Colombo, M. I., \& Stahl, P. D. (1994). Structural Features of the Gtp-Binding Defective Rab5 Mutants Required for Their Inhibitory Activity on Endocytosis. Journal of Biological Chemistry, 269(20), 14631-14635. 
Liu, D., \& Cowburn, D. (2016). Combining biophysical methods to analyze the disulfide bond in SH2 domain of C-terminal Src kinase. Biophys Rep, 2(1), 33-43. doi:10.1007/s41048-016-0025-4

Marshall, S. (1985). Degradative processing of internalized insulin in isolated adipocytes. J Biol Chem, 260(25), 13517-13523.

Murholm, M., Dixen, K., \& Hansen, J. B. (2010). Ras signalling regulates differentiation and UCP1 expression in models of brown adipogenesis. Biochim Biophys Acta, 1800(6), 619-627. doi:10.1016/j.bbagen.2010.03.008

Nam, D., Guo, B., Chatterjee, S., Chen, M. H., Nelson, D., Yechoor, V. K., \& Ma, K. (2015). The adipocyte clock controls brown adipogenesis through the TGF-beta and BMP signaling pathways. J Cell Sci, 128(9), 1835-1847. doi:10.1242/jcs. 167643

Nielsen, E., Christoforidis, S., Uttenweiler-Joseph, S., Miaczynska, M., Dewitte, F., Wilm, M., Hoflack, B., \& Zerial, M. (2000). Rabenosyn-5, a novel Rab5 effector, is complexed with hVPS45 and recruited to endosomes through a FYVE finger domain. Journal of Cell Biology, 151(3), 601-612. doi:DOI 10.1083/jcb.151.3.601

Onishi, M., Nosaka, T., Misawa, K., Mui, A. L. F., Gorman, D., McMahon, M., Miyajima, A., \& Kitamura, T. (1998). Identification and characterization of a constitutively active STAT5 mutant that promotes cell proliferation. Molecular and Cellular Biology, 18(7), 3871-3879. doi:Doi 10.1128/Mcb.18.7.3871

Otomo, A., Hadano, S., Okada, T., Mizumura, H., Kunita, R., Nishijima, H., Showguchi-Miyata, J., Yanagisawa, Y., Kohiki, E., Suga, E., Yasuda, M., Osuga, H., Nishimoto, T., Narumiya, S., \& Ikeda, J. E. (2003). ALS2, a novel guanine nucleotide exchange factor for the small GTPase Rab5, is implicated in endosomal dynamics. Human Molecular Genetics, 12(14), 1671-1687. doi:10.1093/hmg/ddg184

Palamidessi, A., Frittoli, E., Ducano, N., Offenhauser, N., Sigismund, S., Kajiho, H., Parazzoli, D., Oldani, A., Gobbi, M., Serini, G., Di Fiore, P. P., Scita, G., \& Lanzetti, L. (2013). The GTPase-activating protein RN-tre controls focal adhesion turnover and cell migration. Curr Biol, 23(23), 2355-2364. doi:10.1016/j.cub.2013.09.060

Penengo, L., Mapelli, M., Murachelli, A. G., Confalonieri, S., Magri, L., Musacchio, A., Di Fiore, P. P., Polo, S., \& Schneider, T. R. (2006). Crystal structure of the ubiquitin binding domains of rabex-5 reveals two modes of interaction with ubiquitin. Cell, 124(6), 1183-1195. doi:10.1016/j.cell.2006.02.020

Pfeffer, S. (2005). Filling the Rab GAP. Nat Cell Biol, 7(9), 856-857. doi:10.1038/ncb0905-856 
Phillips, J. C., Braun, R., Wang, W., Gumbart, J., Tajkhorshid, E., Villa, E., Chipot, C., Skeel, R. D., Kale, L., \& Schulten, K. (2005). Scalable molecular dynamics with NAMD. J Comput Chem, 26(16), 1781-1802. doi:10.1002/jcc.20289

Qamra, R., \& Hubbard, S. R. (2013). Structural basis for the interaction of the adaptor protein grb14 with activated ras. PLoS One, 8(8), e72473. doi:10.1371/journal.pone.0072473

Saito, K., Murai, J., Kajiho, H., Kontani, K., Kurosu, H., \& Katada, T. (2002). A novel binding protein composed of homophilic tetramer exhibits unique properties for the small GTPase Rab5. J Biol Chem, 277(5), 3412-3418. doi:10.1074/jbc.M106276200

Saltiel, A. R., \& Kahn, C. R. (2001). Insulin signalling and the regulation of glucose and lipid metabolism. Nature, 414(6865), 799-806. doi:10.1038/414799a

Scheidel, J., Lindauer, K., Ackermann, J., \& Koch, I. (2015). Quasi-Steady-State Analysis based on Structural Modules and Timed Petri Net Predict System's Dynamics: The Life Cycle of the Insulin Receptor. Metabolites, 5(4), 766-793. doi:10.3390/metabo5040766

Shin, D., Lee, S. Y., Han, S., Ren, S., Kim, S., Aikawa, Y., \& Lee, S. (2012). Differential polyubiquitin recognition by tandem ubiquitin binding domains of Rabex-5. Biochem Biophys Res Commun, 423(4), 757-762. doi:10.1016/j.bbrc.2012.06.032

Shukla, A., Grisouard, J., Ehemann, V., Hermani, A., Enzmann, H., \& Mayer, D. (2009). Analysis of signaling pathways related to cell proliferation stimulated by insulin analogs in human mammary epithelial cell lines. Endocr Relat Cancer, 16(2), 429-441. doi:10.1677/ERC-08-0240

Siddhanta, U., Mcllroy, J., Shah, A., Zhang, Y., \& Backer, J. M. (1998). Distinct roles for the p110alpha and hVPS34 phosphatidylinositol 3'-kinases in vesicular trafficking, regulation of the actin cytoskeleton, and mitogenesis. J Cell Biol, 143(6), 1647-1659.

Stenmark, H., Vitale, G., Ullrich, O., \& Zerial, M. (1995). Rabaptin-5 Is a Direct Effector of the Small Gtpase Rab5 in Endocytic Membrane-Fusion. Cell, 83(3), 423-432. doi:Doi 10.1016/0092-8674(95)90120-5

Su, X., Kong, C., \& Stahl, P. D. (2007). GAPex-5 mediates ubiquitination, trafficking, and degradation of epidermal growth factor receptor. J Biol Chem, 282(29), 21278-21284. doi:10.1074/jbc.M703725200 
Tall, G. G., Barbieri, M. A., Stahl, P. D., \& Horazdovsky, B. F. (2001). Ras-Activated Endocytosis Is Mediated by the Rab5 Guanine Nucleotide Exchange Activity of RIN1. Developmental Cell, 1, 73-82.

Tam, S. Y., Lilla, J. N., Chen, C. C., Kalesnikoff, J., \& Tsai, M. (2015). RabGEF1/Rabex-5 Regulates TrkA-Mediated Neurite Outgrowth and NMDAInduced Signaling Activation in NGF-Differentiated PC12 Cells. PLoS One, 10(11), e0142935. doi:10.1371/journal.pone.0142935

Terzyan, S., Zhu, G., Li, G., \& Zhang, X. C. (2003). Refinement of the structure of human Rab5a GTPase domain at $1.05 \AA$ resolution. Acta Crystallographica Section $D$ Biological Crystallography, 60(1), 54-60. doi:10.1107/s0907444903021632

Watanabe, M., Hayasaki, H., Tamayama, T., \& Shimada, M. (1998). Histologic distribution of insulin and glucagon receptors.pdf. Braz J Med Biol Res, 31(2), 243256.

Wilfling, F., Wang, H., Haas, J. T., Krahmer, N., Gould, T. J., Uchida, A., Cheng, J. X., Graham, M., Christiano, R., Frohlich, F., Liu, X., Buhman, K. K., Coleman, R. A., Bewersdorf, J., Farese, R. V., Jr., \& Walther, T. C. (2013). Triacylglycerol synthesis enzymes mediate lipid droplet growth by relocalizing from the ER to lipid droplets. Dev Cell, 24(4), 384-399. doi:10.1016/j.devcel.2013.01.013

Woller, B., Luiskandl, S., Popovic, M., Prieler, B. E. M., Ikonge, G., Mutzl, M., Rehmann, H., \& Herbst, R. (2011). Rin-like, a novel regulator of endocytosis, acts as guanine nucleotide exchange factor for Rab5a and Rab22. Biochimica Et Biophysica Acta-Molecular Cell Research, 1813(6), 1198-1210. doi:10.1016/j.bbamcr.2011.03.005

Wu, W. J., Mo, D. L., Zhao, C. Z., Zhao, C., Chen, Y. S., Pang, W. J., \& Yang, G. S. (2015). Knockdown of CTRP6 inhibits adipogenesis via lipogenic marker genes and Erk1/2 signalling pathway. Cell Biol Int, 39(5), 554-562. doi:10.1002/cbin.10422

Xu, L., Lubkov, V., Taylor, L. J., \& Bar-Sagi, D. (2010). Feedback regulation of Ras signaling by Rabex-5-mediated ubiquitination. Curr Biol, 20(15), 1372-1377. doi:10.1016/j.cub.2010.06.051

Yen, Y. C., Hsiao, J. R., Jiang, S. S., Chang, J. S., Wang, S. H., Shen, Y. Y., Chen, C. H., Chang, I. S., Chang, J. Y., \& Chen, Y. W. (2015). Insulin-like growth factorindependent insulin-like growth factor binding protein 3 promotes cell migration and lymph node metastasis of oral squamous cell carcinoma cells by requirement of integrin beta1. Oncotarget, 6(39), 41837-41855. doi:10.18632/oncotarget.5995 
Zecchin, H. G., Priviero, F. B., Souza, C. T., Zecchin, K. G., Prada, P. O., Carvalheira, J. B., Velloso, L. A., Antunes, E., \& Saad, M. J. (2007). Defective insulin and acetylcholine induction of endothelial cell-nitric oxide synthase through insulin receptor substrate/Akt signaling pathway in aorta of obese rats. Diabetes, 56(4), 1014-1024. doi:10.2337/db05-1147

Zhang, Z., Zhang, T., Wang, S., Gong, Z., Tang, C., Chen, J., \& Ding, J. (2014). Molecular mechanism for Rabex-5 GEF activation by Rabaptin-5. Elife, 3. doi:10.7554/eLife.02687

Zhu, H., Zhu, G., Liu, J., Liang, Z., Zhang, X. C., \& Li, G. (2007). Rabaptin-5independent membrane targeting and Rab5 activation by Rabex-5 in the cell. Mol Biol Cell, 18(10), 4119-4128. doi:10.1091/mbc.E07-02-0100 
VITA

YONGJUN HAUNG

Education

2015 - present

Ph. D. Candidate

Department of Chemistry and Biochemistry

Florida International University, USA

$2011-2012$

NO.4 People's Hospital

Wuxi, China

Intern

2009

The First Affiliated Hospital of Soochow University Suzhou, China

Professional practice

2008

Xiangyang Maternity and Child Health Care Hospital

Xiangyang, China

Professional practice

$2008-2009$

$2007-2012$

Leader of Research group of Anti-cancer Association

Soochow University, China

BA in Clinical Medicine

Department of Medicine

Soochow University, China

Work Experience

2013 - 2015;

2017 - present

Teaching Assistant

Department of Chemistry and Biochemistry; Department of Biological Sciences

Florida International University, USA

$2015-2017$

Confocal Facility Assistant Manager

Department of Biological Sciences

Florida International University, USA 
Publication

Birth of the adipocyte: Early adipogenesis, the MAPK pathway, and mitotic clonal expansion 2017

S. Abood, Y. Huang, M. A. Barbieri. Current Topics in Biochemical Research 18: 1 (2017)

A single amino acid change in Ras Interference 1 alters its function 2018 Y. Huang, M. L. Veisaga, V. S. Nadar, B. P. Rosen, and M. A. Barbieri. Under revision

IGF-1 drives activation of Rab5 via Rin1 augmenting proliferation and invasion of MCF-7 cells

2018

N. Porther, Y. Huang, M. L. Veisaga, and M. A. Barbieri. In preparation

GTP hydrolysis of Rab5 controls differentiation of prediapocytes

Y. Huang, M. L. Veisaga, N. Villaverde, and M. A. Barbieri. In preparation

Oral Presentation

30th European Immunogenetics and Histocompatibility Complex May. 2016

S. K. Singh, Y. Huang, A. Caobi, M. A. Barbieri, M. T. Dorak. Functional Annotations of Common Disease Markers in Immune Regulatory Genes

19th Biology Research Symposium of FIU

Feb. 2017

Y. Huang, M. L. Veisaga and M. A. Barbieri. Effects of Rin1 and its mutants on adipogenesis

2018 FIU Biomedical And Comparative Immunology Symposium

Mar. 2018

Y. Huang. M. A. Barbieri. RIN1 Dictates the Fate of Fat Cell Formation

Poster

2015 ASCB Annual Meeting

Dec. 2015

Y. Huang, E. Ocasio, M. L. Veisaga and M. A. Barbieri. A single amino acid change in Ras Interference 1 alters its function.

2016 ASCB Annual Meeting

Dec. 2016

Y. Huang, W. Zhang, M. L. Veisaga and M. A. Barbieri. Selective effect of

Rin1 mutants on insulin signaling during pre-adipocyte differentiation

2017 ASCB Annual Meeting

Dec. 2017

Y. Huang, M. L. Veisaga and M. A. Barbieri. Role of Small GTPases on differentiation of pre-adipocyte

20th Biology Research Symposium of FIU

Feb. 2018

Y. Huang, M. L. Veisaga and M. A. Barbieri. Small GTPases: friend or foe of adipogenesis? 